MARISA MARTIN CRIVELARO ROMÃO

\title{
O método Kumon para remediação cognitiva de portadores de esquizofrenia: um ensaio clínico randomizado, controlado com placebo
}

\author{
Dissertação apresentada à Faculdade de \\ Medicina da Universidade de São Paulo para \\ obtenção do título de Mestre em Ciências \\ Programa de: Psiquiatria \\ Orientador: Prof. Dr. Mario Rodrigues Louzã Neto
}

São Paulo 2013 


\section{Dados Internacionais de Catalogação na Publicação (CIP)}

\section{Preparada pela Biblioteca da}

Faculdade de Medicina da Universidade de São Paulo

Creprodução autorizada pelo autor

Romão, Marisa Martin Crivelaro

O método Kumon para remediação cognitiva de portadores de esquizofrenia: um ensaio clínico randomizado, controlado com placebo / Marisa Martin Crivelaro Romão. -- São Paulo, 2013.

Dissertação (mestrado)--Faculdade de Medicina da Universidade de São Paulo.

Programa de Psiquiatria.

Orientador: Mario Rodrigues Louzã Neto.

Descritores: 1. Cognição 2.Reabilitação 3.Neuropsicologia 4.Esquizofrenia 5. Ensaio clínico controlado aleatório

USP/FM/DBD-129/13 
Aos meus queridos pais, pelo carinho e exemplo de vida marcante que me ensinaram a enfrentar as dificuldades e acreditar no potencial humano de superação e transformação dos sonhos em realidade.

Aos meus amados marido e filho, pelo incansável apoio, companheirismo, paciência e compreensão dos momentos de ausência ao longo do período de elaboração deste trabalho. 
AGRADECIMENTOS 
Ao Prof. Dr. Mario Rodrigues Louzã Neto pela confiança, incentivo e oportunidade de aprender com sua experiência.

À psicóloga Luciana de Carvalho Monteiro pela indicação e auxílio na escolha das baterias neuropsicológicas da pesquisa.

A toda equipe de profissionais - Paula Andréia Martins, Monia Michele Musskopf, Rosa Bertinho, Suely Pacheco de Araujo, Silvia Arcuri, Zilda Celidonio - pela dedicada colaboração, sem o qual não seria possível concretizar o estudo.

Às secretarias do Projesq - Josefina Nacarato e Débora Zambroni - pelo apoio e auxílio constante mesmo em meio a tantos compromissos.

Às equipes do Projesq e LIM-27, por colocar à disposição o ambulatório e encaminhamento de pacientes.

Aos pacientes do Projesq e do LIM-27, pela disponibilidade e atenção.

Ao Projesq pelo apoio financeiro, possibilitando a realização desta pesquisa.

À Coordenação de Aperfeiçoamento de Pessoal de Nível Superior - CAPES - pela concessão da bolsa de mestrado. 


\section{NORMALIZAÇÃO ADOTADA}

Esta dissertação ou tese está de acordo com as seguintes normas, em vigor no momento desta publicação:

Referências: adaptado de International Committee of Medical Journals Editors (Vancouver).

Universidade de São Paulo. Faculdade de Medicina. Serviço de Biblioteca e Documentação. Guia de apresentação de dissertações, teses e monografias. Elaborado por Anneliese Carneiro da Cunha, Maria Julia de A. L. Freddi, Maria F. Crestana, Marinalva de Souza Aragão, Suely Campos Cardoso, Valéria Vilhena. 2a ed. São Paulo: Serviço de Biblioteca e Documentação; 2005.

Abreviaturas dos títulos dos periódicos de acordo com List of Journals Indexed in Index Medicus. 
SUMÁRIO 
Lista de Siglas

Lista de Tabelas

Lista de gráficos

Resumo

\section{INTRODUÇÃO}

1.1. A terapia de remediação cognitiva (CRT) na esquizofrenia.................1

1.2. O método Kumon como remediação cognitiva errorless learning......13

1.3. Dificuldade em aprendizagem matemática.....................................16

1.4. Alterações cognitivas e dificuldade em aprendizagem matemática....23

1.4.1. Memória de trabalho......................................................30

1.4.2. Função executiva........................................................46

1.4.3. Atenção ..................................................................65

2. JUSTIFICATIVAS PARA O ESTUDO ........................................100

3. OBJETIVOS

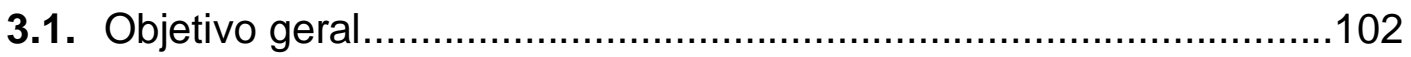

3.2. Objetivos específicos............................................................102

\section{HIPÓTESES}

4.1. Hipótese principal.................................................................103

4.2. Hipóteses secundárias.............................................................103

\section{MATERIAIS E MÉTODOS}

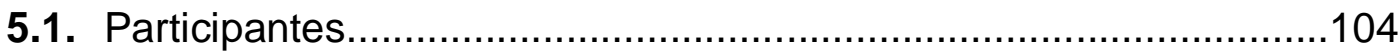

5.2. Desenho do estudo.............................................................

5.2.1. Instrumentos de avaliação...........................................................108

5.2.1A. Avaliação neuropsicológica.........................................................113

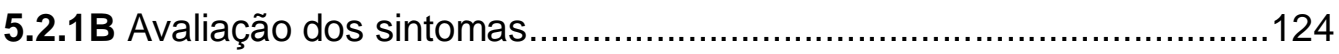

5.2.1C Avaliação do desempenho social e pessoal...................................127

5.3. Intervenções.......................................................................... 128

5.4. Cálculo do número de sujeitos.............................................129

5.5. Randomização.....................................................................131

5.6. Análise estatística.....................................................................131 


\section{RESULTADOS}

6.1. Participantes 134

6.2. Análise demográfica. 136

6.3. Comparações intra e entre os grupos no início da intervenção 143

6.4. Comparações intra e entre grupos ao final da intervenção e após 12 meses

6.4.1. Resultados das medidas neuropsicológicas 149

6.4.2. Resultados quanto à sintomatologia. 177

6.4.3. Resultados de desempenho social e pessoal. 183

\section{DISCUSSÃO}

7.1. Perfil demográfico 184

7.2. Considerações sobre o treinamento matemático Kumon 186

7.3. Cognição e fatores motivacionais. 192

7.4. Psicopatologia e funcionamento social. 196

8. LIMITAÇÕES DO ESTUDO 199

9. CONCLUSÕES 206

10. REFERÊNCIAS BIBLIOGRÁFICAS. 207 


\section{LISTAS}




\section{LISTA DE FIGURAS}

Figura 1 - Modelo de desenvolvimento da memória de trabalho......................... 42

Figura 2 - Modelo revisado de memória de trabalho......................................... 45

Figura 3 - Modelo de memória operacional proposto por Baddeley .................... 60

Figura 4 - Diagrama CONSORT - perfil de inclusão dos pacientes na pesquisa. 135

\section{LISTA DE TABELAS}

Tabela 1 - Principais características e metas do Kumon

Tabela 2 - Estudos randomizados, controlados de Remediação Cognitiva na esquizofrenia.

Tabela 3 - Estudos de avaliação cognitiva subjacente à matemática................ 72

Tabela 4 - Ensaios randomizados, controlados de treinamento matemático....

Tabela 5 - Estudos de revisão e meta-análise de cognição subjacente à matemática

Tabela 6 - Estudos de corte em avaliação matemática..

Tabela 7 - Fluxograma da pesquisa.

Tabela 8 - Medidas neuropsicológicas e escalas usadas no estudo.

Tabela 9 - Distribuição da amostra de acordo com o ambulatório, o sexo e o estado civil - $\mathrm{n}$ e (\%).

Tabela 10 - Distribuição da freqüência e porcentagem por raça em cada grupo.

Tabela 11 - Distribuição da freqüência e porcentagem de subtipos de esquizofrenia em cada grupo

Tabela 12 - Distribuição da freqüência e porcentagem do histórico de internação em cada grupo.

Tabela 13 - Médias e desvios-padrão dos dados demográficos totais.

Tabela 14 - Médias e desvios-padrão dos dados demográficos em cada grupo.

Tabela 15 - Tipo de medicação - n e (\%) 
Tabela 16 - Comparações entre os grupos quanto a medidas de inteligência no início da intervenção.

Tabela 17 - Comparações entre grupos quanto a medidas neuropsicológicas de atenção no início da intervenção

Tabela 18 - Comparações entre grupos quanto a medidas neuropsicológicas de função executiva no início da intervenção.

Tabela 19 - Comparações entre grupos quanto a medidas neuropsicológicas de memória no início da intervenção.

Tabela 20 - Comparações entre grupos quanto a medidas de PANSS no início da intervenção.

Tabela 21 - Resultados das medidas de inteligência (WASI reduzido)......

Tabela 22 - Resultados das medidas atencionais

Tabela 23 - Resultados da função executiva................................................... 168

Tabela 24 - Resultados mnêmicos........................................................

Tabela 25 - Resultados da escala de sintomas positivos e negativos PANSS, segundo 5 fatores de Van der Gaag (2006). 


\section{LISTA DE SIGLAS}

ATMT-C Trail making Test for childrens/Teste Trail making para crianças

CNT Contingency naming test/Teste de nomeação contingente

CONSORT Consolidated standards of reporting trials

CPT Continuous performance test

CRT Cognitive remediation therapy/Terapia de remediação cognitiva

DSM-IV Diagnostic and statistical manual of mental disorders $-4^{\circ}$ edition

EF Executive function/Função executiva

$g \quad$ Inteligência geral

gf Inteligência fluída

MLA Mathematic learning achievement/Dificuldade em realização matemática

MLD Mathematic learning disabilities/Dificuldade em aprendizagem matemática

PANSS Positive and negative syndrome scale

PSP Personal and social performance scale

SAS Sistema atencional supervisor

STM Short-term memory/Memória de curto-prazo

TCLE Termo de consentimento livre e esclarecido

TDAH Transtorno de déficit de atenção e hiperatividade

WCST Wisconsin card sorting test

WM Working memory/Memória de trabalho 


\section{LISTA DE GRÁFICOS}

Gráfico 1 - Comparação do desempenho em "matrizes de raciocínio" do WAIS-III entre grupo Kumon e controle após 6 e 12 meses de treinamento.

Gráfico 2 - Comparação do desempenho em medidas de "Quociente intelectual - Ql" entre grupo Kumon e controle após 6 e 12 meses de treinamento.

Gráfico 3 - Comparação do desempenho em "Vocabulário" do WAIS-III entre grupo Kumon e controle após 6 e 12 meses de treinamento.

Gráfico 4 - Comparação do grupo Kumon e controle após 6 e 12 meses de treinamento no fator "omissão" do Continuous Performance Test CPT......

Gráfico 5 - Comparação do desempenho entre grupo Kumon e controle após 6 e 12 meses de treinamento em sub-teste "Stroop parte A" do Stroop Color-Word Test.

Gráfico 6 - Comparação da quantidade de erros entre grupo Kumon e controle após6 e 12 meses de treinamento em sub-teste "Stroop parte A" do Stroop Color-Word Test.

Gráfico 7 - Comparação do grupo Kumon e controle após 6 e 12 meses de treinamento no sub-teste "dígitos de ordem direta" do WISC III.

Gráfico 8 - Comparação do grupo Kumon e controle após 6 e 12 meses de treinamento no fator "comissão" do Continuous Performance Test CPT.

Gráfico 9 - Comparação do grupo Kumon e controle após 6 e 12 meses de treinamento no fator "tempo de resposta" do Continuous Performance Test-CPT.....

Gráfico 10 - Comparação do grupo Kumon e controle após 6 e 12 meses de treinamento no fator "variabilidade" do Continuous Performance TestCPT.

Gráfico 11 - Comparação do grupo Kumon e controle após 6 e 12 meses de treinamento em Trail Making Test parte A.....

Gráfico 12 - Comparação do desempenho entre grupo Kumon e controle após 6 e 12 meses de treinamento em sub-teste "Wisconsin Card testcategorias completas"....

Gráfico 13 - Comparação do desempenho entre grupo Kumon e controle após 6 e 12 meses de treinamento em sub-teste "respostas perseverativas" do Wisconsin Card Test.

Gráfico 14 - Comparação do desempenho entre grupo Kumon e controle após 6 e 12 meses de treinamento em sub-teste "Stroop parte A" do Stroop Color-Word Test.

Gráfico 15 - Comparação do desempenho entre grupo Kumon e controle após 6 e 12 meses de treinamento em sub-teste "Stroop parte B" do Stroop Color-Word Test. 
Gráfico 16 - Comparação do desempenho entre grupo Kumon e controle após 6 e 12 meses de treinamento em sub-teste "Stroop parte C" do Stroop Color-Word Test....

Gráfico 17 - Comparação da quantidade de erros entre grupo Kumon e controle após 6 e 12 meses de treinamento em sub-teste "Stroop parte C" do Stroop Color-Word Test.

Gráfico 18 - Comparação do desempenho entre grupo Kumon e controle após 6 e 12 meses de treinamento em sub-teste "Trail Making Test parte B".

Gráfico 19 - Comparação do desempenho entre grupo Kumon e controle após 6 e 12 meses de treinamento em sub-teste "Wisconsin Card testerros não perseverativos".

Gráfico 20 - Comparação do desempenho entre grupo Kumon e controle após 6 e 12 meses de treinamento em sub-teste "Wisconsin Card testperda de set".

Gráfico 21 - Comparação do desempenho entre grupo Kumon e controle após 6 e 12 meses de treinamento no sub-teste "dígitos ordem indireta " do WAIS III.

Gráfico 22 - Comparação do desempenho em "dígitos de ordem inversa" do WAIS-III entre grupo Kumon e controle após 6 e 12 meses de treinamento.

Gráfico 23 - Comparação do desempenho em "RAVLT - lista A" entre grupo Kumon e controle após 6 e 12 meses de treinamento

Gráfico 24 - Comparação do desempenho em "RAVLT - lista B" entre grupo Kumon e controle após 6 e 12 meses de treinamento

Gráfico 25 - Comparação do desempenho em "RAVLT - lista C" entre grupo Kumon e controle após 6 e 12 meses de treinamento

Gráfico 26 - Comparação do desempenho em "RAVLT - lista D" entre grupo Kumon e controle após 6 e 12 meses de treinamento.

Gráfico 27 - Comparação do desempenho em "RAVLT - lista E" entre grupo Kumon e controle após 6 e 12 meses de treinamento

Gráfico 28 - Comparação do desempenho em "RAVLT - lista F" entre grupo Kumon e controle após 6 e 12 meses de treinamento

Gráfico 29 - Comparação do desempenho em "RAVLT - lista G" entre grupo Kumon e controle após 6 e 12 meses de treinamento

Gráfico 30 - Comparação do grupo Kumon e controle após 6 e 12 meses de treinamento (tempo 2) em PANSS geral. 
Gráfico 31 - Comparação do grupo Kumon e controle após 6 e 12 meses de treinamento (tempo 2) no fator "estresse emocional/ emotional distress" da escala PANSS.

Gráfico 32 - Comparação do grupo Kumon e controle após 6 e 12meses de treinamento (tempo 2) no fator "excitação/ excitement" da PANSS.

Gráfico 33 - Comparação do grupo Kumon e controle após 6 e 12meses de treinamento (tempo 2) no fator "sintomas negativos" da PANSS.

Gráfico 34 - Comparação do grupo Kumon e controle após 6 e 12meses de treinamento (tempo 2) no fator "sintomas positivos" da PANSS.

Gráfico 35 - Comparação do grupo Kumon e controle após 6 e 12meses de treinamento (tempo 2) no fator "desorganização" da PANSS. 
RESUMO 
Crivelaro MM. O método Kumon para remediação cognitiva de portadores de esquizofrenia: um ensaio clínico randomizado, controlado com placebo [dissertation]. São Paulo: "Faculdade de Medicina, Universidade de São Paulo"; 2013. 221p.

Introdução: Déficits cognitivos são parte integrante do quadro clinico da esquizofrenia. Vários estudos procuram métodos de treinamento cognitivo (remediação cognitiva) para melhora destes déficits, pouco responsivos ao tratamento medicamentoso. Ensaios clínicos de treinamento de remediação cognitiva utilizam diversas técnicas, com estimulação de vários domínios cognitivos simultaneamente. Muitos deles utilizam a técnica de errorless learning (aprendizagem sem erros). Pesquisas recentes indicam que alguns domínios cognitivos subjacentes à aprendizagem matemática (atenção, função executiva e memória de trabalho) estão também comprometidos na esquizofrenia. Entretanto não foram encontrados estudos de remediação cognitiva focados no treinamento aritmético em portadores de esquizofrenia. $O$ método de cálculos aritméticos proposto pelo método Kumon utiliza técnica de aprendizagem sem erros e é amplamente utilizado como reforço pedagógico. Dois ensaios randomizados de remediação cognitiva através do método de cálculo aritmético Kumon em idosos sadios e em idosos com Alzheimer mostraram melhora de funções cognitivas com esta intervenção. Este estudo avaliou a eficácia do método de cálculos aritméticos Kumon como remediação cognitiva da memória de trabalho, função executiva e atenção na população com esquizofrenia. Método: 51 sujeitos com o diagnóstico de esquizofrenia (DSM-IV), de ambos os gêneros, idade entre 18 e 55 anos, alfabetizados foram incluídos e randomizados para treinamento de cálculos aritméticos pelo método Kumon (grupo experimental) ou atividades de recreação (grupo controle). Os sujeitos fizeram 48 sessões de intervenção ao longo de 6 meses. Os sujeitos foram avaliados através de uma bateria neuropsicológica, o desfecho clínico através da escala Escala de Síndromes Positiva e Negativa (PANSS) e funcionamento pessoal e social através da PSP no inicio da intervenção, após 6 meses (término da intervenção) e após 6 meses sem a intervenção. Resultados: O grupo experimental apresentou tendência de melhora em atenção sustentada ( $p=0.075)$, mas sem manutenção dos ganhos após 6 meses sem intervenção. Ambos os grupos apresentaram melhora em atenção seletiva e função executiva após 6 meses sem manutenção dos ganhos após 1 ano, sem diferenças entre os grupos. Não foram encontradas diferenças no funcionamento social entre os dois grupos e ao longo dos 12 meses de acompanhamento. Através da análise fatorial da PANSS utilizando 5 fatores (proposto por Van der Gaag 2006) não houve mudança significativa nos fatores „positivo", „negativo", „desorganização" e "estresse emocional" ao longo do tempo e entre os grupos. Apenas o grupo placebo demonstrou melhora significativa no fator "excitação" após 6 meses em comparação com o grupo experimental, que não persistiu após 6 meses sem intervenção. Conclusão: $O$ treino cognitivo aritmético pelo método Kumon tende a melhorar a atenção sustentada após 6 meses, sem impacto na função executiva e na memória de trabalho. Esta tendência não se manteve após 6 meses sem intervenção.

Descritores: Cognição; Neuropsicologia; Esquizofrenia; Reabilitação; Ensaio clínico controlado aleatório 
Crivelaro MM. The Kumon Method for cognitive remediation of individuals with schizophrenia: a randomized, placebo-controlled trial [dissertation]. São Paulo: "Faculdade de Medicina, Universidade de São Paulo"; 2013. 221p.

Introduction: Cognitive deficits are an integral part of the clinical picture of schizophrenia. Various studies seek cognitive training (cognitive remediation) methods in order to improve those deficits, which are poorly responsive to pharmacological treatment. Clinical trials of cognitive remediation training use a variety of techniques, with the stimulation of several cognitive domains simultaneously. Many of them employ the "errorless learning" technique. Recent research indicates that some cognitive domains underlying mathematical learning (attention, executive function and working memory) are also impaired in schizophrenia. However, no cognitive remediation studies were found focusing on arithmetic training in individuals with schizophrenia. The arithmetic calculation method proposed by Kumon employs the errorless learning technique and is widely used for supplemental education. Two randomized trials of cognitive remediation using the arithmetic calculation method Kumon with healthy elderly subjects as well as elderly subjects who had Alzheimer's disease showed cognitive function improvement with this intervention. The present study evaluated the effectiveness of the arithmetic calculation of the Kumon method as cognitive remediation for working memory, executive function and attention in a sample with schizophrenia. Method: 51 subjects with a diagnosis of schizophrenia (DSM-IV), male and female, literate, aged between 18-55 years, were included in the trial and randomized to arithmetic calculation training by the Kumon method (experimental group) or recreational activities (control group). The subjects received 48 intervention sessions over the course of 6 months. The subjects were evaluated through a neuropsychological battery; the clinical outcome was assessed by the Positive and Negative Syndrome Scale (PANSS), and personal and social functioning was evaluated using the Personal and Social Performance (PSP) scale at baseline, at 6 months (discontinuation of interventions) and after 6 months without interventions. Results: The experimental group tended to an improvement in sustained attention $(p=0.075)$, yet this was not maintained after 6 months without interventions. Both groups showed improvements in selective attention and executive function at 6 months, which were not maintained after one year, with no differences between groups. No differences were found in social functioning between the groups and throughout the 12 follow-up months. The factor analysis of the 5-factor PANSS (as proposed by Van der Gaag, 2006) showed no significant change in the factors "positive", "negative", "disorganization" and "emotional distress" over time and between groups. Only the placebo group exhibited a significant improvement in the factor "excitement" after 6 months compared with the experimental group, which was not maintained after 6 months without interventions. Conclusion: The cognitive arithmetic training by the Kumon method tends to improve sustained attention after 6 months, with no impact on either executive function or working memory. This trend was not sustained after 6 months without interventions.

Descriptors: Cognition; Rehabilitation; Neuropsychology; Schizophrenia; Randomized controlled trial. 
Introdução

\section{INTRODUÇÃO}

\subsection{A Terapia de remediação cognitiva (CRT) na esquizofrenia}

A esquizofrenia é considerada uma doença mental grave segundo os critérios do DSM-IV-TR (2002), caracterizada por um conjunto de sintomas presentes por um período de um mês e com alguns sinais do transtorno persistindo por pelo menos seis meses e associados com acentuada disfunção social ou ocupacional. Os sintomas chamados de positivos compreendem distorções do pensamento ou exageros do pensamento inferencial (delírios), da percepção (alucinações), da linguagem e comunicação (discurso desorganizado) e do monitoramento comportamental (comportamento amplamente desorganizado ou catatônico); já os sintomas negativos incluem restrições na amplitude e intensidade da expressão emocional (embotamento do afeto), na fluência e produtividade do pensamento (alogia) e na iniciação de comportamentos dirigidos a um objetivo (avolição). Os subtipos de um quadro de esquizofrenia são do tipo paranóide (quando há presença de delírios ou alucinações auditivas proeminentes no contexto de uma relativa preservação do funcionamento cognitivo e do afeto), do tipo desorganizado (quando o discurso e comportamento são desorganizados e o afeto embotado ou inadequado), do tipo catatônico (quando há uma acentuada perturbação psicomotora, que pode envolver imobilidade motora, atividade motora excessiva, extremo negativismo, mutismo, peculiaridades dos movimentos voluntários, ecolalia ou ecopraxia indiferenciado) e do tipo residual (quando houve pelo menos 
Introdução

um episódio de esquizofrenia, mas o quadro clínico atual não apresenta sintomas psicóticos positivos proeminentes). Para Elkis e Louzã (2007) o quadro clínico da esquizofrenia é bastante polimorfo e heterogêneo. O diagnóstico é feito a partir dos sinais e sintomas apresentados pelo paciente e pelos dados da anamnese uma vez que não há sintomas ou sinais patognomônicos.

A esquizofrenia é considerada por muitos autores uma desordem multidimensional que engloba complexos fatores biológicos, psicológicos e socioculturais que se interagem e prejudicam o funcionamento do pensamento no curso da doença. Do total, cerca de $2 / 3$ dos pacientes não conseguem alcançar ou manter papéis sociais básicos como o emprego, cônjuge, genitor e se integrar na comunidade. As abordagens de reabilitação, como treinamento de habilidades social e vocacional e terapia cognitiva comportamental têm como meta auxiliar os pacientes a adquirir importantes habilidades da vida, além de reduzir os prejuízos no funcionamento de papel social (Seth et al., 2010).

Um campo ainda a ser explorado consiste em reabilitações com foco nos aspectos cognitivos da esquizofrenia e outras doenças mentais severas. Essa nova área tem movido esforços para um alcance além do treinamento de habilidades social e vocacional e se preocupa com a compreensão do modo como os indivíduos lidam com a doença mental no cotidiano. Recentemente, uma série de estudos têm se dedicado a entender a relação entre os déficits cognitivos, social e a funcionalidade dos indivíduos com 
Introdução

esquizofrenia, com a perspectiva de remediar estes déficits e, conseqüentemente, o impacto dos mesmos sobre a vida destes sujeitos (Horan et al., 2009).

Uma técnica de reabilitação consiste nas terapias cognitivas que procuram, basicamente, desenvolver estratégias compensatórias para a aprendizagem e lembrança das informações, agindo especificamente em regiões pré-frontais responsáveis pela memória de trabalho e atenção. Estudos indicam redução dos sintomas e melhora da funcionalidade em pacientes com esquizofrenia através do desenvolvimento de diferentes formas de terapia cognitiva, sendo capazes de se perpetuar anos depois (Swerdlow, 2011).

No entanto, as dificuldades cognitivas são consideradas limitadoras na melhora da aprendizagem em terapia psicossocial e programas de reabilitação bem como no funcionamento social e vocacional. Assim, pesquisadores têm associado à esquizofrenia as dificuldades cognitivas, com um impacto significativo na qualidade de vida e no resultado do tratamento (Kraemer e Kupfter, 2006).

O conhecimento do papel e significado dos déficits cognitivos em esquizofrenia faz-se, portanto, necessário, sendo relevante como alvo do cuidado em esquizofrenia nas remediações cognitivas. Nas últimas décadas surgiram diversas técnicas de remediação computadorizadas e nãocomputadorizadas destinado para grupos ou individual, desenvolvida e adotada em abordagens de tratamento multimodal e estudos analisando a 
Introdução

eficácia deles e, recentemente, quantitativamente revisadas (Vita et al., 2011).

Os indivíduos com esquizofrenia apresentam variações em seu perfil cognitivo, cuja variabilidade faz com que a terapia de remediação cognitiva precise ser individualmente adaptada. Assim, a terapia de remediação cognitiva (CRT) já tem apresentado algumas adaptações para cada dificuldade cognitiva, com um programa mais pautado nas atividades de vida diária do paciente (Delahunty et al., 2001). De fato, a chave para uma maior eficiência apontada pelos estudos reside, principalmente, na terapia de remediação cognitiva apresentar sucesso em uma variedade de dificuldades cognitivas bem como no diagnóstico de esquizofrenia, e se esta melhora cognitiva é capaz de impactar no funcionamento social (Wykes et al., 2007).

Nos últimos dez anos, a Terapia de Remediação Cognitiva tem sido bastante utilizada para a reabilitação das funções cognitivas em pacientes com esquizofrenia, sendo importante para a previsão do funcionamento social. No entanto, alguns autores apontam que seus programas raramente se baseiam em uma teoria clara, dependendo mais da prática do que de uma aprendizagem a priori, o que evidencia uma eficácia variável, de acordo com os componentes específicos do treinamento (Wykes e Van Der Gaag, 2001).

Recentes revisões indicam que todos os domínios cognitivos, exceto aprendizagem visual e memória, respondem à terapia de remediação cognitiva. A heterogeneidade das dificuldades cognitivas é bem estabelecida 
Introdução

em esquizofrenia e uma ampla abordagem que contemple múltiplos domínios pode ser mais benéfica aos pacientes. Também não há indicação de um único domínio capaz de melhorar o funcionamento social (Wykes, 2011)

No entanto, alguns déficits cognitivos mostraram melhoras somente dentro do contexto da CRT, ou seja, as aquisições de habilidades cognitivas e funcionais não conseguiram ser generalizada para a vida cotidiana do sujeito. Assim, não foi possível verificar, por exemplo, melhorias muito significativas em planejamento das ações nas situações do dia-a-dia (Wykes et al., 2007). Por outro lado, a terapia de remediação cognitiva (CRT) pode vir a auxiliar em uma melhora duradoura na memória imediata, que, de forma indireta, pode promover uma melhora no funcionamento dos pacientes nas atividades mais rotineiras do cotidiano (Wykes et al., 2008).

Em relação à memória, um estudo comparativo entre terapia de trabalho convencional associada com remediação cognitiva e terapia de trabalho sozinha realizada em pacientes com esquizofrenia pôde-se observar um aumento significativo no desempenho em memória de trabalho no grupo que recebeu remediação cognitiva, passando de $45 \%$ para $77 \%$ se comparados com uma queda de $56 \%$ para $45 \%$ em relação àqueles em condição de controle (Bell et al., 2003).

Déficits cognitivos e na cognição social fazem parte dos prejuízos observados nos paciente com esquizofrenia, entretanto, ainda não há um consenso nos estudos acerca do impacto da cognição na funcionalidade dos 
Introdução

pacientes. Em alguns estudos embora as tentativas de reabilitação tenham, muitas vezes, se mostrado efetivas na cognição básica (ex: atenção, memória e funções executivas), não demonstraram uma melhora significativa nos aspectos mais amplos do comportamento e do ajustamento social (Hogarty et al; 2004). Já outros estudos sugerem que os déficits cognitivos são mais ligados ao desfecho funcional que os sintomas psiquiátricos. Mudanças ao longo do tempo em habilidades de cognição através de uma aprendizagem apropriada e mais horas de treinamento se mostraram capazes de melhorar as habilidades na vida em indivíduos com esquizofrenia (Veltro et al., 2011).

Nas pesquisas também não encontramos muita clareza em relação à quão grande as mudanças cognitivas são necessárias para uma melhora funcional, salientando-se apenas a durabilidade destas alterações ao longo do tempo. Assim, os objetivos gerais das terapias de remediação cognitiva têm sido a duração das mudanças cognitivas além do foco na aprendizagem de uma habilidade específica (Wykes et al., 2011).

Além disso, podemos perceber que não só o treinamento cognitivo pode influenciar na cognição e na vida prática do indivíduo como estas também dependem de outras variáveis, tais como: a educação, a situação pré-mórbida e adaptação, a inteligência e humor, as circunstâncias sociais e a disponibilidade de uma rede de apoio (Ducharme \& Spencer, 2001). Apesar disso, Hogarty e colaboradores (2004) constataram que muitos dos déficits cognitivos e comportamentais relacionados aos pacientes com 
Introdução

esquizofrenia que se mostravam suficientemente estáveis melhoraram quando expostos à terapia de remediação cognitiva.

Em estudo de meta-análise acerca da eficácia da terapia de remediação cognitiva, foram constatadas melhoras cognitivas significativas e uma modesta melhora no funcionamento social. No entanto, apesar da CRT constituir-se em um processo promissor, o autor recomenda que na prática clínica o treinamento de remediação cognitiva não seja o único processo de reabilitação, mas que ao contrário, seja incluído em abrangentes programas de reabilitação, envolvendo outras atividades como terapia ocupacional, orientação profissional, auto-cuidado, entre outras atividades terapêuticas (Wykes \& Van Der Gaag, 2001).

Em estudo com 42 pacientes com esquizofrenia separados em grupo controle e grupo experimental com intervenção através de um programa de treino cognitivo computadorizado por um período de 12 meses, foi possível constatar, por meio da aplicação de uma bateria neuropsicológica, o quanto o treinamento de remediação cognitivo produz uma melhora significativa na memória de trabalho em relação ao grupo controle. No entanto, também se verificou uma melhora global em ambos os grupos de trabalho com relação às funções executivas, a memória episódica verbal e espacial e a velocidade de processamento da informação (Kurtz et al., 2007).

Confirmando a hipótese da remediação cognitiva como um tratamento fiável para melhora no funcionamento cognitivo e funcionamento psicossocial, um estudo de 85 pacientes com diagnóstico de esquizofrenia e 
Introdução

separados em remediação cognitiva computadorizada e controle foi possível verificar significativa melhora, em 3 meses de treinamento, nas medidas de funcionamento cognitivo geral, velocidade psicomotora e aprendizagem verbal no grupo de remediação cognitiva. Contudo, ambos os grupos demonstraram significativa melhora no período follow-up em sintomas positivos e subescala de depressão PANSS (Lindenmayer, 2008).

Em relação a estes e a todos os estudos que se relacionam com alguma intervenção psicossocial, ressalta-se a existência de variáveis, tais como: uma possível influência das horas despendidas para o treinamento, a interação com o profissional e a estimulação cognitiva não-específica, que podem além do treinamento cognitivo também auxiliar o paciente a melhorar seu desempenho cognitivo (Kurnz et al., 2007).

Em habilidades como prestar atenção, lembrar e processar a informação a ser aprendida são considerados críticas para o desfecho do tratamento, entretanto, a aprendizagem além de depender da cognição também sofre influência de técnicas de instrução e motivação do paciente para o seu engajamento na atividade proposta e aprendizagem de uma nova habilidade (Medalia \& Saperstein, 2011).

Há evidências de que as pessoas com esquizofrenia apresentam déficits cognitivos estabilizados, persistentes e resistentes ao tratamento farmacológico com impacto significativo na funcionalidade, o que explicaria o baixo desempenho nos vários setores sociais aos quais estes indivíduos são submetidos (Kurtz \& Richardson, 2011). Assim, um estímulo para o 
Introdução

desenvolvimento de novos tratamentos farmacológicos com foco nos déficits cognitivos tem sido a identificação dos processos cognitivos básicos preditivos de disfunção social. Contudo, alguns autores acreditam na improbabilidade de intervenções só em cognição básica serem suficientes para o alcance de um bom funcionamento, pois nos estudos somente cerca de $40 \%$ dos indivíduos com esquizofrenia apresentam déficits cognitivos específicos (Horan et al., 2009), embora possam apresentar pouca habilidade social (Horton \&Silverstein, 2008).

Muitos estudos relacionam os prejuízos sociais às altas taxas de recaída e baixa qualidade de vida, entretanto, recentes tentativas de associação do treinamento cognitivo ao treinamento de habilidades sociais tem tido sucesso parcial. Desta forma, o treinamento intenso de cognição primária seria capaz de melhorar os déficits cognitivos em atenção, memória e função executiva, mas não é generalizada à função social (Choi \& Kwon, 2006)

Por isso, existe uma inclinação dos estudos para o desenvolvimento de estratégias de reabilitação cognitiva associando intervenções cognitivas específicas - como a atenção e memória - com os domínios de cognição social - como o processamento de emoção e teoria da mente (Horton \& Silverstein, 2008). Alguns estudos indicam que a remediação cognitiva melhora o desempenho cognitivo, os sintomas e o funcionamento psicossocial, principalmente diante do dispêndio de muitas horas de treinamento. Já para outros autores a remediação cognitiva será ineficaz se 
Introdução

ignorar a cognição social e seus respectivos componentes, sendo que as revisões sugerem que os déficits cognitivos são mais ligados ao desfecho funcional que os sintomas psiquiátricos (Veltro et al., 2011).

Nas últimas décadas, diversas abordagens em treinamento cognitivo foram desenvolvidas, tais como: exercícios cognitivos repetitivos computadorizados ou na versão em lápis e papel; a aprendizagem de estratégias para a organização das informações ou estratégias adaptativas que envolvem o ambiente como fechamento de caixas, empilhamento de pílulas, etc; o comportamento e aprendizagem didática de técnicas tais como: instruções, reforço positivo, etc. (Kraemer \& Kupfter, 2006).

A primeira técnica desenvolvida de terapia de remediação cognitiva denomina-se errorless learning e consiste no ensinamento de tarefas cognitivas reduzindo os erros. Isto significa que a tarefa ou o terapeuta dá suporte a todos os passos requeridos para completar a tarefa. Às vezes, a tarefa é construída como resultado final no começo ou as tarefas são apresentados inicialmente muito lentamente ficando mais rápido com o passar das lições ou as tarefas mais simples são fornecidas primeiro levando a uma mais difícil. Gradualmente, os suportes são removidos quando os participantes começam a adquirir mais habilidades, mais confiança de suas habilidades e então, tornam-se mais independentes do terapeuta ou tarefas de suporte (Wykes et al., 2011).

Errorless learning é um treinamento designado para compensar os prejuízos em cognição que impedem ou restringem a aquisição de uma 
Introdução

habilidade. É baseada teoricamente e empiricamente em um modelo dirigido que propõem uma ocorrência da aprendizagem mais forte e durável através da ausência de erros (Kern et al, 2012).

Achados a respeito da influência dos erros em aprendizagem na esquizofrenia tem sido mais promissor que os achados para aprendizagem implícita. O'Carroll et al (1999) e Pope e Kern (2006) encontraram o impedimento de novas aprendizagens em amostra com esquizofrenia devido à comissão de erros. Estes estudos usaram um paradigma inicialmente descrito por Wilson (1999) com pacientes com cérebros lesionados, envolvendo a aprendizagem sob condições errorfull e errorfree. O estudo de O'Carroll e colaboradores (1999) incluiu dois grupos de pacientes com esquizofrenia classificados como memória prejudicada e não-prejudicada e um grupo controle. A comissão de erros pareceu afetada no desempenho da aprendizagem em memória prejudicada, mas não no grupo de memória nãoprejudicada. Já o estudo de Pope e Kern (2006) incluiu uma amostra de esquizofrenia e desordem esquizoafetivo ambulatorial e demograficamente comparados com adultos saudáveis. Os resultados indicaram um efeito de erros em aprendizagem em pacientes se comparados aos adultos saudáveis.

No entanto, o mecanismo que o errorless learning trabalha não é totalmente entendido. Previamente proposto, o errorless learning compensa os déficits cognitivos em esquizofrenia para a redução da demanda em memória explícita e, simultaneamente, auxilia a memória implícita. A ênfase 
Introdução

em suas correções de estímulo-resposta automáticas sugere envolvimento proeminente em processos de memória implícita, entretanto, ainda há poucas evidências empíricas que dão suporte a esta proposta (Kern et al., 2002).

Kern e colaboradores (2009) avaliaram em seu estudo o impacto do errorless learning no desempenho de trabalho em 40 pacientes ambulatorial com esquizofrenia randomizados em programa de treinamento de trabalho convencional e treinamento errorless learning. Os resultados indicam melhores índices na capacidade de trabalho em errorless learning, embora não tenha indicado impacto significativo em aquisição e bem-estar no trabalho.

Em outro estudo de Kern e colaboradores (2008) o grupo de errorless learning obteve melhor desempenho que o grupo de instrução convencional em escala da qualidade e Inventário de comportamento no trabalho (WBI) avaliado nas semanas 2,4 e 12 . Estas diferenças foram relativamente consistentes ao longo do tempo, entretanto, não houve diferenças em autoestima, satisfação ou estresse no trabalho. A instrução convencional baseou-se em instrução verbal, uma demonstração visual, prática independente e feedback corretivo. 
Introdução

\subsection{O método de cálculo aritmético Kumon como remediação cognitiva}

"Há muitos cavalos que conseguiram correr mil milhas de uma vez, mas são raros os treinadores capazes de fazê-los correr tanto".

Toru kumon

O método Kumon, desenvolvido há cinqüenta anos no Japão e aplicado há trinta anos no Brasil, é um programa de estudo individualizado e planejado de acordo com a capacidade atual do aluno. Neste o aluno freqüenta a unidade duas vezes por semana, no horário que lhe é mais conveniente, além de realizar tarefas diárias em casa. O tempo de estudo é variável, dependendo da complexidade do assunto abordado, mas podendo variar de 20 a 50 minutos conforme for de Ensino Fundamental ou Ensino Médio (Kumon, 2005).

O primeiro passo do treinamento consiste em realizar um teste diagnóstico para o conhecimento do estágio que o aluno já domina e consideram razoavelmente fácil com o intuito de desenvolver, inicialmente, a concentração e os hábitos de estudo. O acúmulo de sensações como "eu consigo" ou "eu consegui" busca motivar o aluno, elevando assim, a habilidade de execução de tarefas e a concentração nos estudos.

No estudo individualizado cada aluno tem um programa desenvolvido de acordo com sua capacidade atual, com seu ritmo de aprendizagem e com metas a serem atingidas. Esse programa independe da idade e da série escolar do aluno, por isso o sistema de estudo individualizado é adequado para todas as idades. 
O material do Kumon é elaborado de acordo com a dificuldade nos cálculos de aritmética, cujas dificuldades são colocadas em ordem crescente para que o aluno consiga estudá-lo praticamente sozinho, sem o auxílio do orientador. Após finalizar os exercícios constantes das folhas do dia, o estudante as entrega ao orientador para a verificação dos acertos, e caso haja erros a folha é devolvida para que ele mesmo faça a correção necessária sem a ajuda do orientador. Este procedimento é repetido até que todos os exercícios estejam inteiramente corretos (Kumon, 2005). Assim, constitui-se em um programa de treino com exercícios repetidos similar ao treinamento de remediação cognitiva errorless learning.

Além da melhora na aprendizagem constatada em alunos sem nenhuma patologia, na literatura encontramos um estudo realizado no Japão com casos de demência tipo Alzheimer demonstrando uma melhora significativa nas funções do córtex pré-frontal e nas atividades de vida diária em grupos que freqüentaram o programa de leitura em voz alta e cálculos de aritmética do método Kumon durante um período de seis meses, ao contrário do grupo controle que não recebeu o treinamento (Kawashima et al., 2005). 
Introdução

Tabela 1 - Principais características e metas do Kumon.

\begin{tabular}{|c|c|}
\hline Características & Benefícios \\
\hline $\begin{array}{c}\text { Ponto de partida - Começando os estudos no } \\
\text { Kumon }\end{array}$ & Auto-estima • Concentração • Autoconfiança \\
\hline Estudo diário - A prática traz a perfeição & $\begin{array}{c}\text { Disciplina } \cdot \text { Organização } \cdot \text { Capacidade de } \\
\text { execução de tarefas }\end{array}$ \\
\hline Tempo para resolução - Estudo concentrado & Concentração • Responsabilidade \\
\hline Revisão & $\begin{array}{c}\text { Tranqüilidade } \cdot \text { Segurança } \cdot \text { Garantia de } \\
\text { assimilação }\end{array}$ \\
\hline Autocorreção & Aprender com os próprios erros \\
\hline Estudo com metas & Disciplina $•$ Organização \\
\hline Avanço além da série escolar & Independência $\cdot$ Segurança \\
\hline Avaliação diária - feedback & Auto-avaliação \\
\hline Autodidatismo & Iniciativa \\
\hline
\end{tabular}

Ref: Kumon T, 2005.

Este trabalho se propõe a investigar o treinamento de cálculos matemáticos pelo método Kumon como um programa de terapia de remediação cognitiva errorless learning, cujo método de treinamento já apresenta conteúdo e material organizado e pré-estabelecido amplamente difundido no Brasil e no mundo. Em termos econômicos, embora não testado neste estudo, acreditamos no potencial de uso do Kumon em larga escala e a baixo custo se comparada ao treinamento de remediação cognitiva convencional, podendo funcionar de maneira similar, alternativa e/ou substitutiva. 
Introdução

Não parece haver, até o momento, estudos específicos sobre treino cognitivo matemático errorless learning em pacientes com esquizofrenia e na população brasileira. Obviamente não se pretende esgotar o assunto, mas sim investigar de modo exploratório as possibilidades de melhora das funções cognitivas subjacentes à matemática em pacientes brasileiros com esquizofrenia.

A seguir, encontram-se os estudos mais recentes das principais funções cognitivas consideradas subjacentes à matemática e, sua posterior descrição, a fim de proporcionar melhor compreensão da relação entre a remediação cognitiva matemática proposta e os domínios cognitivos relacionados à matemática do qual o estudo se propõem a estimular.

\subsection{Dificuldade em aprendizagem matemática}

As crianças nascem com certas habilidades numéricas, como o entendimento intuitivo dos números. Estas habilidades permitem a discriminação entre diversos números de objetos, ações e sons. Há também evidências das crianças adicionarem e subtraírem um grande número de objetos. Estas habilidades são encontradas tanto em alguns animais bem como em culturas humanas, e tem sido referida às vezes como uma habilidade numérica biologicamente primária (Kittalã et al., 2009). 
Introdução

Quando as crianças chegam ao jardim de infância, trazem conceitos baseados em experiências informais. Estas experiências advêm de toda a infância e fornece base para a aquisição cada vez maior de símbolos abstratos. Pesquisas psicológicas têm buscado mais informações sobre a informação informal bem como sobre os mecanismos capazes de mover a criança de um nível de entendimento a outro. Assim, por exemplo, há pesquisas psicológicas que consideram a educação prática como o entendimento das transformações quantitativas em pré-escolares (subtração e adição) através de tarefas não verbais; a dissociação da dificuldade de fração na escola com a noção de parte-todo na vida prática; e coordenação de várias dimensões de quantidade e entendimento destas interações segundo pesquisas Piagetianas (Newcombe et al., 2009).

Vários domínios cognitivos, entendimento da magnitude e contagem são tidos como variáveis preditoras simplificadas de uma habilidade complexa que é a matemática. Cada habilidade básica representa um conhecimento cristalizado construído na base de experiências em casa, na escola e outros ambientes sociais, chamados de vocabulário. No entanto, cada oportunidade de aprendizagem também interage com uma capacidade cognitiva básica de aprendizagem, e o acesso a estas capacidades cognitivas que independem do conhecimento e geralmente menos determinada por fatores sócioeconômicos são essenciais para se engajar em operações cognitivas mais complexas. A esta habilidade biologicamente subjacente para aquisição de conhecimentos durante a vida chamamos de inteligência fluída (Bull, 2008). 
A inteligência fluída e a cristalizada foram originalmente descritas por Raymond Cattel. A inteligência cristalizada está mais associada como sendo dependente da aprendizagem ao passo que a inteligência fluída independe de experiências passadas. Historicamente, a diferença entre estas duas inteligências foram mantidas através do quociente de inteligência verbal e de execução nas escalas Wechsler de Inteligência.

Diversos estudos convincentemente mostram que o senso de números é uma habilidade inata, onde há evidências emergentes de que o desenvolvimento da discalculia seja causado por um déficit aguçado desta representação e no processamento da magnitude de informação numérica (Kittalã et al., 2009).

A característica fundamental de senso numérico inclui o entendimento implícito e potencialmente inerente da quantidade exata de várias ações ou objetos e de símbolos (ex: números arábicos) que eles representam (ex: $3=/ / /)$, e a magnitude aproximada de grandes quantidades (Geary, 2010).

Muitos critérios diagnósticos usam o termo de desenvolvimento da discalculia para descrever dificuldades moderadas a extremas em computação numérica fluente que não pode ser atribuída às dificuldades sensoriais, baixo quociente de inteligência (QI) ou privação educacional. A discalculia é considerada heterogênea em etiologia e na manifestação de dificuldades matemáticas (Rubinsten e Henik, 2009). 
Introdução

Há alta ocorrência de discalculia em população pediátrica e sugerem mecanismos cognitivos e neurofisiológicos subjacentes. As crianças com dificuldades em matemática tendem a apresentar padrão similar de déficit de processamento visual àqueles previamente reportados em outras desordens do desenvolvimento como a dislexia, desordem de desenvolvimento da coordenação, autismo e síndrome de Willians (Sigmundsson, 2010).

A discalculia consiste em uma desordem na habilidade matemática com prejuízo específico na função cerebral. Supõe-se ser um déficit único, não causado por desordem de leitura (dislexia), atenção (TDHA) ou problemas de inteligência geral. Sujeitos com discalculia falham em uma ampla gama de tarefas numéricas, por exemplo, apresentam dificuldade em recuperar fatos numéricos usando procedimentos aritméticos e operação de solução aritmética (Ashknazi, 2009).

Assim, o desenvolvimento da discalculia é uma dificuldade de aprendizagem específica que afeta a aquisição de habilidades matemáticas em crianças normais. Embora a aprendizagem pobre, privação ambiental e menor inteligência têm sido implicadas na etiologia de desenvolvimento da discalculia, dados recentes indicaram que a dificuldade de aprendizagem é uma desordem cerebral associada com pré-disposição genética, cujo substrato neurológico envolve ambos os hemisférios, particularmente áreas parietotemporal esquerda (Shalev e Gross-tur, 2000). 
Introdução

$\mathrm{Na}$ literatura há poucas informações a respeito do prognóstico da discalculia em longo prazo, entretanto, parece persistir pelo menos em curto prazo, em metade dos pré-adolescentes afetados. As conseqüências da discalculia e seu impacto na educação, emprego e bem-estar psicológico dos indivíduos afetados são ainda desconhecidos também (Geary, 1994).

Dois modelos cognitivos têm sido propostos para explicar o processamento aritmético normal e a discalculia. O modelo desenvolvido por McCloskey e colaboradores (1985) dividiu a habilidade matemática em três principais grupos: (1) compreensão do conceito de números; (2) produção de números e (3) cálculos. Este forneceu uma base teórica para explicar déficits isolados em domínios específicos da aritmética, onde outras facetas matemáticas permanecem intactas.

Já o "modelo de código triplo" proposto por Dahaene e Cohen (1995) são neuropsicologicamente e anatomicamente baseados nos elementos verbais, visual e representação da magnitude. De acordo com este modelo, operações matemáticas relativamente simples são processadas pelo sistema verbal sem o hemisfério esquerdo ao passo que os procedimentos aritméticos mais complexos processados - que requer estimativa da magnitude e representação visual - estão bilateralmente localizados. Os dados experimentais deste modelo foram fornecidos através da avaliação de indivíduos com desempenho aritmético normal e por casos de pessoas com lesão cerebral focalizados. 
Introdução

No entanto, a dificuldade em aprendizagem matemática se difere da discalculia na medida em que o termo discalculia é reservado para déficit em habilidade numérica aguçada, como por exemplo, dificuldade em processar quantidades e uma má função relativamente específica no nível comportamental. Em contraste, a dificuldade em aprendizagem matemática é causada por diversos déficits cognitivos como a memória de trabalho, processamento visuo-espacial ou atenção. Ambos são desordens em matemática sem outra desordem não-numérica e podem se manifestar em diferentes comportamentos em estágios precoces de desenvolvimento. No entanto, eles às vezes manifestam comportamentos similares mais tarde na vida por causa da influência de vários fatores de desenvolvimento como a escolaridade (Rubinsten \& Henik, 2009).

A compreensão da dificuldade em matemática é também importante por poder representar um custo econômico. A organização para cooperação econômica e desenvolvimento (OECD) demonstrou que meio desvio-padrão em matemática implica, pela experiência histórica, um acréscimo anual de produto interno bruto per capita de $0,87 \%$ no Reino Unido e de $0,74 \%$ nos Estados Unidos. Em estudo no Reino Unido a baixa numerácia foi apontada como responsáveis por menores salários, menos consumo de bens, maior propensão a doenças e a problemas com a lei e maior necessidade de auxílio na escola (Butterworth et al., 2011). 
Introdução

O DSM-IV define a dificuldade em aprendizagem matemática em termos de discrepância entre testes de desempenho de realização matemática e expectativa de desempenho baseado na idade, inteligência e anos de estudo e para adultos interferem significativamente em suas atividades diárias. Entretanto, não está bem estabelecido se existe diferença nas formas de déficit de cognição matemática entre crianças e adultos com baixo escore de realização matemática e inteligência (Geary, 2011).

Em revisão recente concluiu-se que a competência matemática empobrecida é comum entre os adultos e resultam em dificuldades de empregabilidade e em muitas atividades comuns do dia-a-dia. Entre os estudantes norte-americanos, cerca de $7 \%$ das crianças e adolescentes apresentam dificuldade de aprendizagem matemática (MLD) e cerca de 10\% tem baixa realização matemática (LA) persistente, apesar de habilidade média em muitas outras áreas (Geary, 2011).

Não encontramos, até o momento, estudos acerca de dificuldade matemática em população de esquizofrenia adulta e brasileira, entretanto, a dificuldade matemática parece também estar associada aos prejuízos de mecanismos cognitivos subjacentes da própria doença, tais como a memória de trabalho, função executiva e atenção (Kraemer \& Kupfter, 2006). Ainda não se sabe se há um padrão de dificuldade matemática relacionada à cognição, mas a sua conseqüência pode ser constatada nas altas taxas de desemprego, baixo nível educacional e funcionalidade também apresentada 
por grande parte dos pacientes com esquizofrenia (Dawes et al., 2011; Vita et al., 2011).

\subsection{Alterações cognitivas e dificuldade em aprendizagem matemática}

Na literatura, vários déficits cognitivos foram relacionados como subjacentes e preditivos de dificuldade matemática, tais como, déficits de atenção, memória de trabalho, memória verbal e função executiva (Pavuluri et al., 2006).

Em revisão recente, a compreensão das propriedades numéricas (ex: magnitude dos números e cardinalidade) são consideradas o bloco de construção básico do qual a aritmética é construída. Além disso, a recuperação dos fatos e cálculos é considerada funções mediadoras da proficiência aritmética. Assim, a memória de trabalho (ex: armazenamento temporário e manipulação da informação) faz-se necessária quando a informação não pode ser facilmente recuperada e precisa ser calculada baseada em mecanismos de decomposição e/ou outras regras. Em conjunto com este processo mnêmico, recursos atencionais, operações de seqüência mental e decisão também influenciam na velocidade e precisão do desempenho. Estes recursos cognitivos de domínio geral são apontados como tão vitais quanto o conhecimento numérico aprendido em sala de aula (Menon, 2010). 
Em estudo de avaliação cognitiva em alunos de primeira série do ensino fundamental composta por tarefas que dão acesso à - habilidade de compreensão e produção de números, conhecimento de contagem, habilidade aritmética, memória de trabalho e facilidade de recuperação da informação para memória de longo prazo - foram encontrados diferentes padrões de déficit de cognição e cognição intacta nos diferentes grupos constituídos por alunos com dificuldade de aprendizagem, de leitura ou ambos. Estes resultados sugerem a existência de diferentes déficits cognitivos subjacentes às diferentes formas de dificuldade de aprendizagem (Geary et al., 1999).

Em outra pesquisa de Geary (2011), buscou-se fornecer uma visão global do domínio cognitivo geral preditor de desfechos entre os domínios acadêmicos e a cognição matemática. Para isto, se avaliou 177 estudantes da pré-escola a quinta série utilizando medidas de realização matemática e controlando medidas de inteligência, memória de trabalho e velocidade de processamento. Os seus resultados também indicaram uma quantidade precoce de competências que contribuem unicamente com a aprendizagem matemática. 
Introdução

Em estudo de Berg (2008), através da avaliação de 90 alunos canadenses da terceira a sexta série do ensino fundamental e médio, demonstrou que a velocidade de processamento, a memória de curto prazo (verbal e visuo-espacial) e a memória de trabalho contribuem para o desempenho de cálculos aritméticos. Além disso, a idade cronológica também foi apontada como fator de influência na aritmética.

Pacientes com esquizofrenia exibem uma variedade de déficits cognitivos, do qual também podem afetar seu desempenho em tarefas de cálculos (para uma visão geral, ver Frith, 1992; Gray et al., 1991). Em particular, os prejuízos em funções da memória de trabalho, como por exemplo, o armazenamento de curto prazo e manipulação da informação, pode ser observado. Estes déficits dizem respeito, principalmente, ao componente de controle executivo da memória de trabalho, envolvida na manipulação flexível das informações (Norman e Shallice, 1986). A habilidade matemática é acessada nos estudos, principalmente, através de tarefas aritméticas complexas de baterias de testes de inteligência tais como o WAIS-R (Wechsler, 1981), no qual são baseados em várias funções cognitivas (Green, 1996; Bilder, 1997).

Em estudo de avaliação neuropsicológica de pacientes com esquizofrenia demonstrou o mesmo processo cognitivo subjacente envolvido nas tarefas aritméticas que o grupo controle saudável, com pior desempenho em tarefas de função executiva nos pacientes com esquizofrenia (Kiefer e Weisbrod, 2002). 
Em muitos estudos pacientes com esquizofrenia demonstram alterações no desempenho em uma grande variedade de testes neuropsicológicos, principalmente no que se refere à atenção, memória e funções executivas (Monteiro \& Louzã, 2007), funções cognitivas estas apontadas em outras pesquisas com diferentes populações como sendo subjacentes à matemática.

As pesquisas têm demonstrado relação entre funções neuropsicológicas e academia em crianças bipolares. Em primeiro estudo relacionando déficits cognitivos e academia através da aplicação de uma bateria neuropsicológica em uma amostra de 55 crianças e adolescentes bipolares com e sem déficit de atenção e hiperatividade (TDHA), indicou a influência de alguns domínios cognitivos como a função executiva, atenção, memória de trabalho e habilidade para solução de problemas nas dificuldades acadêmicas (Pavuluri et al., 2006). 
Introdução

A investigação de diferentes componentes cognitivos de desempenho matemático em jovens com outras doenças médicas tem identificado déficit cognitivo particular associado com déficits matemáticos específicos. Assim, por exemplo, crianças com Síndrome de Turner apresentaram pior habilidade visuo-espacial e organizacional em procedimentos matemáticos ao passo que homens com déficit de atenção e hiperatividade (TDHA) demonstraram pior solução de problemas e desempenho computacional em aritmética. No caso de jovens bipolares, as dificuldades matemáticas não envolveram simplesmente computador (adição básica, subtração, multiplicação ou divisão), mas também envolveram organização, espaço e aspectos meta-cognitivos de desempenho matemático, fortalecendo a hipótese de que os prejuízos nos processos cognitivos podem estar subjacentes ao padrão de déficits matemáticos (Lagace et al., 2003; Cirino, 2010)

Por outro lado, uma explicação total das dificuldades matemáticas não pode ser encontrada em estudos que investigam somente os mecanismos cognitivos, mas devem também considerar a influência de outros fatores na aprendizagem da matemática tais como social, motivacional e os fatores educacionais (Bull et al., 1999). 
Introdução

Em estudo com 119 participantes, adolescentes com remissão de bipolaridade tem um perfil de dificuldade matemática que os diferencia de adolescentes com depressão unipolar e sujeitos saudáveis. Seu resultado demonstra, principalmente, que os déficits matemáticos não derivam simplesmente mais de déficits globais de inteligência não-verbal ou função executiva, mas pode estar associada com anormalidades neuroanatomicas que resultam em déficits cognitivos, incluindo um tempo de resposta mais lento. Estes prejuízos sugerem também a necessidade de avaliação especializada de avaliação da matemática como parte de um plano de tratamento clínico follow-up (Lagace et al., 2003).

$\mathrm{Na}$ literatura encontramos poucos estudos longitudinais de avaliação cognitiva de treinamentos específicos de matemática, apesar de vários estudos apontarem para um prejuízo cognitivo subjacente à dificuldade matemática. Assim, embora a pesquisa de Navarro e colaboradores (2011) tenham demonstrado relativa estabilidade no nível de habilidade matemática entre estudantes de 5 a 7 anos de idade, ainda não é claro um padrão de desenvolvimento matemático entre os estudos. 
Introdução

Um dos poucos estudos randomizados de treinamento matemático foi realizado no Japão com 32 idosos diagnosticados com demência tipo Alzheimer e outro composto por 124 idosos normais, ambos submetidos a um treinamento de solução de problemas aritméticos e de leitura em voz alta durante um período de 6 meses, com resultados significativamente positivos na cognição. No primeiro estudo chegou-se a uma melhora, principalmente, em flexibilidade mental e sensibilidade à interferência ao passo que no segundo estudo houve maior melhora significativa em similaridades e comunicação verbal avaliada por uma escala de exame mini-mental (MMSE) (Kawashima et al, 2005; Uchida e Kawashima, 2008).

No entanto, ao longo da década passada, os pesquisadores demonstraram a eficiência da instrução de estratégias de planejamento (também referida como facilitador de planejamento) em diversos contextos acadêmicos e não acadêmicos em estudantes com dificuldade de aprendizagem e deficiência mental leve. Os resultados destes estudos indicaram que crianças com déficit de atenção e hiperatividade (TDAH) também se beneficiam de instruções de planejamento estratégico em matemática (Iseman \& Naglieri, 2011). 
Introdução

Até o momento, não encontramos na literatura estudos específicos das dificuldades matemáticas em pacientes com esquizofrenia, apesar de muitos estudos constatarem os déficits cognitivos como limitadores de suas atividades diárias e serem preditores de desfecho em longo prazo. Por esta razão, os déficits cognitivos devem ser considerados quando se planeja uma terapia e um programa de reabilitação.

Para compreender como estas funções cognitivas podem influenciar o desempenho matemático e vice-versa, cada uma deve ser considerada. Acreditamos que uma terapia de remediação cognitiva que faça uso de ferramentas para o desenvolvimento de habilidades matemáticas seja capaz de melhorar o desempenho de diversas funções cognitivas subjacentes a matemática, melhorando conseqüentemente prejuízos cognitivos freqüentes para esta população, já apontados em diversos estudos.

\subsubsection{Memória de trabalho}

Estudar o desenvolvimento da memória de trabalho ainda é um desafio. Apesar do surgimento de instrumentos e tarefas voltadas para a investigação da memória de trabalho, ainda não existem medidas específicas capazes de avaliar cada um de seus componentes. Habilidades cognitivas tais como a atenção seletiva, o controle inibitório, a flexibilidade cognitiva e a memória de trabalho propriamente dita apresentam fronteira muito tênues, dificultando assim o estudo mais detalhado de cada uma dessas funções. Ao mesmo tempo, compreender o desenvolvimento dessas funções na criança, que está em constante crescimento, torna a tarefa mais 
árdua ainda. Mesmo com todas essas dificuldades, é possível traçar um panorama geral acerca da memória de trabalho (Uechara \& LandeiraFernandez, 2010).

Para Alloway (2006), a memória de trabalho tem papel-chave no suporte na aprendizagem ao longo dos anos escolares, além da idade adulta. A memória de trabalho é crucialmente requerida para estocar informações enquanto outros materiais são mentalmente manipulados durante a atividade de aprendizagem, formando fundações para a aquisição de complexas habilidades e conhecimento. Um indivíduo com capacidade de memória de trabalho empobrecido muitas vezes se esforça e falha em cada atividade, atrasando a aprendizagem.

$\mathrm{Na}$ literatura encontramos distinção conceitual em relação à memória explicita e implícita. A memória explicita ou declarativa refere-se à retenção de experiências sobre fatos e eventos do passado, ou seja, o indivíduo tem acesso consciente ao conteúdo da informação, e envolve o arquivamento de associações arbitrárias mesmo após uma única experiência, sendo flexível e prontamente aplicável a novos conceitos. Em contrapartida, a memória implícita ou não declarativa é revelada quando a experiência prévia facilita o desempenho numa tarefa que não requer a evocação consciente ou intencional daquela experiência, e requer treinamento repetitivo com uma aquisição gradual ao longo de diversas experiências, portanto, é inflexível e pouco acessível a outros sistemas (Squire, 1988; Reber \& Squire, 1994). 
Introdução

Assim, a memória pode ser compreendida como a capacidade de adquirir, armazenar e recuperar as informações disponíveis. Em outras palavras, a chamada memória declarativa, como o nome sugere, é aquela que pode ser declarada (fatos, nomes, acontecimentos, etc.) e é mais facilmente adquirida, mas também mais rapidamente esquecida. Memórias explicitas chegam ao nível consciente e esse sistema de memória está associado com estruturas no lobo temporal medial (ex: hipocampo, amígdala). Já outra memória é conhecida como não-declarativa, também chamada de implícita ou procedural, e inclui procedimentos motores (como andar de bicicleta, desenhar com precisão ou quando nos distraímos e vamos no "piloto automático" quando dirigimos). Essa memória depende dos gânglios basais (incluindo o corpo estriado) e não atinge o nível de consciência. Ela em geral requer mais tempo para ser adquirida, mas é bastante duradoura. 
Introdução

O termo memória de trabalho evoluiu de um conceito mais precoce de memória em curto prazo e os dois ainda são usados alternadamente. A memória de curto prazo se refere ao armazenamento temporário simples da informação, em contraste à memória de trabalho, que implica em uma combinação de estoque/armazenamento e manipulação. A memória de trabalho constitui-se em uma série de fluídos que requer somente ativação temporária ao passo que a memória de longo prazo constitui-se em uma habilidade permanente mais cristalizada e com maior conhecimento (Baddeley, 2012). Como bem apontam Helene e Xavier (2003), a memória de trabalho se diferencia da memória de curto-prazo por privilegiar a utilização da informação, e não apenas o simples decorrer do tempo, como fator determinante na manutenção ou descarte das informações.

A memória de trabalho é um espaço mental que pode flexivelmente ser usada como suporte para atividades cognitivas diárias que requerem processamento e estocagem, tais como a aritmética mental. Podemos imaginar, por exemplo, uma tentativa para multiplicar dois números falados para você por outra pessoa, sem fazer uso de lápis e papel ou calculadora. Primeiro de tudo, você precisará segurar os dois números na memória de trabalho. O próximo passo será usar regras de multiplicação aprendidas para calcular os produtos de sucessivos pares de números, acrescentando para a memória de trabalho os novos produtos que você processou. Finalmente, você precisará adicionar os produtos aprendidos em memória de trabalho, resultando na solução correta. Assim, sem a memória de trabalho, nós não executaríamos este tipo de atividade mental complexa no qual algumas 
Introdução

informações são mantidas na mente enquanto outros materiais são processados (Alloway et al., 2004).

A matemática é um domínio complexo em que há a contribuição de uma série de habilidades cognitivas para seu desempenho adequado e uma delas é a memória de trabalho. A relação entre a memória de trabalho e as habilidades aritméticas varia de acordo com a idade e com a complexidade das tarefas matemáticas (Gross-Tsur et al., 1996).

À medida que o desenvolvimento progride, há uma melhora em todo funcionamento cognitivo da criança. Segundo Gathercole e Baddeley (1998), a principal mudança que ocorre durante o desenvolvimento da memória de trabalho é o aumento da eficácia operacional e da velocidade de processamento de informação, bem como uma maior utilização de estratégias nas resoluções de problemas. Ou seja, a criança passa a processar informações mais rapidamente e de forma automática, permitindo lidar com maior número de informações ao mesmo tempo. Entretanto, a habilidade que tem sido mais investigada são os armazenadores temporários fonológicos e visuo-espacial, muito provavelmente devido à simplicidade destes subcomponentes da memória de trabalho. 
Em pesquisa que avaliou o desempenho em tarefas aritméticas para avaliação da memória de trabalho em 24 pacientes jovens (23 anos) e 24 idosos (71 anos), os grupos de idade atingiram resultados equivalentes em precisão e velocidade das operações aritméticas, mas os idosos foram mais lentos em relação aos jovens em demanda de memória de trabalho. Isto se deu em função de um tempo adicional requerido para acessar novos objetos em memória de trabalho como as bases de computação. Já em relação à comutação de tarefas a demanda de memória aumentou, mas não foi afetado pela idade, indicando que adultos idosos não têm déficit em acesso seletivo para memória de trabalho (Oberauer et al., 2003).

A memória de trabalho é apontada como fundamental na atividade cognitiva do dia-a-dia assim como para o desempenho acadêmico. Estudos cognitivos da avaliação matemática provêm da avaliação do quanto os déficits podem estar subjacentes às dificuldades em aprender matemática. Muitos estudos têm usado o modelo de memória de trabalho de Baddeley, e recentes trabalhos indicam a memória de trabalho como um mecanismo subjacente individual de crianças em fluídos de inteligência (Bull, 2008). 
Introdução

Os resultados de uma pesquisa com medidas múltiplas de memória de trabalho, memória de curto prazo, velocidade de processamento e inteligência fluída geral de 120 adultos jovens saudáveis sugerem a memória de curto prazo e a velocidade de processamento como bons preditores de inteligência fluída em jovens saudáveis, não ocorrendo o mesmo em relação à memória de trabalho. No entanto, não há tarefas neuropsicológicas com medidas puras destes componentes, ou seja, quanto mais rápido for o avaliador, maior a quantidade de informações que podem ser processadas em uma única unidade de tempo. Então, um indivíduo com memória de trabalho acima da média pode funcionalmente ter uma maior capacidade que outros, mas as causas atribuídas serem a velocidade de processamento global (Conway et al., 2001).

De maneira geral, as habilidades cognitivas são influenciadas por idade, educação e inteligência. Entretanto, função executiva, atenção e memória verbal são bastante específicas e independentes de QI, por isso, podem ser consideradas como um marcador cognitivo em pessoas com esquizofrenia (Walker \& Standen, 2011).

Poucos estudos têm examinado as diferença de desempenho em memória de trabalho entre os gêneros em pacientes com desordem bipolar segundo DSM-IV em fase eutímica, apesar das evidências de dismorfismo sexual em estruturas cerebrais normais, bem como diferenças de gêneros na cognição em pacientes saudáveis e em pacientes com esquizofrenia. No entanto, em estudo de Barret e colaboradores (2008) os gêneros foram 
Introdução

capazes de influenciar a detecção de déficits de memória de trabalho em pacientes bipolares, com melhor desempenho estratégico nos pacientes feminino se comparado aos masculinos. Em pacientes com esquizofrenia, não foi encontrado estudos comparativos da memória de trabalho em relação ao gênero de pacientes com esquizofrenia.

A contribuição da memória de trabalho para habilidade matemática em diferentes idades é mais pronunciada em relação às tarefas de memória de trabalho verbal. Por exemplo, Bull e Scerif (2001) encontraram relacionamento entre memória e matemática em crianças de sete anos, mas esta associação não foi significativa na população adolescente (Gathercole \& Pickering, 2000).

Muitos estudos em pacientes com esquizofrenia apontam para um prejuízo na memória verbal, relacionado à perda de função temporal e préfrontal do cérebro. Já outras pesquisas evidenciam um prejuízo de memória não específica, apresentando a memória não-verbal também prejudicada (Mesholam-Gately et al., 2009). A memória e as funções de aprendizagem são apontadas como mais seriamente prejudicadas que a função intelectual geral, incluindo pacientes sem medicação e em primeiro episódio (Mulholand et al., 2008).

As evidências em relação às habilidades intelectuais (quociente de inteligência - QI) em pacientes com esquizofrenia ainda são divergentes. No entanto, estudos apontam para a existência de uma relação entre os déficits cognitivos e o funcionamento intelectual (Ruiz et al., 2007). 
Introdução

Uma questão importante do relacionamento entre memória de trabalho e dificuldade de aprendizagem é se a memória de trabalho é simplesmente uma extensão do quociente de inteligência (QI). Desde 1980, com o maior desenvolvimento teórico e empírico do constructo de memória de trabalho (WM), diversos investigadores afirmaram que memória de trabalho e habilidade intelectual está fortemente relacionada ou são constructos idênticos.

No entanto, em revisão de 86 trabalhos a respeito do relacionamento entre memória de trabalho e inteligência chegou-se à conclusão de que memória de trabalho não é isomorfo à inteligência geral $(g)$ e inteligência fluída $(g f)$, raciocínio ou algum outro tipo de fator de inteligência. Parte das razões deste ceticismo é explicada pelo fato de não conseguirmos uma boa qualidade nas estimativas de inteligência utilizando apenas uma única escala de raciocínio não verbal como o Raven, mas necessitarem serem geradas a partir de múltiplos testes compostos por diferentes formatos, conteúdos e processos (Ackerman et al., 2005). Este estudo também salienta as limitações e insuficiência dos dados na literatura sobre o relacionamento entre constructos de WM e constructos de habilidade (por exemplo: verbal, espacial, numérico ou raciocínio).

Na meta-análise de Ackerman e colaboradores (2005) encontraram-se diferenças entre as médias de correlação para memória de trabalho (WM) e medidas de habilidade intelectual $(P=.397)$ e entre memória de curto prazo (STM) e medida de habilidade intelectual $(p=.260)$, o que equivale a uma 
Introdução

diferença de $15,8 \%$ de variância entre WM e habilidade intelectual e 6,8\% de variância entre STM e habilidade intelectual. Se esta diferença pode ser considerada grande ou pequena, segundo o autor, depende da perspectiva teórica de orientação individual do pesquisador em explicar as diferenças individuais em inteligência. $O$ grau de conhecimento e de habilidades é apontado por alguns autores como determinante para a existência de diferenças individuais em executivo ou controle atencional, diminuindo a capacidade de detecção da memória de trabalho nas tarefas neuropsicológicas.

Assim, há algumas evidências nos estudos de dissociação entre memória de trabalho e habilidades gerais, o que explicaria as diferenças individuais entre memória e realização escolar. Entretanto, pesquisas recentes têm confirmado uma associação específica entre memória de trabalho e realização após controle estatístico das diferenças de QI em crianças (Swanson \& Saez, 2003; Gathercole et al., 2006).

As crianças com comorbidade matemática e dificuldade de leitura apresentam maior deficiência com solução de problemas aritméticos e cálculo exato de combinações aritméticas, onde seus problemas em outras áreas de cognição matemática (por exemplo: recuperação de fatos aritméticos, aritmética aproximada, valor de lugar, princípios de cálculo, escrita computacional) se equivalem àquelas de crianças com dificuldade matemática somente. Assim, crianças que apresentam somente dificuldade matemática demonstram vantagem em relação às com dificuldade 
Introdução

matemática e dificuldade de leitura em áreas que podem ser medidas pela linguagem (por exemplo: história dos problemas, cálculo exato de combinações aritméticas), mas não em áreas que dependem da magnitude numérica e automaticidade (por exemplo: aritmética aproximada, recuperação de fatos aritméticos) (Geary et al., 1991; Fuchs \& Fuchs, 2002).

Pesquisadores indicam que crianças com comorbidade aritmética e dificuldade de leitura apresentam déficit de memória de trabalho geral ao passo que crianças com apenas dificuldade em matemática podem ter déficits em memória de trabalho específicos. No entanto, na literatura apenas encontramos estudos empíricos de domínio específico da memória de trabalho em amostras com adultos e crianças mais velhas, o que não ocorre em relação ao domínio geral da memória de trabalho, demonstrado em diferentes populações de adultos, crianças e pacientes neuropsicológicos (Baddeley, 1996).

Nos estudos recentes, a memória de trabalho e a função executiva desempenham papel-chave como preditores da precisão em solução de problemas aritméticos, mas as habilidades básicas adquiridas em meios acadêmicos específicos (leitura e matemática) podem compensar a influência da memória de trabalho em solução de problemas (Zheng et al., 2011).

Ao longo do desenvolvimento, o funcionamento e a relação entre os componentes da memória de trabalho podem variar. Crianças aprendem a utilizar os componentes de inúmeras maneiras, seja através do emprego de 
Introdução

novas estratégias ou por um maior grau de velocidade no processamento da informação. Assim, a memória de curto prazo e a memória de trabalho está associada com dificuldades de aprendizagem e podem ser minimizados através de métodos apropriados de remediação cognitiva (Gathercole e Alloway, 2006).

A solução de problemas matemáticos depende da memória de trabalho, compreendido como um sistema de capacidade limitada envolvido na conservação da informação enquanto o mesmo ou outras informações são processados. Baddeley fornece um modelo popular de memória de trabalho para entender as diferenças individuais na solução de problemas. $O$ modelo caracteriza a memória de trabalho como um sistema que interage com dois sistemas de estocagem subsidiária: o discurso baseado no laço fonológico e o esboço visuo-espacial (Miyake et al., 2000).

O laço fonológico é responsável pelo armazenamento temporário da informação verbal. Já o esboço visuo-espacial é responsável pelo armazenamento da informação visuo-espacial por períodos mais breves e desempenha papel-chave na geração e manipulação de imagens mentais. De acordo com a fig. 1, o sistema executivo central é considerado primariamente responsável pela coordenação das atividades do sistema fonológico e sistema visuo-espacial, mas também obtém recursos para memória de longo prazo quando a capacidade destes sistemas subsidiários é excedida (Baddeley \& Della Sala, 1996; Swanson \& Sachse-Lee, 2001). 


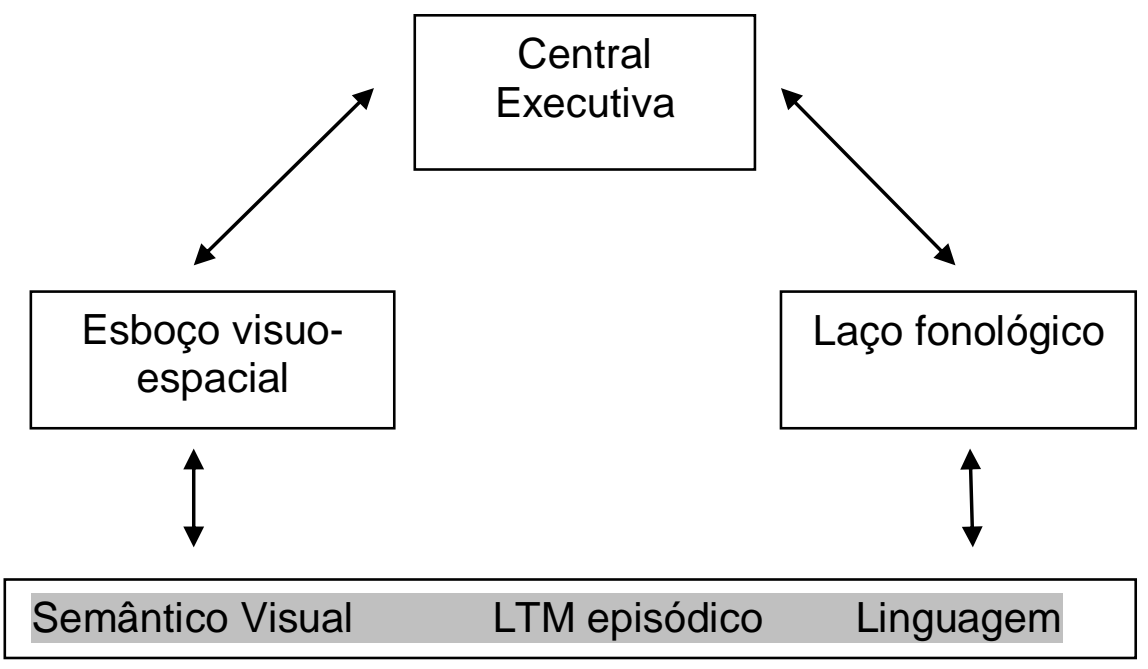

Figura 1 - O modelo de desenvolvimento da memória de trabalho.

Diferentes experimentos foram realizados por Fürst e Hitch (2000) na tentativa de mapear diferentes aspectos do processo de cálculos dentro dos componentes executivos e fonológicos da memória de trabalho identificados pelo modelo de Baddeley e Hitch (1974). Os seus resultados indicaram, principalmente, que o componente de transporte da aritmética mental ocupa um lugar substancial no processo executivo, onde a necessidade de reter informações é conhecida pelo laço fonológico. Os seus dados também foram consistentes com a interpretação de que o processo executivo apresenta uma capacidade limitada para inibir fortemente operações de rotina.

O laço fonológico compreende um sistema de armazenamento temporário e um sistema de recitação verbal-auditivo, semelhante à fala subvocal (Repovs \& Baddeley, 2006). A informação verbal tem acesso automático ao laço fonológico através da nomeação dos estímulos, mas o conteúdo verbal advindo das outras modalidades, por exemplo, da leitura, entra no sistema pela recodificação fonológica (nomeação). Dado este 
Introdução

processo, a informação é armazenada, porém, ainda sujeita à interferência de outras informações ou ao decaimento do conteúdo por causa da passagem do tempo (Henson, Burguess \& Frith, 2000).

Logie (1995) supôs que um processo semelhante ocorre para a modalidade visuo-espacial, onde existe um armazenador passivo denominado cache visual dedicado ao armazenamento da informação visual e um mecanismo ativo de recitação chamado de inner scribe relacionado ao processo de recitação do conteúdo visual através de processos de movimento.

Existem muitas outras razões também apontadas como fatores contribuintes para a falha em aprendizagem matemática. Dentre estas, destacam-se os sentimentos de ansiedade em relação à matemática, pouca experiência, motivação empobrecida, dificuldade em leitura e prejuízo neuropsicológico. No entanto, evidências sugerem que os diferentes componentes de memória de trabalho podem ter papéis especializados na matemática. Desta forma, os estudos sugerem a associação dos déficits cognitivos com a aprendizagem matemática, principalmente a memória de trabalho. Por exemplo, um componente chamado de alça fonológica parece estar envolvido na contagem e na retenção de informação de cálculos complexos e o outro denominado esboço visuo-espacial parece ser um componente importante para a resolução de problemas com muitos dígitos, onde a representação mental do posicionamento das colunas é fundamental 
Introdução

para a resolução dos cálculos aritméticos (Ashcraft, 1995; McLean \& Hitch, 1999).

$\mathrm{Na}$ literatura, os diferentes componentes da memória de trabalho estabelecem diferentes relacionamentos com diferentes habilidades matemáticas. Assim, a memória de trabalho é capaz de explicar estatisticamente a variação - nos números escritos (ex: dezenove=19), no julgamento da magnitude (noção de quantidade) e nos dígitos-únicos aritméticos (adição) - com papel crucial do esboço visuo-espacial no desenvolvimento da escrita de números e julgamento da magnitude (simmons et al., 2012).

O retentor episódico corresponde ao quarto e último componente do modelo de memória de trabalho proposto por Baddeley e Hitch em 1974. Este compreende um sistema de capacidades limitadas que fornece estocagem limitada para manutenção da informação em um código multimodal, no qual é capaz de ligar a informação aos sistemas subsidiários e à memória de longo prazo, dentro de uma representação episódica unitária. A consciência deste componente corresponde ao principal modo de tamponamento da recuperação de informações e se difere dos princípios antigos ao focar na atenção para o processo de integração da informação mais do que nos subsistemas isolados. Juntos, esses componentes estariam envolvidos em atividades cognitivas superiores tais como a aprendizagem, compreensão da linguagem, leitura, aritmética, resolução de problemas e na produção da própria consciência (Baddeley, 2000). 
Introdução

Para Baddeley e colaboradores (2011), o retentor episódico corresponde a um sistema puramente passivo, mas desempenha um papel crucial integrativo com capacidade de ligar as informações a um número de diferentes dimensões dentro de episódios unitários ou pedaços. Sensações como o cheiro e o gosto também podem ter acesso ao sistema, embora não existam nos estudos recentes evidências diretas disto. Assim, a consciência para acessar o esboço visuo-espacial e o laço fonológico opera via retentor. Os subsistemas visuo-espacial e verbal atuam como um retentor menor permitindo, em alguns casos, a combinação da informação visual, espacial, sinestésico e tácito. No caso do laço fonológico, um número de recursos da linguagem relacionada à informação pode estar combinado, não somente o discurso, mas também a escrita, a leitura labial e a linguagem. Podemos deslumbrar este modelo na figura 2 a seguir.
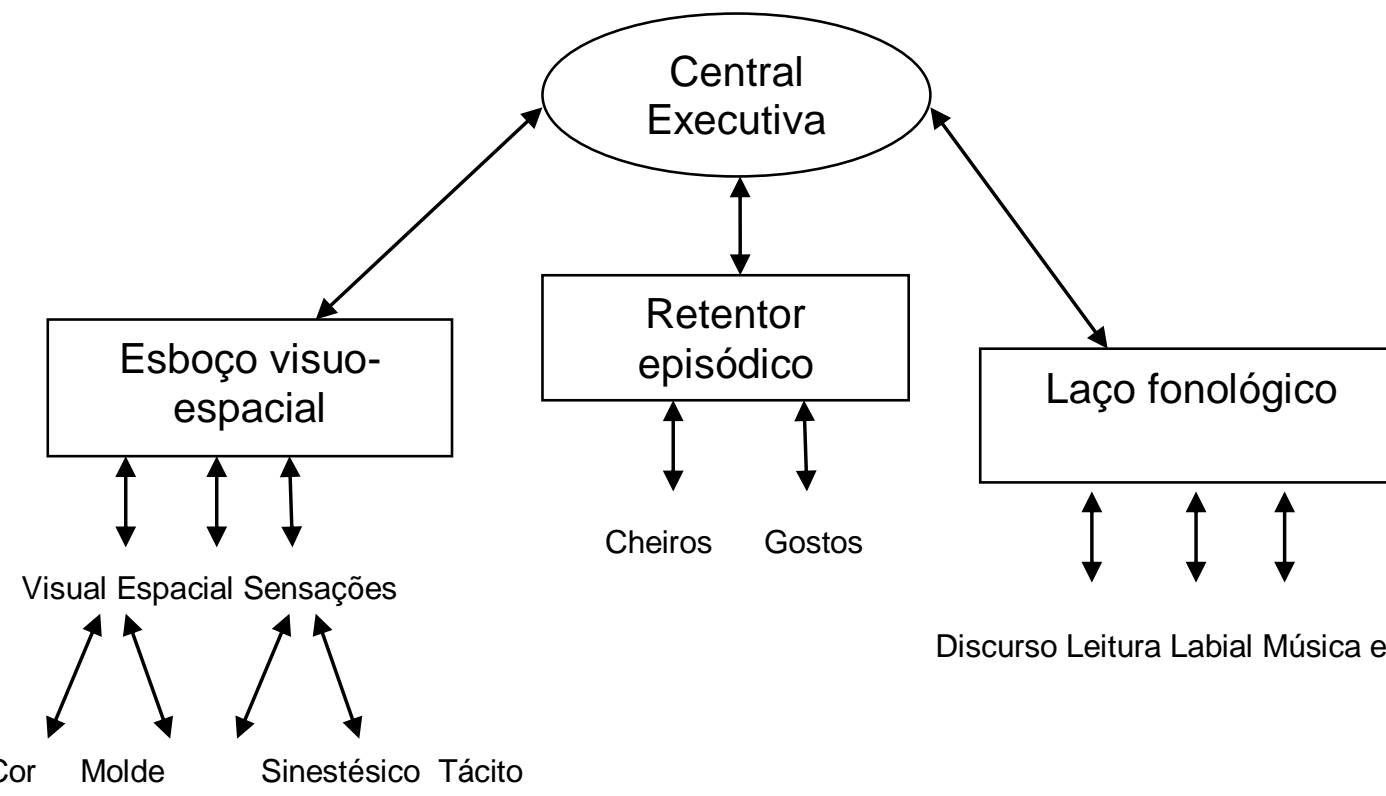

Discurso Leitura Labial Música e som

Figura 2 - O modelo revisado de memória de trabalho. 


\subsubsection{Função executiva}

Os problemas de funcionamento executivo são um dos mais freqüentes déficits cognitivos observados em muitas desordens cerebrais. Seguindo a abordagem de Luria (1966), o termo "função executiva" ficou conhecido principalmente através dos estudos de Lezak (1982), e foi, inicialmente, definido como um definidor de metas, responsável pelo controle inibitório, planejamento e flexibilidade mental.

As pesquisas com função executiva têm raízes históricas em estudos neuropsicológicos com prejuízos de lobo frontal. Já se sabe há um tempo que pacientes com prejuízo de lobo frontal e posterior, demonstram severos problemas no controle e regulação de seu comportamento e cotidiano. Embora alguns destes pacientes demonstrem desempenho intacto em várias tarefas cognitivas bem definidas através de testes de baterias neuropsicológicas e quociente de inteligência (QI), eles tendem a mostrar alguns prejuízos no lobo frontal complexo ou tarefas executivas como no Wisconsin Card Test (WCST), Torre de Londres, Trail Making Task e Fluência verbal (Miyake, 2000; Roussel et al., 2012). 
Introdução

As funções de lobo frontal do cérebro incluem o controle dos processos cognitivos. Esta função de controle, do qual tem sido pensado para comportamento direto, tem sido nomeado de executivo. Mais do que o desempenho das operações cognitivas como a memorização, aprendizagem e raciocínio, as regiões frontal estão preocupadas com a implantação de tais capacidades, do qual são levadas a cabo pelo cérebro. Assim, o papel do lobo frontal é considerado como supervisor ou administrador e não limitado ao desempenho de alguma função cognitiva específica (Baddeley et al., 1997).

As funções executivas constituem-se em medidas organizadas no córtex pré-frontal e suas conexões, e suas principais funções são: a intenção, o planejamento, a tomada de decisão, o pensamento antecipatório, a formação de conceitos, a flexibilidade mental, a auto-monitorização e a crítica sobre o próprio erro (Kraus \& Keefe, 2007). Assim, acredita-se que os sintomas psicóticos exercem um papel importante no ajustamento psicossocial e são parcialmente mediados pela função executiva (Simon et al., 2003).

Pesquisas mais recente indicaram que o comprometimento da função cerebral associada com déficit na função executiva não é necessariamente irreversível. $O$ fato de existirem zonas com um excesso de atividade sugere que existe um desequilíbrio na dinâmica entre as diferentes áreas cerebrais ao invés de uma perda global da função cerebral. E, como as ligações entre os neurônios podem ser modificadas, há esperança de 
Introdução

uma reorganização da atividade cerebral, o que implica na possibilidade deles serem tratados por terapêuticas farmacológicas ou psicossociais $\left(O^{\prime}\right.$ Donnel, 2007).

Um grande número de estudos clínicos e experimentais tem mostrado que pacientes com esquizofrenia também apresentam dificuldades significativas principalmente em relação às funções executivas, que pode ser definida como processos cognitivos de controle e integração de estratégias, apreensão de novas informações e comunicação com o meio, destinado à execução de um comportamento dirigido a objetivos. Para tanto, necessitam de subcomponentes como: atenção, programação e planejamento de seqüências, inibição de processos e informações concorrentes e monitoramento (Banhato et al., 2007). Tais déficits causam um impacto significativo na vida pessoal, social e ocupacional dos pacientes prejudicando seu funcionamento global (Monteiro e Louzã, 2007).

Em estudos realizados sobre função executiva em pacientes com diagnóstico de esquizofrenia, ainda não há um consenso acerca de seu desempenho em pacientes com ou sem sintomas psicóticos. Segundo pesquisa com 157 pacientes, divididos em pacientes com esquizofrenia, psicóticos e não psiquiátricos, verificou-se que o mau funcionamento das funções executivas não se relaciona aos sintomas agudos da psicose ou desorganização psicótica, mas é componente essencial de outros problemas de cognição e, possivelmente, da esquizofrenia (Reed et al., 2002). 
Introdução

$\mathrm{Na}$ literatura estudantes com dificuldade matemática apresentam inúmeros processos cognitivos prejudicados, tais como: a atenção (Zentall e Ferkis, 1993), o processamento auditivo, a memória (Siegel e Ryan, 1989), a velocidade de processamento e a memória (Orrantia et al., 2002).

Já em um estudo realizado com 32 pacientes com esquizofrenia, não há evidência de relação entre quantidade ou qualidade na função cognitiva em relação à qualidade das respostas. No entanto, as variações na regulação emocional e funcionamento social nas respostas podem estar associados com os sintomas psicóticos (Bak et al., 2008).

Em relação à memória de trabalho os estudos têm demonstrado a importância do executivo central na execução de tarefas aritméticas. A coordenação, a seqüenciação e o monitoramento dos vários passos exigidos nos cálculos, bem como o controle atencional exigido nos momentos de transporte das unidades de cálculo são tarefas apontadas como mediadas pelo executivo central. Além disso, o executivo central é o responsável pela recuperação dos fatos básicos da memória de longo prazo, pois não possui capacidade de armazenamento, destinando a informação recuperada para os dois subcomponentes controlados por ele onde esta informação será usada - a alça fonológica e o esboço visuo-espacial (Baddeley, 1996).

O achado de estudo comparativo das três medidas de memória de trabalho - função executiva, laço fonológico e esboço visuo-spacial também indicou a capacidade de cada fator aumentar a partir dos 4 anos de idade até a adolescência. Contudo, apesar da similaridade de 
Introdução

desenvolvimento geral das funções, os relacionamentos entre os componentes da memória de trabalho variam, ou seja, a central executiva se relaciona com laço fonológico e esboço visuo-espacial de maneiras relativamente independentes. $E$, esta organização estrutural de memória de trabalho é mais ou menos constantes ao longo da adolescência (Gathercole et al., 2004).

O conceito de memória de trabalho desenvolvido por Baddeley e Hitch (1974) atribuiu um papel crucial no componente de controle executivo central, compreendendo a função executiva como uma central unitária e não fracionada. Estes propuseram um modelo múltiplo de memória de trabalho também chamado de memória operacional que veio substituir o conceito de memória de curto-prazo, deixando de ser apenas um armazenador temporário para ser um processador ativo capaz de manipular um conjunto limitado de informações por um curto período de tempo.

Para Baddeley (1996) um modelo de execução central adequado deve apresentar uma gama de outros subprocessos, tais como o papel de controlador da atenção, organizador da aprendizagem e planejador de recuperação. Uma função importante reside na seleção da atenção e na capacidade de focar a atenção em uma informação enquanto deixa de fora um material irrelevante. Esta demanda de memória de trabalho é fornecida para acessar e manipular as informações na memória de longo prazo.

Tanto a memória de trabalho quanto a flexibilidade mental podem ser medidas por testes neuropsicológicos como o Stroop Test, Trail Making e 
Introdução

Wisconsin Card Test (WCST), respectivamente. Em pacientes com esquizofrenia utilizando-se o Wisconsin Card Test (WCST) encontrou-se pior desempenho dos pacientes, sugerindo um comprometimento na capacidade de usar o feedback para orientar o comportamento, em conseqüência ao desempenho do córtex pré-frontal do cérebro (Prentice et al., 2007). Contudo, muitos estudos são vagos ao assumir o que a execução deve ser, tratando-a como um sistema único, mais do que tentando entender teoricamente como as dificuldades encontradas nas tarefas executivas podem surgir e o que isto significa (Bull \& Scerif, 2001).

De acordo com Baddeley (2002), o executivo central teria a função de coordenar as informações advindas dos outros subsistemas, ou seja, focar a atenção, dividi-la, deslocá-la e de realizar o intercâmbio entre memória de trabalho e memória de longo prazo. Esta relação é estabelecida, por exemplo, nas operações de ativação de esquemas cognitivos pré-existentes (estratégias) para realização de tarefas complexas (Norman \& Shallice, 1986; Ang \& Lee, 2010). Neste sentido, além dos recursos cognitivos específicos subjacentes à memória visuo-espacial e verbal, recursos cognitivos gerais também estariam envolvidos com a retenção das informações.

Assim, os resultados de um estudo com 20 participantes em avaliação de tarefas duplas indicaram que recursos atentivos (do executivo central) estão envolvidos na codificação e na manutenção ativa da informação integrada na memória visuo-espacial, assim como na manutenção dos objetivos das tarefas a serem realizadas simultaneamente. Isto demonstra o 
Introdução

quanto o executivo central encontra-se envolvido na codificação da informação visuo-espacial ao relacionar-se com a coordenação de processos de nível inferior (informação sensorial) e superior (processos motores de resposta, por exemplo) em função de um objetivo da tarefa. Desta forma, uma vez estabelecida uma representação interna do objetivo, mecanismos de controle direcionam a codificação da informação (Santana e Galera, 2012; Miller e Cohen, 2001).

No entanto, a contribuição dos três componentes da memória de trabalho ao desenvolvimento da habilidade matemática ainda é pouco compreendida. A relação entre os componentes da memória de trabalho e as operações numéricas e o raciocínio matemático em alunos do $2^{\circ}$ e $3^{\circ}$ ano primário foram neuropsicologicamente avaliados, sugerindo a relevância da central executiva e do laço fonológico como facilitadores para a aprendizagem matemática durante os seus estágios iniciais ao passo que as representações visuo-espaciais desempenham papel cada vez mais importante em estágios posteriores (Meyer et al., 2009).

Em estudo investigativo do desenvolvimento da função executiva através da avaliação com o teste Trail Making avançado para crianças (ATMT-C) em indivíduos saudáveis com idade que variam de 6 a 28 anos, ficou evidenciado um amadurecimento gradual não estável e um estágio de maturação mais importante antes dos 12 anos de idade. Contudo, as diferenças de eficiência visuo-espacial podem variar também conforme as condições de desenvolvimento dos subsistemas cognitivos. Não foram 
Introdução

encontradas diferenças significativas em relação ao gênero, lateralidade e teste solicitado (Kokubo et al., 2011).

Ainda não existe um consenso nos estudos em relação à especificidade dos déficits de memória de trabalho em sujeitos com dificuldade matemática. Estudos prévios baseados no modelo de 3 componentes de Baddeley sugere que crianças com dificuldade matemática específicos (por exemplo: habilidade de leitura normal) podem ter problemas com executivo central, onde o laço fonológico e esboço visuo-espacial aparecem intactos. Já crianças com comorbidade matemática e dificuldade de leitura, em contraste, apresentam déficit em memória de trabalho geral, envolvendo todos os 3 componentes e mais o executivo central especificamente afetado (Geary et al., 1991, 1996).

Em estudo comparativo utilizando-se tarefas de memória de trabalho em 31 crianças de 10 anos com dificuldade em matemática e 37 criança com dificuldade matemática e leitura em relação a 50 sujeitos controle de indivíduos mais jovens e 47 indivíduos pareados por idade encontrou-se principalmente pior desempenho em tarefas de executivo central (por exemplo: matrix visual span) e em laço fonológico (por exemplo: span de palavras) no grupo de crianças com dificuldade matemática se comparados com idade controle. O grupo de dificuldade matemática obteve pior desempenho que o controle mais jovem em apenas tarefas de couting span e o grupo com dificuldade matemática e dificuldade em leitura apresentaram pior desempenho em couting span e tarefas de span matrix visual. Estes 
Introdução

achados sugerem que crianças com dificuldade matemática apresentam déficit em executivo central conectado ao processamento concorrente e estocagem de informação numérica e visual (Andersson e Lyxell, 2006).

Em estudo com amostra brasileira, composta por 79 alunos de $3^{\circ}$ a $6^{\circ}$ série do ensino fundamental, divididos em grupos com dificuldade de leitura, com dificuldade matemática, com dificuldade de leitura e dificuldade matemática comórbidos e sem dificuldade de leitura ou dificuldade matemática, confirma as pesquisas internacionais de prejuízo na central executiva da memória de trabalho nas crianças, principalmente com dificuldade matemática, sendo mais acentuado naquelas que apresentam dificuldade matemática associada com dificuldade de leitura (Corso, 2008).

No entanto, enquanto algumas pesquisas indicam prejuízos gerais na memória de trabalho, outros estudos experimentais sugerem que somente componentes específicos, como o executivo central, se apresentam prejudicados. Além disso, algumas pesquisas sugerem a existência de prejuízo somente quando as tarefas contêm informação numérica, assim a memória de trabalho não estaria prejudicada para as informações verbais (Geary et al., 1999; Geary et al., 2004; Hitch e MCAuley, 1991).

Bull (1999) encontrou associação entre crianças com baixo rendimento em matemática e pior desempenho em função executiva (medida pelo Wisconsin Card Test - WCST), entretanto, esta dificuldade com as tarefas se restringiu às respostas perseverativas. Crianças com dificuldade em matemática apresentam maior dificuldade em deslocar-se de um set para 
Introdução

outro, uma vez que persevera mais nas respostas. No entanto, não fica claro se tratar de um problema executivo geral (pior desempenho em todas as medidas de função executiva) ou de um problema específico (somente um aspecto de função executiva).

Bull e Scerif (2001) também propõem a inibição em memória de trabalho mais empobrecida como específicas da função executiva e subjacente à dificuldade de aprendizagem da matemática. Assim, a habilidade matemática se correlaciona significativamente com todas as medidas de função executiva, incluindo Wisconsin Card Test (WCST), Stroop Test e Couting Span.

Em estudo de Passolunghi e Siegel (2001) foram avaliadas 49 crianças em medidas neuropsicológicas de memória de trabalho e solução de problemas aritméticos, demonstrando que o desempenho em solução de problemas se relaciona à habilidade de reduzir o acesso à informação irrelevante na memória, com pior desempenho na retenção de informação numérica em crianças que apresentam dificuldade em solução aritmética.

Nos estudos longitudinais acerca do relacionamento entre função executiva e habilidade matemática apesar de serem extensivamente estudados, seus resultados são controversos. Contudo, um estudo prospectivo de 211 alunos de segunda série do $1^{\circ}$ grau avaliado em quatro momentos diferentes demonstrou um forte relacionamento entre atualização e a matemática, sugerindo a habilidade em atualizar como peça-chave para o processo de aprendizagem matemática (Sanne et al., 2011). 
Introdução

Lee e colaboradores (2010) definiram o termo "tarefas padrões" de proficiência aritmética e numeral como atividades introdutórias ao conceito de mudanças às crianças, onde desde a pré-escola os alunos trabalham com padrões simples que requer o que vem no próximo (ex: $5,7,5,5,7,5, ?, 7$, 5). Estas tarefas variariam em complexidade e influenciariam na capacidade de identificar as mudanças e no que permanece constante. Neste requisito de tarefas padrões, somente o fator de atualização do funcionamento executivo foi capaz de exercer influência em seu desempenho, ao invés dos fatores de inibição e flexibilidade mental também.

Apesar das dificuldades matemáticas em crianças serem freqüentemente explicadas em termos de déficit em memória de trabalho, suas causas subjacentes também não são claras ainda. No entanto, resultados comparativos de avaliação de alunos da quinta série do $2^{\circ}$ grau com desempenho matemático normal e abaixo do esperado em estudo de Passolunghi e Siegel (2004), sugeriram déficit em memória de trabalho geral nos alunos que apresentaram dificuldade matemática, especificamente no componente de central executiva proposto por Baddeley e, principalmente, na habilidade para inibir informações irrelevantes.

Em pacientes esquizofrênicos a literatura relata que entre as dificuldades mais significativas observadas estão os processos relacionados às habilidades de abstração e de flexibilidade conceitual envolvidas na solução de problemas (Adad et al., 2000). A flexibilidade mental constitui-se na habilidade para interromper um comportamento-resposta conforme o 
Introdução

contexto da situação, além de contribuir para uma adaptação eficiente para os desafios da tarefa. É um processo cognitivo específico que partilha muito pouco com o funcionamento intelectual geral (Réthelyi et al., 2011).

Em estudo com 178 crianças com idades que variam de 6 a 11 anos, constatou-se melhora em função executiva em diversas funções obtidas pelos testes de matemática e teste de contingência de nomes (CNT), dando suporte à noção de que distintos aspectos de função executiva apresentam diferentes taxas de maturação. Além disso, demonstrou-se que em geral a habilidade em função executiva nos anos primários poderia melhorar, exceto no $3^{\circ}$ ano, sugerindo que diferentes aspectos matemáticos são mais associados com a função executiva do que outros, mas que esta associação também se difere conforme a idade (Mazzoco \& Kover, 2007).

Geary (1991) comparou em seu estudo o desempenho cognitivo de dois grupos compostos por 60 indivíduos cada um em idades diferentes. Não foram encontradas diferenças significativas na recuperação de fatos aditivos na memória de longo prazo entre os grupos, mas o grupo de idosos foram mais lento para decodificar dígitos e nas respostas de produção verbal. 
Introdução

Ainda não se sabe se funções como atenção seletiva, desempenho de tarefas duplas e ativação das informações em longo prazo é desempenhada por sistemas cognitivos separados que podem apresentar prejuízos seletivos ou se são subsistemas de um único controle executivo, possivelmente como componentes dissociados (Bull \& Scerif, 2001). No entanto, os resultados de estudos têm enfatizado o papel crucial da central executiva componente da memória de trabalho na resolução de cálculos mentais simples e não mais dependente somente de representações da memória de longo prazo (Kaufmann, 2010; Sanne et al., 2011).

Em recentes anos, as funções executivas têm sido investigadas usando quadros de referências desenhados para psicologia cognitiva, permitindo uma abordagem mais experimental ao estudo destas funções, além das funções cognitivas serem assumidas pelo lobo frontal. Além disso, a especificação detalhada em termos de arquitetura cognitiva permite aos pesquisadores fazer predições. Diversos modelos têm sido propostos na tentativa de dar luz ao funcionamento executivo, por exemplo, a supervisão do sistema atencional (Shallice, 1988) e o modelo de memória de trabalho (Baddeley, 1986; Baddeley et al., 1997).

Para Shallice e Burguess (1996) existe uma variedade de processos realizados por diferentes subsistemas, mas operando juntos para se ter uma função globalmente integrada. Estes elaboraram um modelo relativamente recente descrevendo 3 estágios de estabilização para aquisição de novos esquemas temporários diante do enfrentamento de novas situações: 
- Estágio 1: geração de estratégia espontânea ou surgimento de pensamentos para algum tipo de solução de problemas. Sugere-se que a geração de estratégias é auxiliada pela formação e realização das intenções e recuperação relacionadas à informação da memória episódica que pode ajudar a tratar com situações novas.

- Estágio 2: envolve a manutenção de esquemas temporários ativados em memória de trabalho.

- Estágio 3: monitoramento da efetividade de novos esquemas para rejeição ou alteração do esquema. 
Introdução

Assim, segundo o modelo neuropsicológico de Norman e Shallice (1980), o controle da ação se dá através de um sistema atencional supervisor (SAS), cujas ações aprendidas e automatizadas pelo treinamento extensivo são guiadas por "esquemas" adquiridos por treinamento prévio disparado por conjuntos de estímulos ou contextos. Por exemplo, andar de bicicleta envolve esquemas que ativam sub-rotinas como pedalar, inclinar, virar, equilibrar e brecar. Ao se andar de bicicleta, essas sub-rotinas tornamse pré-ativadas; um obstáculo à frente seria um estímulo ambiental suficiente para acionar um "esquema" para brecar ou para desviar. Eventuais conflitos entre as atividades (em curso) de diferentes esquemas seriam solucionados rotineiramente por um "catalogador de conflitos", também treinado previamente. Porém, quando atividades novas estão envolvidas, ou quando um estímulo urgente ou ameaçador é apresentado, o SAS assume o controle da ação (fig. 3). Este sistema teria a prerrogativa de inibir e de ativar esquemas diretamente, e sua atividade predominaria sobre a do catalogador de conflitos (Helene \& Xavier, 2003).

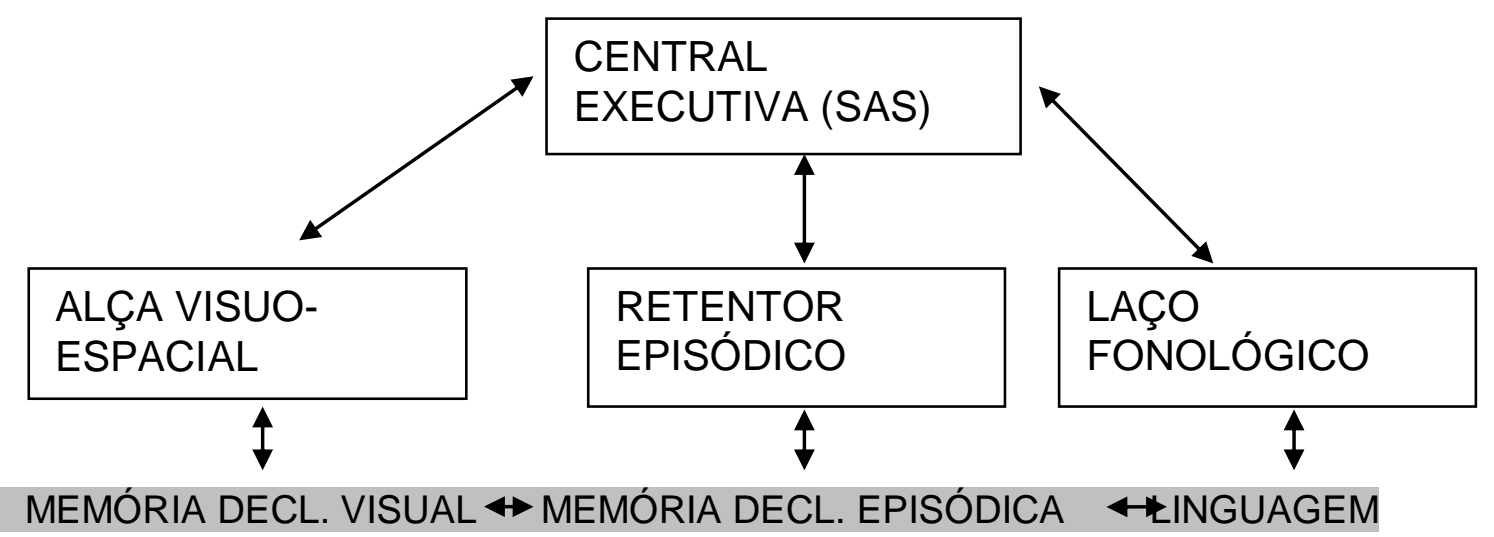

Figura 3 - Modelo de memória operacional proposto por Baddeley (2000). As áreas em branco representam os componentes atencionais e de retenção temporária de informações, e as áreas em cinza, os sistemas de retenção de longa duração. 
Introdução

A central executiva, proposto por Norman e Shallice (1982), estabeleceu duas fontes de ação de controle. Um lida com padrão habitual de aprendizagem e outro com o controle da atenção, a capacidade de um padrão de respostas habituais para iniciar novo comportamento. Outras funções têm sido propostas subjacentes ao controle da função executiva. Isto inclui planejamento e direção de objetivos, função inibitória (onde as tendências de ação dominantes são suprimidas em favor de um objetivo comportamental mais apropriado), atenção seletiva e capacidade para mudar a atenção e recuperar as informações da memória de longo prazo.

As dificuldades cognitivas associadas com função executiva pobre incluem habilidade organizacional e planejamento disruptivo, déficit de memória generalizada, dificuldade com flexibilidade mental e tarefa de iniciativa pobre bem como dificuldade comportamental, distratibilidade e problemas com atenção sustentada (Bull et al., 1999).

$\mathrm{Na}$ tentativa de conceituar mais detalhadamente Baddeley foi fortemente influenciado por Shallice (1982) através do modelo de controle de ações propostos e relacionados no funcionamento de lobo frontal e o colapso de controle comportamental na síndrome frontal. No entanto, ele dissociou o funcionamento de aspectos anatômicos no conceito executivo. 
Introdução

Enquanto no trabalho descrito por Shallice foi sugerido danos frontal bilateral rompendo o processo executivo, Baddeley não desejou impedir a possibilidade de outras partes do cérebro estar envolvidas. Além disso, dado o processo executivo envolvendo a comunicação entre subsistemas localizados em outro lugar no cérebro, possibilita que o rompimento pode ter ocorrido antes ou depois do envolvimento frontal. Dado a grande ocupação em proporção do lobo frontal no córtex, parece possibilitar a preocupação com outras funções mais do que com o processamento executivo em si, cujos danos do lobo frontal podem não necessariamente resultar em déficits executivos. Por esta razão foi introduzido o termo "síndrome disexecutiva" como uma descrição funcional de um padrão de comportamento que explicitamente deixa em aberto a anatomia subjacente (Baddeley et al., 1996).

Conceitos mais recentes de uma central executiva como de Baddeley e Miyake dão suporte à idéia de funções executivas distintas, algumas dos quais são mais relatadas na inteligência fluída do que outras. Estas funções executivas distintas incluem inibição (supressão de tendências de ação dominantes em favor de objetivos comportamentais mais apropriados), mudanças (desengajamento em set de tarefas irrelevantes ou estratégias e subseqüente ativação de uma mais apropriada) e atualização (decodificação e avaliação da informação para tarefas relevantes e revisão da informação na memória, mais associada com tarefas complexas) (Bull, 2008). 
Introdução

Devido à presença de dissociações e baixas correlações nos estudos, vários autores como Miyake propuseram um sistema executivo multicomponente. Este buscou separar as funções executivas que podem variar mais e independentemente entre os indivíduos nos quais são seletivamente prejudicadas ou poupadas pelos prejuízos cerebrais. No entanto, Baddeley acredita em uma abordagem holística abrangente que está implicada na suposição de uma central executiva unitária e não fracionada, compreendendo a central executiva como uma central (Miyake, 2000).

Ao longo de trinta e cinco anos, o modelo de executivo central sofreu alterações em sua estrutura (Baddeley e Hitch, 1974; Baddeley, 1986, 1992; 2000). Atualmente, o executivo central compõem a memória de trabalho e desempenha determinadas funções:

a) Atenção seletiva: habilidade de focar a atenção em uma informação relevante enquanto inibe outras informações distratoras;

b) Flexibilidade mental: capacidade de coordenar múltiplas atividades cognitivas simultaneamente;

c) Selecionar e executar planos e estratégias;

d) Capacidade de alocar recursos em outras partes da memória de trabalho;

e) Capacidade de evocar informações armazenadas na memória de longo prazo. 
Introdução

A central executiva é descrita como sendo a responsável por coordenar operações de 2 sistemas subsidiários subordinados, o laço fonológico que negocia com o discurso baseado em informações e o bloco de desenho que lança mão de informações visuo-espaciais. Um defeito executivo leva a uma dificuldade em coordenar estas operações simultaneamente, com resultados de desempenho em dupla-tarefa suscetíveis aos efeitos dos dados. Assim, o desempenho em dupla-tarefa é um marcador potencialmente útil de comportamento disexecutivo, entretanto, nem todos os pacientes com danos de lobo frontal demonstram déficit em dupla-tarefa ou desordem comportamental característica (Baddeley et al., 1996; Baddeley, 2012).

Estudos neuropsicológicos têm demonstrado que o desenvolvimento do executivo central, bem como da capacidade da memória de trabalho em geral, estão relacionados à maturação do córtex pré-frontal. Quando comparado aos outros componentes da memória de trabalho, o executivo central apresenta seu desenvolvimento tardiamente, alcançando seu pleno amadurecimento no final da adolescência. A alça fonológica e o esboço visuo-espacial desenvolvem-se de forma relativamente independente, entretanto, a partir do amadurecimento do executivo central estes dois componentes passam a apresentar um maior grau de interdependência, uma vez que cabe ao executivo central mediar uma comunicação entre eles (Uechara e Landeira-Fernandez, 2010). 
Introdução

Para Baddeley e colaboradores (1996) há um óbvio perigo em postular um número limitado de processos executivos. Inventando novas tarefas simples com princípios a priori e então nomeá-los como medidas de processos executivos básicos não é uma solução satisfatória ao problema de analisar central executiva. É necessário primeiro de tudo, postular somente processos que operam através de uma gama de diferentes materiais e situações, e então demonstrar esta generalidade. Ainda está em aberto se esta organização é hierárquica, com um ou mais subsistemas dominantes ou se há uma ou mais estruturas hierárquicas envolvidas.

\subsubsection{Atenção}

Os prejuízos da atenção e das funções executivas têm implicações importantes para o cotidiano, pois o bom funcionamento social, ocupacional e a autonomia do indivíduo implicam na habilidade para aprender novas informações e usá-las de forma adaptativa (Monteiro e Louzã, 2007).

Já o funcionamento atencional tem sido difícil de ser investigado, uma vez que o mesmo acaba modulando e melhorando o funcionamento de outras áreas cognitivas, como a percepção, a memória e a seleção de respostas; além de interagir com a memória de trabalho e o controle do sistema executivo, o que torna difícil separar os prejuízos da atenção das dificuldades de outras áreas cognitivas. Assim, o controle da atenção tem sido considerado alvo prioritário para as pesquisas e tratamentos na esquizofrenia, por exemplo, utilizando-se para isso, principalmente, do 
Introdução

Stroop Task como protótipo da seleção de estímulos nas tarefas (Luck e Gold, 2008).

Em estudos com o uso do Stroop Task, os pacientes com esquizofrenia demonstraram-se mais lentos, com pior tempo de reação e erros, refletindo uma possível anormalidade no processamento da interferência em esquizofrenia (Szöke et al., 2008).

Em muitos trabalhos de Baddeley (2012) foram utilizados tarefas concorrentes para interromper vários componentes de memória de trabalho, assumindo tipicamente que as tarefas de demanda de atenção ocupam lugar como uma demanda específica de central executiva em contraste com tarefas que requerem apenas manutenção. O seu modelo de fracionamento executivo foi assim delineado:

$1^{\circ}$ ) Foco na atenção: há evidências do impacto da atenção reduzida em tarefas complexas como o xadrez.

$2^{\circ}$ ) Capacidade de dividir a atenção entre os alvos ou estímulos importantes.

$3^{\circ}$ ) Comutação envolvida entre as tarefas, que pode ser um sistema de controle específico. Não há uma capacidade unitária para tarefas comutantes.

$4^{\circ}$ ) Interface com memória de longo prazo: há interação fonológica e de sistemas semânticos mais do que um simples efeito aditivo, consistente com estudos de dupla-tarefa. 
Em estudos recentes, as tarefas concorrentes fornecem mais detrimento à condição de vinculação do que tarefas sozinhas em relação à vinculação visual e memória de trabalho. No entanto, embora a atenção seja útil para a manutenção de vinculação visual, os dados mostram que para forma e cor não há demanda atencional (Baddeley, 2012).

A seguir encontram-se resumidos em tabelas os estudos apresentados. Os mesmos foram classificados e divididos por nível de evidência, ordenados de acordo com a data da publicação. No quarto nível de evidência pode ser observado nosso desconhecimento, até o momento, de estudos randomizados, controlados de treino cognitivo matemático na população com esquizofrenia e brasileira. 
Introdução

Tabela 2 - Estudos randomizados, controlados de Remediação Cognitiva na esquizofrenia.

\begin{tabular}{|c|c|c|c|}
\hline Estudos & Tipo de estudo & $\begin{array}{l}\text { Frequência e duração total do } \\
\text { treino }\end{array}$ & Resultados principais \\
\hline Delahunty et al, 2001 & $\begin{array}{l}\text { Comparação de } 85 \text { indivíduos que } \\
\text { apresentam o diagnóstico de } \\
\text { esquizofrenia randomizados em } \\
\text { terapia de remediação cognitiva e } \\
\text { tratamento usual. }\end{array}$ & $\begin{array}{c}\text { Participação em } 40 \text { sessões de um } \\
\text { programa de Remediação } \\
\text { Cognitiva composta por } 40 \\
\text { sessões. }\end{array}$ & $\begin{array}{l}\text { Melhora durável em memória de } \\
\text { trabalho e flexibilidade mental. } \\
\text { Melhora na memória predispõe a } \\
\text { uma melhora em funcionamento } \\
\text { social. }\end{array}$ \\
\hline Bell et al, 2003 & $\begin{array}{c}\text { Comparação de } 102 \text { pacientes com } \\
\text { esquizofrenia ou esquizoafetivo } \\
\text { randomizados em Terapia para } \\
\text { melhora cognitiva + trabalho } \\
\text { assistido e trabalho assistido } \\
\text { sozinho. }\end{array}$ & $\begin{array}{c}\text { Exercícios cognitivos } 2 \text { ou } 3 \text { vezes } \\
\text { por semana e } 1 \text { sessão de grupo } \\
\text { de processamento social semanal } \\
\text { durante } 6 \text { meses. }\end{array}$ & $\begin{array}{c}\text { Melhora significativa em memória } \\
\text { de trabalho àqueles que } \\
\text { receberam Terapia para melhora } \\
\text { cognitiva e trabalho assistido, mas } \\
\text { sem interação com a severidade } \\
\text { dos sintomas. } \\
\text { Os ganhos cognitivos se } \\
\text { mantiveram após } 6 \text { meses sem } \\
\text { intervenção. }\end{array}$ \\
\hline Hogarty et al, 2004 & $\begin{array}{l}\text { Comparação de } 121 \text { indivíduos com } \\
\text { diagnóstico de esquizofrenia ou } \\
\text { esquizoafetivo crônicos } \\
\text { randomizados em Terapia para } \\
\text { melhora cognitiva e terapia de apoio. }\end{array}$ & $\begin{array}{c}75 \text { horas de treinamento } \\
\text { computadorizado em atenção, } \\
\text { memória e resolução de problemas } \\
+56 \text { sessões }(1,5 \text { horas semanais }) \\
\text { de treinamento em cognição } \\
\text { social. }\end{array}$ & $\begin{array}{l}\text { Após } 12 \text { meses, observou-se uma } \\
\text { melhora neuropsicológica. No } \\
\text { entanto, o comportamento é pouco } \\
\text { afetado. } \\
\text { Após } 24 \text { meses, observou-se uma } \\
\text { melhora significativa da cognição e } \\
\text { do ajustamento social. No entanto, } \\
\text { não foram observadas diferenças } \\
\text { no sintoma residual. }\end{array}$ \\
\hline
\end{tabular}


Introdução

\begin{tabular}{|c|c|c|c|}
\hline Estudos & Tipo de estudo & $\begin{array}{c}\text { Frequência e duração total do } \\
\text { treino }\end{array}$ & Resultados principais \\
\hline Pope e Kern, 2006 & $\begin{array}{l}\text { Comparação de } 26 \text { indivíduos com } \\
\text { diagnóstico esquizoafetivo e } 22 \\
\text { adultos saudáveis que receberam } \\
\text { tarefas "errorfree" e "errorful". }\end{array}$ & -- & $\begin{array}{l}\text { Maior comprometimento em } \\
\text { relação ao controle "errorful" se } \\
\text { comparado a condição "errorfree". }\end{array}$ \\
\hline Choi \& Kwon, 2006 & $\begin{array}{c}\text { Comparação de } 34 \text { pacientes com } \\
\text { diagnóstico de esquizofrenia } \\
\text { randomizados em Treinamento em } \\
\text { cognição social plus e tramento } \\
\text { usual. }\end{array}$ & $\begin{array}{l}\text { Participação em treinamento em } \\
\text { reabilitação psiquiátrica padrão } \\
\text { plus durante } 6 \text { meses. }\end{array}$ & $\begin{array}{l}\text { Algumas habilidades de cognição } \\
\text { social rapidamente melhoraram } \\
\text { após } 2 \text { meses de tratamento, } \\
\text { entretanto, outras habilidades } \\
\text { melhoraram somente após } 6 \\
\text { meses de tratamento. }\end{array}$ \\
\hline Kurtz et al, 2007 & $\begin{array}{c}\text { Comparação de } 42 \text { indivíduos com o } \\
\text { diagnóstico de esquizofrenia } \\
\text { randomizados em CRT } \\
\text { computadorizada e atividade } \\
\text { inespecífica. }\end{array}$ & $\begin{array}{l}\text { Participação em Remediação } \\
\text { Cognitiva Computadorizada por } \\
\text { um período de } 12 \text { meses. }\end{array}$ & $\begin{array}{l}\text { A CRT provoca sensível melhora } \\
\text { na memória de trabalho, na função } \\
\text { executiva, na memória episódica } \\
\text { verbal e espacial e na velocidade } \\
\text { de processamento. }\end{array}$ \\
\hline Wykes et al, 2007 & $\begin{array}{c}\text { Comparação de } 40 \text { Indivíduos com } \\
\text { diagnóstico de esquizofrenia } \\
\text { randomizados em CRT e tratamento } \\
\text { usual. }\end{array}$ & $\begin{array}{c}\text { Participação em um programa de } \\
\text { Remediação Cognitiva composta } \\
\text { por } 40 \text { sessões ou em tratamento } \\
\text { usual. }\end{array}$ & $\begin{array}{c}\text { Uma melhora significativa em } \\
\text { memória de trabalho e flexibilidade } \\
\text { cognitiva. }\end{array}$ \\
\hline Wykes et al, 2008 & $\begin{array}{l}\text { Comparação de } 40 \text { Indivíduos } \\
\text { jovens com esquizofrenia } \\
\text { randomizados em CRT individual e } \\
\text { tratamento usual. }\end{array}$ & $\begin{array}{c}\text { Reabilitação Cognitiva individual } \\
\text { durante o período de } 3 \text { meses e } \\
\text { com freqüência de, pelo menos, } 3 \\
\text { sessões por semana. }\end{array}$ & $\begin{array}{c}\text { Melhora na cognição (memória, } \\
\text { flexibilidade mental e } \\
\text { planejamento) através da } \\
\text { Remediação Cognitiva. }\end{array}$ \\
\hline
\end{tabular}


Introdução

\begin{tabular}{|c|c|c|c|}
\hline Estudos & Tipo de estudo & $\begin{array}{c}\text { Frequência e duração total do } \\
\text { treino }\end{array}$ & Resultados principais \\
\hline Horan et al., 2008 & $\begin{array}{l}\text { Comparação de } 31 \text { pacientes com } \\
\text { diagnóstico de esquizofrenia } \\
\text { randomizados em treinamento de } \\
\text { cognição social e treinamento } \\
\text { relacionado à prevenção de } \\
\text { recaídas. }\end{array}$ & $\begin{array}{l}\text { Participação em } 12 \text { sessões de } \\
\text { programa de treinamento em } \\
\text { cognição social. }\end{array}$ & $\begin{array}{l}\text { Os participantes do grupo de } \\
\text { treinamento social apresentaram } \\
\text { melhora significativa em percepção } \\
\text { da afetação facial. }\end{array}$ \\
\hline Lindenmayer et al, 2008 & $\begin{array}{c}85 \text { indivíduos com o diagnóstico de } \\
\text { esquizofrenia randomizados em } \\
\text { Terapia de Remediação Cognitiva } \\
\text { computadorizada e atividade } \\
\text { inespecífica. }\end{array}$ & $\begin{array}{l}12 \text { horas de treinamento composto } \\
\text { por } 45 \text { minutos a sessão, por um } \\
\text { período de } 3 \text { meses, e uma } \\
\text { discussão semanal para } \\
\text { transferência na vida diária. }\end{array}$ & $\begin{array}{l}\text { Os indivíduos do grupo de CRT } \\
\text { demonstraram significativa } \\
\text { melhora em medidas de } \\
\text { funcionamento cognitivo geral, } \\
\text { velocidade psicomotora, } \\
\text { aprendizagem verbal e follow-up } \\
\text { em sintomas positivos e de } \\
\text { depressão PANSS. }\end{array}$ \\
\hline Kern et al, 2009 & $\begin{array}{c}\text { Comparação de } 40 \text { pacientes com } \\
\text { esquizofrenia randomizados em } \\
\text { treinamento de instrução } \\
\text { convencional e terapia de } \\
\text { remediação cognitiva errorless } \\
\text { learning. }\end{array}$ & $\begin{array}{l}\text { Duas horas semanais de } \\
\text { treinamento por um período de } 3 \\
\text { meses. }\end{array}$ & $\begin{array}{l}\text { Melhor desempenho na } \\
\text { capacidade de trabalho nos } \\
\text { pacientes que freqüentaram o } \\
\text { treinamento de "errorless } \\
\text { learning". }\end{array}$ \\
\hline
\end{tabular}


Introdução

\begin{tabular}{|c|c|c|c|}
\hline Estudos & Tipo de estudo & $\begin{array}{c}\text { Frequência e duração total do } \\
\text { treino }\end{array}$ & Resultados principais \\
\hline Veltro et al, 2011 & $\begin{array}{c}\text { Comparação de } 24 \text { pacientes com } \\
\text { esquizofrenia randomizados em } \\
\text { Reabilitação cognitiva-emocional e } \\
\text { Treinamento de solução de } \\
\text { problemas. }\end{array}$ & $\begin{array}{l}\text { Sessões semanais de pelo menos } \\
90 \text { minutos, seguidos por } 2 \\
\text { exercícios (freqüência semanal) } \\
\text { planejada entre as sessões } \\
\text { durante } 6 \text { meses. }\end{array}$ & $\begin{array}{l}\text { O grupo de Treinamento de } \\
\text { solução de problemas } \\
\text { melhorou cognitivamente em } \\
\text { planejamento e memória, } \\
\text { enquanto que o grupo de } \\
\text { reabilitação cogitiva-emociona } \\
\text { melhorou em cognição social. }\end{array}$ \\
\hline Vita et al, 2011 & $\begin{array}{l}\text { Comparação de } 26 \text { pacientes com } \\
\text { esquizofrenia em Terapia } \\
\text { psicológica integrada, } 30 \text { pacientes } \\
\text { em Remediação cognitiva assistida } \\
\text { por computador e } 28 \text { pacientes em } \\
\text { tratamento usual. }\end{array}$ & $\begin{array}{l}2 \text { sessões semanais de } 45 \text { minutos } \\
\text { cada por } 3 \text { meses. }\end{array}$ & $\begin{array}{l}\text { Ambos os grupos de Terapia } \\
\text { psicológica integrada e } \\
\text { Remediação cognitiva por } \\
\text { computador melhoraram o } \\
\text { desempenho cognitivo em } \\
\text { velocidade de processamento } \\
\text { e memória de trabalho. }\end{array}$ \\
\hline
\end{tabular}


Introdução

Tabela 3 - Estudos de avaliação cognitiva subjacente à matemática.

\begin{tabular}{|c|c|c|c|c|c|c|c|c|}
\hline Estudos & Tipo de estudo & Testes utilizados & $\mathbf{N}$ & $\begin{array}{l}\text { Diagnóstico e } \\
\text { condição } \\
\text { clínica } \\
\text { experimental }\end{array}$ & Faixa etária & $\begin{array}{l}\text { Condição } \\
\text { controle }\end{array}$ & $\begin{array}{l}\text { Freqüência } \\
\text { e duração } \\
\text { total do } \\
\text { treino }\end{array}$ & Resultados principais \\
\hline $\begin{array}{c}\text { Geary, } \\
1991\end{array}$ & $\begin{array}{c}\text { Avaliação de } \\
\text { escolha de } \\
\text { estratégias e } \\
\text { velocidade de } \\
\text { processamento. }\end{array}$ & $\begin{array}{l}\text { Teste de estímulo } \\
\text { aditivo, teste de } \\
\text { mecanismo } \\
\text { clocking. }\end{array}$ & $\begin{array}{l}\text { T: } 120 \text { (adultos } \\
\text { jovens: } 60, \\
\text { idosos: } 60 \text { ) }\end{array}$ & $\begin{array}{l}\text { Grupo de } \\
\text { universitários } \\
\text { mais jovens e } \\
\text { grupo de } \\
\text { idosos. }\end{array}$ & $\begin{array}{l}\text { Média de } 19.8 \\
\text { anos no grupo } \\
\text { de adultos } \\
\text { jovens e } 71.3 \\
\text { anos no grupo } \\
\text { de idosos. }\end{array}$ & $\begin{array}{l}\text { Não } \\
\text { houve }\end{array}$ & Não houve & $\begin{array}{c}\text { O grupo de idosos } \\
\text { demonstrou melhor } \\
\text { desempenho em } \\
\text { medidas de habilidades } \\
\text { e desenvolvimento da } \\
\text { maturidade em diversas } \\
\text { estratégias de solução } \\
\text { de problemas, mas o } \\
\text { grupo jovem } \\
\text { demonstrou melhor } \\
\text { tempo em todas as } \\
\text { soluções. }\end{array}$ \\
\hline
\end{tabular}


Introdução

\begin{tabular}{|c|c|c|c|c|c|c|c|c|}
\hline Estudos & Tipo de estudo & Testes utilizados & $\mathbf{N}$ & $\begin{array}{c}\text { Diagnóstico e } \\
\text { condição } \\
\text { clínica } \\
\text { experimental }\end{array}$ & Faixa etária & $\begin{array}{c}\text { Condição } \\
\text { controle }\end{array}$ & $\begin{array}{l}\text { Freqüência } \\
\text { e duração } \\
\text { total do } \\
\text { treino }\end{array}$ & Resultados principais \\
\hline $\begin{array}{l}\text { Baddeley et } \\
\text { al, } 1997\end{array}$ & $\begin{array}{l}\text { Aplicação de } \\
\text { bateria } \\
\text { neuropsicológica } \\
\text { composta por } \\
\text { tarefas de } \\
\text { desempenho em } \\
\text { dupla tarefa e } \\
\text { duas tarefas de } \\
\text { medida da função } \\
\text { do lobo frontal } \\
\text { (WCST e fluência } \\
\text { verbal) em grupo } \\
\text { disexecutivo e } \\
\text { normal. }\end{array}$ & $\begin{array}{l}\text { Dígitos Span, } \\
\text { Rastreamento, } \\
\text { Fluência de } \\
\text { palavras, } \\
\text { Wisconsin Card } \\
\text { Test - WCST. }\end{array}$ & $\begin{array}{c}\text { T: } 24 \text { (12 } \\
\text { sujeitos em } \\
\text { cada grupo) }\end{array}$ & $\begin{array}{c}\text { Pacientes com } \\
\text { lesão cerebral } \\
\text { restrito ao lobo } \\
\text { frontal } \\
\text { demonstrado } \\
\text { em tomografia } \\
\text { computadoriza } \\
\text { da apesar de } \\
\text { golpes, tumor } \\
\text { ou prejuízos } \\
\text { na cabeça e } \\
\text { sem história } \\
\text { prévia de } \\
\text { doença } \\
\text { neurológica ou } \\
\text { psiquiátrica. }\end{array}$ & $\begin{array}{l}\text { Média de } \\
\text { idade de } 50.4 \\
\text { anos no grupo } \\
\text { não- } \\
\text { disexecutivo e } \\
\text { de } 52.8 \text { anos } \\
\text { no grupo } \\
\text { dysexecutivo. }\end{array}$ & $\begin{array}{l}\text { Não } \\
\text { houve }\end{array}$ & Não houve & $\begin{array}{c}\text { O grupo disexecutivo } \\
\text { diferiu significativamente } \\
\text { do grupo não- } \\
\text { disexecutivo ao } \\
\text { apresentar capacidade } \\
\text { prejudicada em } \\
\text { coordenação de dupla- } \\
\text { tarefa, mas não houve } \\
\text { diferença significativa } \\
\text { em no WCST e fluência } \\
\text { verbal. }\end{array}$ \\
\hline $\begin{array}{l}\text { Bull et al, } \\
1999\end{array}$ & $\begin{array}{c}\text { Avaliação } \\
\text { neuropsicológica } \\
\text { acerca do papel } \\
\text { dos mecanismos } \\
\text { de WM em } \\
\text { habilidades } \\
\text { aritméticas, } \\
\text { chamadas de } \\
\text { central executiva } \\
\text { e esboço de } \\
\text { desenho visuo- } \\
\text { espacial. }\end{array}$ & $\begin{array}{l}\text { Wisconsin Card } \\
\text { Sorting Test } \\
\text { (WCST), Blocos } \\
\text { Corsi, Teste de } \\
\text { grupo matemático } \\
\text { (estratégias de } \\
\text { contagem em } \\
\text { adição simples), } \\
\text { Escala de } \\
\text { habilidade } \\
\text { Britânica (BAS), } \\
\text { Teste de leitura } \\
\text { de palavras. }\end{array}$ & $\begin{array}{c}\mathrm{T}: 44 ; \mathrm{E}: \mathrm{n}=24 \\
\text { grupo de alta } \\
\text { habilidade } \\
\text { matemática e } \\
\mathrm{n}=20 \text { grupo de } \\
\text { baixa } \\
\text { habilidade } \\
\text { matemática. }\end{array}$ & $\begin{array}{c}\text { Alunos do } 3^{\circ} \\
\text { ano primário } \\
\text { de uma escola } \\
\text { escocesa. }\end{array}$ & $\begin{array}{l}\text { Média de } 7.3 \\
\text { anos }\end{array}$ & $\begin{array}{l}\text { Não } \\
\text { houve }\end{array}$ & Não houve & $\begin{array}{c}\text { Crianças com alta e } \\
\text { baixa habilidade se } \\
\text { diferem } \\
\text { significativamente em } \\
\text { medidas de WCST após } \\
\text { o controle de diferenças } \\
\text { na habilidade de leitura } \\
\text { e QI, mas não se } \\
\text { diferem em seqüência } \\
\text { de memória visual. }\end{array}$ \\
\hline
\end{tabular}


Introdução

\begin{tabular}{|c|c|c|c|c|c|c|c|c|}
\hline Estudos & Tipo de estudo & Testes utilizados & $\mathbf{N}$ & $\begin{array}{c}\text { Diagnóstico e } \\
\text { condição } \\
\text { clínica } \\
\text { experimental }\end{array}$ & Faixa etária & $\begin{array}{c}\text { Condição } \\
\text { controle }\end{array}$ & $\begin{array}{l}\text { Freqüência } \\
\text { e duração } \\
\text { total do } \\
\text { treino }\end{array}$ & Resultados principais \\
\hline $\begin{array}{c}\text { Geary et al, } \\
1999\end{array}$ & $\begin{array}{c}\text { Avaliação } \\
\text { cognitiva da } \\
\text { habilidade de } \\
\text { compreensão e } \\
\text { produção dos } \\
\text { números, } \\
\text { conhecimento de } \\
\text { contagem, } \\
\text { habilidade } \\
\text { aritmética, } \\
\text { memória de } \\
\text { trabalho e } \\
\text { recuperação da } \\
\text { informação para } \\
\text { memória de longo } \\
\text { prazo. }\end{array}$ & $\begin{array}{c}\text { Sub-testes } \\
\text { Vocabulário e } \\
\text { Bloco de } \\
\text { desenhos (WISC- } \\
\text { III), escala de } \\
\text { inteligência } \\
\text { Stanford-Binet, } \\
\text { sub-teste Matriz } \\
\text { de raciocínio } \\
\text { (WISC-III), sub- } \\
\text { testes ataque de } \\
\text { palavras e } \\
\text { identificação de } \\
\text { carta-palavras, } \\
\text { bateria de } \\
\text { discalculia. }\end{array}$ & $\begin{array}{c}\mathrm{T}: 114 ; \mathrm{E}: 55 ; \\
\mathrm{C}: 35\end{array}$ & $\begin{array}{c}\text { Alunos de pr } \\
\text { imeira série de } \\
\text { uma escola } \\
\text { pública com } \\
\text { dificuldade de } \\
\text { aprendizagem } \\
\text { em } \\
\text { matemática, } \\
\text { leitura ou } \\
\text { ambos. }\end{array}$ & $\begin{array}{l}\text { Média de } 7 \\
\text { anos }\end{array}$ & $\begin{array}{l}\text { Não } \\
\text { houve }\end{array}$ & $\begin{array}{l}\text { Alunos de } \\
\text { primeira } \\
\text { série } \\
\text { academicam } \\
\text { ente normal. }\end{array}$ & $\begin{array}{l}\text { Foram encontrados } \\
\text { diferentes padrões de } \\
\text { déficit de cognição e } \\
\text { cognição intacta nos } \\
\text { diferentes grupos de } \\
\text { risco, fornecendo } \\
\text { insights de déficit } \\
\text { cognitivo subjacentes às } \\
\text { diferentes formas de } \\
\text { dificuldade de } \\
\text { aprendizagem. }\end{array}$ \\
\hline
\end{tabular}


Introdução

\begin{tabular}{|c|c|c|c|c|c|c|c|c|}
\hline Estudos & Tipo de estudo & Testes utilizados & $\mathbf{N}$ & $\begin{array}{l}\text { Diagnóstico e } \\
\text { condição } \\
\text { clínica } \\
\text { experimental }\end{array}$ & Faixa etária & $\begin{array}{l}\text { Condição } \\
\text { controle }\end{array}$ & $\begin{array}{l}\text { Freqüência } \\
\text { e duração } \\
\text { total do } \\
\text { treino }\end{array}$ & Resultados principais \\
\hline $\begin{array}{l}\text { Miyake et } \\
\text { al, } 2000\end{array}$ & $\begin{array}{c}\text { Avaliação acerca } \\
\text { da divisão de três } \\
\text { funções } \\
\text { executivas } \\
\text { freqüentemente } \\
\text { postuladas - } \\
\text { flexibilidade } \\
\text { mental, } \\
\text { atualização das } \\
\text { informações e } \\
\text { monitoramento, } \\
\text { inibição de } \\
\text { respostas - e } \\
\text { seus papéis no } \\
\text { completo "lobo } \\
\text { frontal" ou tarefas } \\
\text { "executivas". }\end{array}$ & $\begin{array}{l}\text { Wisconsin Card } \\
\text { Sorting Test- } \\
\text { WCST, Torre de } \\
\text { Hanoi-TOH, } \\
\text { Geração de } \\
\text { números } \\
\text { randomizados } \\
\text { (RNG), Operação } \\
\text { Span, Testes de } \\
\text { dupla tarefa, } \\
\text { Stroop Task, } \\
\text { Tarefas de } \\
\text { manutenção do } \\
\text { controle, Tarefas } \\
\text { de memória em } \\
\text { cartas, tarefas de } \\
\text { monitoramento } \\
\text { tom. }\end{array}$ & $\mathrm{T}: 137$ & $\begin{array}{l}\text { Universitários } \\
\text { saudáveis }\end{array}$ & - & $\begin{array}{l}\text { Não } \\
\text { houve }\end{array}$ & Não houve & $\begin{array}{c}\text { A análise fatorial } \\
\text { confirmatória indicou } \\
\text { que as três funções } \\
\text { executivas estão } \\
\text { correlacionadas, mas } \\
\text { são claramente } \\
\text { separadas. Além disso, } \\
\text { um modelo de equação } \\
\text { estrutural sugeriu que as } \\
\text { três funções contribuem } \\
\text { diferentemente no } \\
\text { desempenho de tarefas } \\
\text { executivas complexas. } \\
\text { Especificamente, WCST } \\
\text { foi relacionado mais } \\
\text { fortemente à } \\
\text { flexibilidade mental, } \\
\text { Torre de Hanói à } \\
\text { inibição, geração de } \\
\text { números randomizados } \\
\text { à inibição e atualização } \\
\text { e operação span à } \\
\text { atualização. } \\
\text { Desempenho em dupla } \\
\text { tarefa não se relacionou } \\
\text { com nenhuma das três } \\
\text { medidas. }\end{array}$ \\
\hline
\end{tabular}


Introdução

\begin{tabular}{|c|c|c|c|c|c|c|c|c|}
\hline Estudos & Tipo de estudo & Testes utilizados & $\mathbf{N}$ & $\begin{array}{c}\text { Diagnóstico e } \\
\text { condição } \\
\text { clínica } \\
\text { experimental }\end{array}$ & Faixa etária & $\begin{array}{c}\text { Condição } \\
\text { controle }\end{array}$ & $\begin{array}{c}\text { Freqüência } \\
\text { e duração } \\
\text { total do } \\
\text { treino }\end{array}$ & Resultados principais \\
\hline $\begin{array}{c}\text { Swanson e } \\
\text { Sachse- } \\
\text { Lee, } 2001\end{array}$ & $\begin{array}{c}\text { Avaliação } \\
\text { neuropsicológica } \\
\text { de medidas de } \\
\text { memória de } \\
\text { trabalho e } \\
\text { solução de } \\
\text { problemas } \\
\text { matemáticos. }\end{array}$ & $\begin{array}{c}\text { Tarefas } \\
\text { matemáticas, } \\
\text { teste de } \\
\text { processamento } \\
\text { cognitivo } \\
\text { Swanson, teste } \\
\text { de sentenças, } \\
\text { Teste de dígitos } \\
\text { rápido, eliminação } \\
\text { fonêmica, dígitos, } \\
\text { dígitos auditory } \\
\text { seqüencial, } \\
\text { recontagem de } \\
\text { histórias, matrix } \\
\text { visual, } \\
\text { mapeamento e } \\
\text { direção. }\end{array}$ & $\begin{array}{c}\text { T: 73; E1: 29; } \\
\text { E2:20. }\end{array}$ & $\begin{array}{l}\text { Crianças com } \\
\text { dificuldade de } \\
\text { aprendizagem. }\end{array}$ & $\begin{array}{c}\text { Média de } 11.5 \\
\text { anos no grupo } \\
\text { de crianças } \\
\text { com } \\
\text { dificuldade de } \\
\text { aprendizagem } \\
\text { e média de } 8.9 \\
\text { anos no grupo } \\
\text { de crianças } \\
\text { com } \\
\text { dificuldade de } \\
\text { aprendizagem } \\
\text { mais jovem. }\end{array}$ & $\begin{array}{l}\text { Não } \\
\text { houve }\end{array}$ & Não houve & $\begin{array}{c}\text { Crianças com } \\
\text { dificuldade de } \\
\text { aprendizagem obtiveram } \\
\text { medidas inferiores na } \\
\text { precisão de solução de } \\
\text { palavras, componentes } \\
\text { da solução de } \\
\text { problemas, } \\
\text { processamento } \\
\text { fonológico, memória de } \\
\text { trabalho geral e } \\
\text { memória de trabalho } \\
\text { verbal quando } \\
\text { comparado com } \\
\text { crianças de mesma } \\
\text { faixa etária. Crianças } \\
\text { com dificuldade } \\
\text { matemática foram } \\
\text { comparáveis em todas } \\
\text { as medidas, exceto } \\
\text { medidas de memória de } \\
\text { trabalho geral e visuo- } \\
\text { espacial, eliminação } \\
\text { fonêmica e problemas. } \\
\text { Memória de trabalho } \\
\text { verbal e visuo-espacial } \\
\text { contribuíram } \\
\text { significativamente para } \\
\text { solução do } \\
\text { processamento } \\
\text { fonológico. }\end{array}$ \\
\hline
\end{tabular}


Introdução

\begin{tabular}{|c|c|c|c|c|c|c|c|c|}
\hline Estudos & Tipo de estudo & Testes utilizados & $\mathbf{N}$ & $\begin{array}{c}\text { Diagnóstico e } \\
\text { condição } \\
\text { clínica } \\
\text { experimental }\end{array}$ & Faixa etária & $\begin{array}{c}\text { Condição } \\
\text { controle }\end{array}$ & $\begin{array}{l}\text { Freqüência } \\
\text { e duração } \\
\text { total do } \\
\text { treino }\end{array}$ & Resultados principais \\
\hline $\begin{array}{l}\text { Passolunghi } \\
\text { e Siegel, } \\
2001\end{array}$ & $\begin{array}{c}\text { Avaliação } \\
\text { neuropsicológica } \\
\text { da memória de } \\
\text { trabalho, memória } \\
\text { de curto prazo e } \\
\text { controle inibitório. }\end{array}$ & $\begin{array}{l}\text { Teste de escuta } \\
\text { span, teste duplo } \\
\text { animal, teste } \\
\text { completo de } \\
\text { escuta, teste de } \\
\text { contagem span, } \\
\text { teste de palavra } \\
\text { span e dígitos de } \\
\text { ordem direta e } \\
\text { inversa. }\end{array}$ & $\begin{array}{c}\text { T: 49; E1: } 23 ; \\
\text { C: } 26\end{array}$ & $\begin{array}{c}\text { Crianças com } \\
\text { desempenho } \\
\text { de solução de } \\
\text { problemas } \\
\text { empobrecida. }\end{array}$ & --- & $\begin{array}{c}\text { Crianças } \\
\text { com bom } \\
\text { desempe } \\
\text { nho em } \\
\text { solução } \\
\text { de } \\
\text { problema } \\
\text { s }\end{array}$ & Não houve & $\begin{array}{c}\text { Crianças com } \\
\text { desempenho de solução } \\
\text { de problemas } \\
\text { empobrecida } \\
\text { apresentaram déficit em } \\
\text { memória de trabalho } \\
\text { geral. }\end{array}$ \\
\hline $\begin{array}{c}\text { Bull e } \\
\text { Scerif, } 2001\end{array}$ & $\begin{array}{c}\text { Avaliação } \\
\text { neuropsicológica } \\
\text { da relação entre } \\
\text { habilidade } \\
\text { matemática e } \\
\text { função executiva. }\end{array}$ & $\begin{array}{c}\text { Wisconsin Card } \\
\text { Sorting Task } \\
\text { (WCST), } \\
\text { desempenho em } \\
\text { dupla-tarefa, } \\
\text { Stroop Task, } \\
\text { Couting Span. }\end{array}$ & $\mathrm{T}: 105$ & $\begin{array}{c}\text { Alunos de seis } \\
\text { escolas } \\
\text { primárias. }\end{array}$ & $\begin{array}{l}\text { Média de } 7.4 \\
\text { anos }\end{array}$ & $\begin{array}{c}\text { Não } \\
\text { houve }\end{array}$ & Não houve & $\begin{array}{l}\text { Encontrou-se que a } \\
\text { habilidade matemática } \\
\text { foi significativamente } \\
\text { correlacionada com } \\
\text { todas as medidas de } \\
\text { funcionamento } \\
\text { executivo, exceto } \\
\text { desempenho em dupla- } \\
\text { tarefa. Análise de } \\
\text { regressão revelou que } \\
\text { cada medida de função } \\
\text { executiva prediz uma } \\
\text { única variância em } \\
\text { habilidade matemática. } \\
\text { As dificuldades } \\
\text { particulares em crianças } \\
\text { com baixa habilidade } \\
\text { matemática são perda } \\
\text { de inibitória e WM } \\
\text { pobre. }\end{array}$ \\
\hline
\end{tabular}

Continua 
Introdução

\begin{tabular}{|c|c|c|c|c|c|c|c|c|}
\hline Estudos & Tipo de estudo & Testes utilizados & $\mathbf{N}$ & $\begin{array}{c}\text { Diagnóstico e } \\
\text { condição } \\
\text { clínica } \\
\text { experimental }\end{array}$ & Faixa etária & $\begin{array}{c}\text { Condição } \\
\text { controle }\end{array}$ & $\begin{array}{c}\text { Freqüência } \\
\text { e duração } \\
\text { total do } \\
\text { treino }\end{array}$ & Resultados principais \\
\hline $\begin{array}{c}\text { Conway et } \\
\text { al, } 2001\end{array}$ & $\begin{array}{c}\text { Avaliação } \\
\text { neuropsicológica } \\
\text { em medidas da } \\
\text { capacidade em } \\
\text { memória de curto } \\
\text { prazo, memória } \\
\text { de trabalho e } \\
\text { velocidade de } \\
\text { processamento. }\end{array}$ & $\begin{array}{c}\text { Leitura Span, } \\
\text { Operação Span, } \\
\text { Couting Span, } \\
\text { Tarefa de palavra } \\
\text { simples span, } \\
\text { Substituição } \\
\text { dígito-símbolo, } \\
\text { Enfrentamento de } \\
\text { dígitos e palavras, } \\
\text { Comparação } \\
\text { padrão e tom, } \\
\text { Matriz } \\
\text { progressiva de } \\
\text { Raven, Teste de } \\
\text { feira da cultura } \\
\text { Cattell }\end{array}$ & T: 120 & $\begin{array}{c}\text { Adultos jovens } \\
\text { saudáveis, } \\
\text { pós- } \\
\text { graduandos da } \\
\text { Universidade } \\
\text { de Illinois em } \\
\text { Chicago(EUA). } \\
\text { Todos usavam } \\
\text { a língua } \\
\text { inglesa. }\end{array}$ & -- & $\begin{array}{l}\text { Não } \\
\text { houve }\end{array}$ & Não houve & $\begin{array}{l}\text { Encontrou-se a } \\
\text { capacidade de memória } \\
\text { de trabalho como } \\
\text { melhor preditora de } \\
\text { inteligência geral fluida } \\
\text { se comparada à } \\
\text { capacidade de memória } \\
\text { de curto-prazo e } \\
\text { velocidade de } \\
\text { processamento em } \\
\text { adultos jovens } \\
\text { saudáveis. }\end{array}$ \\
\hline $\begin{array}{c}\text { Kiefer e } \\
\text { Weisbrod, } \\
2002\end{array}$ & $\begin{array}{l}\text { Avaliação } \\
\text { aritmética e } \\
\text { medidas de } \\
\text { memória de } \\
\text { trabalho. }\end{array}$ & $\begin{array}{l}\text { Subteste dígitos } \\
\text { de ordem direta e } \\
\text { inversa (HAWIE- } \\
\text { R), Fluência de } \\
\text { leitura, fluência de } \\
\text { categorias, } \\
\text { tarefas } \\
\text { aritméticas. }\end{array}$ & $\begin{array}{c}\mathrm{T} ; 48 ; \mathrm{E}: 24 ; \\
\mathrm{C}: 24\end{array}$ & $\begin{array}{l}\text { Pacientes com } \\
\text { esquizofrenia. }\end{array}$ & $\begin{array}{l}\text { Média de } 10.3 \\
\text { anos no grupo } \\
\text { experimental e } \\
10.2 \text { anos no } \\
\text { grupo controle. }\end{array}$ & $\begin{array}{l}\text { Sujeitos } \\
\text { saudáveis }\end{array}$ & Não houve & $\begin{array}{c}\text { Pacientes com } \\
\text { esquizofrenia } \\
\text { demonstraram pior } \\
\text { desempenho em tarefas } \\
\text { de função executiva. } \\
\text { Dígito de ordem direta } \\
\text { foi preservado. Em } \\
\text { tarefas aritméticas o } \\
\text { desempenho dos grupos } \\
\text { não se diferiu, e um } \\
\text { padrão de manipulação } \\
\text { da tarefa foi obtido. }\end{array}$ \\
\hline
\end{tabular}

Continua 
Introdução

\begin{tabular}{|c|c|c|c|c|c|c|c|c|}
\hline Estudos & Tipo de estudo & Testes utilizados & $\mathbf{N}$ & $\begin{array}{c}\text { Diagnóstico e } \\
\text { condição } \\
\text { clínica } \\
\text { experimental }\end{array}$ & Faixa etária & $\begin{array}{l}\text { Condição } \\
\text { controle }\end{array}$ & $\begin{array}{l}\text { Freqüência } \\
\text { e duração } \\
\text { total do } \\
\text { treino }\end{array}$ & Resultados principais \\
\hline $\begin{array}{l}\text { Passolunghi } \\
\text { e Siegel, } \\
2003\end{array}$ & $\begin{array}{c}\text { Avaliação } \\
\text { neuropsicológica } \\
\text { do } \\
\text { relacionamento } \\
\text { entre memória de } \\
\text { trabalho e } \\
\text { habilidade } \\
\text { matemática. }\end{array}$ & $\begin{array}{l}\text { Teste matemático } \\
\text { padrão, teste de } \\
\text { vocabulário } \\
\text { padrão, teste de } \\
\text { compreensão de } \\
\text { leitura padrão, } \\
\text { tarefas de } \\
\text { processamento } \\
\text { matemático, } \\
\text { tarefas de } \\
\text { memória de } \\
\text { trabalho, tarefas } \\
\text { de memória de } \\
\text { curto-prazo, } \\
\text { tarefas de } \\
\text { fluência } \\
\text { articulatória. }\end{array}$ & $\begin{array}{c}\mathrm{T}: 49 ; \mathrm{E}: 22 \\
\mathrm{C} ; 27\end{array}$ & $\begin{array}{c}\text { Alunos da } \\
\text { quinta série do } \\
2^{\circ} \text { grau. }\end{array}$ & $\begin{array}{c}\text { Média de } 10.4 \\
\text { anos. }\end{array}$ & $\begin{array}{l}\text { Alunos } \\
\text { com } \\
\text { dificuldad } \\
\text { ematemát } \\
\text { ica } \\
\text { normal }\end{array}$ & Não houve & $\begin{array}{l}\text { Déficit de memória de } \\
\text { trabalho geral em } \\
\text { crianças com dificuldade } \\
\text { matemática, } \\
\text { especificamente no } \\
\text { componente de central } \\
\text { executiva do modelo de } \\
\text { Baddeley e, } \\
\text { principalmente, na } \\
\text { habilidade de inibir } \\
\text { informações } \\
\text { irrelevantes. }\end{array}$ \\
\hline $\begin{array}{l}\text { Oberauer et } \\
\text { al, } 2003\end{array}$ & $\begin{array}{l}\text { Avaliação do } \\
\text { desempenho em } \\
\text { tarefas } \\
\text { aritméticas com } \\
\text { memória de } \\
\text { trabalho. }\end{array}$ & $\begin{array}{c}\text { Teste de } \\
\text { substituição } \\
\text { dígito-simbolo, } \\
\text { Vocabulário- } \\
\text { HAWIE, Tarefas } \\
\text { de cadeia } \\
\text { aritmética, } \\
\text { Tarefas de } \\
\text { atualização da } \\
\text { memória } \\
\text { aritmética }\end{array}$ & $\begin{array}{c}\text { T:48, } \\
\text { comparação } \\
\text { de um grupo } \\
\text { composto por } \\
24 \text { adultos } \\
\text { jovens com } \\
\text { um grupo de } \\
24 \text { idosos. }\end{array}$ & -- & $\begin{array}{c}\text { Média de } 23 \\
\text { anos em um } \\
\text { grupo e } 71 \\
\text { anos em outro } \\
\text { grupo. }\end{array}$ & $\begin{array}{l}\text { Não } \\
\text { houve }\end{array}$ & Não houve & $\begin{array}{c}\text { Os grupos de idade } \\
\text { foram equivalentes em } \\
\text { medidas de precisão e } \\
\text { velocidade de } \\
\text { operações aritméticas } \\
\text { abaixo do mínimo em } \\
\text { memória de trabalho, } \\
\text { mas o grupo composto } \\
\text { por idosos foram mais } \\
\text { lentos que os de adultos } \\
\text { jovens com demanda de } \\
\text { memória }>1 \text {. }\end{array}$ \\
\hline
\end{tabular}

Continua 
Introdução

\begin{tabular}{|c|c|c|c|c|c|c|c|c|}
\hline Estudos & Tipo de estudo & Testes utilizados & $\mathbf{N}$ & $\begin{array}{l}\text { Diagnóstico e } \\
\text { condição } \\
\text { clínica } \\
\text { experimental }\end{array}$ & Faixa etária & $\begin{array}{l}\text { Condição } \\
\text { controle }\end{array}$ & $\begin{array}{l}\text { Freqüência } \\
\text { e duração } \\
\text { total do } \\
\text { treino }\end{array}$ & Resultados principais \\
\hline $\begin{array}{l}\text { Lagace et } \\
\text { al, } 2003\end{array}$ & $\begin{array}{l}\text { Avaliação } \quad \text { da } \\
\text { habilidade } \\
\text { matemática. }\end{array}$ & $\begin{array}{l}\text { WRAT-R2, Teste } \\
\text { de realização } \\
\text { individual para } \\
\text { ortografia, } \\
\text { matemática e } \\
\text { leitura }\end{array}$ & $\begin{array}{c}\text { T: } 119 ; \mathrm{E}: 44 \\
\text { grupo em } \\
\text { remissão da } \\
\text { desordem } \\
\text { bipolar, } 30 \\
\text { grupo de } \\
\text { desordem } \\
\text { depressiva } \\
\text { maior; } \mathrm{C}: \mathrm{n}= \\
45\end{array}$ & $\begin{array}{c}\text { Adolescentes } \\
\text { com desordem } \\
\text { bipolar tipo I e } \\
\text { adolescentes } \\
\text { com desordem } \\
\text { depressivo } \\
\text { maior }\end{array}$ & $\begin{array}{l}\text { Média de } 19.4 \\
\text { anos no grupo } \\
\text { de desordem } \\
\text { bipolar do tipo } \\
\text { l, } 18.5 \text { anos } \\
\text { dos sujeitos do } \\
\text { grupo de } \\
\text { depressão } \\
\text { maior e } 18.2 \\
\text { anos no grupo } \\
\text { controle. }\end{array}$ & $\begin{array}{l}\text { Sujeitos } \\
\text { sem } \\
\text { histórico } \\
\text { psiquiátric } \\
\text { o }\end{array}$ & Não houve & $\begin{array}{c}\text { Escores de testes } \\
\text { WRAT-R2 e realização } \\
\text { para ortografia, } \\
\text { matemática e leitura } \\
\text { revelou que } \\
\text { adolescentes com } \\
\text { desordem bipolar } \\
\text { apresentam realização } \\
\text { significativamente mais } \\
\text { lenta em matemática, } \\
\text { comparada aos sujeitos } \\
\text { com desordem bipolar } \\
\text { maior e comparação dos } \\
\text { sujeitos. Resultados aos } \\
\text { testes de inteligência } \\
\text { não-verbal-2 não foi } \\
\text { encontrado diferença } \\
\text { significativa entre os } \\
\text { grupos. Adolescentes } \\
\text { cm desordem bipolar } \\
\text { completaram } \\
\text { significativamente mais } \\
\text { as tarefas matemáticas } \\
\text { de avaliação de } \\
\text { desempenho na área } \\
\text { funcional Bay. }\end{array}$ \\
\hline
\end{tabular}

Continua 
Introdução

\begin{tabular}{|c|c|c|c|c|c|c|c|c|}
\hline Estudos & Tipo de estudo & Testes utilizados & $\mathbf{N}$ & $\begin{array}{c}\text { Diagnóstico e } \\
\text { condição } \\
\text { clínica } \\
\text { experimental }\end{array}$ & Faixa etária & $\begin{array}{l}\text { Condição } \\
\text { controle }\end{array}$ & $\begin{array}{c}\text { Freqüência } \\
\text { e duração } \\
\text { total do } \\
\text { treino }\end{array}$ & Resultados principais \\
\hline $\begin{array}{l}\text { Gathercole } \\
\text { et al, } 2004\end{array}$ & $\begin{array}{l}\text { Avaliação } \\
\text { neuropsicológica } \\
\text { em medidas de } \\
\text { memória de } \\
\text { trabalho. }\end{array}$ & $\begin{array}{c}\text { Oito subtestes da } \\
\text { bateria de testes } \\
\text { de memória de } \\
\text { trabalho para } \\
\text { crianças, teste } \\
\text { padrão visual, } \\
\text { dígitos, lista de } \\
\text { palavras, lista de } \\
\text { não-palavras, } \\
\text { recuperação de } \\
\text { blocos, teste de } \\
\text { padrão visual, } \\
\text { memória de } \\
\text { labirintos, } \\
\text { recuperação } \\
\text { ouvida e de } \\
\text { contagem. }\end{array}$ & $\begin{array}{l}\text { T: 595; E1: 43; } \\
\text { E2: 101; E3: } \\
\text { 91; E4: 96; E5: } \\
\text { 63; E6: 101; } \\
\text { E7: 37; E5: 45; } \\
\text { E6: 14; E7: } 4\end{array}$ & $\begin{array}{c}\text { Alunos de } \\
\text { cinco escolas } \\
\text { inglesas. }\end{array}$ & $\begin{array}{c}\text { Entre } 4 \text { e } 15 \\
\text { anos de idade }\end{array}$ & $\begin{array}{l}\text { Não } \\
\text { houve }\end{array}$ & Não houve & $\begin{array}{c}\text { Funções lineares } \\
\text { similares e a idade } \\
\text { caracterizaram todas as } \\
\text { medidas de memória de } \\
\text { trabalho. }\end{array}$ \\
\hline $\begin{array}{l}\text { Andersson } \\
\text { e Lyxell, } \\
2005\end{array}$ & $\begin{array}{c}\text { Avaliação } \\
\text { neuropsicológica } \\
\text { de alunos que } \\
\text { freqüentam } \\
\text { classes de } \\
\text { Instruções } \\
\text { especiais } \\
\text { adaptadas para } \\
\text { cada dificuldade } \\
\text { específica da } \\
\text { criança, } \\
\text { conduzidas em } \\
\text { pequenos grupos } \\
\text { de } 2 \text { ou } 4 \text {. }\end{array}$ & $\begin{array}{l}\text { Tarefa de fluência } \\
\text { verbal, Trail } \\
\text { Making Test, } \\
\text { Color Stroop } \\
\text { Task, Crossing } \\
\text { Out Task, } \\
\text { Number-matching } \\
\text { Task, Animal Dual } \\
\text { Task, Couting } \\
\text { Span Task, Visual } \\
\text { Matrix Span Task, } \\
\text { Dígitos Span, } \\
\text { Tarefa de Palavra } \\
\text { Span. }\end{array}$ & $\begin{array}{l}\text { T: 138; E: } \\
\text { dificuldades } \\
\text { matemática } \\
\text { (MDs) 31, } \\
\text { dificuldades } \\
\text { matemáticas e } \\
\text { dificuldade de } \\
\text { leitura 37; C: } \\
\text { pareados por } \\
\text { idade 47, } \\
\text { controle mais } \\
\text { jovem } 50 .\end{array}$ & $\begin{array}{l}\text { Crianças com } \\
\text { dificuldades } \\
\text { em } \\
\text { matemática, } \\
\text { com } \\
\text { dificuldades } \\
\text { matemática e } \\
\text { de leitura. } \\
\text { Todas fluentes } \\
\text { na língua } \\
\text { sueca, com } \\
\text { acuidade } \\
\text { visual normal } \\
\text { e TDHA. }\end{array}$ & $\begin{array}{lr}\text { A amostra } \\
\text { total apresenta } \\
\text { média re } \\
\text { idade de } 121 \\
\text { meses } \\
S D=9,44 .\end{array}$ & $\begin{array}{l}\text { Grupos } \\
\text { controle } \\
\text { pareados } \\
\text { por idade } \\
\text { consiste } \\
\text { em } \\
\text { alunos do } \\
3^{\circ} \text { e } 4^{\circ} \\
\text { ano. } \\
\text { Alunos do } \\
3^{\circ} \text { ano em } \\
\text { ambos os } \\
\text { grupos. }\end{array}$ & $\begin{array}{l}\text { Instruções } \\
\text { especiais } \\
\text { somente em } \\
\text { matemática } \\
\text { ou em } \\
\text { matemática e } \\
\text { leitura no } \\
\text { momento do } \\
\text { estudo. }\end{array}$ & $\begin{array}{l}\text { Comparados com os } \\
\text { grupos controle } \\
\text { pareados por idade, } \\
\text { ambos os grupos com } \\
\text { dificuldade matemática } \\
\text { apresentaram pior } \\
\text { desempenho em tarefas } \\
\text { tapping de central } \\
\text { executiva e laço } \\
\text { fonológico Desempenho } \\
\text { pior do grupo MD que o } \\
\text { controle mais jovem em } \\
\text { tarefas de couting span. }\end{array}$ \\
\hline
\end{tabular}

Continua 
Introdução

\begin{tabular}{|c|c|c|c|c|c|c|c|c|}
\hline Estudos & Tipo de estudo & Testes utilizados & $\mathbf{N}$ & $\begin{array}{c}\text { Diagnóstico e } \\
\text { condição } \\
\text { clínica } \\
\text { experimental }\end{array}$ & Faixa etária & $\begin{array}{c}\text { Condição } \\
\text { controle }\end{array}$ & $\begin{array}{l}\text { Freqüência } \\
\text { e duração } \\
\text { total do } \\
\text { treino }\end{array}$ & Resultados principais \\
\hline $\begin{array}{l}\text { Pavuluri et } \\
\text { al, } 2006\end{array}$ & $\begin{array}{c}\text { Avaliação } \\
\text { neuropsicológica. }\end{array}$ & $\begin{array}{l}\text { Vocabulário e } \\
\text { matriz de } \\
\text { raciocínio do } \\
\text { WASI, Trail } \\
\text { Making Test, } \\
\text { Teste de } \\
\text { aprendizagem } \\
\text { Verbal California- } \\
\text { versão infantil, } \\
\text { Espacial Span e } \\
\text { Dígito Span do } \\
\text { WMS-III, Teste de } \\
\text { exclusão } \\
\text { condicional, } \\
\text { Continuous } \\
\text { Performance } \\
\text { Test-CPT, Teste } \\
\text { de Mudança de } \\
\text { Set-SST, Teste } \\
\text { de associação de } \\
\text { palavras oral } \\
\text { controlada- } \\
\text { COWAT. }\end{array}$ & $\begin{array}{c}\text { T: } 55 ; \text { E: } 28 \\
\text { grupo de } \\
\text { desordem } \\
\text { bipolar e } 27 \\
\text { grupo de } \\
\text { transtorno } \\
\text { bipolar + } \\
\text { transtorno de } \\
\text { déficit de } \\
\text { atenção e } \\
\text { hiperatividade }\end{array}$ & $\begin{array}{l}\text { Crianças com } \\
\text { desordem } \\
\text { bipolar e } \\
\text { crianças com } \\
\text { transtorno } \\
\text { bipolar+transto } \\
\text { rno de déficit } \\
\text { de atenção e } \\
\text { hiperatividade } \\
\text { (TDAH) }\end{array}$ & - & $\begin{array}{c}\text { Não } \\
\text { houve }\end{array}$ & Não houve & $\begin{array}{l}\text { Escore de função } \\
\text { executiva, memória de } \\
\text { trabalho e memória } \\
\text { verbal foram mais } \\
\text { pobres naquelas com } \\
\text { dificuldade de leitura e } \\
\text { escrita. Uma análise de } \\
\text { regressão logística } \\
\text { separada encontrou que } \\
\text { disfunção atencional } \\
\text { prediz dificuldade } \\
\text { matemática. Este } \\
\text { relacionamento entre } \\
\text { função neuropsicológica } \\
\text { e dificuldade acadêmica } \\
\text { não se diferenciou em } \\
\text { relação àqueles com } \\
\text { transtonro } \\
\text { bipolar+TDAH e com } \\
\text { apenas transtorno } \\
\text { bipolar. }\end{array}$ \\
\hline
\end{tabular}


Introdução

\begin{tabular}{|c|c|c|c|c|c|c|c|c|}
\hline Estudos & Tipo de estudo & Testes utilizados & $\mathbf{N}$ & $\begin{array}{l}\text { Diagnóstico e } \\
\text { condição } \\
\text { clínica } \\
\text { experimental }\end{array}$ & Faixa etária & $\begin{array}{l}\text { Condição } \\
\text { controle }\end{array}$ & $\begin{array}{l}\text { Freqüência } \\
\text { e duração } \\
\text { total do } \\
\text { treino }\end{array}$ & Resultados principais \\
\hline $\begin{array}{l}\text { Barret et al, } \\
2008\end{array}$ & $\begin{array}{c}\text { Avaliação de } \\
\text { medidas de } \\
\text { função executiva. }\end{array}$ & $\begin{array}{l}\text { Testes que } \\
\text { avaliam memória } \\
\text { de trabalho } \\
\text { espacial, } \\
\text { planejamento, } \\
\text { atenção dividida e } \\
\text { fluência verbal. }\end{array}$ & $\begin{array}{l}\text { T; 52; E: } 26 ; \\
\text { C: } 26\end{array}$ & $\begin{array}{c}\text { Pacientes } \\
\text { eutímicos com } \\
\text { desordem } \\
\text { bipolar } \\
\text { segundo DSM- } \\
\text { IV. }\end{array}$ & $\begin{array}{l}\text { Média de } \\
52.50 \text { anos } \\
\text { nos pacientes } \\
\text { masculinos e } \\
41.43 \text { anos } \\
\text { femininos } \\
\text { como } \\
\text { desordem } \\
\text { bipolar; } 49.75 \\
\text { anos nos } \\
\text { homens saudáveis e } \\
\text { 40.07 anos } \\
\text { nas mulheres } \\
\text { saudáveis. }\end{array}$ & $\begin{array}{l}\text { Sujeitos } \\
\text { saudáveis }\end{array}$ & Não houve & $\begin{array}{l}\text { No geral, todos os } \\
\text { pacientes demonstraram } \\
\text { déficit em memória de } \\
\text { trabalho, com mais erros } \\
\text { em memória de trabalho } \\
\text { se comparado ao grupo } \\
\text { controle. Estes déficits } \\
\text { são mais aparentes } \\
\text { entre os homens se } \\
\text { comparados às } \\
\text { mulheres. De forma } \\
\text { isolada, o grupo controle } \\
\text { masculino demonstrou } \\
\text { melhor desempenho em } \\
\text { memória de trabalho do } \\
\text { que o grupo feminino } \\
\text { saudável. Pacientes } \\
\text { masculinos } \\
\text { demonstraram pior } \\
\text { escore estratégico se } \\
\text { comparado ao grupo de } \\
\text { pacientes feminino, mas } \\
\text { um número similar de } \\
\text { erros em memória de } \\
\text { trabalho. }\end{array}$ \\
\hline
\end{tabular}


Introdução

\begin{tabular}{|c|c|c|c|c|c|c|c|c|}
\hline Estudos & Tipo de estudo & Testes utilizados & $\mathbf{N}$ & $\begin{array}{l}\text { Diagnóstico e } \\
\text { condição } \\
\text { clínica } \\
\text { experimental }\end{array}$ & Faixa etária & $\begin{array}{l}\text { Condição } \\
\text { controle }\end{array}$ & $\begin{array}{c}\text { Freqüência } \\
\text { e duração } \\
\text { total do } \\
\text { treino }\end{array}$ & Resultados principais \\
\hline Berg, 2008 & $\begin{array}{l}\text { Avaliação da } \\
\text { velocidade de } \\
\text { processamento, } \\
\text { memória de curto } \\
\text { prazo, memória } \\
\text { de trabalho e } \\
\text { leitura para } \\
\text { cálculos } \\
\text { aritméticos. }\end{array}$ & $\begin{array}{c}\text { WRAT3, } \\
\text { nomeaçãa e } \\
\text { articulação de } \\
\text { dígitos, dígitos de } \\
\text { ordem direta e } \\
\text { inversa, categoria } \\
\text { semântica, } \\
\text { seqüenciamento } \\
\text { de dígitos } \\
\text { auditory, matrix } \\
\text { visual, tarefas de } \\
\text { blocos corsi. }\end{array}$ & $\mathrm{T}: 90$ & $\begin{array}{l}\text { Alunos da } 3^{\circ} \text { a } \\
6^{\circ} \text { série do } \\
\text { ensino } \\
\text { fundamental e } \\
\text { médio. }\end{array}$ & $\begin{array}{l}\text { Entre } 98 \text { e } 145 \\
\text { meses }\end{array}$ & $\begin{array}{l}\text { Não } \\
\text { houve }\end{array}$ & Não houve & $\begin{array}{c}\text { A velocidade de } \\
\text { processamento } \\
\text { contribuiu somente para } \\
\text { cálculos aritméticos em } \\
\text { relação à idade. } \\
\text { Velocidade de } \\
\text { processamento e } \\
\text { memória de curto prazo } \\
\text { não eliminou a } \\
\text { contribuição da memória } \\
\text { de trabalho para } \\
\text { cálculos aritméticos. Os } \\
\text { componentes de } \\
\text { memória de trabalho } \\
\text { individual - verbal e } \\
\text { visuo-espacial - } \\
\text { contribuiu para cálculos } \\
\text { aritméticos na presença } \\
\text { de outras variáaeis. A } \\
\text { idade cronológica } \\
\text { contribuiu } \\
\text { significativamente para } \\
\text { cálculos aritméticos. }\end{array}$ \\
\hline
\end{tabular}


Introdução

\begin{tabular}{|c|c|c|c|c|c|c|c|c|}
\hline Estudos & Tipo de estudo & Testes utilizados & $\mathbf{N}$ & $\begin{array}{c}\text { Diagnóstico e } \\
\text { condição } \\
\text { clínica } \\
\text { experimental }\end{array}$ & Faixa etária & $\begin{array}{c}\text { Condição } \\
\text { controle }\end{array}$ & $\begin{array}{c}\text { Freqüência } \\
\text { e duração } \\
\text { total do } \\
\text { treino }\end{array}$ & Resultados principais \\
\hline Corso, 2008 & $\begin{array}{l}\text { Avaliação do } \\
\text { desempenho de } \\
\text { alunos em tarefas } \\
\text { envolvendo } \\
\text { componente } \\
\text { fonológico e } \\
\text { central executiva } \\
\text { da memória de } \\
\text { trabalho. }\end{array}$ & $\begin{array}{c}\text { Tarefas de } \\
\text { memória } \\
\text { fonológica de } \\
\text { dígitos, frases e } \\
\text { relatos, } \\
\text { consciência } \\
\text { fonológica e } \\
\text { velocidade de } \\
\text { processamento; } \\
\text { senso numérico; } \\
\text { memória de } \\
\text { trabalho e } \\
\text { contagem. }\end{array}$ & $\mathrm{T}: 79$ & $\begin{array}{c}\text { Alunos com } \\
\text { dificuldades na } \\
\text { matemática e } \\
\text { com a } \\
\text { coexistência } \\
\text { de dificuldades } \\
\text { na leitura e na } \\
\text { matemática. }\end{array}$ & $\begin{array}{l}\text { Entre } 9 \text { e } 12 \\
\text { anos de idade }\end{array}$ & $\begin{array}{l}\text { Não } \\
\text { houve }\end{array}$ & Não houve & $\begin{array}{c}\text { O grupo com } \\
\text { dificuldades na } \\
\text { matemática demonstrou } \\
\text { problemas com o } \\
\text { componente fonológico } \\
\text { e aquele com } \\
\text { dificuldades nas duas } \\
\text { áreas evidenciou } \\
\text { problemas com o } \\
\text { executivo central, } \\
\text { envolvendo tanto } \\
\text { informação numérica } \\
\text { quanto não numérica. }\end{array}$ \\
\hline $\begin{array}{l}\text { Ashkenazi } \\
\text { et al, } 2009\end{array}$ & $\begin{array}{l}\text { Avaliação de } \\
\text { desempenho do } \\
\text { grupo com } \\
\text { discalculia e } \\
\text { grupo de } \\
\text { participantes } \\
\text { controle em } \\
\text { Stroop Task } \\
\text { Numérico. }\end{array}$ & $\begin{array}{c}\text { Stroop Task } \\
\text { Numérico }\end{array}$ & $\begin{array}{c}\text { T: 26; E:13 } \\
\text { grupo com } \\
\text { discalculia; C: } \\
13 \text { grupo de } \\
\text { marcadores } \\
\text { por idade e } \\
\text { sexo }\end{array}$ & $\begin{array}{l}\text { Estudantes de } \\
\text { graduação } \\
\text { com } \\
\text { diagnóstico de } \\
\text { discalculia. }\end{array}$ & -- & $\begin{array}{c}\text { Estudante } \\
\text { s de } \\
\text { graduaçã } \\
\text { omarcado } \\
\text { res de } \\
\text { idade e } \\
\text { sexo, sem } \\
\text { nenhum } \\
\text { problema } \\
\text { para } \\
\text { aprender }\end{array}$ & Não houve & $\begin{array}{l}\text { Efeitos opostos em } \\
\text { interferência e } \\
\text { facilidade. Facilidade } \\
\text { eliminada e aumento da } \\
\text { interferência no grupo } \\
\text { controle. Aumento de } \\
\text { interferência somente } \\
\text { em tarefas físicas no } \\
\text { grupo com discalculia. }\end{array}$ \\
\hline
\end{tabular}


Introdução

\begin{tabular}{|c|c|c|c|c|c|c|c|c|}
\hline Estudos & Tipo de estudo & Testes utilizados & $\mathbf{N}$ & $\begin{array}{l}\text { Diagnóstico e } \\
\text { condição } \\
\text { clínica } \\
\text { experimental }\end{array}$ & Faixa etária & $\begin{array}{l}\text { Condição } \\
\text { controle }\end{array}$ & $\begin{array}{l}\text { Freqüência } \\
\text { e duração } \\
\text { total do } \\
\text { treino }\end{array}$ & Resultados principais \\
\hline $\begin{array}{l}\text { Lee et al, } \\
2010\end{array}$ & $\begin{array}{c}\text { Avaliação } \\
\text { matemática e de } \\
\text { função executiva. }\end{array}$ & $\begin{array}{l}\text { Bateria de testes } \\
\text { de função } \\
\text { executiva } \\
\text { (atualização, } \\
\text { inibitório e } \\
\text { flexibilidade } \\
\text { mental) e } \\
\text { proficiência } \\
\text { numérica e } \\
\text { aritmética (tarefa } \\
\text { de operação } \\
\text { numérica do teste } \\
\text { de realização } \\
\text { individual } \\
\text { Wechsler-III). }\end{array}$ & T: 163 & $\begin{array}{l}\text { Alunos da } \\
\text { primeira série } \\
\text { do ensino } \\
\text { primário. }\end{array}$ & $\begin{array}{c}6 \\
\text { anos de idade }\end{array}$ & $\begin{array}{l}\text { Não } \\
\text { houve }\end{array}$ & Não houve & $\begin{array}{l}\text { Em testes padrões, } \\
\text { somente o fator de } \\
\text { atualização se } \\
\text { relacionou com } \\
\text { proficiência numérica e } \\
\text { aritmética. }\end{array}$ \\
\hline $\begin{array}{l}\text { Meyer et al, } \\
2010\end{array}$ & $\begin{array}{c}\text { Avaliação } \\
\text { neuropsicológica } \\
\text { de medidas de } \\
\text { memória de } \\
\text { trabalho e } \\
\text { desempenho } \\
\text { matemático. }\end{array}$ & $\begin{array}{c}\text { WIAT-II; } \\
\text { subtestes } \\
\text { recuperação de } \\
\text { contagem, dígitos } \\
\text { ordem direta e } \\
\text { inversa e } \\
\text { recuperação de } \\
\text { blocos - WMTB. }\end{array}$ & $\begin{array}{c}\text { T: 98; E1: 48; } \\
\text { E2: } 50\end{array}$ & $\begin{array}{l}\text { Alunos que } \\
\text { freqüentam o } \\
\text { segundo e o } \\
\text { terceiro ano do } \\
\text { ensino } \\
\text { fundamental. }\end{array}$ & $\begin{array}{c}\text { Média de } 7.59 \\
\text { anos no grupo } \\
\text { de alunos do } \\
2^{\circ} \text { ano e } \\
\text { média de } 8.52 \\
\text { anos no grupo } \\
\text { de alunos do } \\
3^{\circ} \text { ano. }\end{array}$ & $\begin{array}{l}\text { Não } \\
\text { houve }\end{array}$ & Não houve & $\begin{array}{l}\text { Nos alunos do } 2^{\circ} \text { ano, o } \\
\text { componente central } \\
\text { executivo e laço } \\
\text { fonológico predizem } \\
\text { habilidade para } \\
\text { raciocínio matemático, } \\
\text { ao passo que o esboço } \\
\text { visuo-espacial prediz } \\
\text { raciocínio matemático e } \\
\text { operação numérica em } \\
\text { alunos do } 3^{\circ} \text { ano. }\end{array}$ \\
\hline
\end{tabular}

Continua 
Introdução

\begin{tabular}{|c|c|c|c|c|c|c|c|c|}
\hline Estudos & Tipo de estudo & Testes utilizados & $\mathbf{N}$ & $\begin{array}{c}\text { Diagnóstico e } \\
\text { condição } \\
\text { clínica } \\
\text { experimental }\end{array}$ & Faixa etária & $\begin{array}{c}\text { Condição } \\
\text { controle }\end{array}$ & $\begin{array}{l}\text { Freqüência } \\
\text { e duração } \\
\text { total do } \\
\text { treino }\end{array}$ & Resultados principais \\
\hline $\begin{array}{c}\text { Sigmundss } \\
\text { on, } 2010\end{array}$ & $\begin{array}{l}\text { Avaliação acerca } \\
\text { dos déficits em } \\
\text { sensibilidade para } \\
\text { movimento visual } \\
\text { evidentes em } \\
\text { crianças que } \\
\text { apresentam } \\
\text { habilidade } \\
\text { matemática pobre } \\
\text { em relação às } \\
\text { outras crianças } \\
\text { da mesma idade. }\end{array}$ & $\begin{array}{c}\text { Testes de } \\
\text { realização } \\
\text { matemática } \\
\text { (Conhecimento } \\
\text { Básico em } \\
\text { Matemática - } \\
\text { BKM) e tarefas de } \\
\text { processamento } \\
\text { visual. }\end{array}$ & $\mathrm{T}: 73$ & $\begin{array}{c}\text { Grupo de } \\
\text { alunos de } 10 \\
\text { anos de duas } \\
\text { escolas } \\
\text { primárias que } \\
\text { apresentaram } \\
\text { baixa } \\
\text { realização } \\
\text { matemática. }\end{array}$ & $\begin{array}{c}\text { Média de } 10.6 \\
\text { anos no grupo } \\
\text { com baixa } \\
\text { realização } \\
\text { matemática e } \\
10.3 \text { anos no } \\
\text { grupo com alta } \\
\text { realização } \\
\text { matemática }\end{array}$ & $\begin{array}{c}\text { Grupo de } \\
\text { alunos de } \\
10 \text { anos } \\
\text { de duas } \\
\text { escolas } \\
\text { primárias } \\
\text { que } \\
\text { apresenta } \\
\text { ram alta } \\
\text { realização } \\
\text { matemáti } \\
\text { ca }\end{array}$ & Não houve & $\begin{array}{c}\text { Crianças com habilidade } \\
\text { matemática abaixo de } \\
10 \% \text { do cohort foram } \\
\text { menos sensíveis que o } \\
\text { grupo controle marcador } \\
\text { de idade para } \\
\text { movimento coerente, } \\
\text { mas eles foram } \\
\text { equivalentes aos } \\
\text { limiares controles em } \\
\text { medida de controle } \\
\text { coerente. Crianças com } \\
\text { dificuldade matemática } \\
\text { tendem a apresentar } \\
\text { padrão similar de déficit } \\
\text { no processamento } \\
\text { visual àqueles } \\
\text { previamente reportados } \\
\text { em outras desordens do } \\
\text { desenvolvimento. }\end{array}$ \\
\hline
\end{tabular}


Introdução

\begin{tabular}{|c|c|c|c|c|c|c|c|c|}
\hline Estudos & Tipo de estudo & Testes utilizados & $\mathbf{N}$ & $\begin{array}{l}\text { Diagnóstico e } \\
\text { condição } \\
\text { clínica } \\
\text { experimental }\end{array}$ & Faixa etária & $\begin{array}{l}\text { Condição } \\
\text { controle }\end{array}$ & $\begin{array}{c}\text { Freqüência } \\
\text { e duração } \\
\text { total do } \\
\text { treino }\end{array}$ & Resultados principais \\
\hline $\begin{array}{c}\text { Kyttälä et } \\
\text { al, } 2010\end{array}$ & $\begin{array}{c}\text { Avaliação } \\
\text { neuropsicológica } \\
\text { em WM, } \\
\text { linguagem e } \\
\text { inteligência fluída. }\end{array}$ & $\begin{array}{c}\text { Tarefa } \\
\text { Matrix,Teste de } \\
\text { Blocos Corsi, } \\
\text { Odd-one-out, } \\
\text { Tarefas de não- } \\
\text { palavras } \\
\text { repetidas, } \\
\text { Recuperação de } \\
\text { palavras, Teste } \\
\text { de Matriz } \\
\text { Progressiva } \\
\text { Colorida Raven, } \\
\text { Teste de } \\
\text { nomeação } \\
\text { Boston, Teste de } \\
\text { símbolos para } \\
\text { crianças }\end{array}$ & $\mathrm{T}: 116$ & $\begin{array}{l}\text { Alunos pré- } \\
\text { escolares com } \\
\text { habilidade } \\
\text { matemática } \\
\text { precoce } \\
\text { empobrecida } \\
\text { antes da } \\
\text { educação } \\
\text { matemática } \\
\text { formal. }\end{array}$ & $\begin{array}{l}\text { Entre } 4 \text { e } 6 \\
\text { anos }\end{array}$ & $\begin{array}{c}\text { Não } \\
\text { houve }\end{array}$ & Não houve & $\begin{array}{c}\text { Crianças com } \\
\text { dificuldade matemática } \\
\text { empobrecida } \\
\text { demonstraram } \\
\text { desempenho pobre em } \\
\text { tarefas WM verbal e } \\
\text { visuo-espacial bem } \\
\text { como em testes de } \\
\text { inteligência fluída e } \\
\text { linguagem indicaram } \\
\text { baixa base cognitiva. } \\
\text { Desempenho pobre em } \\
\text { WM não foi moderado } \\
\text { pela inteligência fluida, } \\
\text { mas a extensão dos } \\
\text { déficits em WM foi } \\
\text { relacionada à habilidade } \\
\text { de linguagem. }\end{array}$ \\
\hline
\end{tabular}


Introdução

\begin{tabular}{|c|c|c|c|c|c|c|c|c|}
\hline Estudos & Tipo de estudo & Testes utilizados & $\mathbf{N}$ & $\begin{array}{l}\text { Diagnóstico e } \\
\text { condição } \\
\text { clínica } \\
\text { experimental }\end{array}$ & Faixa etária & $\begin{array}{l}\text { Condição } \\
\text { controle }\end{array}$ & $\begin{array}{l}\text { Freqüência } \\
\text { e duração } \\
\text { total do } \\
\text { treino }\end{array}$ & Resultados principais \\
\hline $\begin{array}{c}\text { Zheng et al, } \\
2011\end{array}$ & $\begin{array}{c}\text { Avaliação } \\
\text { neuropsicológica } \\
\text { composta por } \\
\text { uma bateria de } \\
\text { testes para } \\
\text { acessar solução } \\
\text { de problemas } \\
\text { precisos, } \\
\text { processos de } \\
\text { solução de } \\
\text { problemas, } \\
\text { memória de } \\
\text { trabalho, leitura e } \\
\text { cálculo } \\
\text { matemáticos. }\end{array}$ & $\begin{array}{l}\text { Computação } \\
\text { mental de } \\
\text { problemas em } \\
\text { palavras, } \\
\text { estrutura } \\
\text { semântica de } \\
\text { problemas em } \\
\text { palavras variadas, } \\
\text { Dígitos de ordem } \\
\text { direta e em } \\
\text { palavras, tarefa } \\
\text { Matrix visual e } \\
\text { tarefa de } \\
\text { mapeamento e } \\
\text { direção, teste de } \\
\text { sentença, teste } \\
\text { de sentença } \\
\text { ouvida, tarefas } \\
\text { aritméticas. }\end{array}$ & $\begin{array}{l}\text { T: } 310 ; \mathrm{E} 1: \\
\text { 110, E2: } 82 \\
\text { E3: } 118\end{array}$ & $\begin{array}{c}\text { Crianças } \\
\text { saudáveis que } \\
\text { freqüentam }{ }^{\circ} \\
2^{\circ} 3^{\circ} \text { e } 4^{\circ} \text { ano } \\
\text { primário. }\end{array}$ & $\begin{array}{l}\text { Média de } 8.78 \\
\text { anos no grupo } \\
\text { de alunos } \\
\text { total, média de } \\
7.71 \text { anos em } \\
\text { alunos do } 2^{\circ} \\
\text { ano; média de } \\
8.81 \text { anos em } \\
\text { alunos do } 3^{\circ} \\
\text { ano e média } \\
\text { de } 9.76 \text { anos } \\
\text { no grupo do } 4^{\circ} \\
\text { ano }\end{array}$ & $\begin{array}{c}\text { Não } \\
\text { houve }\end{array}$ & Não houve & $\begin{array}{c}\text { Os três componentes de } \\
\text { memória de trabalho } \\
\text { (função executiva, laço } \\
\text { fonológico e esboço } \\
\text { visuo-espacial) } \\
\text { predizem } \\
\text { significativamente a } \\
\text { precisão de solução de } \\
\text { problemas, habilidade } \\
\text { em leitura e cálculo é } \\
\text { mediado pelo sistema } \\
\text { central executivo e laço } \\
\text { fonológico, e } \\
\text { mediadores cognitivos } \\
\text { falham para moderar o } \\
\text { relacionamento entre } \\
\text { esboço visuo-espacial e } \\
\text { precisão da solução. }\end{array}$ \\
\hline $\begin{array}{c}\text { Roussel et } \\
\text { al, } 2011\end{array}$ & $\begin{array}{c}\text { Avaliação } \\
\text { neuropsicológica } \\
\text { de componentes } \\
\text { da memória de } \\
\text { trabalho e } \\
\text { exames de } \\
\text { imagem. }\end{array}$ & $\begin{array}{l}\text { Subteste dígitos } \\
\text { de ordem direta e } \\
\text { inversa, fluência } \\
\text { de palavras e } \\
\text { animais, } \\
\text { Wisconsin Card } \\
\text { Test, Torre de } \\
\text { Londres, Trail } \\
\text { Making Test, } \\
\text { Stroop Task. }\end{array}$ & $\begin{array}{l}\text { T: } 58 ; \mathrm{E}: 29 \\
\text { C: } 29\end{array}$ & $\begin{array}{l}\text { Pacientes com } \\
\text { lesão cerebral } \\
\text { frontal e } \\
\text { posterior. }\end{array}$ & $\begin{array}{l}\text { Média de } 47 \\
\text { anos no grupo } \\
\text { lesão cerebral } \\
\text { frontal, média } \\
\text { de } 43.3 \text { anos } \\
\text { com lesão } \\
\text { cerebral } \\
\text { posterior e } \\
46.3 \text { anos no } \\
\text { grupo controle. }\end{array}$ & $\begin{array}{l}\text { Indivíduos } \\
\text { saudáveis }\end{array}$ & Não houve & $\begin{array}{c}\text { Prejuízos na central } \\
\text { executiva dependem da } \\
\text { lesão cerebral frontal e } \\
\text { posterior. }\end{array}$ \\
\hline
\end{tabular}

Continua 
Introdução

\begin{tabular}{|c|c|c|c|c|c|c|c|c|}
\hline Estudos & Tipo de estudo & Testes utilizados & $\mathbf{N}$ & $\begin{array}{c}\text { Diagnóstico e } \\
\text { condição } \\
\text { clínica } \\
\text { experimental }\end{array}$ & Faixa etária & $\begin{array}{c}\text { Condição } \\
\text { controle }\end{array}$ & $\begin{array}{c}\text { Freqüência } \\
\text { e duração } \\
\text { total do } \\
\text { treino }\end{array}$ & Resultados principais \\
\hline Cirino, 2011 & $\begin{array}{l}\text { Avaliação do } \\
\text { relacionamento } \\
\text { entre precursores } \\
\text { cognitivos de } \\
\text { domínios da } \\
\text { quantidade, } \\
\text { lingüística e } \\
\text { atenção espacial } \\
\text { para realização } \\
\text { matemática. }\end{array}$ & $\begin{array}{c}\text { Testes de } \\
\text { comparação não } \\
\text { simbólica, } \\
\text { comparação } \\
\text { simbólica, rótulo } \\
\text { simbólico, rótulo } \\
\text { de contagem, } \\
\text { conhecimento de } \\
\text { contagem, } \\
\text { memória de } \\
\text { trabalho visuo- } \\
\text { espacial, } \\
\text { consciência } \\
\text { fonológica e } \\
\text { nomeação rápida } \\
\text { automatizada. }\end{array}$ & $\mathrm{T}: 286$ & $\begin{array}{l}\text { Crianças que } \\
\text { freqüentam o } \\
\text { jardim de } \\
\text { infância. }\end{array}$ & $\begin{array}{l}\text { Média de } 6.13 \\
\text { anos de idade }\end{array}$ & $\begin{array}{l}\text { Não } \\
\text { houve }\end{array}$ & Não houve & $\begin{array}{l}\text { Foram encontradas } \\
\text { cinco estruturas para o } \\
\text { domínio de quantidade, } \\
\text { com maior distinção } \\
\text { entre tarefas simbólicas } \\
\text { e não-simbólicas. } \\
\text { Domínios lingüísticos e } \\
\text { de atenção espacial } \\
\text { demonstraram } \\
\text { relacionamento indireto } \\
\text { com os desfechos, com } \\
\text { seus efeitos mediados } \\
\text { por medidas simbólicas } \\
\text { de quantidade. }\end{array}$ \\
\hline $\begin{array}{c}\text { Geary, } \\
2011\end{array}$ & $\begin{array}{c}\text { Avaliação } \\
\text { neuropsicológica } \\
\text { de medidas de } \\
\text { números, } \\
\text { contagem e } \\
\text { competências } \\
\text { aritméticas. }\end{array}$ & $\begin{array}{c}\text { Vocabulário e } \\
\text { Matriz de } \\
\text { raciocínio } \\
\text { (WASI), operação } \\
\text { numérica e leitura } \\
\text { de palavras } \\
\text { (Wechsler, 2001), } \\
\text { testes } \\
\text { matemáticos, } \\
\text { recuperação da } \\
\text { escuta, } \\
\text { recuperação da } \\
\text { contagem, dígitos } \\
\text { direto e inverso. }\end{array}$ & $\mathrm{T}: 177$ & $\begin{array}{c}\text { Alunos de } 12 \\
\text { escolas que } \\
\text { cursavam da } \\
\text { pré-escola a } \\
\text { quinta série do } \\
1^{\circ} \text { grau. }\end{array}$ & --- & $\begin{array}{l}\text { Não } \\
\text { houve }\end{array}$ & Não houve & $\begin{array}{l}\text { Inteligência, velocidade } \\
\text { de processamento e } \\
\text { função executiva } \\
\text { componente da } \\
\text { memória de trabalho } \\
\text { foram preditoras de } \\
\text { realização matemática. } \\
\text { O laço fonológico foi } \\
\text { preditivo de leitura de } \\
\text { palavras e o esboço } \\
\text { visuo-spacial de } \\
\text { matemática. }\end{array}$ \\
\hline
\end{tabular}

Continua 
Introdução

\begin{tabular}{|c|c|c|c|c|c|c|c|c|}
\hline Estudos & Tipo de estudo & Testes utilizados & $\mathbf{N}$ & $\begin{array}{c}\text { Diagnóstico e } \\
\text { condição } \\
\text { clínica } \\
\text { experimental }\end{array}$ & Faixa etária & $\begin{array}{c}\text { Condição } \\
\text { controle }\end{array}$ & $\begin{array}{l}\text { Freqüência } \\
\text { e duração } \\
\text { total do } \\
\text { treino }\end{array}$ & Resultados principais \\
\hline $\begin{array}{l}\text { Simmons et } \\
\text { al, } 2012\end{array}$ & $\begin{array}{c}\text { Avaliação } \\
\text { neuropsicológica } \\
\text { de medidas de } \\
\text { memória de } \\
\text { trabalho e } \\
\text { desempenho } \\
\text { matemático. }\end{array}$ & $\begin{array}{l}\text { Avaliação de } \\
\text { memóriade } \\
\text { trabalho } \\
\text { automática } \\
\text { (AWMA), teste de } \\
\text { recuperação de } \\
\text { blocos, subteste } \\
\text { de recuperação } \\
\text { de palavras,teste } \\
\text { de habilidade } \\
\text { fônica e } \\
\text { recognição de } \\
\text { palavras (WRaPs } \\
\text { II), escala de } \\
\text { vocabulário } \\
\text { britânico (BPVS } \\
\text { II) e testes de } \\
\text { aritmética. }\end{array}$ & $\begin{array}{c}\mathrm{T}: 100 ; \mathrm{E} 1: 49 ; \\
\mathrm{E} 2: 41\end{array}$ & $\begin{array}{c}\text { Alunos do } \\
\text { primeiro e } \\
\text { terceiro ano do } \\
\text { ensino } \\
\text { fundamental. }\end{array}$ & $\begin{array}{c}\text { Média de } 7.11 \\
\text { anos no grupo } \\
\text { de alunos do } 3 \\
\text { ano e média } \\
\text { de } 5.10 \text { anos } \\
\text { no grupo de } \\
\text { alunos do } 1^{\circ} \\
\text { ano. }\end{array}$ & $\begin{array}{l}\text { Não } \\
\text { houve }\end{array}$ & Não houve & $\begin{array}{l}\text { Memória de trabalho } \\
\text { explica estatisticamente } \\
\text { a variação em escrita } \\
\text { dos números, } \\
\text { julgamento da } \\
\text { magnitude e dígitos- } \\
\text { únicos aritméticos, mas } \\
\text { os diferentes } \\
\text { componentes da } \\
\text { memória de trabalho } \\
\text { tiveram diferentes } \\
\text { relacionamentos com as } \\
\text { diferentes habilidades. }\end{array}$ \\
\hline $\begin{array}{l}\text { Kokubo et } \\
\text { al, } 2012\end{array}$ & $\begin{array}{c}\text { Avaliação } \\
\text { neuropsicológica } \\
\text { de medidas de } \\
\text { memória de } \\
\text { trabalho visuo- } \\
\text { espacial. }\end{array}$ & $\begin{array}{c}\text { Teste Trail } \\
\text { Making avançado } \\
\text { (ATMT-C). }\end{array}$ & $\mathrm{T}: 94$ & $\begin{array}{c}\text { Sujeitos } \\
\text { saudáveis de } \\
6 \text { a } 28 \text { anos }\end{array}$ & --- & $\begin{array}{l}\text { Não } \\
\text { houve }\end{array}$ & Não houve & $\begin{array}{l}\text { A memória de trabalho } \\
\text { visuo-espacial em } \\
\text { crianças gradualmente } \\
\text { amadurece de uma } \\
\text { maneira não estável e } \\
\text { há um importante } \\
\text { estágio para a } \\
\text { maturação da memória } \\
\text { de trabalho visuo- } \\
\text { espacial antes dos } 12 \\
\text { anos de idade }\end{array}$ \\
\hline
\end{tabular}

Continua 
Tabela 4 - Ensaios randomizados, controlados de treinamento matemático.

\begin{tabular}{|c|c|c|c|c|c|c|c|c|c|}
\hline Estudos & $\begin{array}{c}\text { Programas } \\
\text { utilizados }\end{array}$ & $\begin{array}{l}\text { Formato } \\
\text { Treino }\end{array}$ & $\mathbf{N}$ & $\begin{array}{c}\text { Diagnóstico e } \\
\text { condição } \\
\text { clínica }\end{array}$ & Faixa etária & Medicação & $\begin{array}{l}\text { Condição } \\
\text { controle }\end{array}$ & $\begin{array}{l}\text { Freqüência e } \\
\text { duração total } \\
\text { do treino }\end{array}$ & Resultados \\
\hline $\begin{array}{c}\text { Kawashima } \\
\text { et al, } 2005\end{array}$ & $\begin{array}{l}\text { Treinamento } \\
\text { cognitivo de } \\
\text { leitura em voz } \\
\text { alta e solução } \\
\text { de problemas } \\
\text { aritméticos. }\end{array}$ & Individual & $\begin{array}{c}\text { T: } 32 ; \mathrm{E}: \\
\text { 16; C: } \\
16\end{array}$ & $\begin{array}{c}\text { Idosos } \\
\text { clinicamente } \\
\text { diagnosticados } \\
\text { com demência } \\
\text { tipo Alzheimer. }\end{array}$ & $\begin{array}{l}\text { Média de } \\
85.1 \text { anos } \\
\text { no grupo } \\
\text { experimental } \\
\text { e } 86.3 \text { anos } \\
\text { no grupo } \\
\text { controle }\end{array}$ & -- & Não houve & $\begin{array}{c}\text { Resolução } \\
\text { sistematizada de } \\
\text { problemas } \\
\text { básicos em } \\
\text { aritmética de } 2 \text { - } \\
6 \text { dias por } \\
\text { semana durante } \\
\text { o período de } 6 \\
\text { meses. }\end{array}$ & $\begin{array}{c}\text { O grupo } \\
\text { experimental } \\
\text { demonstrou } \\
\text { melhora cognitiva } \\
\text { significativa. O } \\
\text { grupo controle } \\
\text { apresentou } \\
\text { diminuição } \\
\text { cognitiva ao } \\
\text { longo do estudo, } \\
\text { com diferenças } \\
\text { entre o grupo } \\
\text { experimental e } \\
\text { controle, e } \\
\text { restauração da } \\
\text { comunicação e } \\
\text { independência no } \\
\text { grupo } \\
\text { experimental. }\end{array}$ \\
\hline $\begin{array}{l}\text { Uchida e } \\
\text { Kawashima, } \\
2008\end{array}$ & $\begin{array}{l}\text { Treinamento } \\
\text { cognitivo de } \\
\text { leitura e solução } \\
\text { de problemas } \\
\text { aritméticos. }\end{array}$ & Individual & T: 124 & $\begin{array}{l}\text { Idosos } \\
\text { residentes de } \\
\text { uma casa de } \\
\text { repouso } \\
\text { normais. }\end{array}$ & $\begin{array}{c}70 \text { a } 86 \\
\text { anos }\end{array}$ & -- & $\begin{array}{l}\text { Programa de } \\
\text { intervenção } \\
\text { semelhante ao } \\
\text { experimental, } \\
\text { durante o } \\
\text { mesmo período } \\
\text { de } 6 \text { meses. }\end{array}$ & $\begin{array}{c}\text { Resolução de } \\
\text { problemas em } \\
\text { leitura e } \\
\text { aritmética } \\
\text { diariamente } \\
\text { durante } 6 \\
\text { meses. } \\
\end{array}$ & $\begin{array}{l}\text { Treinamento } \\
\text { mental diário } \\
\text { melhorou as } \\
\text { funções } \\
\text { cognitivas de } \\
\text { idosos normais. }\end{array}$ \\
\hline
\end{tabular}


Introdução

\begin{tabular}{|c|c|c|c|c|c|c|c|c|c|}
\hline Estudos & Tipo de estudo & $\begin{array}{c}\text { Testes } \\
\text { utilizados }\end{array}$ & $\mathbf{N}$ & $\begin{array}{c}\text { Diagnóstico e } \\
\text { condição } \\
\text { clínica } \\
\text { experimental }\end{array}$ & Faixa etária & $\begin{array}{c}\text { Condição } \\
\text { controle }\end{array}$ & $\begin{array}{c}\text { Freqüência e } \\
\text { duração total } \\
\text { do treino }\end{array}$ & $\begin{array}{c}\text { Resultados } \\
\text { principais }\end{array}$ & Estudos \\
\hline $\begin{array}{l}\text { Iseman e } \\
\text { Naglieri, } \\
2011\end{array}$ & $\begin{array}{l}\text { Instrução de } \\
\text { estratégia } \\
\text { cognitiva breve } \\
\text { para facilitar o } \\
\text { desenvolvimento } \\
\text { e aplicação de } \\
\text { computação } \\
\text { matemática. }\end{array}$ & Grupo & $\begin{array}{c}\text { T: } 29 ; \mathrm{E}: \\
\text { 14; C: } \\
15 .\end{array}$ & $\begin{array}{c}\text { Estudantes } \\
\text { com TDAH e } \\
\text { dificuldade de } \\
\text { aprendizagem, } \\
\text { e sem TDAH. }\end{array}$ & $\begin{array}{c}10 \text { a } 15 \\
\text { anos } \\
(\mathrm{M}=13 \text { anos })\end{array}$ & --- & $\begin{array}{c}\text { Instrução de } \\
\text { matemática } \\
\text { padrão. }\end{array}$ & $\begin{array}{l}\text { Instrução de } \\
\text { estratégias } \\
\text { cognitivas breve } \\
\text { em } 10 \text { dias, } \\
\text { desenhadas } \\
\text { para facilitar o } \\
\text { desenvolvimento } \\
\text { e aplicação de } \\
\text { computação } \\
\text { matemática }\end{array}$ & $\begin{array}{c}\text { Após } 1 \text { ano } \\
\text { follow-up o grupo } \\
\text { experimental } \\
\text { continuou com } \\
\text { melhor } \\
\text { desempenho em } \\
\text { provas } \\
\text { matemáticas, } \\
\text { agora } \\
\text { transferidas para } \\
\text { testes padrões } \\
\text { de matemática } \\
\text { (habilidade de } \\
\text { generalização } \\
\text { das estratégias } \\
\text { aprendidas para } \\
\text { outras tarefas } \\
\text { similares) em } \\
\text { comparação ao } \\
\text { grupo controle. }\end{array}$ \\
\hline
\end{tabular}


Tabela 5 - Estudos de revisão e meta-análise de cognição subjacente à matemática.

\begin{tabular}{|c|c|c|c|c|c|c|}
\hline Estudos & Medidas utilizadas & $\mathbf{N}$ & $\begin{array}{l}\text { Faixa } \\
\text { etária }\end{array}$ & Medicação & $\begin{array}{c}\text { Diagnóstico e condição } \\
\text { clínica }\end{array}$ & Resultados principais \\
\hline $\begin{array}{l}\text { Ackerman et } \\
\text { al, } 2005\end{array}$ & $\begin{array}{l}\text { Avaliação conjunta } \\
\text { de medidas de } \\
\text { memória de trabalho } \\
\text { e habilidade } \\
\text { intelectual. }\end{array}$ & & $\begin{array}{l}\text { Entre } 13 \text { e } \\
70 \text { anos. }\end{array}$ & Não houve & $\begin{array}{l}\text { Foram excluídos da } \\
\text { análise os estudos com } \\
\text { população clínica (ex: } \\
\text { prejuízo cerebral e } \\
\text { Alzheimer) }\end{array}$ & $\begin{array}{c}\text { A correlação média entre } \\
\text { estimativas de WM e g foi } \\
\text { significativamente menor que a } \\
\text { unidade }(\mathrm{p}=.479) \text {. Os autores } \\
\text { também focam na distinção entre } \\
\text { memória de curto prazo e WM com } \\
\text { respeito à inteligência em uma } \\
\text { meta-análise suplementar. Os } \\
\text { autores discutem como } \\
\text { considerações em perpectivas } \\
\text { psicométricas e teóricas auxiliam } \\
\text { mais na discussão da relação WM- } \\
g \text {. }\end{array}$ \\
\hline $\begin{array}{l}\text { Rubinsten e } \\
\text { Henik, } 2008\end{array}$ & $\begin{array}{c}\text { Revisão dos } \\
\text { achados biológicos } \\
\text { e sem discalculia e } \\
\text { desenha um quadro } \\
\text { para o estudo das } \\
\text { bases } \\
\text { neurocognitivas da } \\
\text { discalculia. }\end{array}$ & -- & -- & -- & $\begin{array}{c}\text { Sujeitos que apresentam } \\
\text { discalculia. }\end{array}$ & $\begin{array}{l}\text { O artigo propõe três quadros } \\
\text { alternativos com potencial } \\
\text { facilitador de futuras discussões, } \\
\text { trabalhos no campo e tem } \\
\text { implicações para estudos de } \\
\text { desordens similares, tais como a } \\
\text { dislexia e déficit de atenção e } \\
\text { hiperatividade. }\end{array}$ \\
\hline
\end{tabular}


Introdução

\begin{tabular}{|c|c|c|c|c|c|c|}
\hline Estudos & Medidas utilizadas & $\mathbf{N}$ & $\begin{array}{l}\text { Faixa } \\
\text { etária }\end{array}$ & Medicação & $\begin{array}{c}\text { Diagnóstico e condição } \\
\text { clínica }\end{array}$ & Resultados principais \\
\hline $\begin{array}{c}\text { Geary et al, } \\
2011\end{array}$ & $\begin{array}{l}\text { Revisão na literatura } \\
\text { das conseqüências } \\
\text { educacionais e } \\
\text { econômicas em } \\
\text { realização } \\
\text { matemática pobre e } \\
\text { integrada com } \\
\text { revisão } \\
\text { epidemiológica, } \\
\text { comportamento } \\
\text { genético e cognição } \\
\text { de realização } \\
\text { matemática pobre. }\end{array}$ & -- & -- & $-\cdots$ & $-\cdots$ & $\begin{array}{c}\text { Competências matemáticas } \\
\text { empobrecidas são comuns entre } \\
\text { adultos e resultam em dificuldades } \\
\text { no emprego e em muitas } \\
\text { atividades diárias. Dentre os } \\
\text { estudantes, cerca de } 7 \% \text { das } \\
\text { crianças e adolescentes } \\
\text { apresentaram MLD e outras 10\% } \\
\text { demonstraram baixa LA em } \\
\text { matemática apesar das habilidades } \\
\text { médias em muitas outras áreas. } \\
\text { Crianças com MLD e LA têm déficit } \\
\text { em entender e representar a } \\
\text { magnitude numérica, dificuldade } \\
\text { em recuperar fatos aritméticos } \\
\text { básicos em memória de longo } \\
\text { prazo, e atraso em procedimento } \\
\text { de aprendizagem matemática. } \\
\text { Estes déficits e atrasos não podem } \\
\text { ser atribuídas à inteligência, mas } \\
\text { se relacionam com déficits em WM } \\
\text { para crianças com MLD, mas não } \\
\text { com crianças que apresentam } \\
\text { déficit em LA. Intervenções com } \\
\text { alvo nestes déficits cognitivos } \\
\text { estão em desenvolvimento e } \\
\text { resultados preliminares são } \\
\text { promissores. }\end{array}$ \\
\hline
\end{tabular}


Introdução

\begin{tabular}{|c|c|c|c|c|c|c|}
\hline Estudos & Medidas utilizadas & $\mathbf{N}$ & $\begin{array}{l}\text { Faixa } \\
\text { etária }\end{array}$ & Medicação & $\begin{array}{c}\text { Diagnóstico e condição } \\
\text { clínica }\end{array}$ & Resultados principais \\
\hline $\begin{array}{l}\text { Butterworth et } \\
\quad \text { al, } 2011\end{array}$ & $\begin{array}{c}\text { Revisão de } \\
\text { pesquisas recentes } \\
\text { em cognição e } \\
\text { neurociências do } \\
\text { desenvolvimento } \\
\text { para o entendimento } \\
\text { da discalculia. }\end{array}$ & -- & -- & -- & $\begin{array}{c}\text { Sujeitos que apresentam } \\
\text { discalculia. }\end{array}$ & $\begin{array}{c}\text { As bases neural no processamento } \\
\text { numérico tem sido investigado em } \\
\text { estudos de neuroimagem estrutural } \\
\text { e funcional de adultos e crianças, e } \\
\text { marcadores neurais destes } \\
\text { prejuízos em discalculia têm sido } \\
\text { identificados. Novas intervenções } \\
\text { para fortalecimento do } \\
\text { processamento numérico, incluindo } \\
\text { software adaptado, são } \\
\text { promissores para a educação de } \\
\text { alunos com discalculia. }\end{array}$ \\
\hline
\end{tabular}


Introdução

Tabela 6 - Estudos de Corte em avaliação matemática.

\begin{tabular}{|c|c|c|c|c|c|c|c|c|}
\hline Estudos & $\begin{array}{l}\text { Desenho do } \\
\text { estudo }\end{array}$ & $\begin{array}{c}\text { Medidas } \\
\text { utilizadas }\end{array}$ & $\mathbf{N}$ & $\begin{array}{c}\text { Diagnóstico e } \\
\text { condição } \\
\text { clínica } \\
\text { experimental } \\
\end{array}$ & $\begin{array}{l}\text { Faixa } \\
\text { etária }\end{array}$ & $\begin{array}{c}\text { Condição } \\
\text { controle }\end{array}$ & $\begin{array}{c}\text { Freqüência } \\
\text { e duração } \\
\text { total do } \\
\text { treino }\end{array}$ & Resultados \\
\hline $\begin{array}{c}\text { Mazzoco e } \\
\text { Kover, } \\
2007\end{array}$ & $\begin{array}{c}\text { Prospectivo, com } \\
\text { avaliação } \\
\text { neuropsicológica } \\
\text { em três momentos } \\
\text { diferentes. }\end{array}$ & $\begin{array}{c}\text { Teste de } \\
\text { Nomeação } \\
\text { Contingente } \\
(\mathrm{CNT}) \text {, Teste de } \\
\text { habilidades } \\
\text { matemáticas } \\
\text { precoce } 2^{\circ} \mathrm{Ed} \text {, } \\
\text { Subtestes da } \\
\text { bateria } \\
\text { Woodcock- } \\
\text { Johnson } \\
\text { Revisada. }\end{array}$ & $\mathrm{T}: 178$ & $\begin{array}{c}\text { Alunos de } \\
\text { diversas } \\
\text { escolas } \\
\text { públicas e } \\
\text { fluentes na } \\
\text { língua inglesa. }\end{array}$ & $\begin{array}{l}\text { Idades de } 6 \\
\text { a } 7 \text { anos, } 8 \\
\text { a } 9 \text { anos e } \\
10 \text { a } 11 \\
\text { anos }\end{array}$ & Não houve & Não houve & $\begin{array}{c}\text { Efeito principal da } \\
\text { idade em todas as } \\
\text { medidas CNT de EF, } \\
\text { taxas de melhora em } \\
\text { EF variou como uma } \\
\text { função de demanda da } \\
\text { memória de trabalho } \\
\text { presente durante as } \\
\text { tarefas, com } \\
\text { diferenças em } \\
\text { correlações } \\
\text { concorrentes e } \\
\text { preditivas de } \\
\text { diferentes medidas de } \\
\text { CNT. Escores de EF } \\
\text { obtidos durante a } \\
\text { primeira avaliação } \\
\text { apresentou forte } \\
\text { associação com as } \\
\text { demais medidas assim } \\
\text { como escores de EF } \\
\text { obtidos } 4 \text { anos depois. } \\
\text { Escores EF de idade } \\
\text { entre } 6 \text { a } 7 \text { anos foram } \\
\text { associadas com } \\
\text { escores matemáticos } \\
\text { concorrentes e tardio. }\end{array}$ \\
\hline
\end{tabular}


Introdução

\begin{tabular}{|c|c|c|c|c|c|c|c|c|}
\hline Estudos & $\begin{array}{l}\text { Desenho do } \\
\text { estudo }\end{array}$ & $\begin{array}{l}\text { Medidas } \\
\text { utilizadas }\end{array}$ & $\mathbf{N}$ & $\begin{array}{l}\text { Diagnóstico e } \\
\text { condição } \\
\text { clínica } \\
\text { experimental }\end{array}$ & $\begin{array}{l}\text { Faixa } \\
\text { etária }\end{array}$ & $\begin{array}{l}\text { Condição } \\
\text { controle }\end{array}$ & $\begin{array}{c}\text { Freqüência } \\
\text { e duração } \\
\text { total do } \\
\text { treino }\end{array}$ & Resultados \\
\hline $\begin{array}{l}\text { Bull et al, } \\
2008\end{array}$ & $\begin{array}{l}\text { Prospectivo, com } \\
\text { avaliação } \\
\text { neuropsicológica } \\
\text { usando medidas } \\
\text { de memória de } \\
\text { curto prazo, WM e } \\
\text { funcionamento } \\
\text { executivo; } \\
\text { medidas de } \\
\text { matemática e } \\
\text { desfecho em } \\
\text { leitura. }\end{array}$ & $\begin{array}{c}\text { Avaliação PIPS, } \\
\text { Escola Shape, } \\
\text { Torre de } \\
\text { Londres, Blocos } \\
\text { Corsi, Dígitos } \\
\text { Span ordem } \\
\text { direta e inversa. }\end{array}$ & $\begin{array}{c}\mathrm{T}: 124 ; \mathrm{E}: \\
\mathrm{n}=124 \text { grupo } \\
\text { pré-escolar, } \\
\mathrm{n}=108 \text { ao fim } \\
\text { do } 1^{\circ} \text { ano } \\
\text { primário e } \mathrm{n}= \\
88 \text { ao fim do } \\
3^{\circ} \text { ano } \\
\text { primário. }\end{array}$ & $\begin{array}{l}\text { Crianças do } \\
\text { berçário no } \\
\text { início do } \\
\text { estudo, todas } \\
\text { iniciando ano } \\
\text { pré-escolar. } \\
\text { Todas usavam } \\
\text { como língua } \\
\text { nativa o inglês. }\end{array}$ & $\begin{array}{c}\text { Média de } \\
4.99 \text { anos } \\
\text { no início } \\
\text { das } \\
\text { testagens, } \\
5,7 \text { anos na } \\
2^{\circ} \\
\text { testagem e } \\
7,71 \text { anos } \\
\text { na } 3^{\circ} \\
\text { testagem. }\end{array}$ & Não houve & Não houve & $\begin{array}{c}\text { Melhor habilidade em } \\
\text { Dígitos Span e função } \\
\text { executiva fornecida } \\
\text { por crianças com início } \\
\text { imediato em } \\
\text { matemática e leitura } \\
\text { em relação ao todo } \\
\text { dos } 3 \text { anos primários. } \\
\text { Memória Span visuo- } \\
\text { espacial de curto- } \\
\text { prazo foi encontrada } \\
\text { como preditora de } \\
\text { habilidade } \\
\text { matemática.Análise } \\
\text { correlacional e } \\
\text { regressão revelou que } \\
\text { memória de curto- } \\
\text { prazo e WM são } \\
\text { especificamente } \\
\text { preditoras da } \\
\text { avaliação matemática } \\
\text { em cada ponto de } \\
\text { tempo, ao passo que a } \\
\text { função executiva é } \\
\text { preditora da } \\
\text { aprendizagem em } \\
\text { geral mais do que a } \\
\text { aprendizagem em um } \\
\text { único domínio } \\
\text { específico. }\end{array}$ \\
\hline
\end{tabular}

Continua 
Introdução

\begin{tabular}{|c|c|c|c|c|c|c|c|c|}
\hline Estudos & $\begin{array}{l}\text { Desenho do } \\
\text { estudo }\end{array}$ & $\begin{array}{l}\text { Medidas } \\
\text { utilizadas }\end{array}$ & $\mathbf{N}$ & $\begin{array}{l}\text { Diagnóstico e } \\
\text { condição } \\
\text { clínica } \\
\text { experimental }\end{array}$ & $\begin{array}{l}\text { Faixa } \\
\text { etária }\end{array}$ & $\begin{array}{l}\text { Condição } \\
\text { controle }\end{array}$ & $\begin{array}{l}\text { Freqüência } \\
\text { e duração } \\
\text { total do } \\
\text { treino }\end{array}$ & Resultados \\
\hline $\begin{array}{l}\text { Sanne et } \\
\text { al, } 2011\end{array}$ & $\begin{array}{l}\text { Prospectivo, com } \\
\text { avaliação } \\
\text { neuropsicológica } \\
\text { de medidas de } \\
\text { função executiva e } \\
\text { matemática em } \\
\text { quatro momentos } \\
\text { diferentes. }\end{array}$ & $\begin{array}{l}\text { Stroop animal, } \\
\text { local global, } \\
\text { Simon Task, } \\
\text { deslocamento } \\
\text { animal, Trail } \\
\text { Making colorido, } \\
\text { deslocamento } \\
\text { de tarefa para } \\
\text { classificação, } \\
\text { dígitos diretos, } \\
\text { um estranho no } \\
\text { ninho, } \\
\text { atualização } \\
\text { acompanhado. }\end{array}$ & $\mathrm{T}: 211$ & $\begin{array}{c}\text { Alunos de } \\
\text { segunda série } \\
\text { do } 1^{\circ} \text { grau em } \\
10 \text { escolas. }\end{array}$ & $\begin{array}{c}\text { Entre } 7 \text { e } 8 \\
\text { anos. }\end{array}$ & Não houve & Não houve & $\begin{array}{c}\text { Análise de fator } \\
\text { confirmatória mostrou } \\
\text { que inibição e } \\
\text { deslocamento não se } \\
\text { distinguem. A } \\
\text { atualização foi um } \\
\text { fator separado, e seu } \\
\text { desenvolvimento foi } \\
\text { fortemente relacionado } \\
\text { ao desenvolvimento } \\
\text { matemático enquanto } \\
\text { a inibição e } \\
\text { atualização não foram } \\
\text { preditoras da } \\
\text { matemática. }\end{array}$ \\
\hline $\begin{array}{c}\text { Navarro et } \\
\text { al, } 2011\end{array}$ & $\begin{array}{c}\text { Prospectivo, com } \\
\text { avaliação } \\
\text { aritmética ao longo } \\
\text { de } 2 \text { anos. }\end{array}$ & $\begin{array}{c}\text { Testes de } \\
\text { numerácia } \\
\text { precoce. }\end{array}$ & $\begin{array}{c}\text { T: } 127 \\
\text { (64 feminino e } \\
63 \text { masculino) }\end{array}$ & $\begin{array}{c}\text { Crianças de } 5 \\
-7 \text { anos. }\end{array}$ & --- & Não houve & Não houve & $\begin{array}{l}\text { Escore de teste de } \\
\text { numerácia precoce foi } \\
\text { mais consistente no } \\
\text { grupo de alto } \\
\text { desempenho do que } \\
\text { no grupo de baixo } \\
\text { desempenho. }\end{array}$ \\
\hline
\end{tabular}




\section{JUSTIFICATIVAS PARA O ESTUDO}

Apesar da grande disponibilidade de dados na literatura na área de treinamento cognitivo para pacientes com esquizofrenia, no Brasil esta área de pesquisa se mostra, até o momento, bastante restrita. Neste sentido, o desenvolvimento deste trabalho se mostra relevante por se tratar de um estudo exploratório para pacientes brasileiros com esquizofrenia e estáveis. Adicionalmente, estudos com maior rigor metodológico ainda são minoria neste campo, e assim, o presente estudo busca contribuir para o desenvolvimento desta área de pesquisa ao se apresentar como um ensaio randomizado e controlado. 
Além disso, a proposta e investigação do treinamento aritmético do Kumon como uma terapia de remediação cognitiva (CRT) de baixo custo e amplamente difundida no país fazem-se socialmente relevantes por facilitar o acesso à estimulação cognitiva destes pacientes através de um serviço extra-hospitalar já pré-estabelecido na comunidade. Quanto à política de saúde mental a metodologia individual empregada pelo Kumon consegue agir de forma a respeitar a singularidade de cada indivíduo ao passo que aos pacientes é oferecido um resgate à cidadania, permitindo a realização de uma atividade realizada fora dos muros do hospital e desempenhada por qualquer pessoa independente de possuir alguma patologia ou não. Embora individual, o mesmo espaço a ser desenvolvido o trabalho é reservado para muitos pacientes ao mesmo tempo, conseguindo agir de forma inclusiva. Por fim, existe uma carência de estudos não farmacológicos no campo da esquizofrenia que investiguem os tratamentos que possam contribuir para redução dos sintomas e dos prejuízos funcionais desta condição bem como não existe, até o momento, estudos específicos de estimulação cognitiva subjacente a um treinamento aritmético com uma população adulta portadora de esquizofrenia, para que assim, ofereçam uma contribuição complementar ao tratamento farmacológico da esquizofrenia. 


\section{OBJETIVOS}

Trata-se de um estudo prospectivo, randomizado, da eficácia do método Kumon como Remediação Cognitiva na esquizofrenia em comparação com placebo (recreação), avaliando os pacientes no início (baseline), após 6 meses, ao término do treino cognitivo (Kumon ou placebo) e após 12 meses (sem treinamento), para verificar se os ganhos obtidos sustentam, mesmo sem a remediação.

\subsection{Objetivo Geral}

Avaliar as funções cognitivas de pacientes com esquizofrenia antes e após o treinamento de cálculos aritméticos pelo método Kumon, por meio de uma bateria de testes neuropsicológicos.

\subsection{Objetivos Específicos}

Analisar a eficácia do treinamento de cálculos aritméticos administrados pelo método Kumon como remediador de funções cognitivas consideradas subjacentes e preditivas de dificuldade matemática - memória de trabalho, função executiva e atenção.

A sustentação dos ganhos cognitivos em pacientes com esquizofrenia, através da comparação dos resultados após seis meses de treinamento e após seis meses do término do treinamento (manutenção do efeito de Remediação Cognitiva). 


\section{HIPÓTESES}

\section{1. $\quad$ Hipótese Principal}

O método de treinamento de cálculos aritméticos, desenvolvido e utilizado pelo Kumon, constitui-se em uma prática capaz de melhorar significativamente os déficits nos domínios cognitivos específicos da matemática em pacientes com esquizofrenia.

\subsection{Hipóteses secundárias}

O treinamento de cálculos aritméticos desenvolvido pelo método Kumon constitui-se em um método capaz de produzir, em conseqüência da melhora cognitiva, uma significativa melhora no funcionamento social de pacientes com esquizofrenia.

O treinamento cognitivo pelo método Kumon mantêm o nível de melhora 6 meses após sua interrupção. 


\section{MATERIAIS E MÉTODOS}

Para a descrição metodológica do estudo procurou-se seguir as recomendações CONSORT - Consolidated Standards of Reporting Trials (Mother et al., 2010).

\subsection{Participantes}

A amostra compreende 25 sujeitos do grupo experimental e 26 sujeitos do grupo controle, de ambos os sexos, idade entre 18 e 55 anos, alfabetizados, provenientes do ambulatório do Programa de Esquizofrenia (PROJESQ) e de outros Ambulatórios do Instituto de Psiquiatria do Hospital das Clínicas da Faculdade de Medicina da Universidade de São Paulo (IPqHCFMUSP).

Todos os pacientes devem preencher os critérios diagnósticos para esquizofrenia segundo o Manual Diagnóstico e Estatístico de Transtornos Mentais-DSM-IV-TR (2004).

Os critérios de inclusão e exclusão da amostra foram os seguintes:

Critérios de inclusão:

a) Preencher os critérios segundo o DSM-IV-TR (2004) para esquizofrenia;

b) Idade entre $18-55$ anos;

c) Escolaridade mínima: 5 anos de educação; 
d) Pacientes estáveis segundo avaliação clínica psiquiátrica, que não tenham sido internados recentemente (3 meses) e com dose da medicação constante durante pelo menos 8 semanas antes da avaliação, antes de assinar o TCLE.

Critérios de exclusão:

a) Comorbidade diagnóstica de dependência de substâncias ou outros quadros psiquiátricos do eixo I;

b) Histórico de traumatismo crânio-encefálico e/ou outros problemas neurológicos;

c) Problemas médicos que comprometam de alguma forma o sistema nervoso central;

d) História de retardo mental ou freqüência em classes especiais;

e) Pacientes que estejam freqüentando outros tratamentos psicossociais;

f) Risco de suicídio. 


\subsection{Desenho do estudo}

Todos os participantes da pesquisa foram voluntários e assinaram o "Termo de Consentimento Livre e Esclarecido", após esclarecimento sobre todos os detalhes do projeto. Uma vez incluídos na pesquisa, foram encaminhados para avaliação psiquiátrica e neuropsicológica. $\mathrm{O}$ projeto foi submetido e aprovado em seus aspectos éticos pelo comitê de Ética para análise de Projetos de Pesquisa (CAPPesq) em 11/03/09. Os sujeitos participantes tiveram suas identidades preservadas (sujeitos e familiares).

Logo após a seleção do grupo, obedecendo aos critérios de inclusão e exclusão da amostra, os objetivos da investigação foram explicados aos sujeitos pelo mesmo profissional que aplicou a bateria de testes neuropsicológicos.

O estudo consiste em uma pesquisa longitudinal prospectiva, com aplicação da escala PANSS, da escala PSP e de uma bateria de testes neuropsicológicos em três momentos diferentes (início, no término do treino/placebo, após 6 meses e no follow-up, 12 meses após o início). Em adição às avaliações psiquiátricas e neuropsicológicas também foram coletadas a história clínica e as características demográficas. Durante o período de ensaio clínico buscou manter a medicação do paciente o mais constante possível, evitando-se troca de medicação ou ajustes elevados de doses. 
A escala PANSS (Positive and Negative Syndrome Scale) é aplicada por dois psiquiatras, os quais receberam treinamento prévio. A duração de aplicação da escala utilizando a entrevista SCI-PANSS é em torno de 40 minutos.

A Escala de Desempenho Pessoal e Social (PSP) é aplicada pelos mesmos psiquiatras que realizaram a aplicação da escala PANSS, sendo efetuado em um segundo momento da sessão e com duração de aproximadamente 15 minutos.

A aplicação dos testes neuropsicológicos se deu sem o conhecimento prévio do resultado das escalas PANSS e PSP. Do mesmo modo, a aplicação das escalas pelos psiquiatras foi efetuada sem o conhecimento anterior do perfil nos testes neuropsicológicos. Anteriormente à aplicação de tais medidas também não é revelado o tipo de treinamento dos pacientes, que foram aleatoriamente separados em grupo controle e grupo experimental.

As baterias neuropsicológicas, aplicadas em três momentos diferentes antes do treinamento, após seis meses de treinamento Kumon e seis meses depois do término do programa - é composta por uma única sessão com duração de duas horas e realizada por duas psicólogas treinadas para a aplicação dos testes e especializada no campo da neuropsicologia.

A seguir, segue o fluxograma da pesquisa. 
Tabela 7 - Fluxograma da pesquisa

\begin{tabular}{|c|c|c|c|c|c|}
\hline & Screening & Baseline & $\begin{array}{c}\text { Atividade } \\
\text { Kumon } \\
\text { 2X/semana } \\
\text { ou Recreação } \\
\text { 2x/semana } \\
\text { durante 6 } \\
\text { meses }\end{array}$ & $\begin{array}{c}\text { Término do } \\
\text { treino } \\
(6 \text { Meses) }\end{array}$ & $\begin{array}{c}\text { Follow-up } \\
\text { (12 meses) }\end{array}$ \\
\hline TCLE & $\mathrm{X}$ & & & & \\
\hline Dados demográficos & $\mathrm{X}$ & $\mathrm{X}$ & & & \\
\hline PANSS & & $\mathrm{X}$ & & $\mathrm{X}$ & $\mathrm{X}$ \\
\hline PSP & & $\mathrm{X}$ & & $\mathrm{X}$ & $\mathrm{X}$ \\
\hline Randomização & & $\mathrm{X}$ & & & \\
\hline $\begin{array}{c}\text { Avaliação } \\
\text { Neuropsicológica }\end{array}$ & & $\mathrm{X}$ & & $\mathrm{X}$ & $\mathrm{X}$ \\
\hline
\end{tabular}

\subsubsection{Instrumentos de avaliação}

$\mathrm{Na}$ literatura encontramos poucos estudos de avaliação neuropsicológica prospectiva longitudinal bem como inexistência de pesquisas randomizadas de desempenho em treinamento específico para melhora dos processos aritméticos. No entanto, o presente estudo consiste em um estudo longitudinal randomizado que propõem uma melhora cognitiva subjacente à matemática mais do que o aprendizado aritmético em si do método Kumon. Por esta razão, optou-se na escolha de uma bateria neuropsicológica composta por testes cognitivos considerados tradicionais de cognição básica encontrados em revisão bibliográfica.

Desta forma, os pacientes foram avaliados por uma bateria neuropsicológica, além das avaliações psiquiátricas, que inclui a escala PANSS (Positive and Negative Syndrome Scale) e a escala PSP (Personal and Social Performance Scale), conforme descrito na tabela 7. 
Tabela 8 - Medidas neuropsicológicas e escalas usadas no estudo.

\begin{tabular}{|c|c|}
\hline & MEDIDAS NEUROPSICOLÓGICAS \\
\hline INTELIGÊNCIA & $\begin{array}{l}\text { Escala Abreviada de Inteligência para adultos Wechsler em sua forma reduzida - WASI Reduzido (Wescheler, } \\
\text { 1999). } \\
\text { - Inteligência cristalizada } \\
\text { a) Conhecimento acadêmico } \\
\text { - Subteste vocabulário } \\
\text { - Inteligência fluída } \\
\text { b) Raciocínio lógico } \\
\text { - Subteste Matrizes de raciocínio }\end{array}$ \\
\hline COGNITIVOS & $\begin{array}{l}\text { a) Atenção } \\
\qquad \text { - Atenção sustentada/vigilância } \\
\text { Continuous Performance Test - CPT-II (Conners, 2002): } \\
\text { - CPT_omissão }\end{array}$ \\
\hline
\end{tabular}




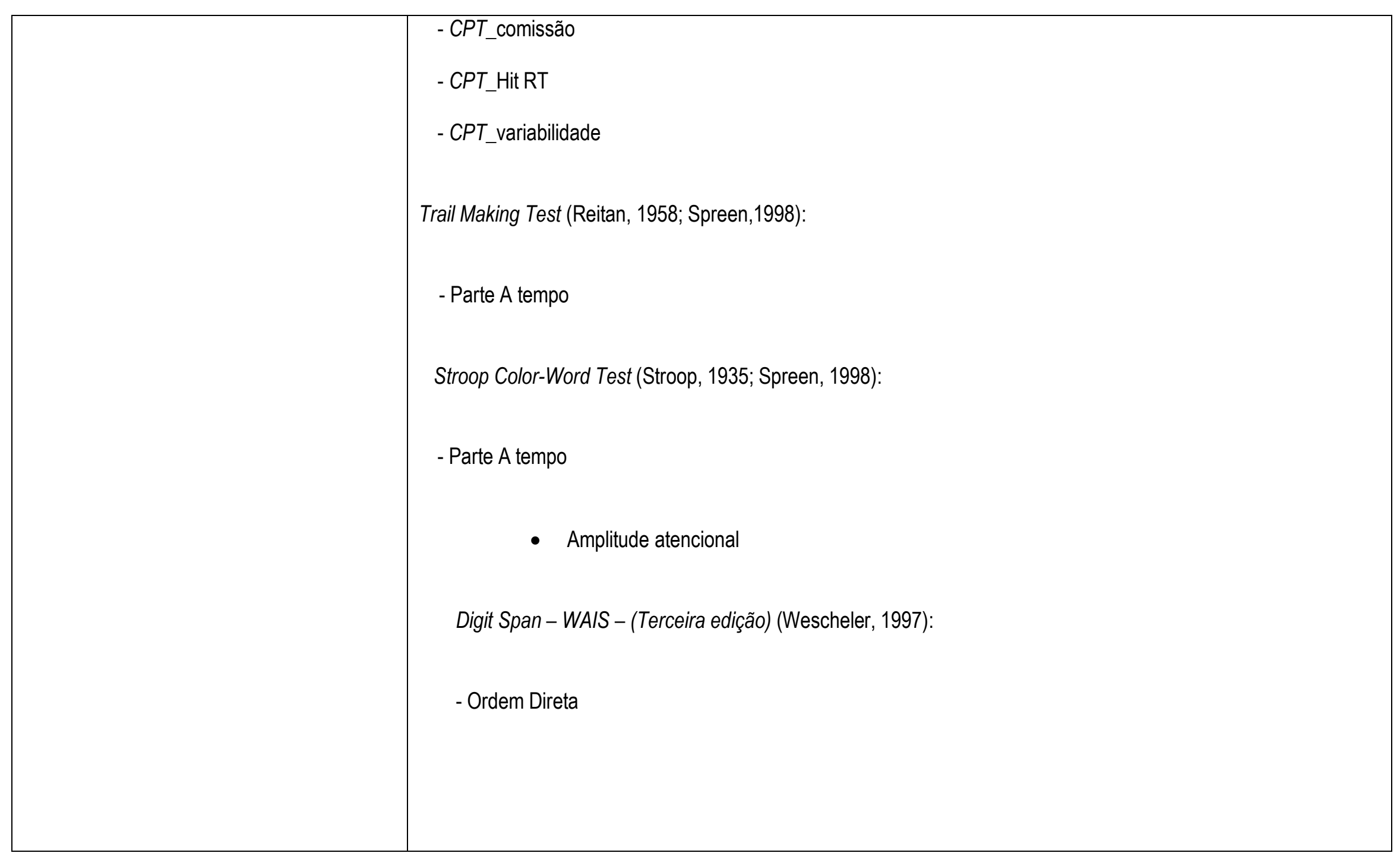




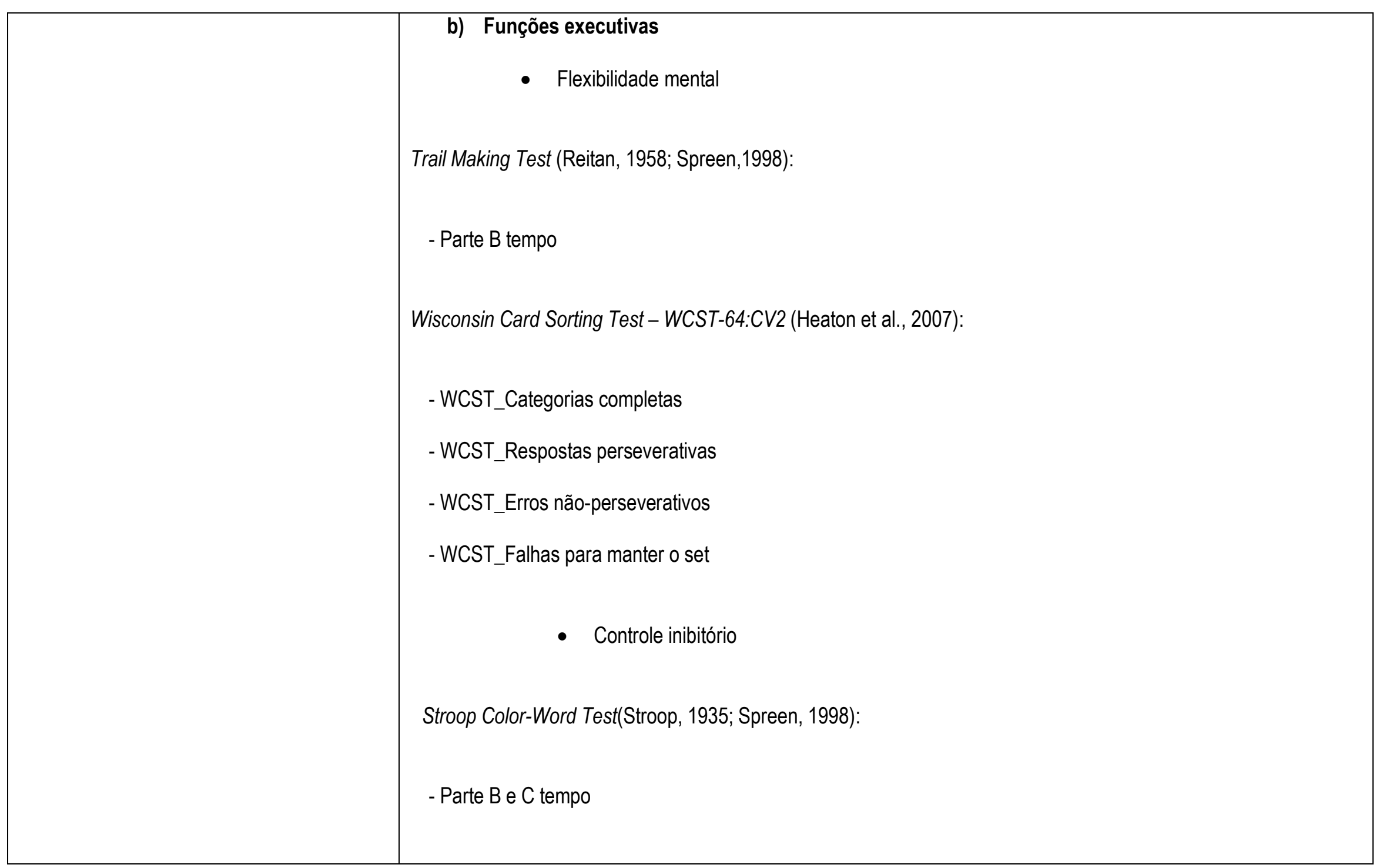




\begin{tabular}{|l|c|}
\hline C) Aprendizagem \\
Rey Auditory (Spreen, 1998) \\
- series totais - 1-5; RAVLT aprendizagem (5-1) \\
D) Memória de trabalho \\
Digit Span - WAIS - (terceira edição) (Wescheler, 1997): \\
- Ordem inversa \\
\hline AVALIAÇÃO DOS SINTOMAS \\
\hline Positive and Negative Syndrome Scale - PANSS (Kay et al., 1987) \\
\hline AVALIAÇÃO DO FUNCIONAMENTO SOCIAL \\
\hline
\end{tabular}




\subsubsection{A Avaliação neuropsicológica}

A Bateria de Avaliação neuropsicológica foi composta pelos seguintes instrumentos:

- Eficiência intelectual estimada (Escala Wechsler de Inteligência Abreviada-WASI):

Subtestes: Vocabulário e Matrizes (Wechsler, 1981; Tradução e Adaptação para a população brasileira: Brandão, 1987)

Objetivo: Avaliar a medida estimada da eficiência intelectual dos sujeitos. Os resultados obtidos poderão fornecer uma medida da influência que a inteligência, ou déficit desta, possa ter sobre o desempenho na avaliação neuropsicológica, além de indicar mais precisamente as condições que possam interferir na capacidade dos sujeitos compreenderem as solicitações do estudo.

Descrição: a edição revisada da Escala Wechsler permite estimar o quociente intelectual a partir de dois subtestes, raciocínio matricial e Vocabulário. A medida destes subtestes é obtida através da conversão dos resultados de acordo com a idade dos sujeitos e transformação em nota ponderada. Em seguida, o resultado ponderado é convertido para o índice de quociente intelectual estimado para a idade (Spreen, 1998).

\section{a) Inteligência cristalizada - Conhecimento acadêmico}

Subteste: vocabulário 
Objetivo: $O$ subteste vocabulário permite avaliar o desenvolvimento da linguagem, o conhecimento semântico das palavras, a inteligência geral (verbal), além da estimulação do ambiente e/ou curiosidade intelectual.

Descrição: é composto de 35 palavras, ordenadas segundo grau de dificuldade crescente. O sujeito é instruído a dizer o significado das palavras ou o seu sinônimo. O subteste é interrompido após o sujeito apresentar cinco erros consecutivos. Todos os significados conhecidos em dicionários são aceitáveis e são pontuados de acordo com a qualidade da definição $(2,1$ ou 0$)$.

\section{b) Inteligência fluída - Raciocínio lógico}

Subteste: Matrizes de raciocínio

Objetivo: Em raciocínio matricial, as funções cognitivas avaliadas consistem em analisar o processamento de informações visuais, o raciocínio abstrato e fluído, o raciocínio analógico e o raciocínio em série.

Descrição: é composto por quatro tipos de tarefas de raciocínio não verbal, cuja proposta feita ao sujeito requer completar figuras com padrões contínuos e discretos, classificação, analogia e raciocínio serial. A pontuação é de acordo com desempenho correto (1 ou 0).

\section{- Atenção}

- Atenção sustentada/vigilância 
Continuous Performance Test - CPT-II (Conners, 2002)

Objetivo: Avaliar a capacidade de sustentação da atenção, também denominada vigilância, sobre estímulos visuais.

Descrição: Consiste em um programa computadorizado para sistema operacional Windows, no qual o sujeito responde pressionando a barra de espaço ou dando um clique com o mouse cada vez que aparecer uma letra na tela do computador, exceto a letra "X". Os intervalos de tempo entre os estímulos são de 1,2 e 4 segundos, com tempo de exposição de 250 milésimos de segundos. Há 6 blocos, com 3 sub-blocos, sendo que cada um contém 20 ensaios (apresentação das letras). A ordem nas quais os intervalos de tempo entre os estímulos são apresentados varia entre os blocos. O tempo total da tarefa é de 14 minutos.

É feito em duas etapas. A primeira corresponde ao treino e a segunda, ao teste propriamente dito. O sujeito deverá pressionar a barra de espaço toda vez que aparecer alguma letra, exceto a letra " $X$ ", até acusar na tela o final da aplicação.

A pontuação é executada pelo programa (CPT-II) e baseada nas seguintes medidas:

1. Tempo de resposta (Hit RT): Os tempos de reação menores do que 100 milésimos de segundos são considerados perseverações. Esta classificação é dada devido à impossibilidade fisiológica de se responder com rapidez. 
Neste sentido, é mais provável que estas respostas sejam perseverativas ou antecipatórias, do que uma legítima resposta ao processamento do sinal.

O tempo de resposta através do erro padrão (Hit RT SE) é a medida que avalia a irregularidade no tempo de reação ao estímulo. Quanto maiores os valores neste índice, menor é a constância no tempo de reação durante a execução do teste.

2. Erros: Os erros fornecem uma medida da precisão da resposta. Eles podem ser categorizados de duas maneiras:

Omissão: ocorre quando a resposta não é dada ao aparecer uma letra que não seja a "X" na tela.

Comissão: ocorre quando a resposta é dada quando a letra "X" aparece na tela.

3. Variabilidade: Consiste em um método diferente de calcular a consistência no tempo de resposta, através da análise estatística feita pelo próprio programa calculada para cada sub-bloco.

- Trail Making Test - A(Reitan, 1958; Spreen, 1998)

Objetivo: Avaliar a capacidade de amplitude atencional. A amplitude corresponde a uma medida, ou seja, o quanto de estímulos auditivos pode ser apreendido pelo sujeito. 
Descrição: O teste de trilhas é composto por duas folhas de respostas. A primeira corresponde à parte "A" que consiste de uma série de números (de 1 a 25) randomizados numa página de papel sulfite branco.No verso de cada uma das páginas há um modelo para treino.

Solicita-se ao sujeito que execute o treino "A", orientando-o a traçar uma linha com lápis, a fim de ligar um número a outro sucessivamente, em ordem crescente. Logo após, inicia-se a prova "A", começando no número 1 e terminando no 25. O examinador deverá registrar o tempo dispendido pelo sujeito para executar esta parte da prova.

O tempo total é registrado em segundos. As performances dos sujeitos são classificadas de acordo com o tempo de execução da tarefa. Quanto maior o tempo gasto, pior o desempenho.

- Stroop Color-Word Test - A (Spreen, 1998)

Objetivo: Avaliar a capacidade de sustentação da atenção.

Descrição: O teste é composto de três cartões: o primeiro (A) é composto de tarjetas coloridas (verde, rosa, azul e marrom). É apresentado ao sujeito o primeiro cartão, solicitando a verbalização do nome das cores das tarjetas, da esquerda para a direita e de cima para baixo (tal como na leitura de um texto), o mais rápido possível. O tempo que o sujeito leva para ler o cartão é registrado e o desempenho é avaliado segundo a rapidez com que ele executa a prova. 
Amplitude atencional

- Digit Span - WAIS - A (Terceira edição) (Wescheler, 1997) - ordem direta

Objetivo: Avaliar a capacidade de amplitude atencional. A amplitude corresponde a uma medida, ou seja, o quanto de estímulos auditivos pode ser apreendido pelo sujeito.

Descrição: O Digit Span é um dos subtestes da Escala Wechsler de Inteligência para adultos, portanto encontra-se traduzido em português e validado pelo CFP (Conselho Federal de Psicologia). É composto de duas tarefas que são aplicadas independentemente uma da outra: Ordem Direta e Ordem Inversa. A ordem Direta é composta por oito seqüências de números Cada uma das seqüências, em ambas as provas, contém duas tentativas, diversas entre si.

Nas duas tarefas é feita a leitura, em voz alta, das seqüências de números para o sujeito. Para cada item da Ordem Direta o sujeito deverá repetir a seqüência numérica na mesma ordem apresentada, em ambas tentativas. Cada uma das seqüências contém duas tentativas, diversas entre si. 
Na tarefa é feita a leitura, em voz alta, das seqüências de números para o sujeito. Para cada item da Ordem Direta o sujeito deverá repetir a seqüência numérica na mesma ordem apresentada, em ambas tentativas. Para cada seqüência poderá ser atribuída uma pontuação que varia entre 2, 1 e 0 . Se o sujeito acerta as duas tentativas, 2 pontos serão atribuídos à seqüência; caso acerte uma tentativa, receber 1 ponto; ao errar ambas tentativas, será atribuído zero ponto à seqüência.

\section{- Função Executiva}

- Trail Making Test-B (Spreen, 1998)

Objetivo: Avaliar a capacidade de alternar a atenção sobre dois estímulos concorrentes.

Descrição: O teste de trilhas é composto por duas folhas de respostas. A segunda folha corresponde à parte "B", na qual constam números (de 1 a 13) e letras (de A até $M$ ), também randomizados na página. No verso de cada uma das páginas há um modelo para treino.

No treino "B" o examinando éorientado a traçar uma linha como anteriormente, mas, desta vez, alternando números e letras, ambos em ordem crescente a partir do número 1 até o número 13. Novamente, o tempo de execução desta parte da prova deverá ser registrado. 
As partes A e B são pontuadas separadamente e o tempo total é registrado em segundos. As performances dos sujeitos são classificadas de acordo com o tempo de execução da tarefa. Quanto maior o tempo gasto, pior o desempenho.

- Wisconsin Card Sorting Test (Heaton, 2003)

Objetivo: Avaliar a flexibilidade mental, atenção sustentada e a capacidade de formação de conceitos.

Descrição: É um programa computadorizado, versão para sistema operacional Windows, no qual o sujeito deverá classificar 64 cartas brancas com figuras geométricas (círculo, estrela, triângulo e cruz) coloridas em verde, azul, vermelho e amarelo, de acordo com a cor, a forma e a quantidade.

O sujeito deverá combinar as cartas segundo as categorias "cor", "forma" e "número". Cada categoria é completada após dez respostas consecutivas corretas, não sendo permitidos erros durante a formação da categoria.

A pontuação é executada pelo próprio programa, o qual indica o número de cada uma das medidas abaixo:

1. Respostas Perseverativas: Número total de tentativas nas quais o sujeito persistiu na combinação das cartas de acordo com o critério anterior, e não com o requerido no momento. 
2. Erros não perseverativos: Número de vezes em que o sujeito combinou os cartões incorretamente, não obedecendo ao critério anterior ou o requerido no momento.

3. Categorias completas: Número total de seqüências de dez respostas correta consecutivo. Cada uma destas seqüências completa uma categoria.

4. Perda de set: Número total de vezes em que o sujeito não conseguiu manter a seqüência de respostas, após cinco combinações consideradas corretas.

Este teste encontra-se, atualmente, validado pelo CFP (Conselho Federal de Psicologia) no Brasil.

\section{- Controle inibitório}

- Stroop Color-Word Test- B (Spreen, 1998)

Objetivo: Avaliar a capacidade de inibição de uma resposta padrão substituindo-a por outra menos usual (controle inibitório).

Descrição: $O$ teste é composto de três cartões. $O$ segundo cartão é constituído por palavras escritas com as cores das tarjetas (exemplos: palavra "cada" escrita em verde, "nunca" em rosa) e com os nomes das cores escritos em cores diferentes (ex: "marrom" escrito em azul, "verde" escrito em rosa). 
Depois, a partir da apresentação do segundo cartão é solicitado o nome das cores com as quais as palavras foram pintadas (e não da palavra em si). Por último, é feita a exposição do terceiro cartão, no qual o sujeito deverá dizer o nome das cores que estão pintadas as palavras e não a palavra escrita.

O tempo que o sujeito leva para ler cada um dos cartões é registrado e o desempenho é avaliado segundo a rapidez com que ele executa a prova.

\section{- Memória}

\section{Aprendizagem}

- Rey Auditory (Spreen, 1998)

Objetivo: Avaliar a capacidade de aprendizagem, com a memorização e evocação de palavras através de repetição contínua.

Descrição: O RAVLT começa com uma lista de 15 palavras (Lista A), que um examinador lê em voz alta. A tarefa do sujeito consiste em repetir todas as palavras que ele pode se lembrar, em qualquer ordem. Este procedimento é realizado um total de cinco vezes. Em seguida, o examinador apresenta uma segunda lista de 15 palavras (Lista B), permitindo uma única tentativa de recordar. Após isso, o sujeito é solicitado a lembrar das palavras da primeira lista. 
A pontuação é obtida através da somatória do número de palavras produzidas em cada lista evocada. No Brasil, para a administração do teste, estas palavras encontram-se traduzidas na língua portuguesa.

\section{Memória de trabalho}

- Digit Span - WAIS- B(terceira edição)(Wechesler, 1997)

Objetivo: A segunda parte do teste (ordem inversa) requer habilidade para apreender os estímulos e manipulá-los (working memory).

Descrição: O Digit Span é um dos subtestes da Escala Wechsler de Inteligência para adultos, portanto encontra-se traduzido em português e validado pelo CFP (Conselho Federal de Psicologia). É composto de duas tarefas que são aplicadas independentemente uma da outra: Ordem Direta e Ordem Inversa. A ordem inversa é composta por sete seqüências de números e cada uma das seqüências contém duas tentativas, diversas entre si.

Nas duas tarefas é feita a leitura, em voz alta, das seqüências de números para o sujeito. Para cada item da Ordem Inversa o sujeito deverá repetir a seqüência, nas duas tentativas, na ordem contrária à apresentada pelo examinador. 
Para cada seqüência poderá ser atribuída uma pontuação que varia entre 2, 1 e 0 . Se o sujeito acerta as duas tentativas, 2 pontos serão atribuídos à seqüência; caso acerte uma tentativa, receber 1 ponto; ao errar ambas tentativas, serão atribuídos zero ponto à seqüência.

\subsubsection{B Avaliação dos sintomas}

A bateria de avaliação psiquiátrica foi composta pelos seguintes instrumentos:

PANSS - Positive and Negative Syndrome Scale (Kay et al, 1987; Chaves e Shirakawa, 2000).

Objetivo: Avaliar as síndromes positiva e negativa na esquizofrenia.

Descrição: A escala é composta pelos 18 itens da BPRS - Brief Psychiatry Rating Scale e por 12 itens adicionais da Psychopathology Rating Scale. A padronização foi feita a partir do estudo de 240 pacientes com diagnóstico de esquizofrenia segundo o DSM-III. Os 30 sintomas e os escores de cada um dos 7 níveis de gravidade da psicopatologia foram definidos segundo critério operacional estrito. Os itens selecionados foram orientados por três pressupostos principais:

a) deveriam ser consistentes com a conceituação teórica da tipologia positiva/negativa;

b) deveriam ser incluídos os sintomas não-ambíguos e que fossem considerados primários; 
c) a validade de conteúdo deveria ser otimizado.

A partir destes pressupostos formou-se um grupo constituído por 7 sintomas positivos e 7 sintomas negativos (Chaves e Shirakawa, 2000).

Esse instrumento foi empregado com o objetivo de controlar a interferência da gravidade dos sintomas da esquizofrenia no programa de reabilitação e possibilitar uma melhor homogeneização da amostra. Trata-se de uma escala constituída de 30 itens, primeiramente divididos em "positivo, negativo e geral".

A diferença entre elas forma a escala composta, a qual avalia a preponderância de uma síndrome sobre a outra. A gravidade do sintoma é avaliada de acordo com a proeminência, extensão e impacto na vida cotidiana e no funcionamento do sujeito.

A avaliação é feita através de informações obtidas pelo clínico, familiar e por uma entrevista clínica acerca da última semana do paciente etem duração prevista entre 30 e 40 minutos, sendo administrada em quatro fases (Chaves e Shirakawa, 2000). A escala foi empregada tendo em mente os sinais críticos de remissão propostos por Andreasen et al (2005).

Como apresentam Chavez e Shirakawa (2000), essa escala foi traduzida e adaptada para a população brasileira por Vessoni (1993). 
No entanto, nosso estudo utilizou o modelo de 5 fatores para a conversão dos 30 itens da PANSS proposto por Gaag et al. (2006) que combina os 2 sintomas de esquizofrenia com "desorganização, excitação/excitement e estresse emocional/distress emotional".

Foram usados apenas os itens que foram incluídos em todas as dez vezes de validação cruzada da análise fatorial confirmatória. Neste caso, apenas alguns itens da PANSS foram incluídos em cada um do modelo de cinco fatores, por exemplo, "o fator de desorganização é composto por pensamento estereotipado (N7), atenção pobre (G11), desorientação (G10), desorganização conceitual (P2) e pensamento abstrato (N5)" (representados em negrito).

A análise confirmatória classificou os 30 itens da seguinte forma:

P1+P3+G9+P6+P5+G1+G12+G16-N5 - sintomas positivos

N6+N1+N2+N4+G7+N3+G16+G8+G13-P2 - sintomas negativos

N7+G11+G10+P2+N5+G5+G12+G13+G15+G9 - desorganização

G14+P4+P7+G8+P5+N3+G4+G16 - excitação/excitement

G2+G6+G3+G4+P6+G1+G15+G16 - estresse emocional/emotional distress 


\subsubsection{Avaliação do desempenho pessoal e social}

PSP - Personal and Social Performance Scale (Morosini et al., 2000).

A PSP é uma entre várias escalas usadas para avaliar o desfecho de funções sociais e pessoais nos pacientes em processo de reabilitação ou em tratamento medicamentoso. Em sua última versão, a PSP apresenta-se subdividida em dez intervalos iguais com um escore total de 100 pontos. Essa escala pode ser usada por profissionais de reabilitação de diferentes formações após um curto período de treinamento, sem perder sua confiabilidade. No estudo de Morosini et al. (2000), a PSP apresentou algumas vantagens quando comparada a SOFAS (Escala de Avaliação do Funcionamento Social e Ocupacional), tais como:

a) a inclusão de instruções claras de manuseio e sobre como indicar a taxa de gravidade ou comprometimento;

b) a especificação das áreas de comprometimento, enquanto a SOFAS refere-se apenas, de forma genérica, ao funcionamento social e ocupacional. Nesta escala, as atividades socialmente úteis, como o trabalho voluntário e a realização de tarefas domésticas, não são inclusos entre as atividades ocupacionais;

c) a não incorporação de aspectos psicopatológicos. 
A PSP é uma escala de classificação de 100 pontos usada pelo profissional de saúde mental que mensura a atividade pessoal e social em quatro domínios do comportamento (atividades socialmente úteis, incluindo trabalho e estudo, relações pessoais e sociais, autocuidado e comportamentos desorganizados e agressivos).

A escala PSP avalia o grau de dificuldade que um paciente apresenta nesses quatro domínios no período de um mês.

\subsection{Intervenções}

A atividade programada para o grupo experimental consistiu em atividades de aritmética do método Kumon, aplicados conforme sua programação original durante o período de seis meses (48 sessões). Foi constituída por duas aulas semanais com duração aproximada de 50 minutos cada, além das atividades para casa.

O grupo controle realizou atividades manuais não-específicas (recreativas) também durante o período de seis meses, e sob condições semelhantes ao desenvolvido pelo método Kumon, tais como dois horários semanais de 50 minutos cada com realização na própria instalação da escola, porém, sem direcionamento específico e sistematizado. 
Durante a atividade recreativa, embora tenha havido um ambiente acolhedor pretendeu-se estabelecer uma relação paciente-profissional o mais restrita possível (sem um direcionamento, fornecimento de instruções, interpretação ou qualquer tipo de reforço positivo e negativo) a fim de evitar qualquer tipo de intervenção terapêutica. Quando os sintomas psicóticos ou afetivos eram relatados pelos pacientes as psicólogas buscaram uma postura neutra tentando compreender, mas não utilizando nenhuma técnica terapêutica (Barreto et al., 2009).

Assim, o grupo controle buscou reproduzir a mesma rotina dos pacientes do grupo Kumon, e foi conduzida por psicólogos, voluntários do grupo de pesquisa Projesq (Programa de Esquizofrenia). As atividades tiveram um caráter recreativo, através da livre escolha por parte dos pacientes de diversos materiais expostos e de fácil manuseio tais como: sulfites, lápis de cor, tintas, revistas, etc. As atividades propostas foram estruturadas em 39 diferentes tipos e subtipos de propostas aleatoriamente alternadas na ordem e no tema abordado ao longo dos 48 períodos oferecidos (apêndice).

\subsection{Cálculo do número de sujeitos}

\section{Tamanho da amostra e poder do estudo}

A hipótese (desfecho primário) é de uma melhora cognitiva, medida pela avaliação neuropsicológica, superior no grupo experimental em relação ao grupo controle. 
O cálculo do tamanho da amostra foi feito com base na comparação da proporção de melhora 0,55 (diferença estandardizada) em cada um dos grupos. Admitindo-se que exista uma melhora cognitiva em $25 \%$ dos pacientes do grupo controle, para que uma melhora cognitiva em $65 \%$ dos pacientes do grupo experimental seja detectada com uma probabilidade de $80 \%$ (poder igual $\mathrm{a}_{1}-\beta$ ) em um teste com nível de significância de $\alpha=5 \%$, são necessárias 50 pessoas em cada grupo. Este cálculo leva em consideração uma possível taxa de abandono de tratamento (dropout) de aproximadamente $40 \%$.

Além disso, com este tamanho de amostra $(\mathrm{N}=30$, levando-se em consideração os possíveis dropouts do estudo) temos que, se uma diferença no z-scores entre os dois grupos (pós-tratamento) é de 0.74 , o poder do teste $t$ com nível de significância de $5 \%$ será $80 \%$.

Assim, consideramos este número de amostra calculado adequado para detectar as possíveis diferenças, inclusive no dia a dia dos pacientes, no desempenho dos pacientes entre os dois grupos após a intervenção. 


\subsection{Randomização}

A pesquisa trata-se de um estudo aleatorizado, controlado comparando Kumon versus placebo. Depois do baseline (avaliação neuropsicológica e psiquiátrica), os pacientes foram randomizados (randomização em bloco de uma série de 10 seqüências até a classificação $100^{\circ}$ ) para um de dois grupos, experimental (método Kumon) e controle (atividade recreativa), através de um programa computadorizado ( $\underline{w w w . r a n d o m i z e d . c o m})$.

De um total de 51 pacientes incluídos, 24 pacientes chegaram a freqüentar o grupo Kumon e 23 freqüentaram o grupo controle (recreação). Destes, foram analisados no estudo 18 pacientes do grupo Kumon e 19 pacientes do grupo controle após 6 meses de intervenção, pois dois pacientes desestabilizaram durante $\mathrm{o}$ período de intervenção e oito pacientes deixaram de freqüentar o grupo por outros motivos.

\subsection{Análise Estatística}

A análise estatística utiliza o principio de "intenção de tratar" (ITT). Para a comparação das características demográficas e clínicas entre grupo experimental e grupo controle no início da intervenção (baseline) foi utilizado qui-quadrado para as variáveis categóricas e teste Mann-Whitnney para as variáveis contínuas (Le, 2003). 
Tendo em vista que o protocolo de pesquisa do estudo é constituído de testes neuropsicológicos que não apresentam dados padronizados disponíveis para a população brasileira, foi considerada de maior valor quantitativo e qualitativo a utilização dos totais brutos dos resultados da amostra.

Os resultados obtidos foram analisados estatisticamente da seguinte forma:

Primeiramente, foi criado um banco de dados no programa SPSS, versão 14.0, composto pelos escores de cada uma das seguintes variáveis: demográficas, testes neuropsicológicos e escalas para sintomas e desempenho pessoal e social.

Através da análise descritiva se obteve a freqüência das variáveis demográficas distribuídas nos grupos controle e experimental.

Todos os resultados são analisados usando um modelo de regressão linear de efeitos mistos, com a montagem de modelos baseados na suposição de normalidade para os termos de erro através do uso de métodos de aproximação dos dados. 
Os valores referentes aos resultados dos modelos incluídos, que poderão ser afetados após a intervenção, são considerados variáveis explicativas. Os fatores randomização (terapêutica ou controle) e tempo (antes, póstratamento ou seguimento) foram incluídos no modelo como efeitos fixos principais e interação grupo $\mathrm{X}$ tempo. Além disso, foram incluídos efeitos aleatórios aos participantes. Quanto à interação significativa será constatado um efeito diferencial em três momentos diferentes do estudo. Caso o efeito da interação não seja significativo, o modelo correspondente será remodelado excluindo este termo, a fim de avaliar o efeito global do grupo. O efeito principal do grupo de randomização deverá, então, ser interpretado como um efeito da intervenção nos três momentos (antes, após 6 meses de tratamento e após 6 meses do término do tratamento). Para a comparação dos dois grupos antes, no término e no follow-updo estudo foi utilizada a análise de medidas repetidas utilizando efeitos mistos (MMRM).

A variável "composite" dos testes neuropsicológicos foi criada utilizandose a análise fatorial exploratória (O'Brien et al., 2005).

Já os resultados das escalas PANSS e PSP foram comparados por testes paramétricos (ou não-paramétricos) conforme indicado. 


\section{RESULTADOS}

\subsection{Participantes}

No total, 102 pacientes passaram por screening, sendo incluídos no estudo 51 pacientes (40 masculino, 11 feminino) randomizados (randomização em bloco de 10). Destes, 26 pacientes foram atendidos no grupo controle e 25 participaram do grupo Kumon. Trinta pacientes completaram 0 primeiro período de 6 meses de treinamento, 10 abandonaram o estudo durante a intervenção e 4 pacientes não chegaram a nem freqüentar o treinamento. Após 1 ano de estudo 34 pacientes foram reavaliados. 


\section{Inclusão}

Avaliados para elegibildade

$(n=102)$

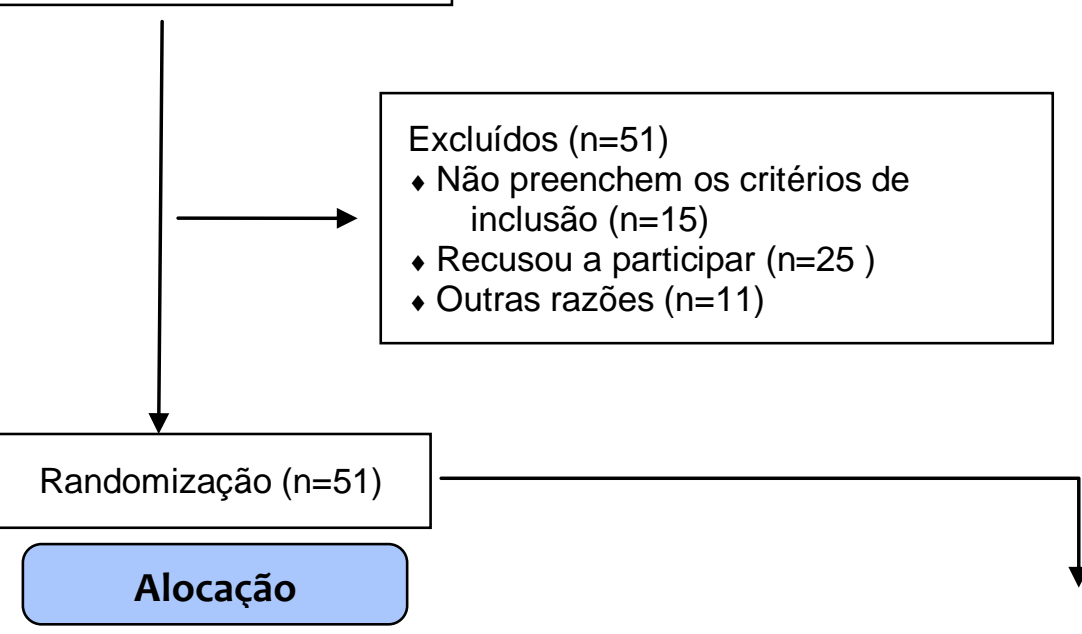

Alocados para intervenção Kumon $(\mathrm{n}=25)$

- Recebeu intervenção $(n=24)$

- Não recebeu intervenção (recusa) $(n=1)$
Alocados para intervenção controle $(n=26)$

- Recebeu intervenção ( $n=23)$

- Não recebeu intervenção

(sintomatologicamente instável, sem companhia para se dirigir ao hospital) $(\mathrm{n}=3)$

\begin{tabular}{|l|l|}
\hline Analisados $(\mathrm{n}=18)$ & Follow-Up (6 meses) \\
$\begin{array}{l}\text {-Perda de follow-up (decisão do paciente, } \\
\text { começou a trabalhar, começou a estudar) }(\mathrm{n}=5) \\
\begin{array}{l}\text {-Intervenção interrompida } \\
\text { (sintomatologicamente instável) }(\mathrm{n}=1)\end{array}\end{array}$ \\
\hline
\end{tabular}

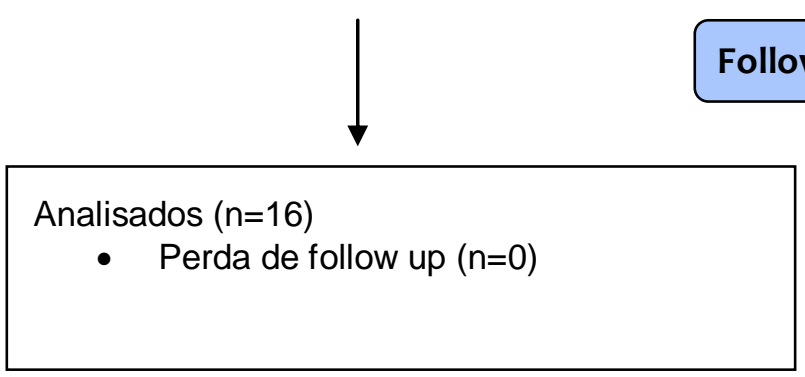

Follow-Up (12 meses)

Figura 4 - Diagrama CONSORT- perfil de inclusão dos pacientes no estudo 
De modo mais detalhado, as principais razões de não inclusão dos pacientes no screening:

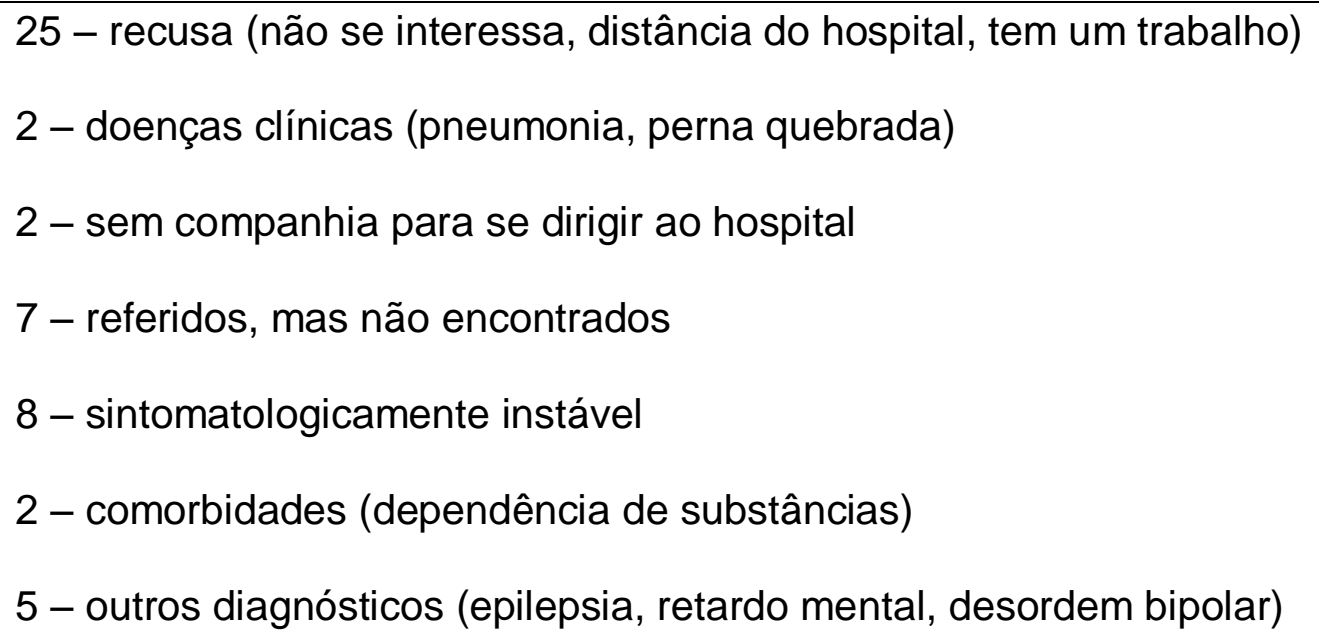

Motivos de dropouts apontados pelos próprios pacientes após 6 meses de intervenção:

4 - decisão do paciente (1=Kumon; 3=Recreação)

1 - começou a estudar ( $1=$ Kumon; $0=$ Recreação)

3 - começou a trabalhar ( $3=$ Kumon; $0=$ Recreação)

2 - desestabilizou clinicamente (1= Kumon; 1 =Recreação)

\subsection{Análise demográfica}

Serão apresentadas as características demográficas dos 51 pacientes que compõem a amostra desta pesquisa, divididos em grupo experimental ( $n=24)$ e grupo controle $(n=23)$, compondo uma análise descritiva dos dados da população. Foram feitos testes qui-quadrados para checar a correlação entre os dados demográficos e a condição a que foi alocado o paciente. 
Resultados

Nos casos dos testes qui-quadrados de Pearson as caselas apresentaram valores menores do que cinco (sexo, raça, estado civil, subtipo de esquizofrenia e histórico de internação), sendo então empregada a simulação de Monte-Carlo e usado valores de $p$ simulado a fim de minimizar a possibilidade de erro (Hope, 1968).

A amostra foi composta por pacientes do Instituto de psiquiatria do HCFMUSP, mais especificamente dos ambulatórios do Projeto esquizofrenia (PROJESQ) e LIM-27. A população atendida nos dois grupos (Kumon e controle) apresenta perfil demográfico similar. No geral, os pacientes da pesquisa são, em sua maioria, homens $(78,4 \%)$, brancos $(80,4 \%)$, solteiros $(92,2 \%)$ e tem o diagnóstico de esquizofrenia paranóide (84,3\%). Conforme demonstra a tabela 6 , não houve diferenças significativas quanto à composição da amostra em termos de instituição a qual os pacientes pertencem, sexo e estado civil. 
TABELA 9 - Distribuição da amostra de acordo com o ambulatório, o sexo e o estado civil - n e (\%).

\begin{tabular}{|c|c|c|c|c|c|}
\hline & \multicolumn{2}{|c|}{ Recreação } & \multicolumn{2}{|c|}{ Kumon } & \multirow[b]{2}{*}{ P-valor } \\
\hline & $N=26$ & $\%$ & $N=25$ & $\%$ & \\
\hline sexo & & & & & 0,789 \\
\hline masculino & 20 & 76,92 & 20 & 80,00 & \\
\hline feminino & 6 & 23,08 & 5 & 20,00 & \\
\hline Ambulatório & & & & & 0,910 \\
\hline projesq & 16 & 61,54 & 15 & 60,00 & \\
\hline $\lim -27$ & 10 & 38,46 & 10 & 40,00 & \\
\hline Estado civil & & & & & 0,471 \\
\hline solteiro & 25 & 96,15 & 22 & 88,00 & \\
\hline casado & 1 & 3,85 & 2 & 8,00 & \\
\hline divorciado & 0 & 0,00 & 1 & 4,00 & \\
\hline
\end{tabular}

\footnotetext{
* Teste exato de Fisher
} 
Resultados

TABELA 10 - Distribuição da freqüência e porcentagem por raça em cada grupo.

\section{Grupo}

\begin{tabular}{|c|c|c|c|c|}
\hline & & Recreação & Kumon & Total \\
\hline \multirow[t]{10}{*}{$\overline{R a c ̧ a}$} & Branca & 19 & 22 & 41 \\
\hline & & $73,1 \%$ & $88,0 \%$ & $80,4 \%$ \\
\hline & Negra & 3 & 2 & 5 \\
\hline & & $11,5 \%$ & $8,0 \%$ & $9,8 \%$ \\
\hline & Amarela & 3 & 1 & 4 \\
\hline & & $11,5 \%$ & $4,0 \%$ & $7,8 \%$ \\
\hline & Outros & 1 & 0 & 1 \\
\hline & & $3,8 \%$ &, $0 \%$ & $2,0 \%$ \\
\hline & Total & 26 & 25 & 51 \\
\hline & & $100,0 \%$ & $100,0 \%$ & $100,0 \%$ \\
\hline
\end{tabular}


TABELA 11 - Distribuição da freqüência e porcentagem de subtipos $d \epsilon$ esquizofrenia em cada grupo.

\section{Grupo}

\section{Recreação Kumon Total}

\begin{tabular}{|c|c|c|c|c|}
\hline Subtipos de & Hebefrênica & 4 & 1 & 5 \\
\hline \multirow[t]{7}{*}{ esquizofrenia } & & $15,4 \%$ & $4,0 \%$ & $9,8 \%$ \\
\hline & \multirow[t]{2}{*}{ Paranóide } & 21 & 22 & 43 \\
\hline & & $80,8 \%$ & $88,0 \%$ & $84,3 \%$ \\
\hline & \multirow[t]{2}{*}{ Residual } & 1 & 1 & 2 \\
\hline & & $3,8 \%$ & $4,0 \%$ & $3,9 \%$ \\
\hline & \multirow{2}{*}{ Indiferenciada } & 0 & 1 & 1 \\
\hline & &, $0 \%$ & $4,0 \%$ & $2,0 \%$ \\
\hline \multirow{2}{*}{\multicolumn{2}{|c|}{ Total }} & 26 & 25 & 51 \\
\hline & & $100,0 \%$ & $100,0 \%$ & $100,0 \%$ \\
\hline
\end{tabular}

$p=0,668 *$ Teste qui-quadrado de Pearson por simulação de Monte Carlo.

Somente podemos perceber diferença significativa na linha de base entre os dois grupos (controle e experimental) em relação ao histórico de internação, com maior número de pacientes que já foram internados pelo menos uma vez ao longo do curso da doença no grupo controle, conforme apresentado na tabela 12 . 
Resultados

TABELA 12- Distribuição da freqüência e porcentagem do histórico de internação em cada grupo.

\begin{tabular}{cccc}
\hline & \multicolumn{3}{c}{ Internação } \\
\cline { 2 - 4 } & Não & Sim & Total \\
Recreação & $3(10,3 \%)$ & $26(89,7 \%)$ & $29(100,0 \%)$ \\
\hline Kumon & $7(31,8 \%)$ & $15(68,2 \%)$ & $22(100,0 \%)$ \\
\hline Total & $10(19,6 \%)$ & $41(80,4 \%)$ & $51(100,0 \%)$
\end{tabular}

$P=0,056$ *Teste qui-quadrado de Pearson por simulação de Monte Carlo.

De acordo com a tabela 13, apesar das diferenças nas médias de idade, anos de estudo, duração da doença, número de internações e idade da primeira internação apresentadas pela população em geral, pode-se perceber pela tabela 14 que quando separada em grupo controle e experimental não foram encontradas diferenças significativas.

TABELA 13 - Médias e desvios-padrão dos dados demográficos totais.

Desvio-

\begin{tabular}{cccccc} 
& N & Mínimo & Máximo & Média & padrão \\
\cline { 2 - 6 } Idade & 51 & 21 & 55 & 36,55 & 8,225 \\
\hline $\begin{array}{c}\text { Anos de } \\
\text { estudo }\end{array}$ & 51 & 5 & 16 & 10,86 & 2,432 \\
\hline $\begin{array}{c}\text { Duração de } \\
\text { doença } \\
\text { (anos) }\end{array}$ & 51 & 2 & 38 & 13,22 & 8,048 \\
\hline No de & & & & & \\
internações & 51 & 0 & 9 & 1,71 & 1,900 \\
\hline
\end{tabular}


Resultados

TABELA 14 - Médias e desvios-padrão dos dados demográficos em cada grupo.

\section{Desvio-}

\begin{tabular}{cccccc} 
& Grupo & N & Média & padrão & P-valor \\
\hline Idade & Recreação & 26 & 36,96 & 9,340 &, 813 \\
& kumon & 25 & 36,12 & 7,049 & \\
\hline Anos de & Recreação & 26 & 10,58 & 2,942 &, 379 \\
estudo & kumon & 25 & 11,16 & 1,908 & \\
\hline Duração de & & 26 & 14,50 & 8,842 &, 871 \\
doença & Recreação & & & & \\
(anos) & kumon & 25 & 11,88 & 7,061 &, 100 \\
\hline No de & Recreação & 26 & 2,17 & 2,054 & \\
internações & Kumon & 25 & 1,36 & 1,497 & \\
\hline $1^{\circ}$ & Recreação & 26 & 18,03 & 10,469 & \\
internação & Kumon & 25 & 16,45 & 12,019 & \\
(idade) & & & & &
\end{tabular}

*Teste Mann-Whitney para amostras independentes.

No quesito medicação, a grande maioria dos pacientes fazia uso de antipsicóticos atípicos. Houve diferença entre os grupos (recreação e Kumon) somente em relação aos anticolinérgicos associados, com maior prevalência no grupo controle. Conforme a metodologia do estudo, houve pouca ou nenhuma alteração estatisticamente significativa no tipo de medicação ao longo do treinamento de seis meses. 
Tabela 15- Tipo de medicação - n e (\%)

\begin{tabular}{|c|c|c|c|c|c|}
\hline & \multicolumn{2}{|c|}{ Recreação } & \multicolumn{2}{|c|}{ Kumon } & \multirow[b]{2}{*}{ P-valor } \\
\hline & $\mathbf{N}$ & $\%$ & $\mathbf{N}$ & $\overline{\%}$ & \\
\hline \multicolumn{6}{|l|}{ Baseline } \\
\hline Atipico & 17 & 80,95 & 11 & 61,11 & 0,170 \\
\hline Típico & 1 & 4,76 & 2 & 11,11 & 0,458 \\
\hline Antidepressivo & 3 & 14,29 & 0 & 0,00 & 0,095 \\
\hline Ansiolítico & 1 & 4,76 & 2 & 11,11 & 0,458 \\
\hline Anticolinérgico & 8 & 38,10 & 2 & 9,52 & $0,030^{* *}$ \\
\hline Estab.humor & 2 & 9,52 & 1 & 5,56 & 0,643 \\
\hline \multicolumn{6}{|l|}{ Após 6 meses } \\
\hline Atípico & 17 & 85,00 & 10 & 55,56 & $0,046^{* *}$ \\
\hline Típico & 1 & 5,00 & 3 & 16,67 & 0,242 \\
\hline Antidepressivo & 3 & 15,00 & 0 & 0,00 & 0,087 \\
\hline Ansiolítico & 1 & 5,00 & 1 & 5,56 & 0,939 \\
\hline Anticolinérgico & 6 & 30,00 & 2 & 9,52 & 0,098 \\
\hline Estab.humor & 3 & 15,00 & 2 & 11,11 & 0,723 \\
\hline
\end{tabular}

*Teste qui-quadrado de Pearson por simulação de Monte Carlo. **Diferenças significativas.

\subsection{Comparações intra e entre os grupos no início da intervenção}

\section{Avaliação de inteligência}

Em relação às medidas de inteligência na linha de base, não foram encontradas diferenças significativas entre os grupos controle e Kumon (tabela 16). 
Resultados

Tabela 16 - Comparações entre os grupos quanto a medidas de inteligência na linha de base

\begin{tabular}{llcc}
\hline \multicolumn{1}{c}{ Instrumentos } & Condição & Média \pm dp & P-valor \\
\hline Vocabulário & Recreação & $43,44 \pm 10,86$ & 0,342 \\
& Kumon & $45,29 \pm 12,83$ & \\
\hline Matriz de raciocínio & Recreação & $20,00 \pm 5,69$ & 0,184 \\
& Kumon & $21,67 \pm 6,60$ & \\
\hline QI & Recreação & $84,60 \pm 13,58$ & 0,724 \\
& Kumon & $86,26 \pm 20,35$ & \\
\hline
\end{tabular}

\section{Avaliação atencional}

No que se refere às medidas atencionais na linha de base, os grupos de mostraram comparáveis conforme pode ser observado na tabela 16. 0 grupo de recreação deixou de dar respostas que não sejam a letra " $x$ ", perseverou mais nas respostas e deu mais respostas na letra " $X$ " (Continuous Performance Test - CPT); e o grupo Kumon apresentou desempenho mais rápido quanto à velocidade de processamento (Trail A), entretanto, estas diferenças não foram estatisticamente significativas. Quanto ao controle inibitório (Stroop Color Word A) e amplitude atencional (Dígitos diretos), as médias de ambos os grupos foram idênticas e não houve diferença significativa. 
Resultados

Tabela 17 - Comparações entre grupos em medidas neuropsicológicas de atenção no início da intervenção

\begin{tabular}{|c|c|c|c|}
\hline Instrumentos & Condição & Média $\pm d p$ & P-valor \\
\hline \multirow[t]{2}{*}{ CPT_omissão } & Recreação & $32,12 \pm 37,35$ & 0,100 \\
\hline & Kumon & $16,04 \pm 25,43$ & \\
\hline \multirow[t]{2}{*}{ CPT_comissão } & Recreação & $16,52 \pm 6,88$ & 0,304 \\
\hline & Kumon & $13,50 \pm 9,05$ & \\
\hline \multirow[t]{2}{*}{ CPT_HitRT } & Recreação & $521,11 \pm 131,01$ & 0,490 \\
\hline & Kumon & $484,34 \pm 112,69$ & \\
\hline \multirow[t]{2}{*}{ CPT_variabilidade } & Recreação & $24,66 \pm 17,84$ & 0,377 \\
\hline & Kumon & $17,65 \pm 22,00$ & \\
\hline \multirow[t]{2}{*}{ Trail Making A (em segundos) } & Recreação & $51,28 \pm 27,41$ & 0,372 \\
\hline & Kumon & $39,96 \pm 17,60$ & \\
\hline \multirow[t]{2}{*}{ Stroop Color Word A (em segundos) } & Recreação & $21,60 \pm 7,40$ & 0,772 \\
\hline & Kumon & $20,57 \pm 14,60$ & \\
\hline \multirow[t]{2}{*}{ Digit span (ordem direta) } & Recreação & $9,96 \pm 2,51$ & 0,419 \\
\hline & Kumon & $9,88 \pm 2,79$ & \\
\hline
\end{tabular}

*Teste Mann-Whitney para amostras independentes.

\section{Avaliação de função executiva}

Sobre a função executiva, observando a tabela 18 pode-se entender que o grupo Kumon apresentou melhor desempenho em atenção alternada (Trail Making B) e em controle inibitório (Stroop Color Word B e C). No entanto, estas diferenças não foram estatisticamente significativas. Nas medidas avaliadas pelo Wisconsin Card Test (WCST), o grupo Kumon apresentou menos respostas perseverativas e mais perdas de set (medida mais específica de perda de concentração) estatisticamente significativas. No entanto, houve pequeníssimas diferenças, sem que houvesse diferenças 
Resultados

significativas, no desempenho entre os grupos em categorias completadas e erros não perseverativos.

Tabela 18 - Comparações entre grupos quanto a medidas neuropsicológicas de função executiva no início da intervenção

\begin{tabular}{lllc}
\hline \multicolumn{1}{c}{ Instrumentos } & \multicolumn{1}{c}{ Condição } & Média \pm dp & P-valor \\
\hline Trail Making B (em segundos) & Recreação & $179,64 \pm 124,92$ & 0,065 \\
& Kumon & $112,83 \pm 69,34$ & \\
\hline WCST_categorias completas & Recreação & $30,00 \pm 11,11$ & 0,071 \\
& Kumon & $38,00 \pm 12,14$ & \\
\hline WCST_respostas perseverativas & Recreação & $23,96 \pm 15,86$ & $0,011^{\star *}$ \\
& Kumon & $14,38 \pm 10,77$ & \\
\hline WCST_errosnãoperseverativos & Recreação & $14,32 \pm 9,63$ & 0,345 \\
& Kumon & $11,08 \pm 4,44$ & \\
\hline WCST_falhasdeset & Recreação & $0,48 \pm 0,71$ & $0,014^{\star *}$ \\
& Kumon & $0,92 \pm 0,83$ & \\
& & & \\
\hline Stroop Color Word B & Recreação & $27,40 \pm 11,60$ & 0,587 \\
& Kumon & $23,83 \pm 16,47$ & \\
\hline Stroop Color Word C & Recreação & $41,60 \pm 18,22$ & 0,611 \\
& Kumon & $37,13 \pm 21,68$ &
\end{tabular}

*Teste Mann-Whitney para amostras independentes. **Diferenças significativas.

\section{Avaliacão mnêmica}

Sobre a memória, observando-se a tabela 19 pode-se entender que ambos os grupos apresentaram medidas praticamente equivalentes ao evocar uma lista de palavras (RAVLT_A, B, C, E), exceto na penúltima lista sem interferência, apresentando maior evocação significativa de palavras no grupo Kumon (RAVLT_D). Em memória de trabalho (Dígitos ordem inversa), o grupo Kumon apresentou ligeira melhora de desempenho, mas estatisticamente não significativo. 
Resultados

Tabela 19 - Comparações entre grupos quanto a medidas neuropsicológicas de memória no início da intervenção

\begin{tabular}{lllc}
\hline \multicolumn{1}{c}{ Instrumentos } & Condição & Média $\pm d p$ & P-valor \\
\hline RAVLT_A & Recreação & $4,04 \pm 1,65$ & 0,357 \\
& Kumon & $4,00 \pm 2,30$ & \\
\hline RAVLT_B & Recreação & $4,04 \pm 1,65$ & 0,225 \\
& Kumon & $4,00 \pm 2,30$ & 0,205 \\
\hline RAVLT_C & Recreação & $5,56 \pm 2,53$ & \\
\hline RAVLT_D & Kumon & $7,63 \pm 5,60$ & $0,028^{* *}$ \\
& Recreação & $6,80 \pm 2,68$ & 0,193 \\
\hline RAVLT_E & Kumon & $8,50 \pm 2,38$ & \\
& Recreação & $6,92 \pm 3,24$ & 0,415 \\
\hline Digit Span_ordem inversa & Recreação & $7,92 \pm 3,67$ & \\
& Kumon & $3,92 \pm 2,00$ & \\
& Kumon & $4,75 \pm 2,01$ & \\
& & &
\end{tabular}

*Teste Mann-Whitney para amostras independentes. **Diferenças significativas.

$\underline{\text { Avaliação sintomatológica e de funcionamento social e pessoal }}$

No geral, a amostra total se apresentou pouco sintomática, havendo pequena diferença a mais no grupo controle quando se avalia a média do subitem "desorganização" da análise fatorial de Van der Gaag. Quase não houve diferenças nos dois grupos quanto aos demais: positiva, negativa, excitação e emocional. Nas cinco medidas o grupo controle apresentou leve superioridade de pontuação, entretanto, nenhuma destas diferenças se mostrou significativa. A mesma diferença estatisticamente não significativa pode ser constatada em relação à escala de desempenho pessoal e social (PSP), demonstrada na tabela 20. Houve pouca diferença entre as médias dos grupos, cuja pontuação varia de 1 a 100 e avaliada de modo positivo, ou seja, quanto maior a pontuação melhor o desempenho funcional. 
Resultados

Tabela 20 - Comparações entre grupos quanto a medidas de PANSS na linha de base

Condição Média \pm Plp $\quad$ P-valor

PANSS Positiva Recreação 12,68 $\pm 5,03 \quad 0,085$

Kumon $\quad 9,80 \pm 3,72$

PANSS Negativa Recreação $\quad 23,40 \pm 5,68 \quad 0,206$

Kumon $\quad 20,75 \pm 6,21$

PANSS Desorganizada Recreação $13,44 \pm 3,16 \quad 0,007^{\star *}$

Kumon $\quad 10,85 \pm 3,91$

PANSS Excitação Recreação $\quad 6,36 \pm 2,69 \quad 0,082$

Kumon $\quad 5,35 \pm 2,11$

PANSS Emocional Recreação $\quad 8,32 \pm 2,90 \quad 0,485$

Kumon $\quad 8,15 \pm 3,15$

Recreação $\quad 36,20 \pm 7,22 \quad 0,286$

PANSS Total Kumon $30,62 \pm 9,30$

$\begin{array}{llll} & \text { Recreação } & 51,08 \pm 13,70 & \\ \text { PSP } & \text { Kumon } & 56,80 \pm 16,62 & 0,185\end{array}$

*Teste Mann-Whitney para amostras independentes. **Diferenças significativas. 
Resultados

6.4. Comparações intra e entre grupos ao final da intervenção e após 12 meses

Conforme mencionado, para as comparações entre os grupos Kumon e Recreação em diferentes momentos, foi utilizado o MODELO DE REGRESSÃO LINEAR DE EFEITOS MISTOS.

\subsubsection{Resultados das medidas neuropsicológicas}

Avaliação da inteligência

Quanto à avaliação de inteligência, percebe-se melhor desempenho cognitivo no subteste matrizes de raciocínio (WASI reduzido) tanto no grupo Kumon quanto no grupo controle em relação ao fator tempo. Já quando o desempenho dos grupos é comparado, não é encontrada diferença significativa $(p \leq 0,05)$, conforme a tabela 21 .

Gráfico 1 - Comparação do desempenho em "matrizes de raciocínio" do WAIS-III entre grupo Kumon e controle após 6 e 12 meses de treinamento

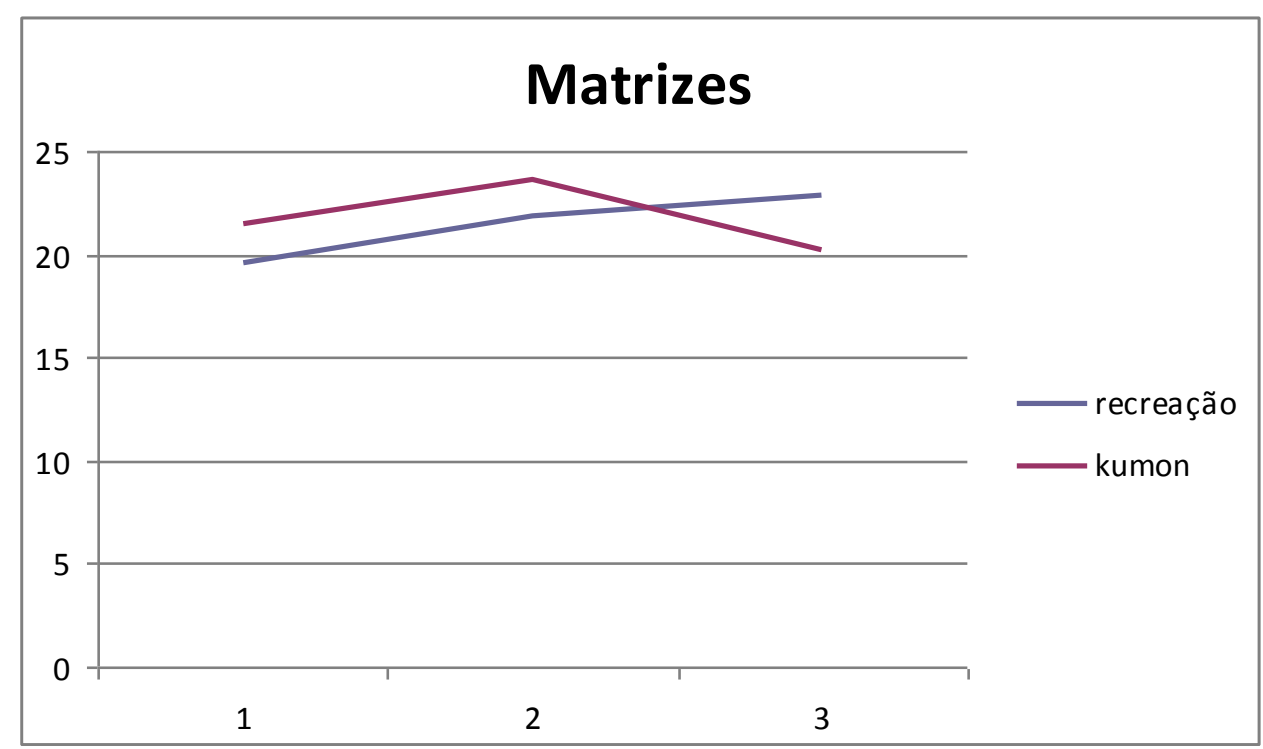


Resultados

Em medidas de QI (quociente de inteligência), pode-se observar que houve efeito de grupo (entre - indivíduos) e melhora no desempenho após 6 meses de treinamento em ambos os grupos. No entanto, em conseqüência a esta melhora de desempenho dos grupos separadamente ao longo do tempo, o grupo Kumon e o grupo controle não apresentaram diferença significativa após 6 meses de intervenção quando comparados (interação). Manteve-se mais esta melhora após 6 meses sem treinamento no grupo controle, porém quando comparado ao grupo Kumon não foi significativo.

Gráfico 2 - Comparação do desempenho em medidas de "Quociente intelectual - Ql" entre grupo Kumon e controle após 6 e 12 meses de treinamento

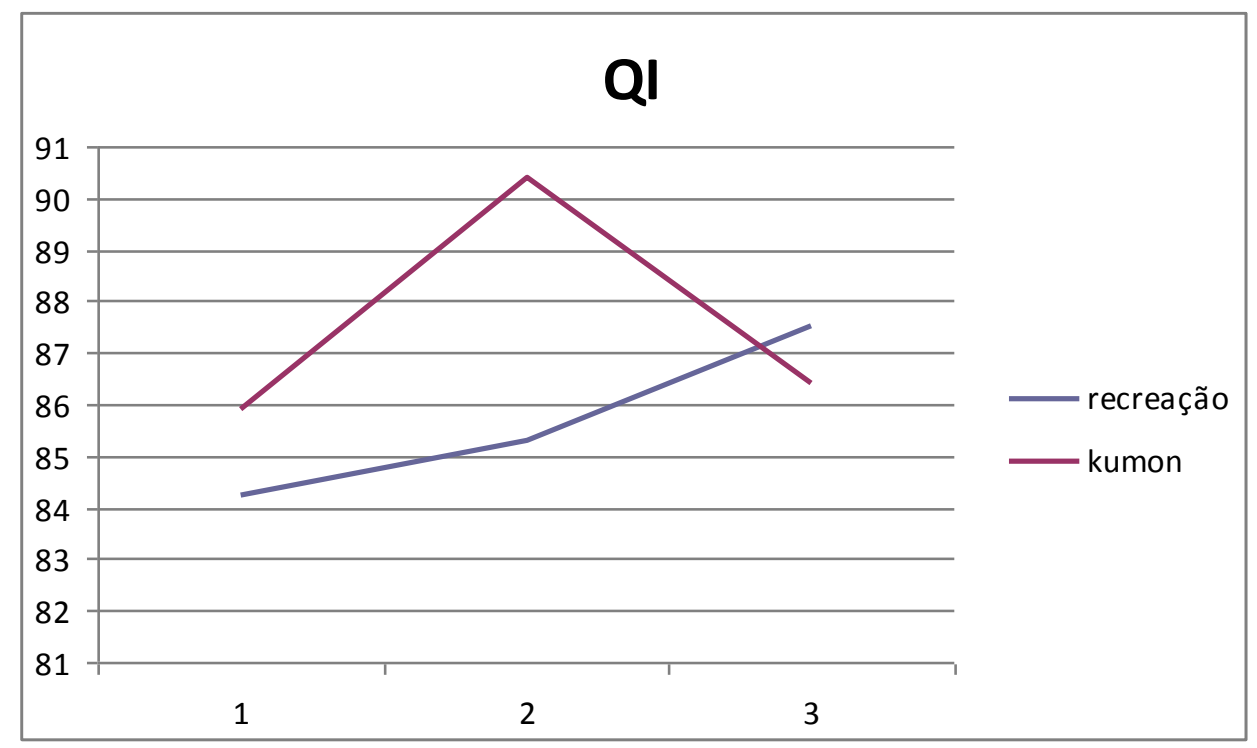

No subteste Vocabulário (WASI reduzido), também não foram encontrados diferenças significativas, entretanto, o grupo Kumon apresentou melhora após 6 meses de intervenção em detrimento do grupo controle. Após 6 meses sem intervenção o grupo Kumon não conseguiu manter os ganhos, porém esta perda também não foi significativa. 
Resultados

Gráfico 3 - Comparação do desempenho em "Vocabulário" do WAIS-III entre grupo Kumon e controle após 6 e 12 meses de treinamento

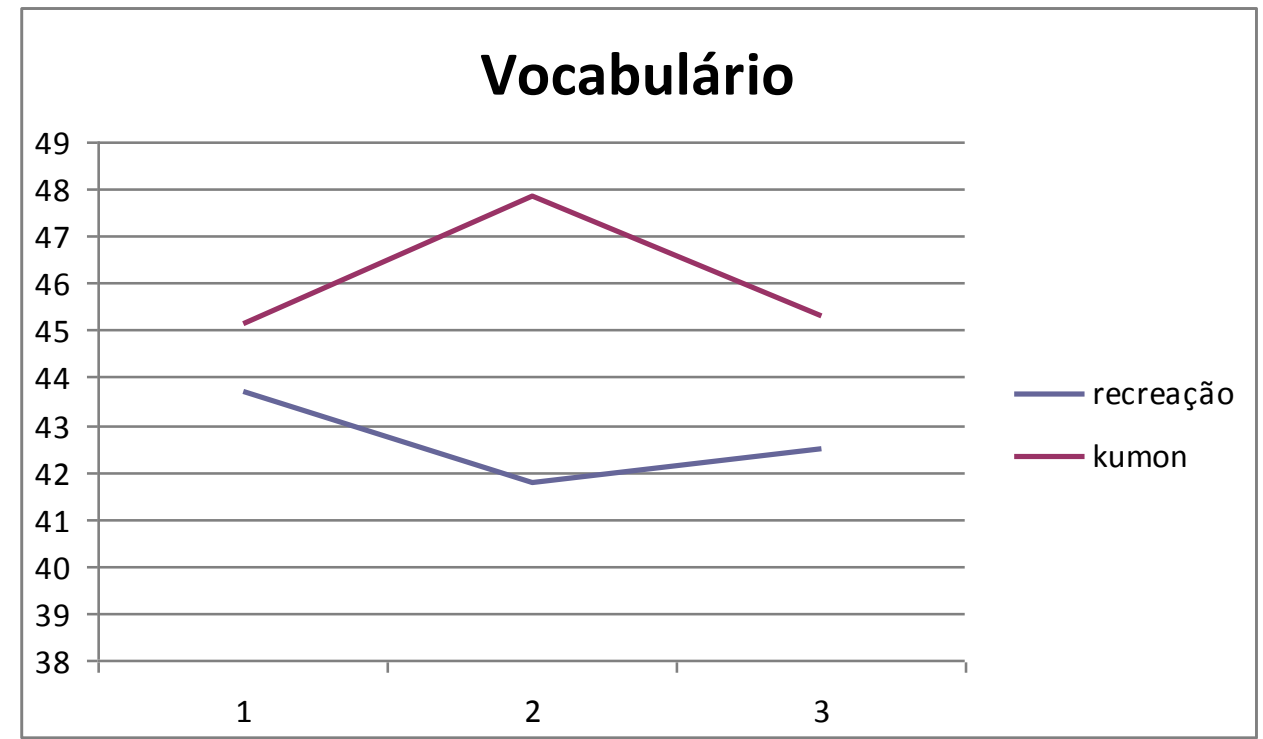


Resultados

Tabela 21 - Resultados das medidas de inteligência (WASI reduzido)

\begin{tabular}{|c|c|c|c|c|c|c|c|c|c|c|}
\hline \multirow[b]{2}{*}{ Instrumentos } & \multirow[b]{2}{*}{ Condição } & \multicolumn{2}{|l|}{ Média $\pm d p$} & \multicolumn{3}{|c|}{ P-valor } & \multirow{2}{*}{$\begin{array}{l}\text { Média } \pm d p \\
\text { Tempo } 3\end{array}$} & \multicolumn{3}{|c|}{ P-valor } \\
\hline & & Baseline & Tempo 2 & $\begin{array}{c}\text { Entre - } \\
\text { indivíduos }\end{array}$ & $\begin{array}{c}\text { Intra - } \\
\text { indivíduos }\end{array}$ & Interação & & $\begin{array}{c}\text { Entre - } \\
\text { indivíduos }\end{array}$ & $\begin{array}{c}\text { Intra - } \\
\text { indivíduos }\end{array}$ & Interação \\
\hline $\begin{array}{l}\text { Matriz de } \\
\text { raciocínio }\end{array}$ & $\begin{array}{c}\text { Experimental } \\
\qquad(n=18) \\
\text { Controle } \\
(n=19)\end{array}$ & $\begin{array}{l}20,00 \pm 5,69 \\
21,67 \pm 6,60\end{array}$ & $\begin{array}{l}21,85 \pm 7,53 \\
23,56 \pm 7,20\end{array}$ & 0,223 & $0,021^{*}$ & 0,908 & $\begin{array}{l}20,23 \pm 4,43 \\
22,81 \pm 11,13\end{array}$ & 0,605 & 0,106 & 0,177 \\
\hline Vocabulário & $\begin{array}{l}\text { Experimental } \\
\qquad(n=18) \\
\text { Controle } \\
(n=19)\end{array}$ & $\begin{array}{l}43,44 \pm 10,86 \\
45,25 \pm 12,83\end{array}$ & $\begin{array}{l}41,75 \pm 8,34 \\
47,83 \pm 8,82\end{array}$ & 0,625 & 0,446 & 0,123 & $\begin{array}{l}45,29 \pm 7,97 \\
42,5 \pm 11,03\end{array}$ & 0,162 & 0,562 & 0,205 \\
\hline QI & $\begin{array}{c}\text { Experimental } \\
\qquad(n=18) \\
\text { Controle } \\
(n=19)\end{array}$ & $\begin{array}{l}84,60 \pm 13,58 \\
86,29 \pm 20,35\end{array}$ & $\begin{array}{l}85,30 \pm 14,5 \\
90,39 \pm 12,0\end{array}$ & $0,024^{*}$ & $0,016^{*}$ & 0,099 & $85,42 \pm 14,88$ & 0,410 & 0,301 & 0,162 \\
\hline
\end{tabular}




\section{Avaliação da atenção}

Quanto às medidas atencionais (tabela 22), pode-se observar que no fator "omissão" do Continuous Performance Test - CPT não houve efeito de grupo (entre-indivíduos). Entretanto, os pacientes de ambos os grupos apresentaram resultados similares de melhora de desempenho quando comparamos os resultados no tempo (intra-indivíduos), com diminuição significativa na pontuação dos grupos, indicando melhora. Conseqüentemente, quando comparados, não houve diferença significativa entre os grupos Kumon e controle após 6 meses de intervenção (Grupo X Tempo). Após 1 ano de estudo, ambos os grupos apresentaram, não significativamente, perda em relação aos ganhos cognitivos.

Gráfico 4 - Comparação do grupo Kumon e controle após 6 e 12 meses de treinamento no fator "omissão" do Continuous Performance Test - CPT

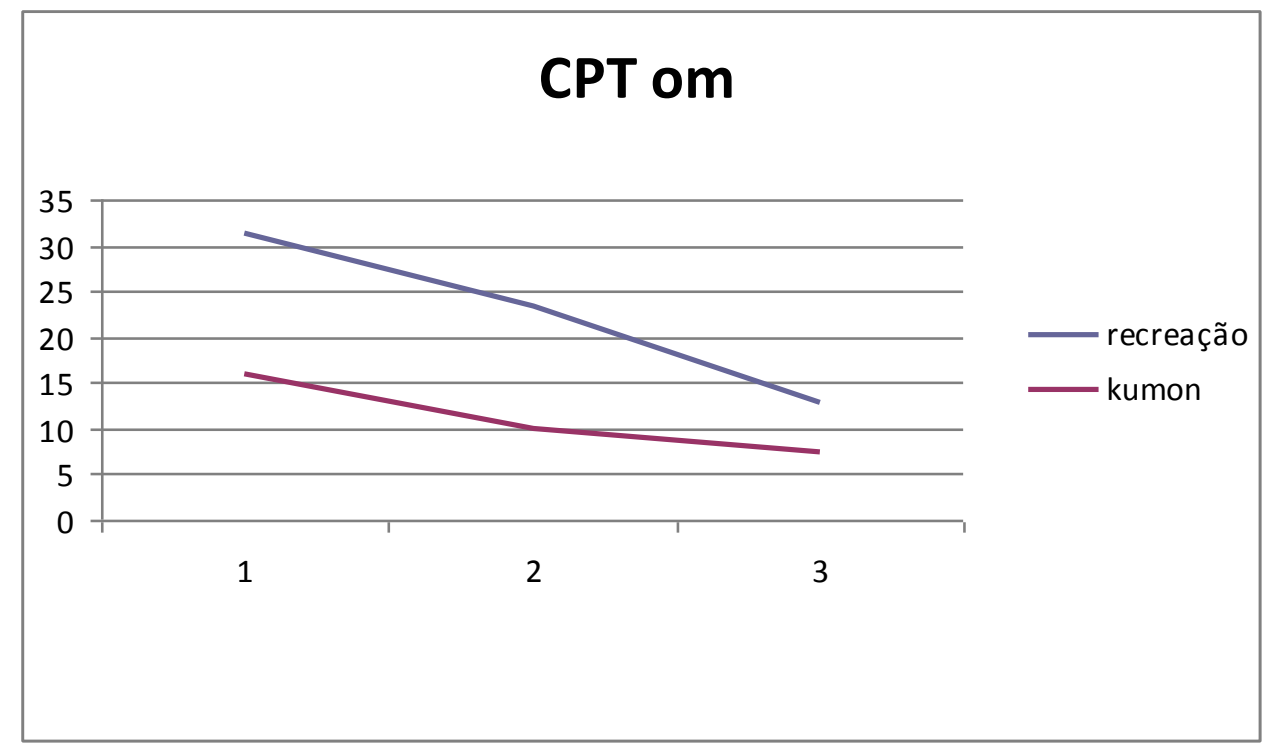


Podemos inferir um desempenho cognitivo no subteste Stroop parte A (cartão 1) superior em cada grupo ao longo do tempo (intra-indivíduos), com diminuição no tempo de resposta. Como separadamente os grupos Kumon e Recreação melhoraram seu desempenho, quando comparados, não demonstraram diferenças significativas (Grupo X Tempo). Em ambos os grupos os ganhos cognitivos se mantiveram após 1 ano, sem diferenças significativas quando comparados.

Gráfico 5 - Comparação do desempenho entre grupo Kumon e controle após 6 e 12 meses de treinamento em sub-teste "Stroop parte A" do Stroop Color-Word Test.

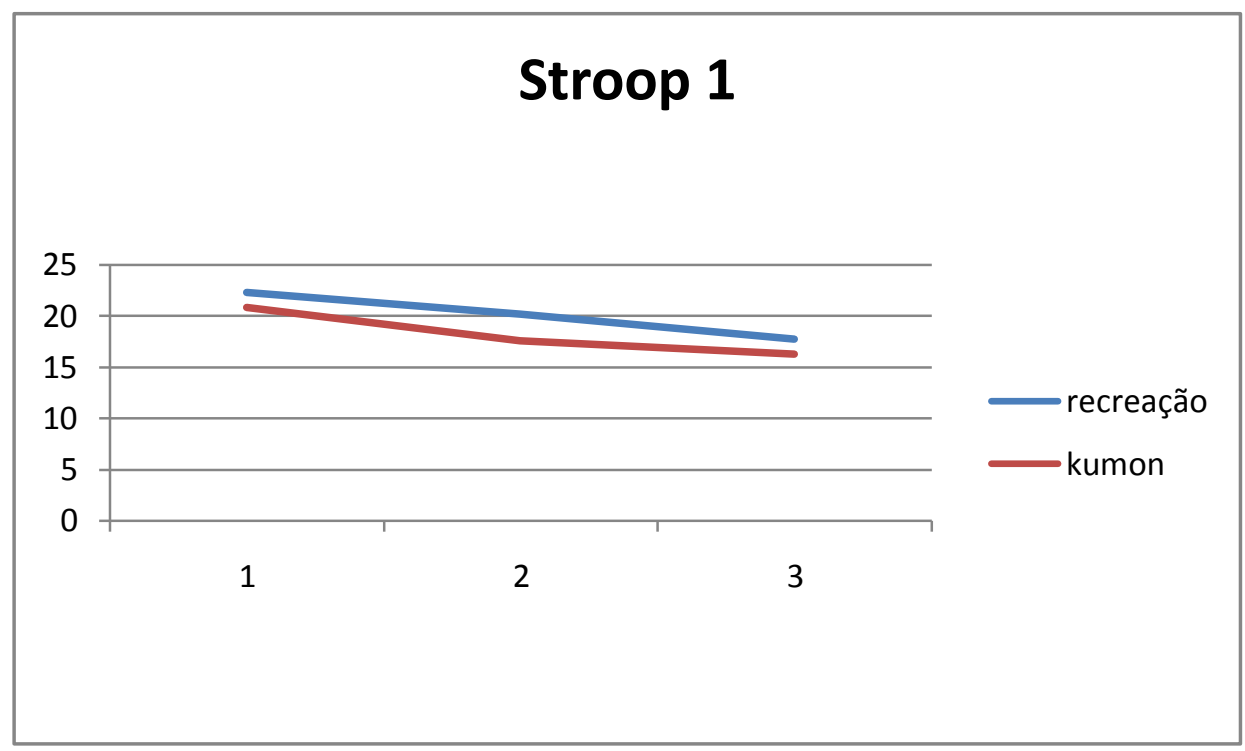


De forma não significativa, o grupo Kumon apresentou menos erros em tarefa atencional parte A do Stroop Color-Word Test após 6 meses de intervenção se comparado ao grupo controle, porém após 6 meses sem atividade este ganho não se manteve.

Gráfico 6 - Comparação da quantidade de erros entre grupo Kumon e controle após 6 e 12 meses de treinamento em sub-teste "Stroop parte A" do Stroop Color-Word Test.

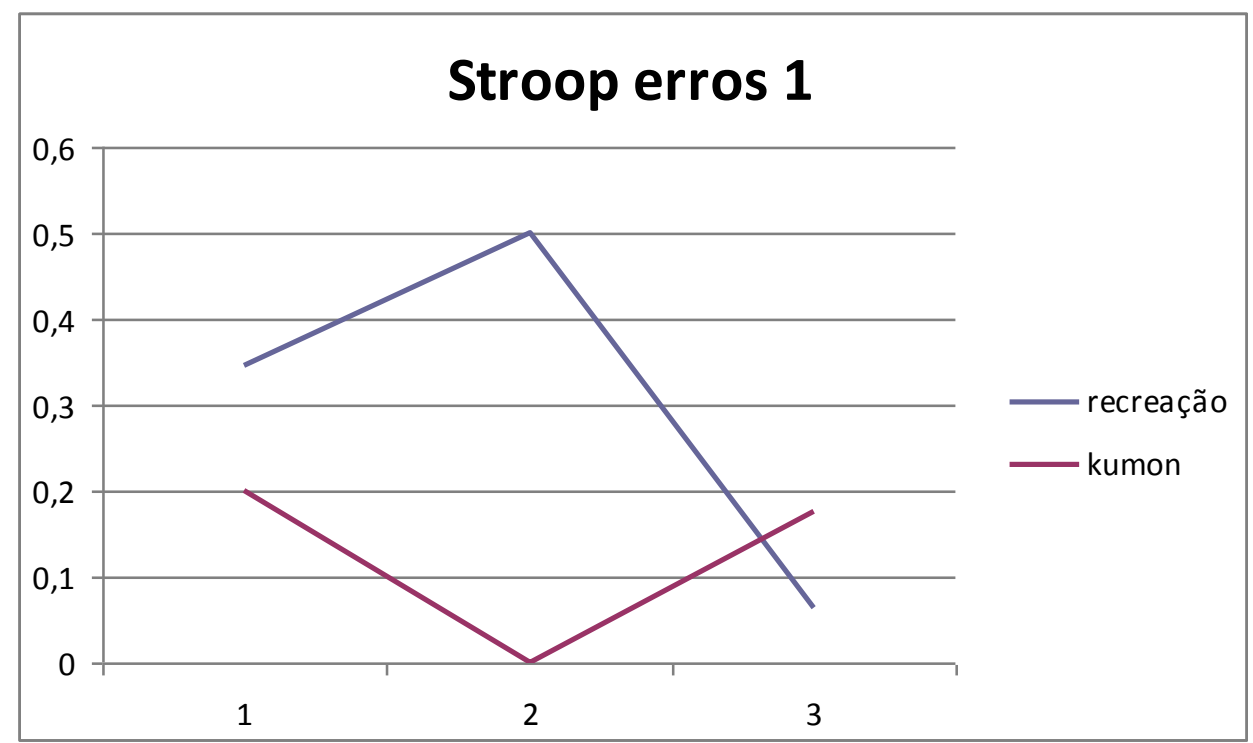

O grupo Kumon apresentou, mesmo que não significativamente, melhor desempenho em memorização de dígitos diretos no subteste do WAIS-III após 6 meses de intervenção, entretanto, esta melhora não conseguiu se manter após 6 meses sem intervenção. 
Resultados

Gráfico 07 - Comparação do grupo Kumon e controle após 6 e 12 meses de treinamento no sub-teste "dígitos de ordem direta" do WISC III

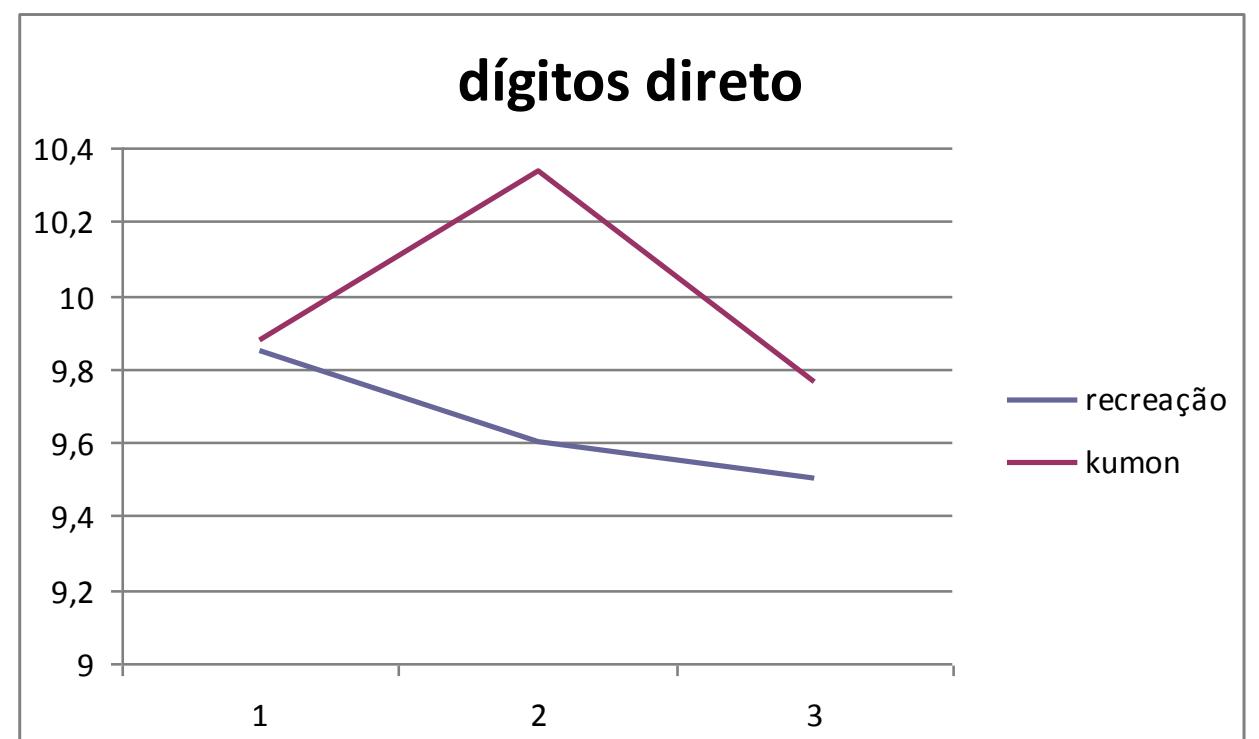

Em relação às medidas avaliadas pelos subtestes comissão, tempo de resposta e variabilidade do Continuous Performance Test e Trail parte A pôde-se observar pouquíssima alteração nas médias de desempenho antes e após 6 meses de treinamento. Estes não apresentaram efeitos de grupo (entre - indivíduos) nem de tempo (intra - indivíduos) e/ou diferenças significativas de interação. 
Resultados

Gráfico 8 - Comparação do grupo Kumon e controle após 6 e 12 meses de treinamento no fator "comissão" do Continuous Performance Test - CPT

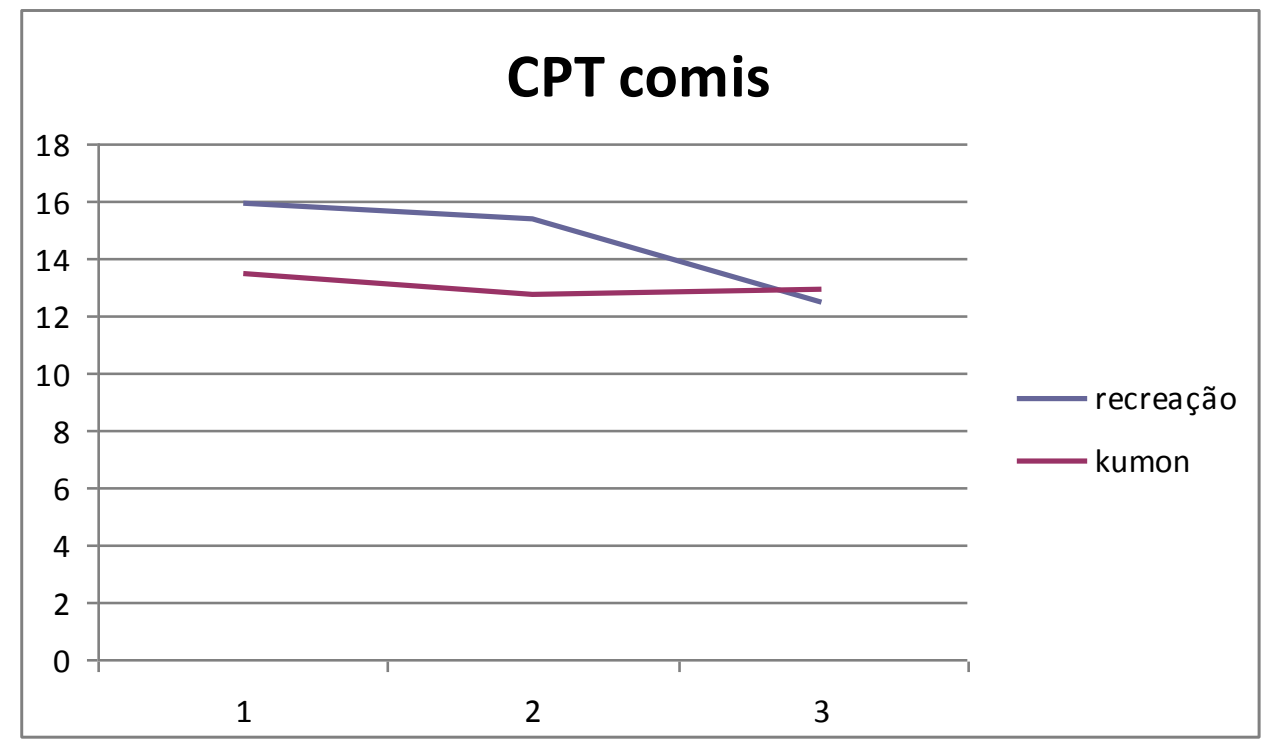

Gráfico 9 - Comparação do grupo Kumon e controle após 6 e 12 meses de treinamento no fator "tempo de resposta" do Continuous Performance Test CPT

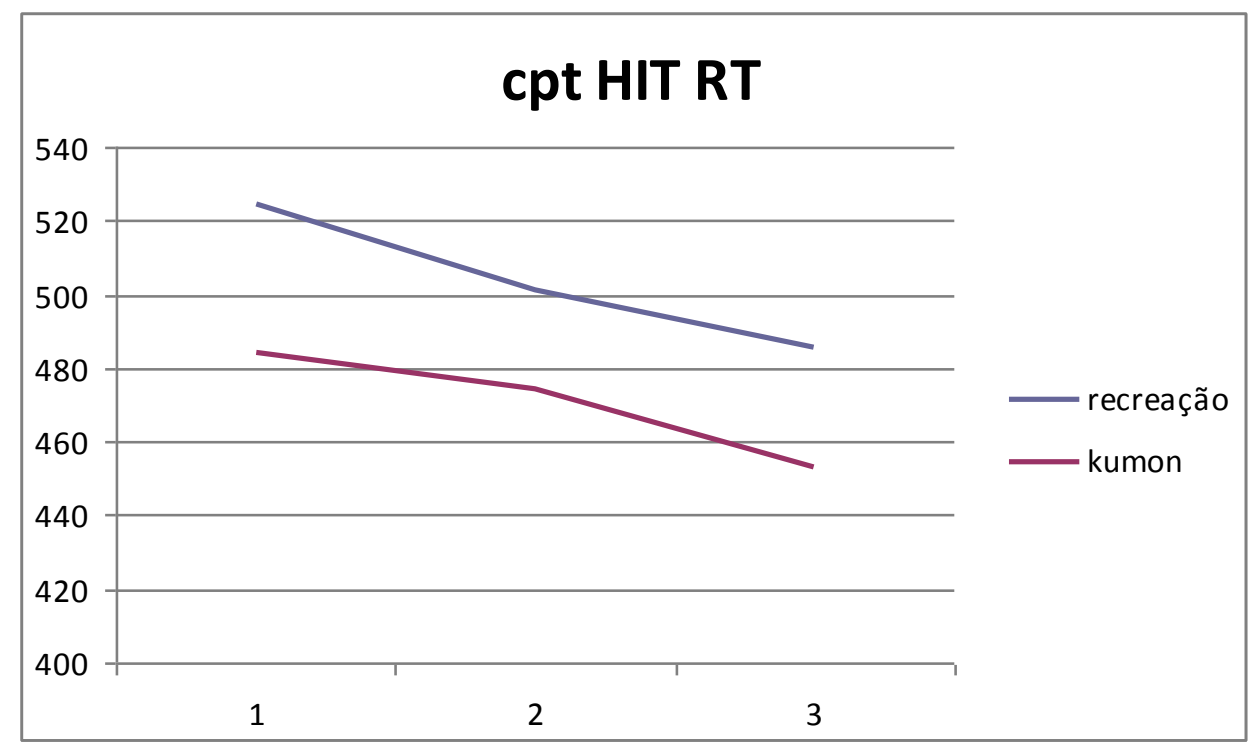


Resultados

Gráfico 10 - Comparação do grupo Kumon e controle após 6 e 12 meses de treinamento no fator "variabilidade" do Continuous Performance Test - CPT

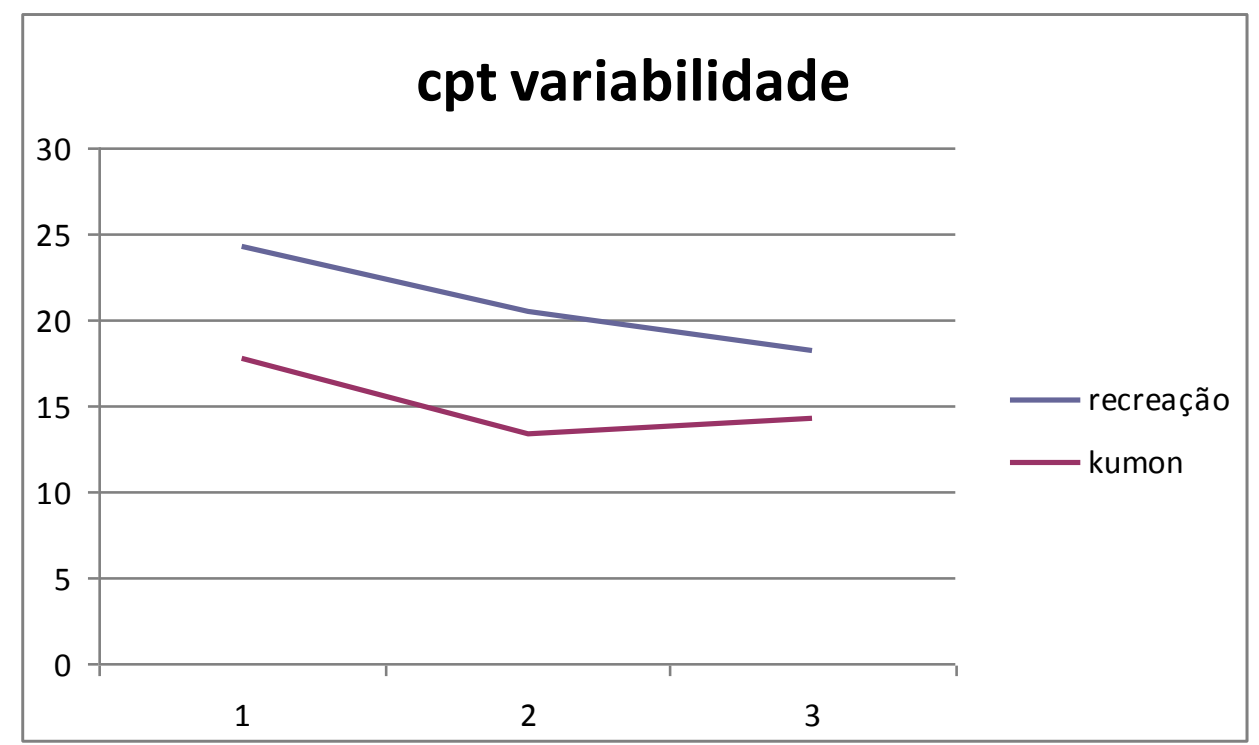

Gráfico 11 - Comparação do grupo Kumon e controle após 6 e 12 meses de treinamento em Trail Making Test parte A

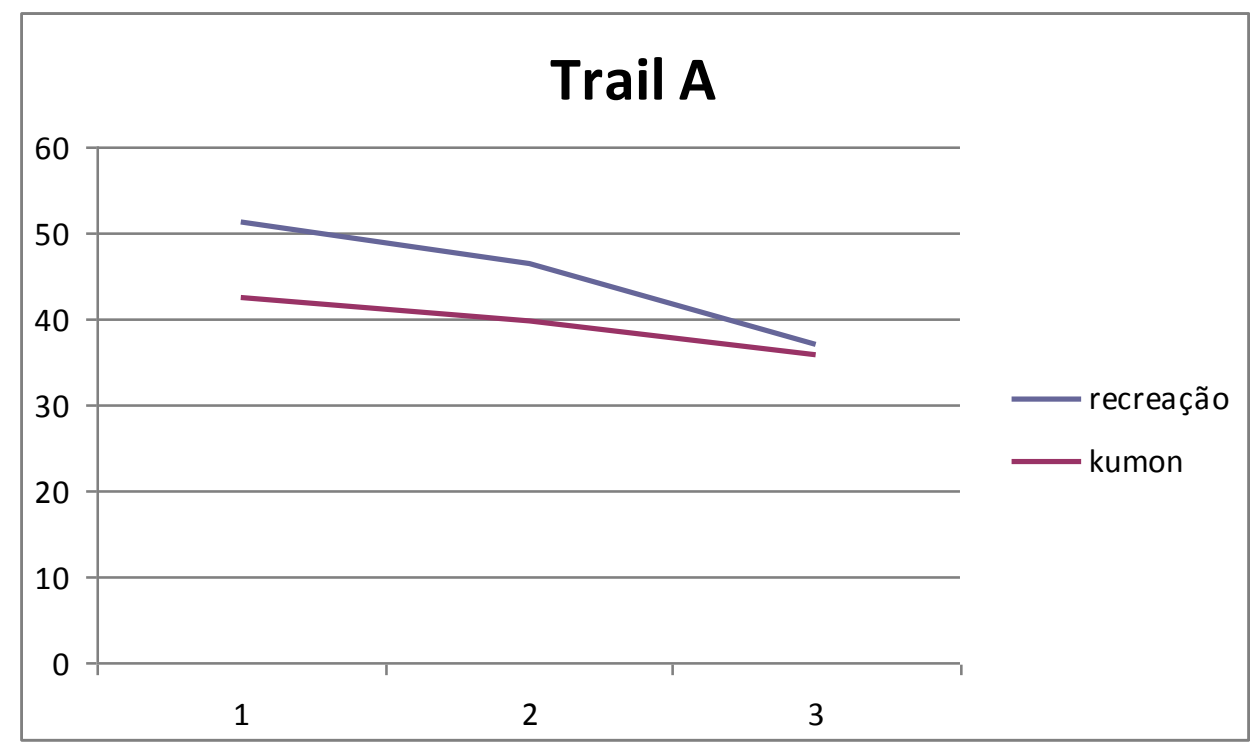




\section{Resultados}

Tabela 22 - Resultados das medidas atencionais

\begin{tabular}{|c|c|c|c|c|c|c|c|c|c|c|}
\hline \multirow[b]{2}{*}{ Instrumentos } & \multirow[b]{2}{*}{ Condição } & \multicolumn{2}{|l|}{ Média $\pm d p$} & \multicolumn{3}{|c|}{ P-valor } & \multicolumn{2}{|l|}{ Média $\pm d p$} & \multicolumn{2}{|l|}{ P-valor } \\
\hline & & Baseline & Tempo 2 & $\begin{array}{l}\text { Entre - } \\
\text { indivíduos }\end{array}$ & $\begin{array}{l}\text { Intra - } \\
\text { indivíduos }\end{array}$ & Interação & Tempo 3 & $\begin{array}{l}\text { Entre - } \\
\text { indivíduos }\end{array}$ & $\begin{array}{l}\text { Intra - } \\
\text { indivíduos }\end{array}$ & Interação \\
\hline CPT_omissão & $\begin{array}{c}\text { Experimental } \\
\text { (n2=19; n3=18) } \\
\text { Controle } \\
(\mathrm{n} 2=18 ; \mathrm{n} 3=16)\end{array}$ & $\begin{array}{l}32,12 \pm 37,35 \\
16,04 \pm 25,43\end{array}$ & $\begin{array}{l}23,20 \pm 24,54 \\
9,83 \pm 10,96\end{array}$ & 0,099 & $0,044^{\star}$ & 0,752 & $\begin{array}{l}7,47 \pm 9,19 \\
12,875 \pm 16,15\end{array}$ & 0,046 & 0,033 & 0,687 \\
\hline CPT_comissão & $\begin{array}{c}\text { Experimental } \\
(\mathrm{n} 2=19 ; \mathrm{n} 3=18) \\
\text { Controle } \\
(\mathrm{n} 2=18 ; \mathrm{n} 3=16)\end{array}$ & $\begin{array}{l}16,52 \pm 6,88 \\
13,50 \pm 9,05\end{array}$ & $\begin{array}{l}15,35 \pm 7,58 \\
12,72 \pm 8,14\end{array}$ & 0,340 & 0,658 & 0,843 & $\begin{array}{l}12,88 \pm 9,90 \\
12,43 \pm 7,22\end{array}$ & 0,541 & 0,416 & 0,550 \\
\hline CPT_HitRT & $\begin{array}{c}\text { Experimental } \\
\text { (n2=19; n3=18) } \\
\text { Controle } \\
\text { (n2=18; n3= 16) }\end{array}$ & $\begin{array}{l}521,11 \pm 131,01 \\
484,34 \pm 112,69\end{array}$ & $\begin{array}{l}501,16 \pm 96,39 \\
474,28 \pm 82,49\end{array}$ & 0,193 & 0,379 & 0,921 & $\begin{array}{c}453 \\
12 \pm 98,46 \\
485,52 \pm 13 \\
98\end{array}$ & 0,145 & 0,234 & 0,993 \\
\hline CPT_variabilidade & $\begin{array}{c}\text { Experimental } \\
\text { (n2=19; n3=18) } \\
\text { Controle } \\
(\mathrm{n} 2=18 ; \mathrm{n} 3=16)\end{array}$ & $\begin{array}{l}24,66 \pm 17,84 \\
17,65 \pm 22,00\end{array}$ & $\begin{array}{l}20,48 \pm 13,71 \\
13,39 \pm 11,75\end{array}$ & 0,208 & 0,423 & 0,881 & $\begin{array}{l}14,16 \pm 8,91 \\
18,11 \pm 13,98\end{array}$ & 0,216 & 0,309 & 0,690 \\
\hline $\begin{array}{l}\text { Trail_A (em } \\
\text { segundos) }\end{array}$ & $\begin{array}{c}\text { Experimental } \\
(\mathrm{n} 2=19 ; \mathrm{n} 3=18) \\
\text { Controle } \\
(\mathrm{n} 2=18 ; \mathrm{n} 3=16)\end{array}$ & $\begin{array}{l}51,28 \pm 27,41 \\
39,96 \pm 17,60\end{array}$ & $\begin{array}{l}46,45 \pm 36,61 \\
39,78 \pm 16,28\end{array}$ & 0,227 & 0,277 & 0,640 & $\begin{array}{l}35,70 \pm 13,14 \\
37,00 \pm 14,31\end{array}$ & 0,306 & 0,072 & 0,776 \\
\hline
\end{tabular}




\section{Resultados}

\begin{tabular}{|c|c|c|c|c|c|c|c|c|c|c|}
\hline & & Média $\pm d p$ & & & P-valor & & Média $\pm d p$ & & P-valor & \\
\hline Instrumentos & Condição & Baseline & Tempo 2 & $\begin{array}{c}\text { Entre - } \\
\text { indivíduos }\end{array}$ & $\begin{array}{c}\text { Intra - } \\
\text { indivíduos }\end{array}$ & Interação & Tempo 3 & $\begin{array}{c}\text { Entre - } \\
\text { indivíduos }\end{array}$ & $\begin{array}{c}\text { Intra - } \\
\text { indivíduos }\end{array}$ & Interação \\
\hline Trail_A (erros) & $\begin{array}{c}\text { Experimental } \\
\text { (n2=19; n3=18) } \\
\text { Controle } \\
(n 2=18 ; n 3=16)\end{array}$ & $\begin{array}{l}0,72 \pm 1,67 \\
0,84 \pm 1,81\end{array}$ & $\begin{array}{l}0,05 \pm 0,23 \\
0,55 \pm 0,88\end{array}$ & 0,228 & 0,062 & 0,722 & $\begin{array}{l}0,11 \pm 0,33 \\
0,25 \pm 0,77\end{array}$ & 0,288 & 0,062 & 0,722 \\
\hline Stroop Test_A & $\begin{array}{c}\text { Experimental } \\
\text { (n2=19; n3=18) } \\
\text { Controle } \\
(n 2=18 ; n 3=16)\end{array}$ & $\begin{array}{c}21,60 \pm 7,40 \\
20,57 \pm 14,60\end{array}$ & $\begin{array}{l}20,20 \pm 6,65 \\
17,56 \pm 3,79\end{array}$ & 0,944 & $0,001^{*}$ & 0,221 & $\begin{array}{l}16,29 \pm 4,45 \\
17,75 \pm 3,51\end{array}$ & 0,607 & 0,091 & 0,981 \\
\hline $\begin{array}{c}\text { Stroop Test_A } \\
\text { (erros) }\end{array}$ & $\begin{array}{c}\text { Experimental } \\
\text { (n2=19; n3=18) } \\
\text { Controle } \\
\text { (n2=18; n3=16) }\end{array}$ & $0,34 \pm 1,29$ & $0,5 \pm 1,79$ & 0,400 & 0,661 & 0,135 & $\begin{array}{l}0,17 \pm 0,52 \\
0,06 \pm 0,25\end{array}$ & 0,400 & 0,661 & 0,135 \\
\hline Dígitos_direto & $\begin{array}{c}\text { Experimental } \\
\text { (n2=19; n3=18) } \\
\text { Controle } \\
(\mathrm{n} 2=18 ; \mathrm{n} 3=16)\end{array}$ & $9,88 \pm 2,79$ & $\begin{array}{l}9,60 \pm 2,82 \\
10,33 \pm 3,24\end{array}$ & 0,966 & 0,434 & $0,080^{*}$ & $\begin{array}{r}9,76 \pm 3,54 \\
9,50 \pm 2,33\end{array}$ & 0,506 & 0,730 & 0,578 \\
\hline
\end{tabular}


Resultados

\section{Avaliação da função executiva}

Em relação à avaliação de função executiva, pôde-se observar uma tendência do desempenho cognitivo do sub-teste "categorias completas" e quantidade de "respostas perseverativas" (Wisconsin Card Test) apresentarem diferenças significativas em ambos os grupos (entreindivíduos). No entanto, não foi encontrado efeito de tempo significativo e interação entre os grupos, demonstrando ausência de diferença significativa entre os grupos de desempenho neste quesito após 6 meses de intervenção, conforme apresentado na tabela 23. Após 1 ano de estudo, os resultados praticamente mantiveram-se estáveis.

Gráfico 12 - Comparação do desempenho entre grupo Kumon e controle após 6 e 12 meses de treinamento em sub-teste "Wisconsin Card testcategorias completas"

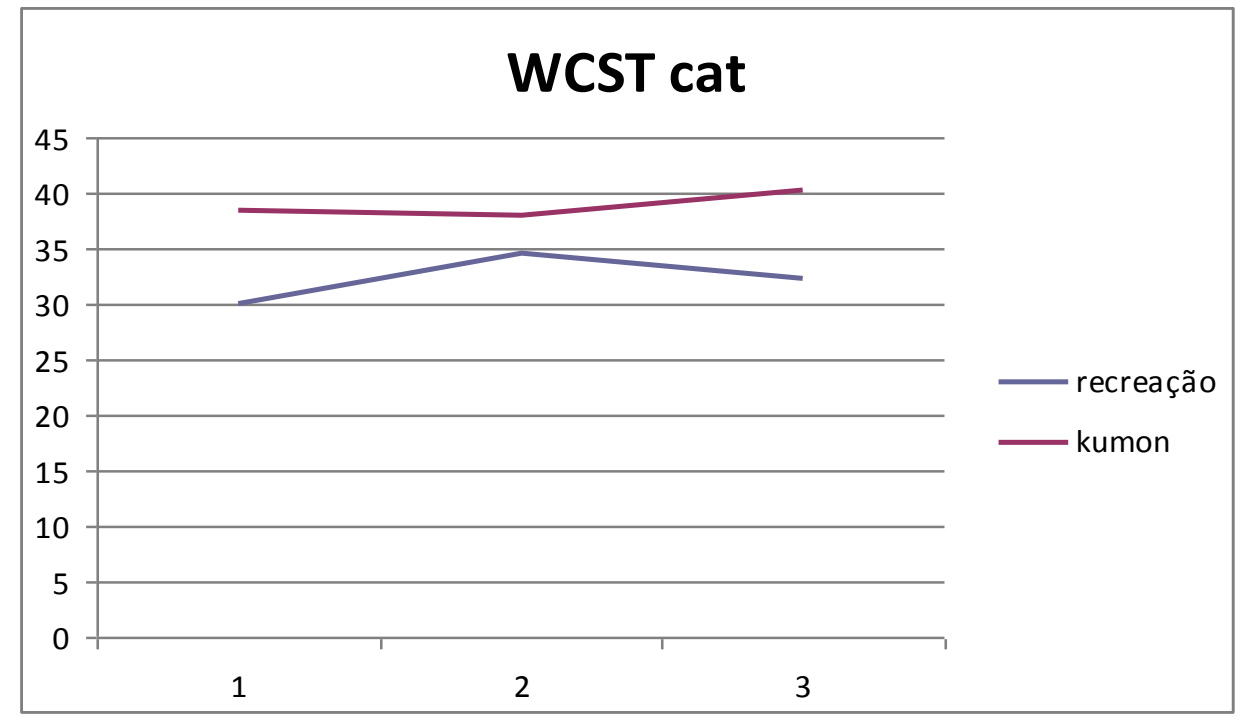


Gráfico 13 - Comparação do desempenho entre grupo Kumon e controle após 6 e 12 meses de treinamento em sub-teste "respostas perseverativas" do Wisconsin Card Test

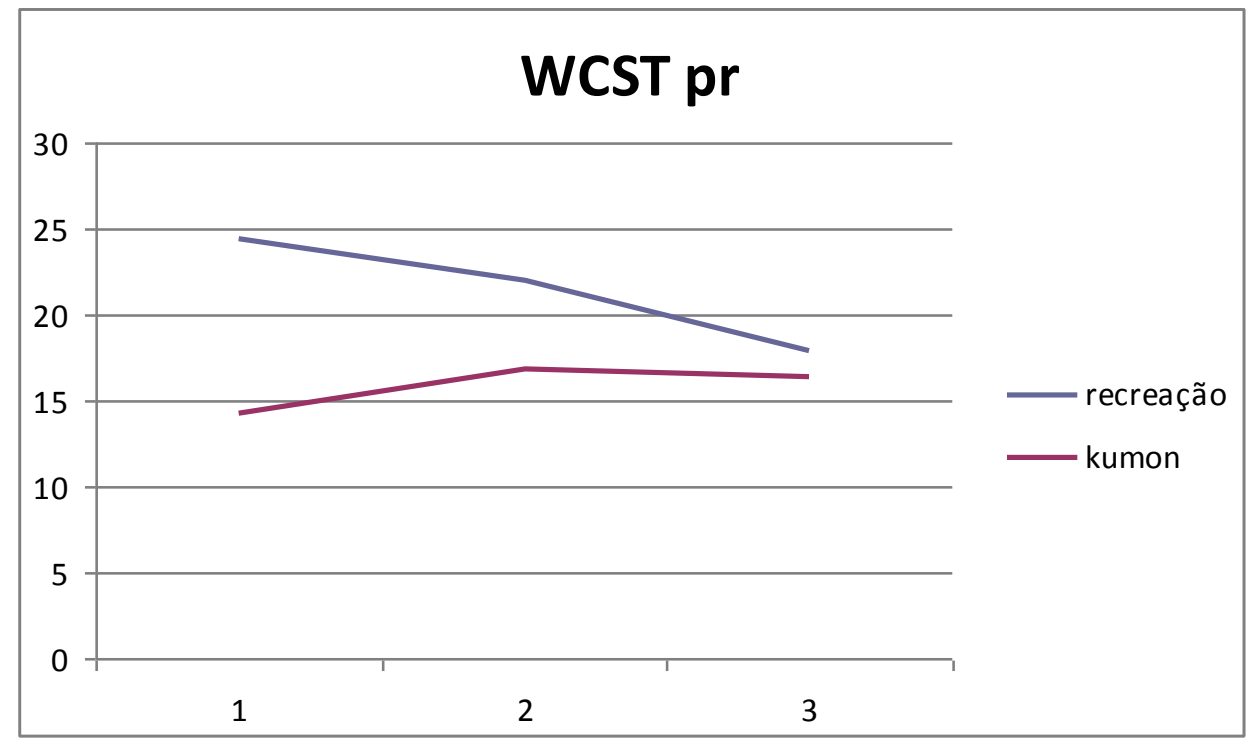

O tempo decorrente do controle inibitório do sub-teste Stroop Color Word Test parte B (cartão 2) se apresenta diferente ao longo do tempo, indicando melhora de desempenho em ambos os grupos. No entanto, por não ter sido encontrado efeito de interação significativo, não é possível avaliar qual grupo melhorou mais ao longo do tempo. Após 6 meses sem atividade, ambos os grupos mantiveram a melhora de desempenho, sem diferença significativa de resultados quando comparados. 
Gráfico 14 - Comparação do desempenho entre grupo Kumon e controle após 6 e 12 meses de treinamento em sub-teste "Stroop parte B" do Stroop Color-Word Test.

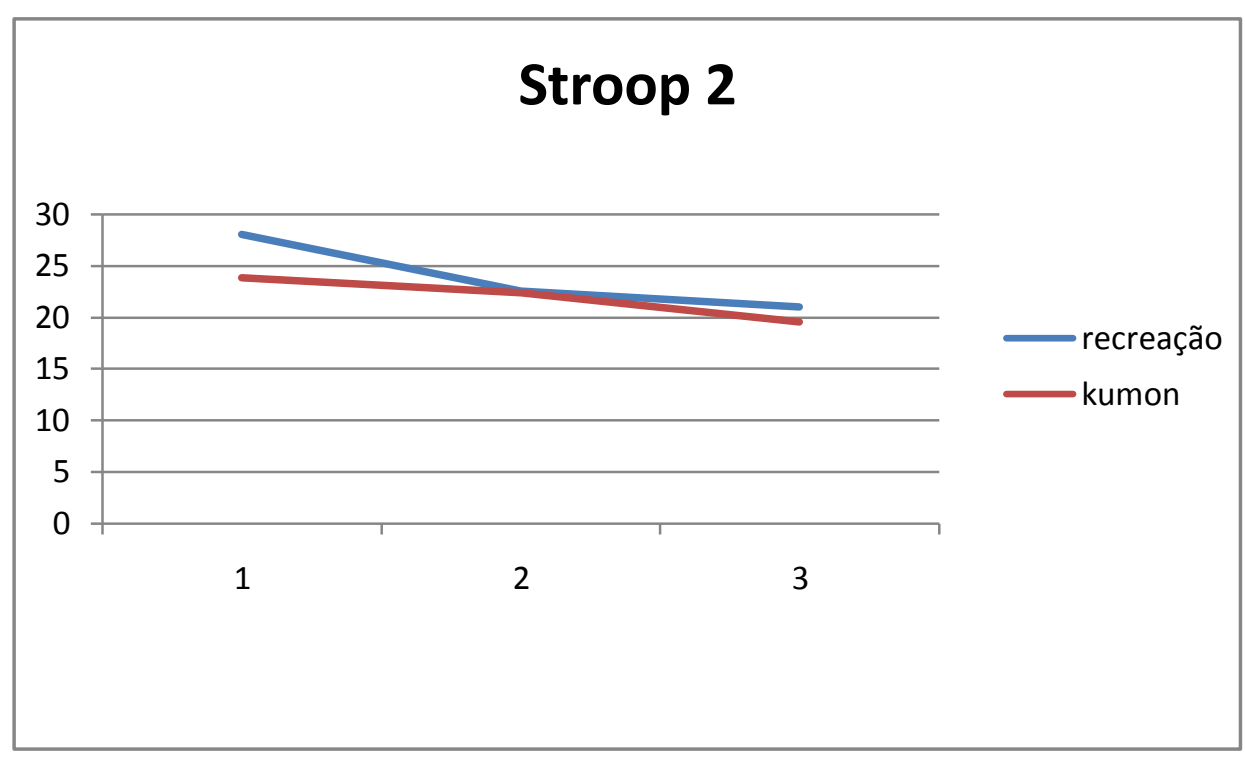

Ambos os grupos também apresentaram menor ocorrência de erros em tarefa de controle inibitório do Stroop parte B ao longo do tempo de 6 meses de atividade (intra-indivíduos), porém não significativo. Quando comparados também não apresentaram diferenças significativas. Após 6 meses sem atividade os dois grupos passaram a demonstrar mais erros, entretanto, não significativo. Quando comparados também não mostraram diferenças significativas. 
Gráfico 15 - Comparação do desempenho entre grupo Kumon e controle após 6 e 12 meses de treinamento em sub-teste "Stroop parte B" do Stroop Color-Word Test

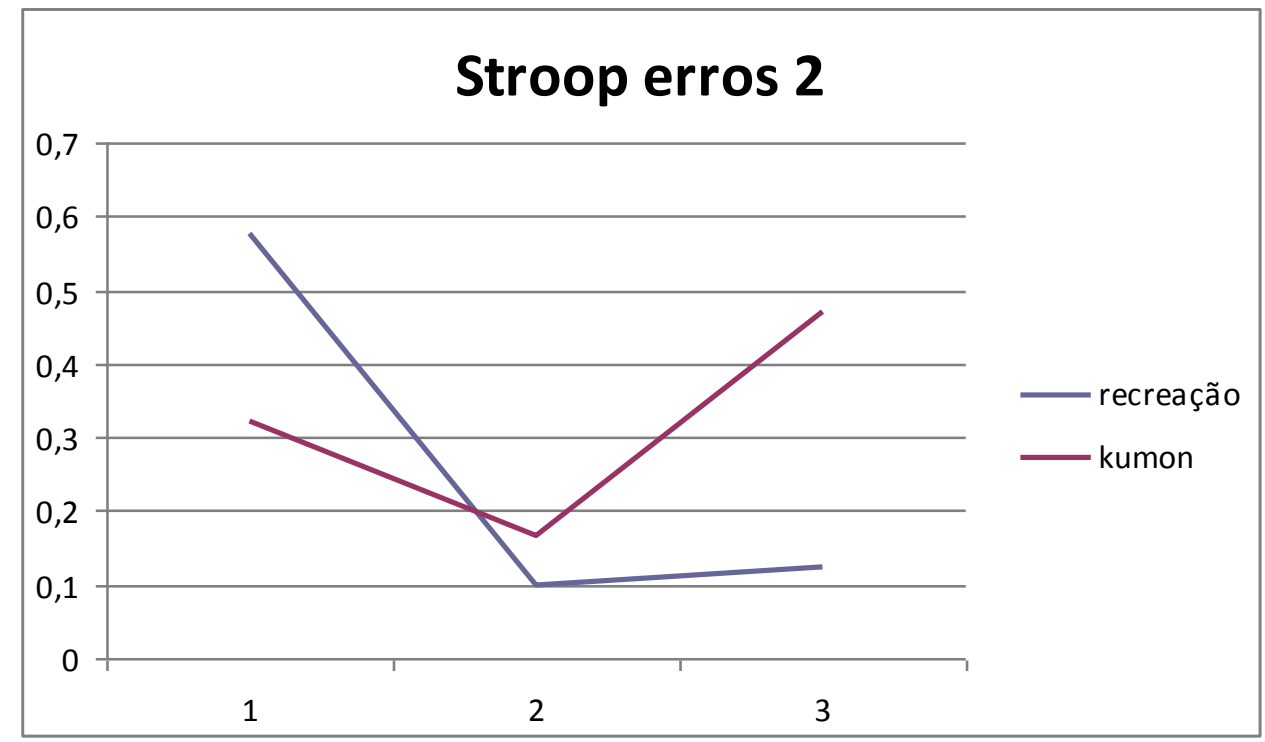

Não foi encontrado efeitos significativos nos seguintes sub-testes: Stroop Color Word Test parte c (cartão 3), Stroop Color Word Test parte c (cartão 3) erros, Trail Making Test parte B; os itens "erros não perseverativos e perda de set" do Wisconsin Card Test. 
Resultados

Gráfico 16 - Comparação do desempenho entre grupo Kumon e controle após 6 e 12 meses de treinamento em sub-teste "Stroop parte C" do Stroop Color-Word Test

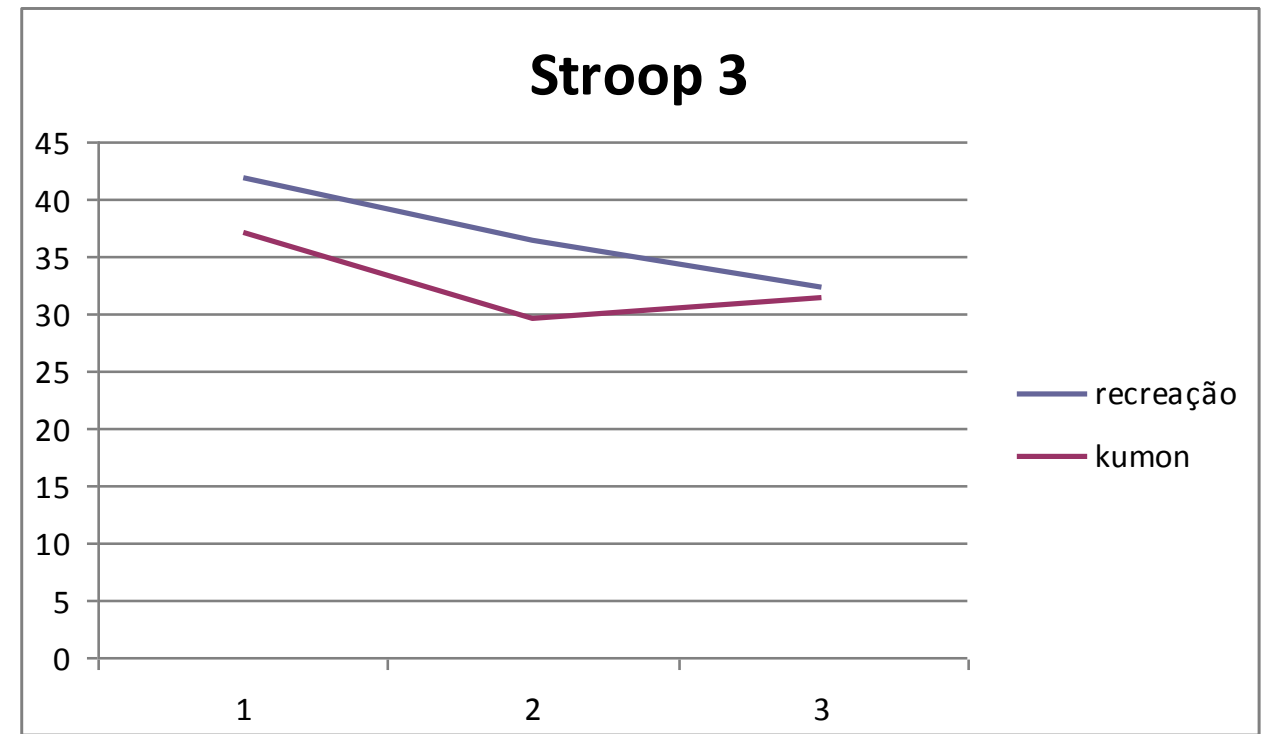

Gráfico 17 - Comparação da quantidade de erros entre grupo Kumon e controle após 6 e 12 meses de treinamento em sub-teste "Stroop parte C" do Stroop Color-Word Test

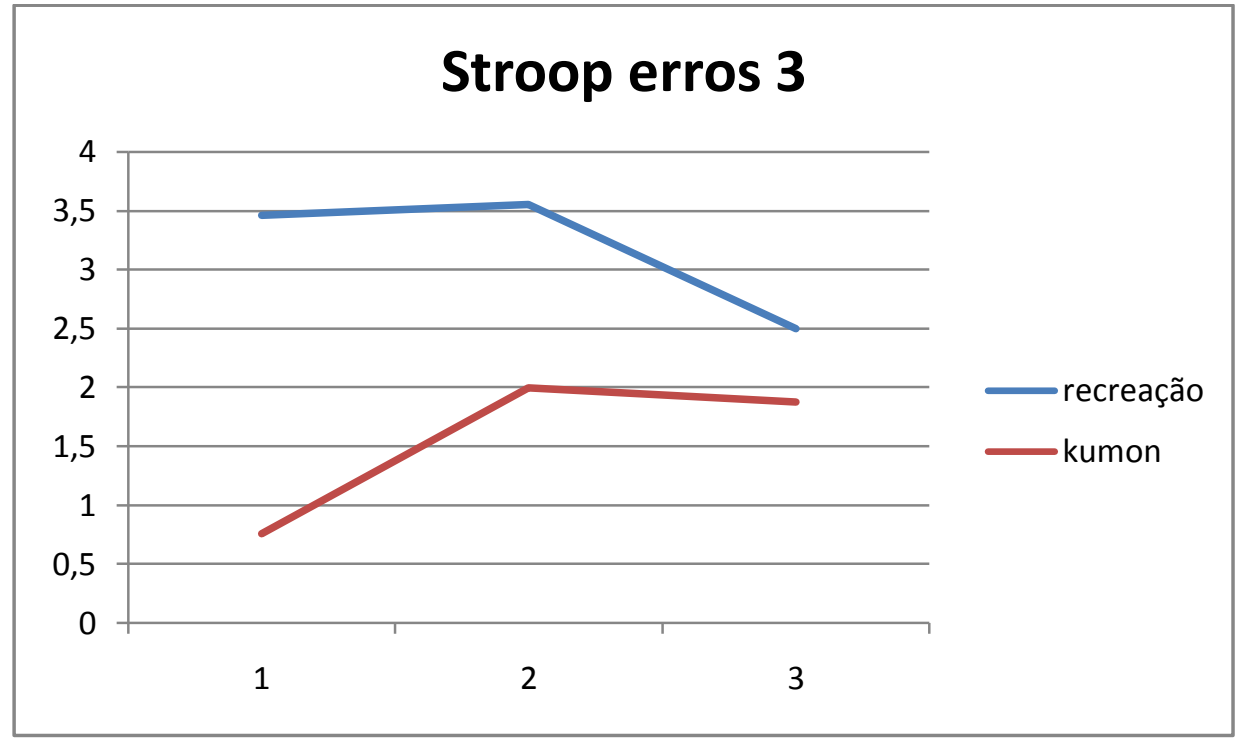


Resultados

Gráfico 18 - Comparação do desempenho entre grupo Kumon e controle após 6 e 12 meses de treinamento em sub-teste "Trail Making Test parte B"

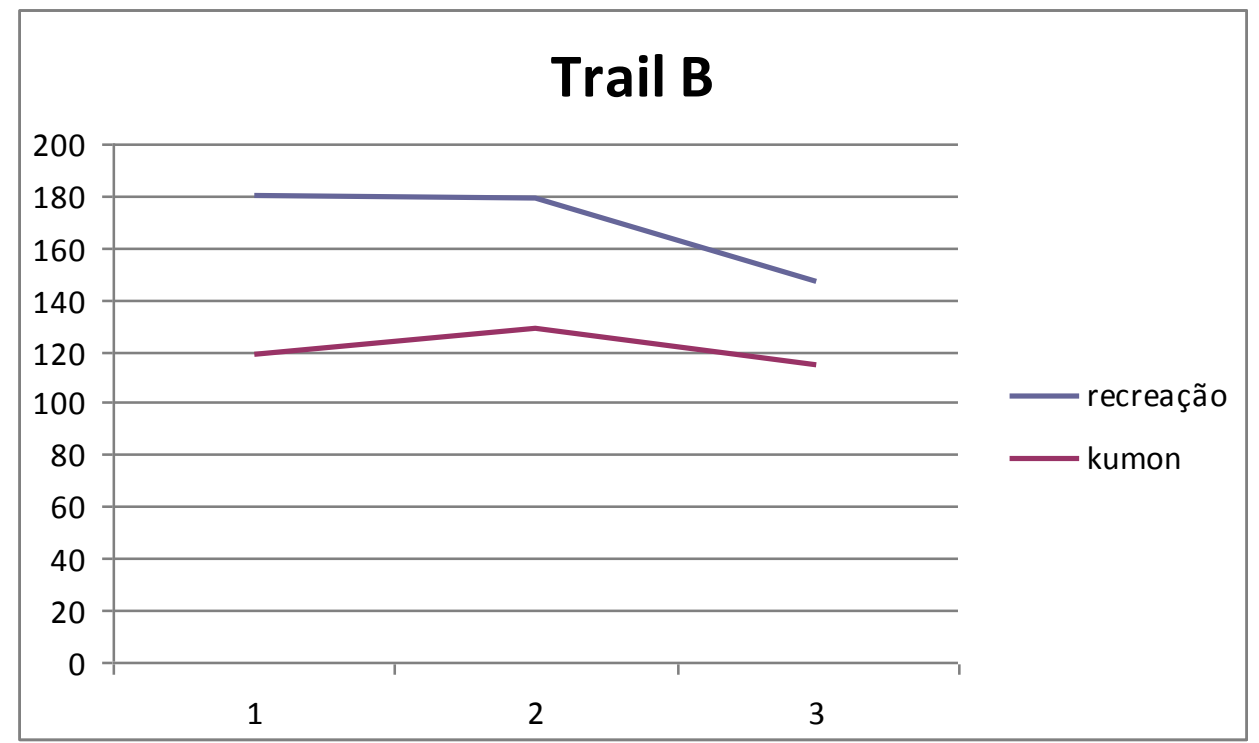

Gráfico 19 - Comparação do desempenho entre grupo Kumon e controle após 6 e 12 meses de treinamento em sub-teste "Wisconsin Card test- erros não perseverativos"

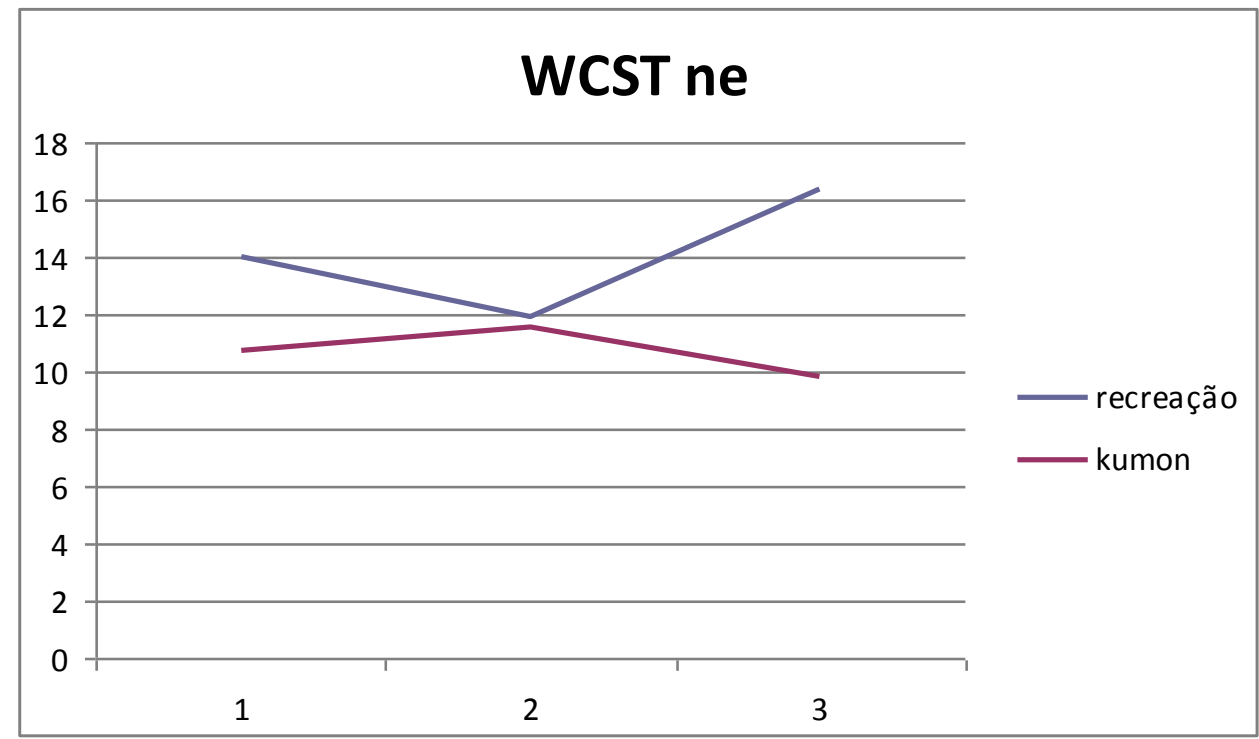


Resultados

Gráfico 20 - Comparação do desempenho entre grupo Kumon e controle após 6 e 12 meses de treinamento em sub-teste "Wisconsin Card testperda de set"

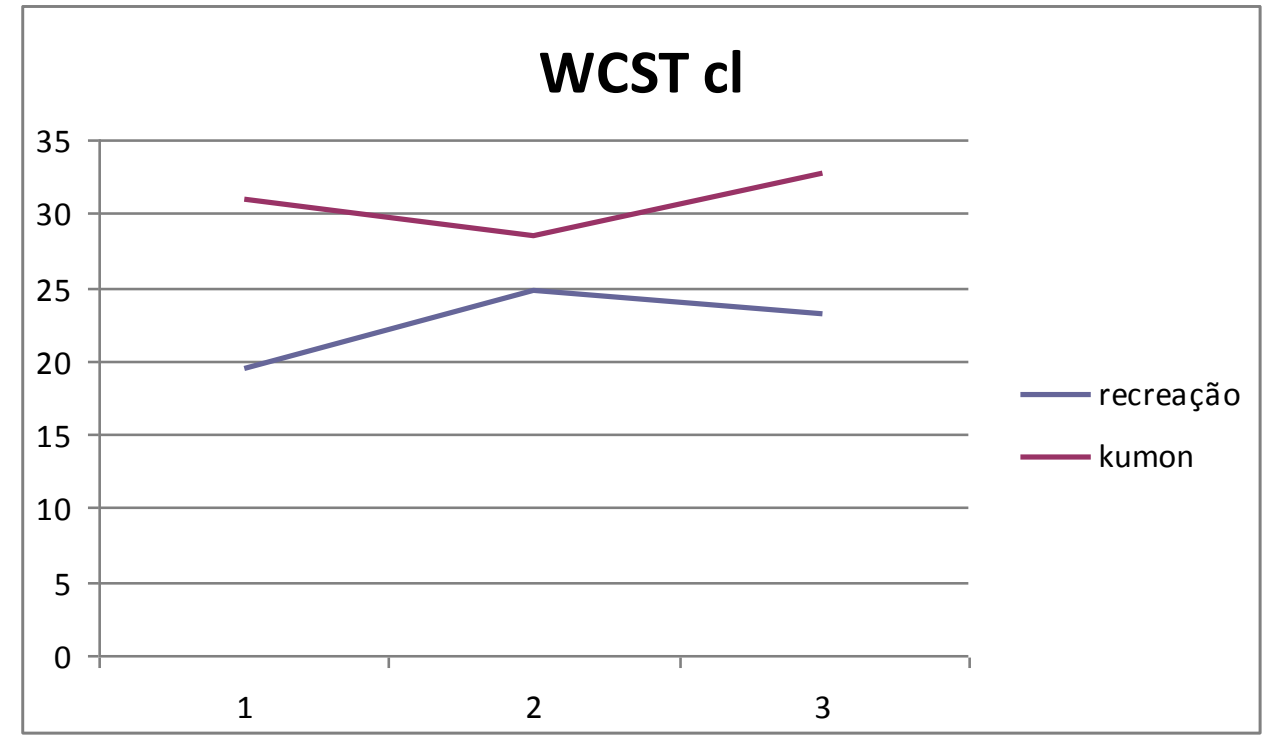

Gráfico 21 - Comparação do desempenho entre grupo Kumon e controle após 6 e 12 meses de treinamento em sub-teste "dígitos ordem indireta "do WAIS III

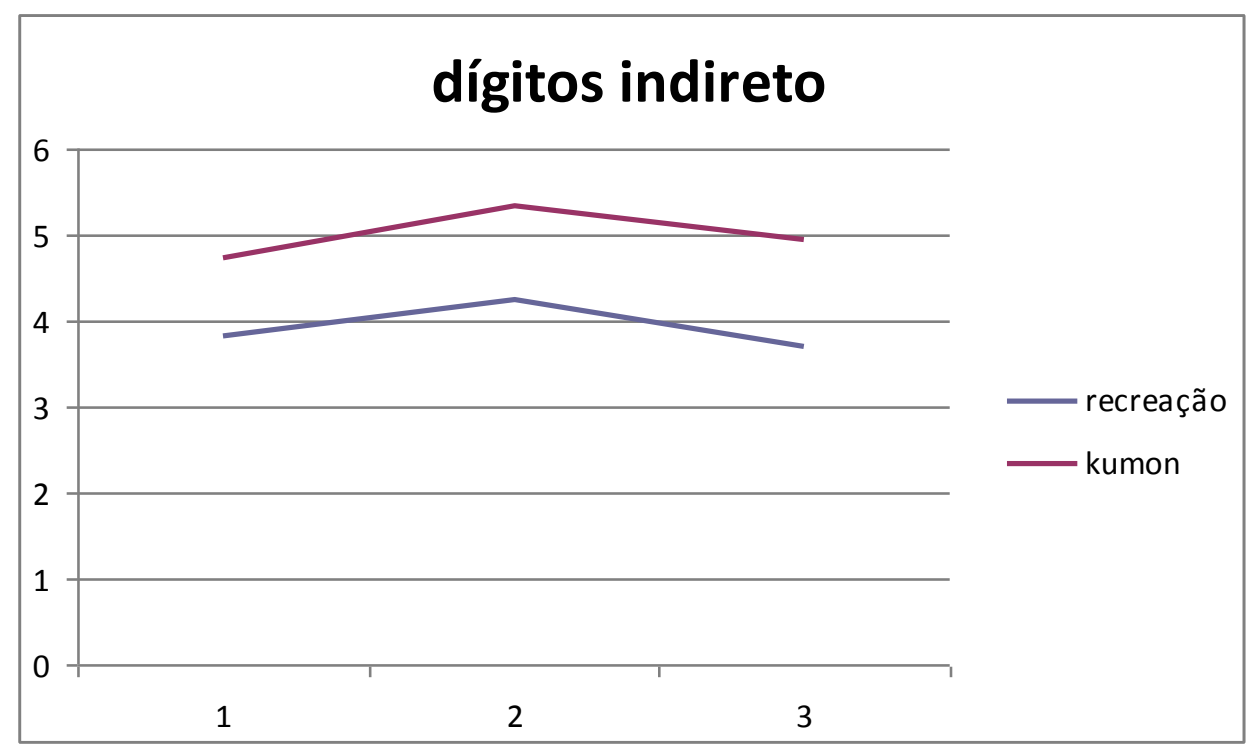


Resultados

Tabela 23 - Resultados da função executiva

\begin{tabular}{|c|c|c|c|c|c|c|c|c|c|c|}
\hline \multirow[b]{2}{*}{ Instrumentos } & \multirow[b]{2}{*}{ Condição } & \multicolumn{2}{|l|}{ Média $\pm d p$} & \multicolumn{3}{|c|}{ P-valor } & \multirow{2}{*}{$\begin{array}{c}\text { Média } \pm d p \\
\text { Tempo } 3\end{array}$} & \multicolumn{3}{|c|}{ P-valor } \\
\hline & & Baseline & Tempo 2 & $\begin{array}{c}\text { Entre - } \\
\text { indivíduos }\end{array}$ & $\begin{array}{c}\text { Intra - } \\
\text { indivíduos }\end{array}$ & Interação & & $\begin{array}{c}\text { Entre - } \\
\text { indivíduos }\end{array}$ & $\begin{array}{c}\text { Intra - } \\
\text { indivíduos }\end{array}$ & Interação \\
\hline $\begin{array}{c}\text { Trail Making_parte B } \\
\text { (em segundos) }\end{array}$ & $\begin{array}{c}\text { Experimental } \\
\text { (n2=19; } 33=18) \\
\text { Controle } \\
(n 2=18 ; n 3=16)\end{array}$ & $\begin{array}{l}179,64 \pm 124,92 \\
112,83 \pm 69,34\end{array}$ & $\begin{array}{l}178,55 \pm 150,02 \\
129,00 \pm 75,89\end{array}$ & 0,055 & 0,541 & 0,740 & $\begin{array}{l}114,11 \pm 80,17 \\
146,93 \pm 72,60\end{array}$ & $0,047^{*}$ & 0,239 & 0,872 \\
\hline $\begin{array}{c}\text { WCST_categorias } \\
\text { completas }\end{array}$ & $\begin{array}{c}\text { Experimental } \\
\text { (n2=19; } 33=18) \\
\text { Controle } \\
(n 2=18 ; n 3=16)\end{array}$ & $\begin{array}{l}1,20 \pm 1,35 \\
1,88 \pm 1,30\end{array}$ & $\begin{array}{l}1,65 \pm 1,63 \\
1,72 \pm 1,41\end{array}$ & 0,066 & 0,207 & 0,221 & $\begin{array}{l}2,17 \pm 2,06 \\
1,31 \pm 1,44\end{array}$ & 0,108 & 0,779 & 0,399 \\
\hline $\begin{array}{c}\text { WCST_respostas } \\
\text { perseverativas }\end{array}$ & $\begin{array}{c}\text { Experimental } \\
\text { (n2=19; n3=18) } \\
\text { Controle } \\
(\mathrm{n} 2=18 ; \mathrm{n} 3=16)\end{array}$ & $\begin{array}{l}23,96 \pm 15,86 \\
14,38 \pm 10,77\end{array}$ & $\begin{array}{l}21,95 \pm 18,13 \\
16,78 \pm 9,05\end{array}$ & $0,010^{*}$ & 0,644 & 0,353 & $\begin{array}{l}16,35 \pm 13,38 \\
17,93 \pm 13,56\end{array}$ & 0,085 & 0,444 & 0,215 \\
\hline $\begin{array}{c}\text { WCST_erros não } \\
\text { perseverativos }\end{array}$ & $\begin{array}{c}\text { Experimental } \\
\text { (n2=19; n3=18) } \\
\text { Controle } \\
(\mathrm{n} 2=18 ; \mathrm{n} 3=16)\end{array}$ & $\begin{array}{l}14,32 \pm 9,63 \\
11,08 \pm 4,44\end{array}$ & $\begin{array}{l}11,90 \pm 9,35 \\
11,56 \pm 6,24\end{array}$ & 0,128 & 0,237 & 0,229 & $\begin{array}{l}9,82 \pm 7,57 \\
16,37 \pm 13,50\end{array}$ & 0,104 & 0,585 & 0,094 \\
\hline $\begin{array}{c}\text { WCST_falhas para } \\
\text { manter o set }\end{array}$ & $\begin{array}{c}\text { Experimental } \\
\text { (n2=19; n3=18) } \\
\text { Controle } \\
(\mathrm{n} 2=18 ; \mathrm{n} 3=16)\end{array}$ & $\begin{array}{l}0,48 \pm 0,71 \\
0,92 \pm 0,83\end{array}$ & $\begin{array}{l}0,50 \pm 1,19 \\
0,67 \pm 0,91\end{array}$ & 0,103 & 0,875 & 0,488 & $\begin{array}{l}0,64 \pm 0,99 \\
0,64 \pm 0,99\end{array}$ & 0,297 & 0,886 & 0,581 \\
\hline $\begin{array}{l}\text { Stroop Color Word } \\
\text { Test_parte B ( em } \\
\text { segundos) }\end{array}$ & $\begin{array}{c}\text { Experimental } \\
\text { (n2=19; n3=18) } \\
\text { Controle } \\
(\mathrm{n} 2=18 ; \mathrm{n} 3=16)\end{array}$ & $\begin{array}{l}27,40 \pm 11,60 \\
23,83 \pm 16,47\end{array}$ & $\begin{array}{l}22,55 \pm 6,10 \\
22,39 \pm 6,63\end{array}$ & 0,228 & $0,042^{*}$ & 0,107 & $\begin{array}{l}19,58 \pm 6,72 \\
21,00 \pm 5,44\end{array}$ & 0,705 & 0,108 & 0,085 \\
\hline
\end{tabular}


Resultados

\begin{tabular}{|c|c|c|c|c|c|c|c|c|c|c|}
\hline & & Média $\pm d p$ & & & P-valor & & Média $\pm d p$ & & P-valor & \\
\hline Instrumentos & Condição & Baseline & Tempo 2 & $\begin{array}{c}\text { Entre - } \\
\text { indivíduos }\end{array}$ & $\begin{array}{c}\text { Intra - } \\
\text { indivíduos }\end{array}$ & Interação & Tempo 3 & $\begin{array}{c}\text { Entre - } \\
\text { indivíduos }\end{array}$ & $\begin{array}{c}\text { Intra - } \\
\text { indivíduos }\end{array}$ & Interação \\
\hline $\begin{array}{l}\text { Stroop Color Word } \\
\text { Test_parte B (erros) }\end{array}$ & $\begin{array}{c}\text { Experimental } \\
\text { (n2=19; } \mathrm{n} 3=18) \\
\text { Controle } \\
(\mathrm{n} 2=18 ; \mathrm{n} 3=16)\end{array}$ & $\begin{array}{l}0,32 \pm 1,21 \\
0,57 \pm 1,36\end{array}$ & $\begin{array}{l}0,16 \pm 0,51 \\
0,1 \pm 0,30\end{array}$ & 0,795 & 0,319 & 0,390 & $\begin{array}{l}0,47 \pm 1,17 \\
0,12 \pm 0,34\end{array}$ & 0,795 & 0,319 & 0,390 \\
\hline $\begin{array}{l}\text { Stroop Color Word } \\
\text { Test_parte C (em } \\
\text { segundos) }\end{array}$ & $\begin{array}{c}\text { Experimental } \\
\text { (n2=19; } n 3=18) \\
\text { Controle } \\
(\mathrm{n} 2=18 ; \mathrm{n} 3=16)\end{array}$ & $\begin{array}{l}41,60 \pm 18,22 \\
37,13 \pm 21,68\end{array}$ & $\begin{array}{l}36,35 \pm 13,01 \\
29,61 \pm 11,46\end{array}$ & 0,358 & 0,300 & 0,990 & $\begin{array}{l}31,41 \pm 14,90 \\
32,18 \pm 11,77\end{array}$ & 0,528 & 0,239 & 0,529 \\
\hline $\begin{array}{l}\text { Stroop Color Word } \\
\text { Test_parte C( erros) }\end{array}$ & $\begin{array}{c}\text { Experimental } \\
(\mathrm{n} 2=19 ; \mathrm{n} 3=18) \\
\text { Controle } \\
(\mathrm{n} 2=18 ; \mathrm{n} 3=16)\end{array}$ & $\begin{array}{l}0,76 \pm 2,00 \\
0,34 \pm 1,29\end{array}$ & $2,00 \pm 4,10$ & 0,400 & 0,661 & 0,135 & $\begin{array}{l}1,88 \pm 3,25 \\
2,5 \pm 3,44\end{array}$ & 0,062 & 0,601 & 0,375 \\
\hline
\end{tabular}

*Diferenças significativas. 


\section{Avaliação da memória}

No sub-teste Dígitos de ordem inversa podemos deslumbrar uma tendência dos pacientes tanto do grupo Kumon quanto do grupo controle apresentar melhora de desempenho após 6 meses de treinamento, quando avaliados sozinhos (intra-indivíduos). Em conseqüência a esta similaridade de desempenho, quando os grupos foram comparados após 6 meses de intervenção não foi encontrada diferença significativa. Após 1 ano, ambos os grupos praticamente mantiveram os ganhos obtidos, sem diferença significativa de desempenho quando comparados.

Gráfico 22 - Comparação do desempenho em "dígitos de ordem inversa" do WAIS-III entre grupo Kumon e controle após 6 e 12 meses de treinamento

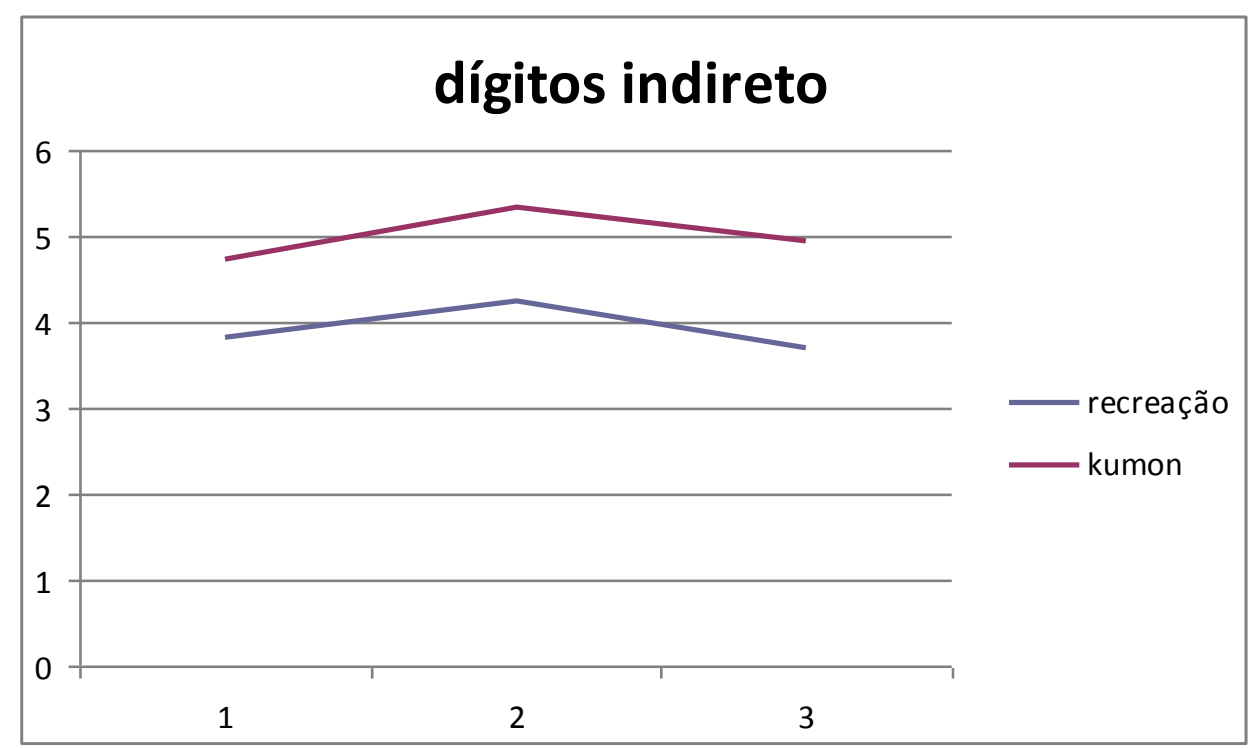


Nas listas do teste Rey Auditory houve pouca diferença na quantidade de palavras evocadas antes e após seis meses de intervenção, não demonstrando diferenças significativas entre - indivíduos, efeito do tempo e interação entre os grupos (tabela 24). Somente podemos encontrar efeito significativo de grupo (entre - indivíduos) na quinta e última lista evocada antes da interferência, indicando que houve uma diferença significativa na pontuação dos grupos tanto no início como ao final da intervenção. No entanto, o efeito de tempo e interação não se mostrou significativo, indicando que esta diferença entre os grupos se deu em função da linha de base heterogênea e não em conseqüência da ação do treinamento. Após 6 meses sem intervenção, ambos os grupos praticamente demonstraram estabilidade nos resultados obtidos, sem perdas significativas.

Gráfico 23 - Comparação do desempenho em "RAVLT - lista A" entre grupo Kumon e controle após 6 e 12 meses de treinamento

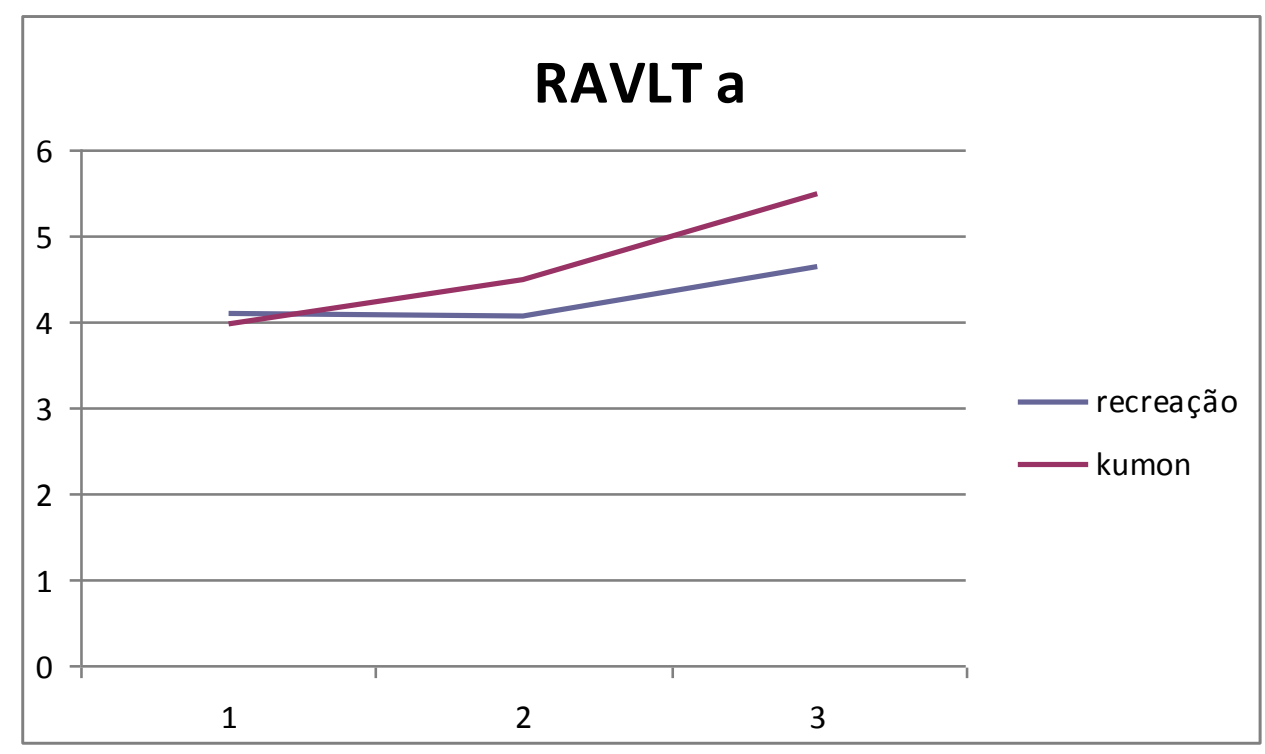


Gráfico 24 - Comparação do desempenho em "RAVLT - lista B" entre grupo Kumon e controle após 6 e 12 meses de treinamento

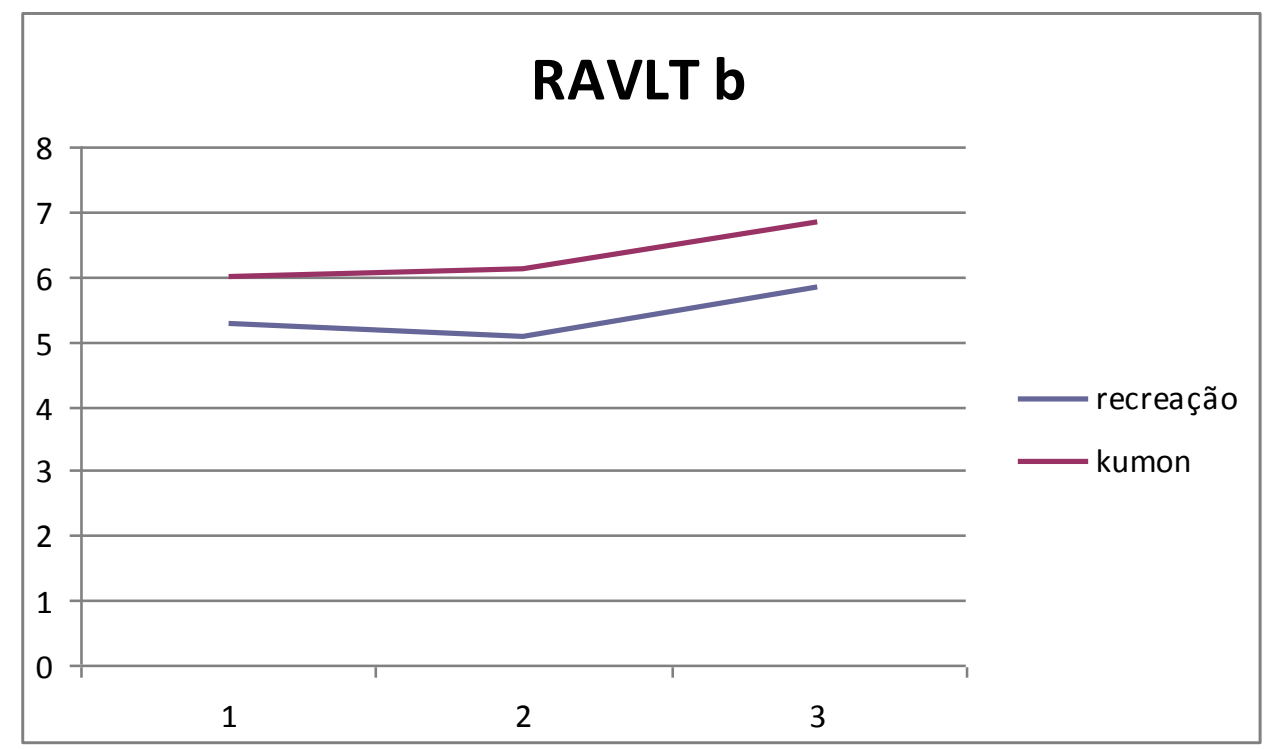

Gráfico 25 - Comparação do desempenho em "RAVLT - lista C" entre grupo Kumon e controle após 6 e 12 meses de treinamento

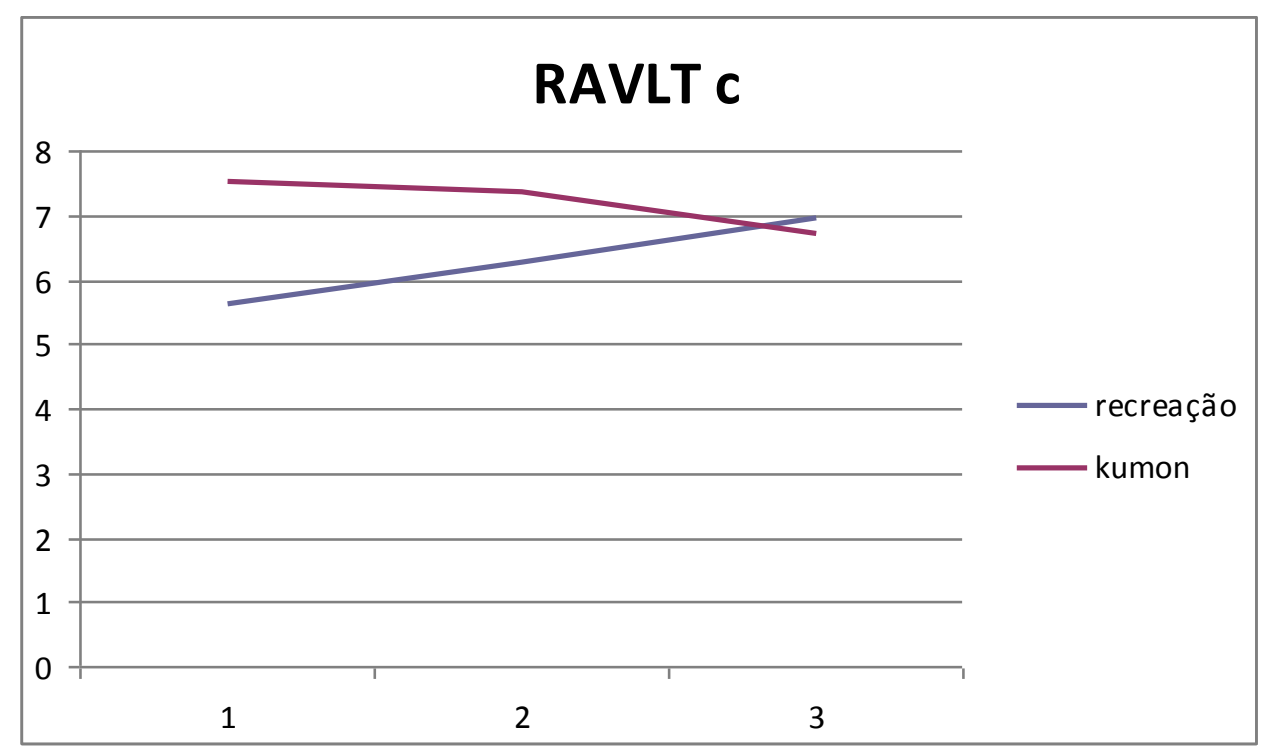


Resultados

Gráfico 26 - Comparação do desempenho em "RAVLT - lista D" entre grupo Kumon e controle após 6 e 12 meses de treinamento

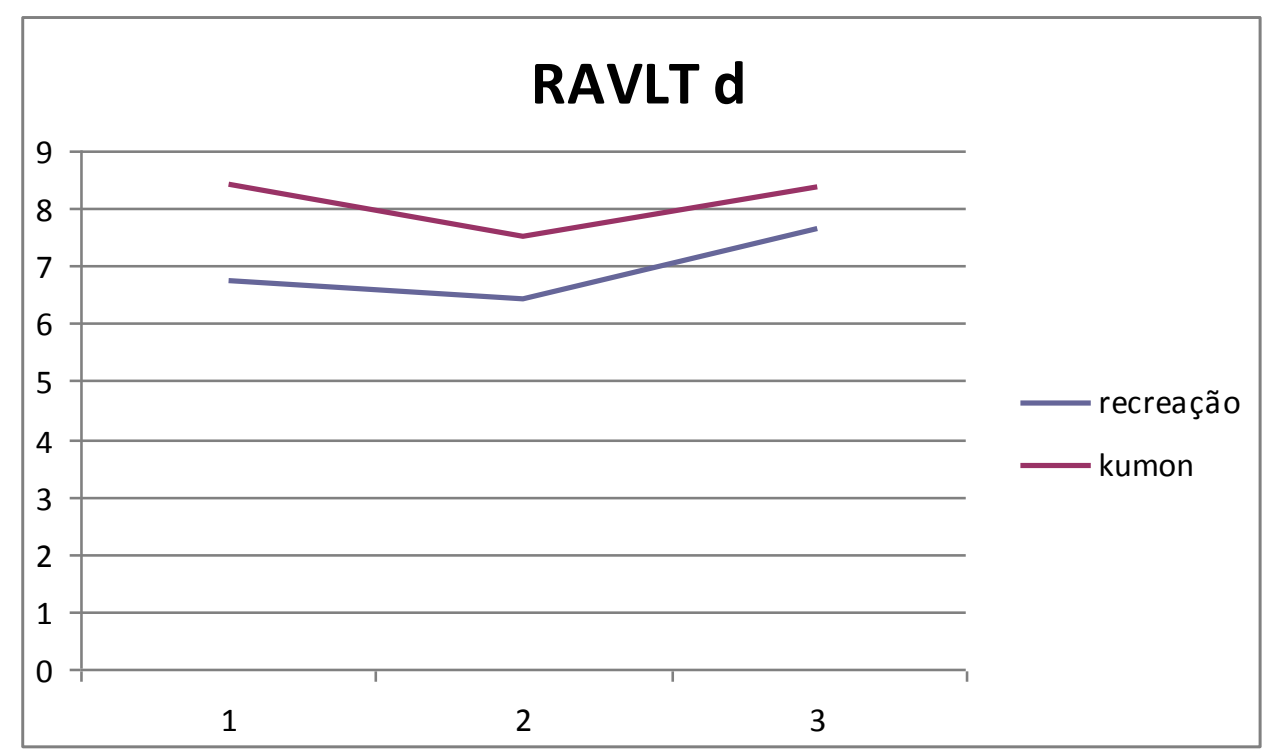

Gráfico 27 - Comparação do desempenho em "RAVLT - lista E" entre grupo Kumon e controle após 6 e 12 meses de treinamento

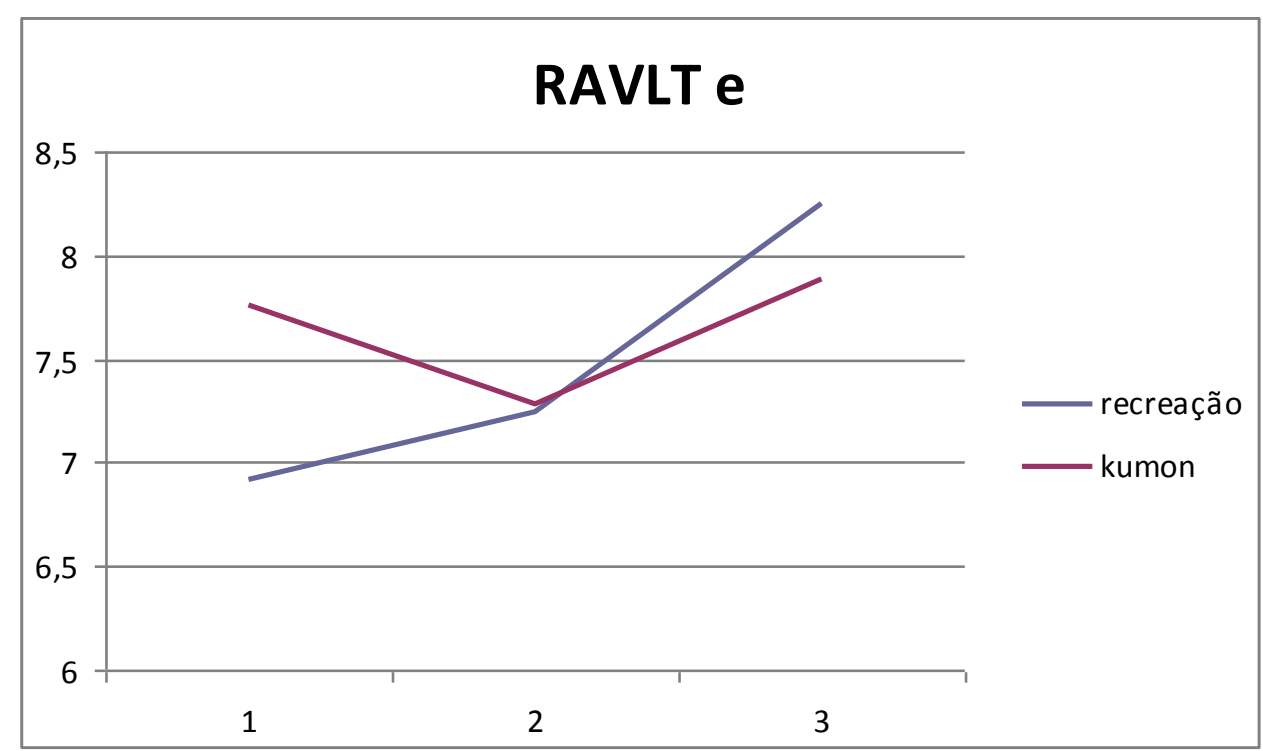


Gráfico 28 - Comparação do desempenho em "RAVLT - lista F" entre grupo Kumon e controle após 6 e 12 meses de treinamento

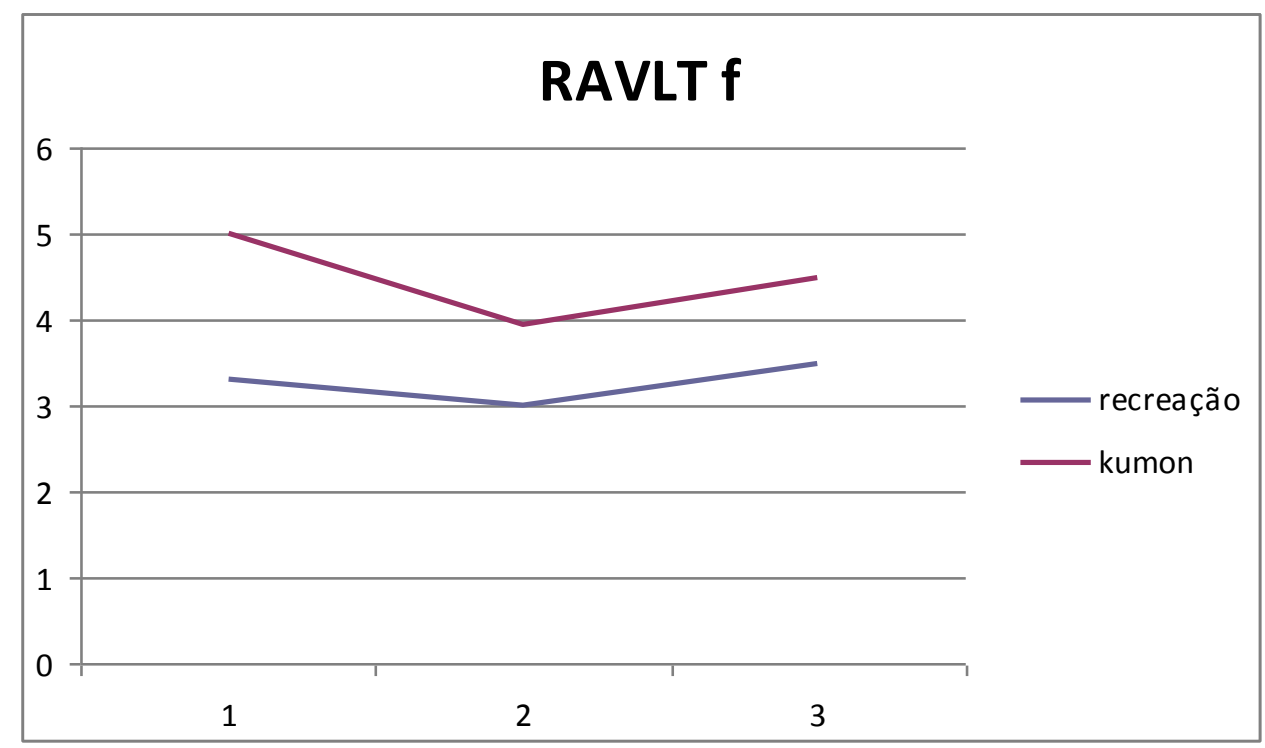

Gráfico 29 - Comparação do desempenho em "RAVLT - lista G" entre grupo Kumon e controle após 6 e 12 meses de treinamento

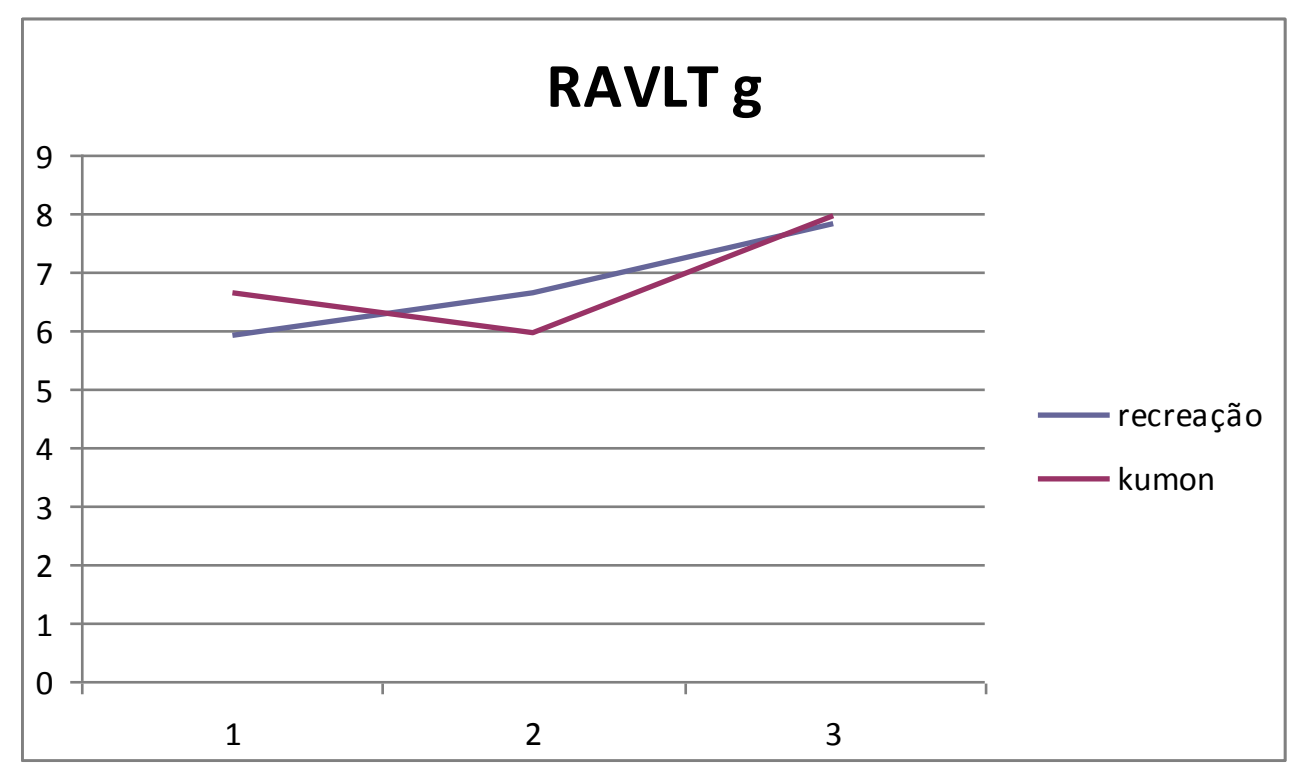


Resultados

Tabela 24 - Resultados mnêmicos

\begin{tabular}{|c|c|c|c|c|c|c|c|c|c|c|}
\hline \multirow[b]{2}{*}{ Instrumentos } & \multirow[b]{2}{*}{ Condição } & \multicolumn{2}{|l|}{ Média $\pm d p$} & \multicolumn{3}{|c|}{ P-valor } & \multirow{2}{*}{$\begin{array}{c}\text { Média } \pm d p \\
\text { Tempo } 3\end{array}$} & \multicolumn{3}{|c|}{ P-valor } \\
\hline & & Baseline & Tempo 2 & $\begin{array}{c}\text { Entre - } \\
\text { indivíduos }\end{array}$ & $\begin{array}{c}\text { Intra - } \\
\text { indivíduos }\end{array}$ & Interação & & $\begin{array}{c}\text { Entre - } \\
\text { indivíduos }\end{array}$ & $\begin{array}{c}\text { Intra - } \\
\text { indivíduos }\end{array}$ & Interação \\
\hline \multirow[t]{2}{*}{ Dígitos_inverso } & $\begin{array}{c}\text { Experimental } \\
\text { (n2=19; n3=18) }\end{array}$ & $3,92 \pm 2,00$ & $4,25 \pm 2,40$ & 0,074 & 0,079 & 0,636 & $4,94 \pm 1,91$ & $0,012^{*}$ & 0,090 & 0,568 \\
\hline & $\begin{array}{c}\text { Controle } \\
(\mathrm{n} 2=18 ; n 3=16)\end{array}$ & $4,75 \pm 2,01$ & $5,33 \pm 1,71$ & & & & $3,68 \pm 1,70$ & & & \\
\hline \multirow[t]{2}{*}{ RAVLT_A } & $\begin{array}{c}\text { Experimental } \\
\text { (n2=19; } 33=18)\end{array}$ & $4,04 \pm 1,65$ & $4,05 \pm 2,09$ & 0,828 & 0,999 & 0,505 & $5,47 \pm 2,62$ & 0,412 & 0,055 & 0,537 \\
\hline & $\begin{array}{c}\text { Controle } \\
(\mathrm{n} 2=18 ; \mathrm{n} 3=16)\end{array}$ & $4,00 \pm 2,30$ & $4,50 \pm 1,50$ & & & & $4,62 \pm 1,58$ & & & \\
\hline \multirow[t]{2}{*}{ RAVLT_B } & $\begin{array}{c}\text { Experimental } \\
\text { (n2=19; n3=18) }\end{array}$ & $4,04 \pm 1,65$ & $5,05 \pm 2,11$ & 0,206 & 0,725 & 0,656 & $6,82 \pm 2,85$ & 0,070 & 0,179 & 0,870 \\
\hline & $\begin{array}{c}\text { Controle } \\
(n 2=18 ; n 3=16)\end{array}$ & $4,00 \pm 2,30$ & $6,11 \pm 2,59$ & & & & $5,81 \pm 1,79$ & & & \\
\hline \multirow[t]{2}{*}{ RAVLT_C } & $\begin{array}{c}\text { Experimental } \\
\text { (n2=19; } 33=18)\end{array}$ & $5,56 \pm 2,53$ & $6,25 \pm 2,81$ & 0,069 & 0,553 & 0,584 & $6,70 \pm 3,19$ & 0,223 & 0,955 & 0,393 \\
\hline & $\begin{array}{c}\text { Controle } \\
(n 2=18 ; n 3=16)\end{array}$ & $7,63 \pm 5,60$ & $7,33 \pm 2,68$ & & & & $6,93 \pm 2,67$ & & & \\
\hline \multirow[t]{2}{*}{ RAVLT_D } & $\begin{array}{c}\text { Experimental } \\
\text { (n2=19; } 33=18)\end{array}$ & $6,80 \pm 2,68$ & $6,40 \pm 2,58$ & $0,027^{*}$ & 0,505 & 0,508 & $8,35 \pm 2,78$ & 0,074 & $0,031^{*}$ & 0,639 \\
\hline & $\begin{array}{c}\text { Controle } \\
(n 2=18 ; n 3=16)\end{array}$ & $8,50 \pm 2,38$ & $6,40 \pm 3,11$ & & & & $7,62 \pm 2,72$ & & & \\
\hline
\end{tabular}


Resultados

\begin{tabular}{|c|c|c|c|c|c|c|c|c|c|c|}
\hline \multirow[b]{2}{*}{ Instrumentos } & \multirow[b]{2}{*}{ Condições } & \multicolumn{2}{|l|}{ Média $\pm d p$} & \multicolumn{3}{|c|}{ P-valor } & \multirow{2}{*}{$\begin{array}{c}\text { Média } \pm d p \\
\text { Tempo } 3\end{array}$} & \multicolumn{3}{|c|}{ P-valor } \\
\hline & & Baseline & Tempo 2 & $\begin{array}{c}\text { Entre - } \\
\text { indivíduos }\end{array}$ & $\begin{array}{c}\text { Intra - } \\
\text { indivíduos }\end{array}$ & Interação & & $\begin{array}{c}\text { Entre - } \\
\text { indivíduos }\end{array}$ & $\begin{array}{c}\text { Intra - } \\
\text { indivíduos }\end{array}$ & Interação \\
\hline \multirow[t]{2}{*}{ RAVLT_E } & $\begin{array}{c}\text { Experimental } \\
(\mathrm{n} 2=19 ; \mathrm{n} 3=18)\end{array}$ & $6,92 \pm 3,24$ & $6,92 \pm 3,24$ & 0,430 & 0,876 & 0,369 & $7,88 \pm 3,07$ & 0,833 & 0,467 & 0,588 \\
\hline & $\begin{array}{c}\text { Controle } \\
(n 2=18 ; n 3=16)\end{array}$ & $7,92 \pm 3,67$ & $7,92 \pm 3,67$ & & & & $8,25 \pm 2,69$ & & & \\
\hline \multirow[t]{2}{*}{ RAVLT_F } & $\begin{array}{c}\text { Experimental } \\
(\mathrm{n} 2=19 ; \mathrm{n} 3=18)\end{array}$ & $5 \pm 6,5$ & $3,94 \pm 1,16$ & 0,244 & 0,461 & 0,939 & $4,47 \pm 1,41$ & 0,077 & 0,489 & 0,775 \\
\hline & $\begin{array}{c}\text { Controle } \\
\text { (n2=18; n3= 16) }\end{array}$ & $3,30 \pm 1,49$ & $3 \pm 1,25$ & & & & $3,5 \pm 1,03$ & & & \\
\hline \multirow[t]{2}{*}{ RAVLT_G } & $\begin{array}{c}\text { Experimental } \\
(\mathrm{n} 2=19 ; \mathrm{n} 3=18)\end{array}$ & $6,64 \pm 3,42$ & $5,94 \pm 3,58$ & 0,797 & 0,684 & 0,237 & $7,94 \pm 2,46$ & 0,993 & $0,037^{*}$ & 0,375 \\
\hline & $\begin{array}{c}\text { Controle } \\
(\mathrm{n} 2=18 ; n 3=16)\end{array}$ & $5,92 \pm 3,95$ & $6,65 \pm 3,01$ & & & & $7,81 \pm 2,73$ & & & \\
\hline
\end{tabular}

*Diferenças significativas. 


\subsubsection{Resultados quanto à sintomatologia}

$\mathrm{Na}$ medida de sintomas avaliada pela escala de sintomas positivos e negativos - PANSS a pontuação é feita de modo positivo, ou seja, quanto pior o sintoma maior é a pontuação. No geral, os pacientes que freqüentaram o grupo Kumon apresentaram melhora de seus sintomas se comparado àqueles que freqüentaram o grupo controle após 6 meses de treinamento. Após 6 meses sem intervenção, o grupo Kumon manteve-se estável ao passo que o grupo controle melhorou seu desempenho.

Gráfico 30 - Comparação do grupo Kumon e controle após 6 e 12 meses de treinamento (tempo 2) em PANSS geral

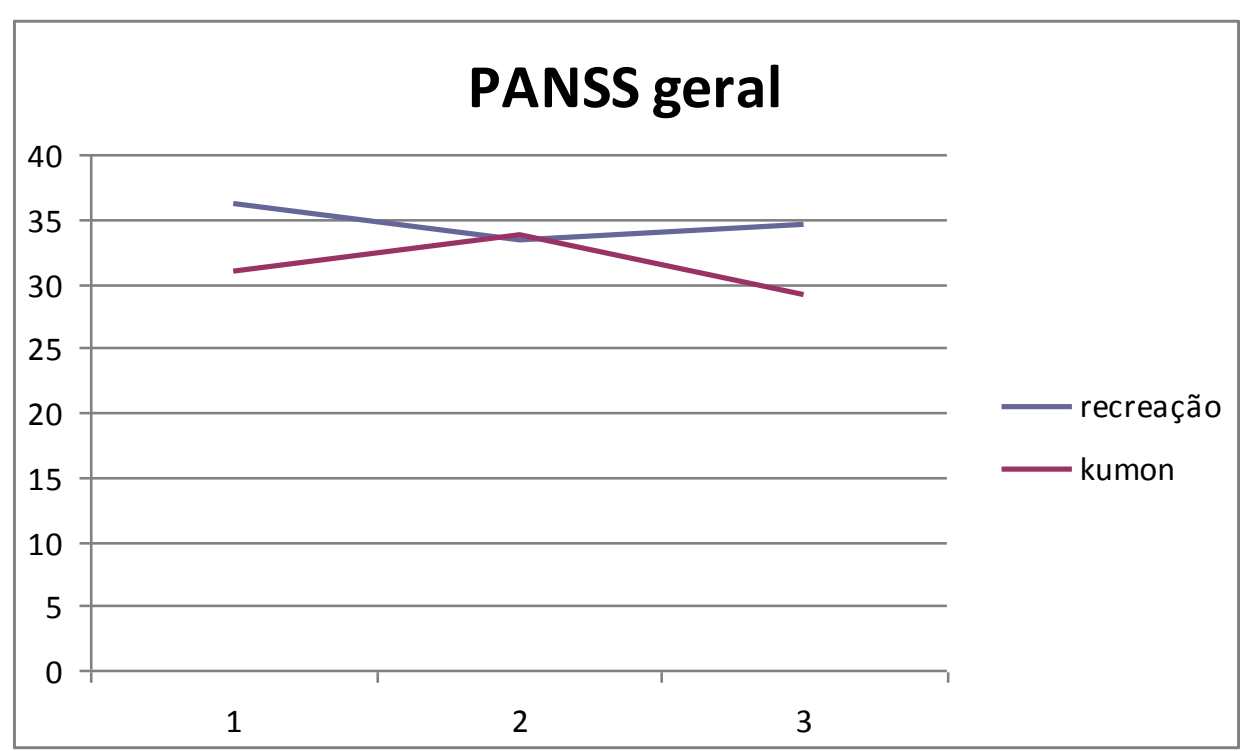


Resultados

Em relação à interação dos grupos Kumon e controle no fator "estresse emocional/ emotional distress" da escala PANSS seguindo o modelo de 5 fatores proposto por Van der Gaag (2006), os pacientes que freqüentaram o grupo Kumon conforme pode-se observar no gráfico 31 apresentaram desempenho abaixo daqueles que freqüentaram o grupo controle após 6 meses de treinamento, entretanto, esta diferença não foi significativa. Após 6 meses sem atividade, o grupo de recreação demonstrou uma tendência de piora destes sintomas anteriormente beneficiados logo depois da intervenção, entretanto, não significativo.

Gráfico 31 - Comparação do grupo Kumon e controle após 6 e 12 meses de treinamento (tempo 2) no fator "estresse emocional/ emotional distress" da escala PANSS

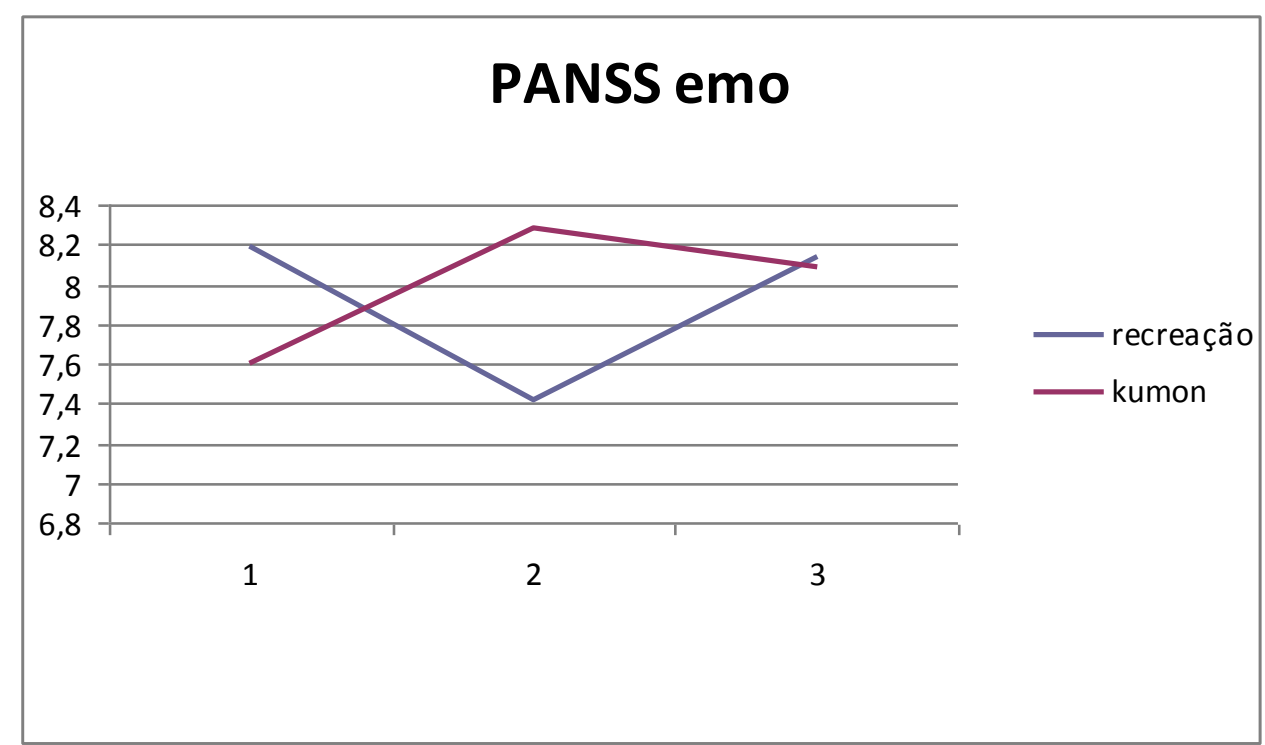


Resultados

O fator "excitação/ excitement" da escala PANSS seguindo o modelo proposto por Van der Gaag (2006) compreende os seguintes itens: controle dos impulsos, hiperatividade, hostilidade e falta de cooperação. $\mathrm{O}$ resultado deste fator apontou efeito de grupo (entre - indivíduos) significativo, indicando que houve uma diferença significativa na pontuação dos grupos tanto no início como ao final da intervenção. O efeito de tempo (intraindivíduos) se mostrou significativo, indicando que apenas um dos grupos pode ter melhorado ao longo do tempo. Como o efeito de interação é significativo, através da observação do gráfico 32 constata-se leve piora de desempenho neste fator no grupo Kumon ao passo que o grupo controle praticamente não apresenta diferença de desempenho no tempo 2. Após 1 ano de estudo, estes resultados praticamente mantiveram-se estáveis.

Gráfico 32 - Comparação do grupo Kumon e controle após 6 e 12meses de treinamento (tempo 2) no fator "excitação/ excitement" da PANSS

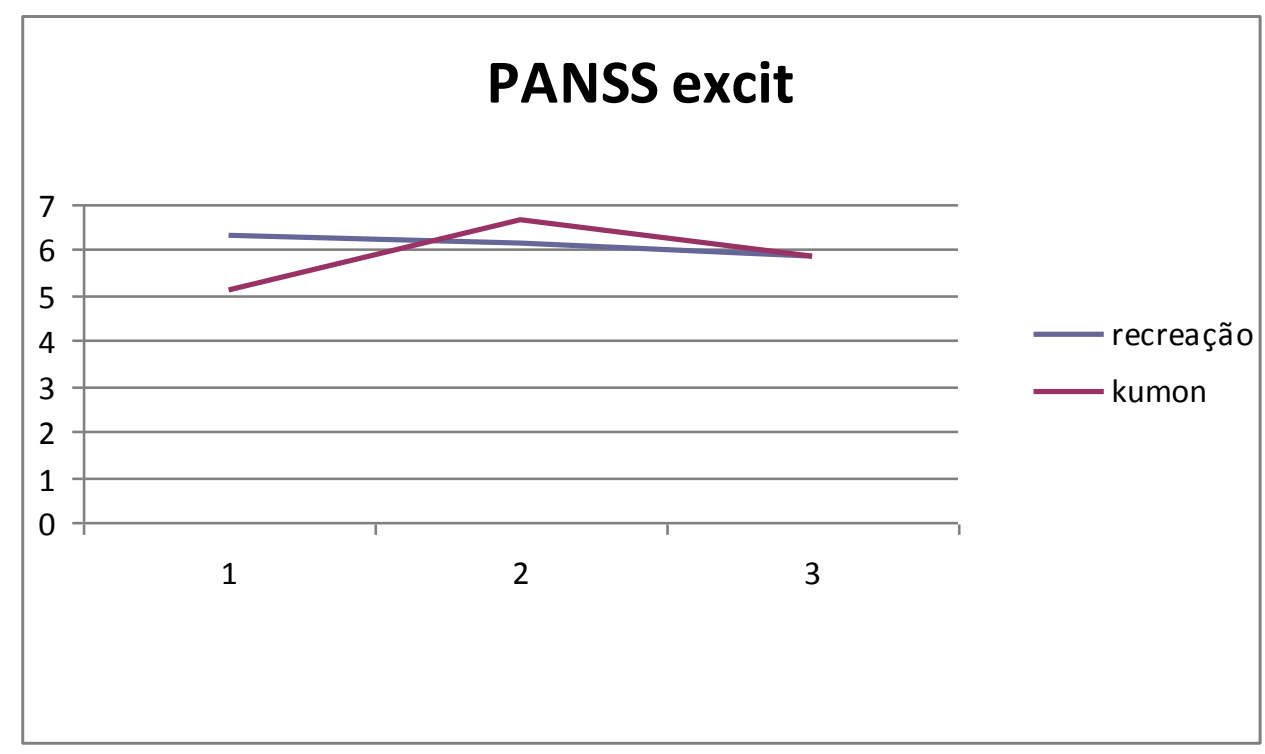


Os demais fatores da escala PANSS seguindo o modelo proposto por Van der Gaag (2006) compreendem medidas de sintomas positivos, negativos e desorganização. Pode-se observar estabilidade destes sintomas após 6 meses de intervenção, demonstrando ausência de efeitos significativos ao longo do tempo e interação. O mesmo pode ser constatado após 6 meses sem intervenção, com manutenção dos resultados obtidos.

Gráfico 33 - Comparação do grupo Kumon e controle após 6 e 12meses de treinamento (tempo 2) no fator "sintomas negativos" da PANSS

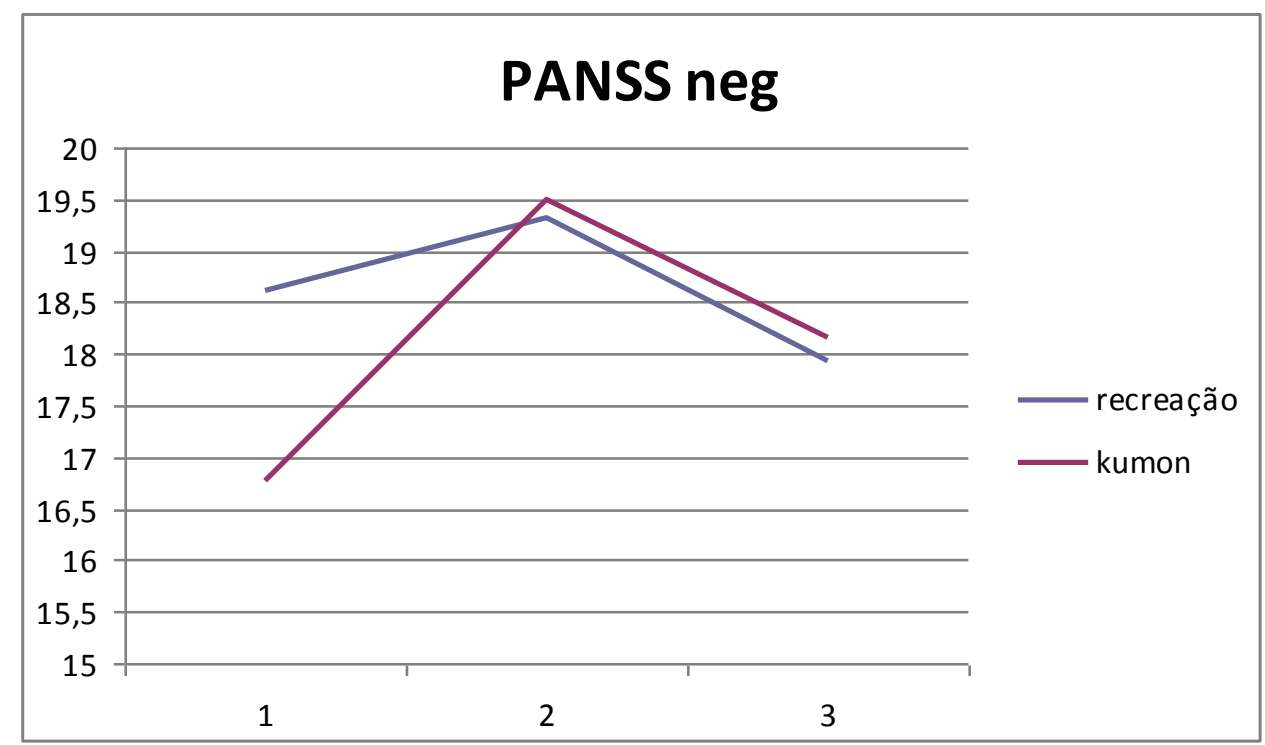


Resultados

Gráfico 34 - Comparação do grupo Kumon e controle após 6 e 12meses de treinamento (tempo 2) no fator "sintomas positivos" da PANSS

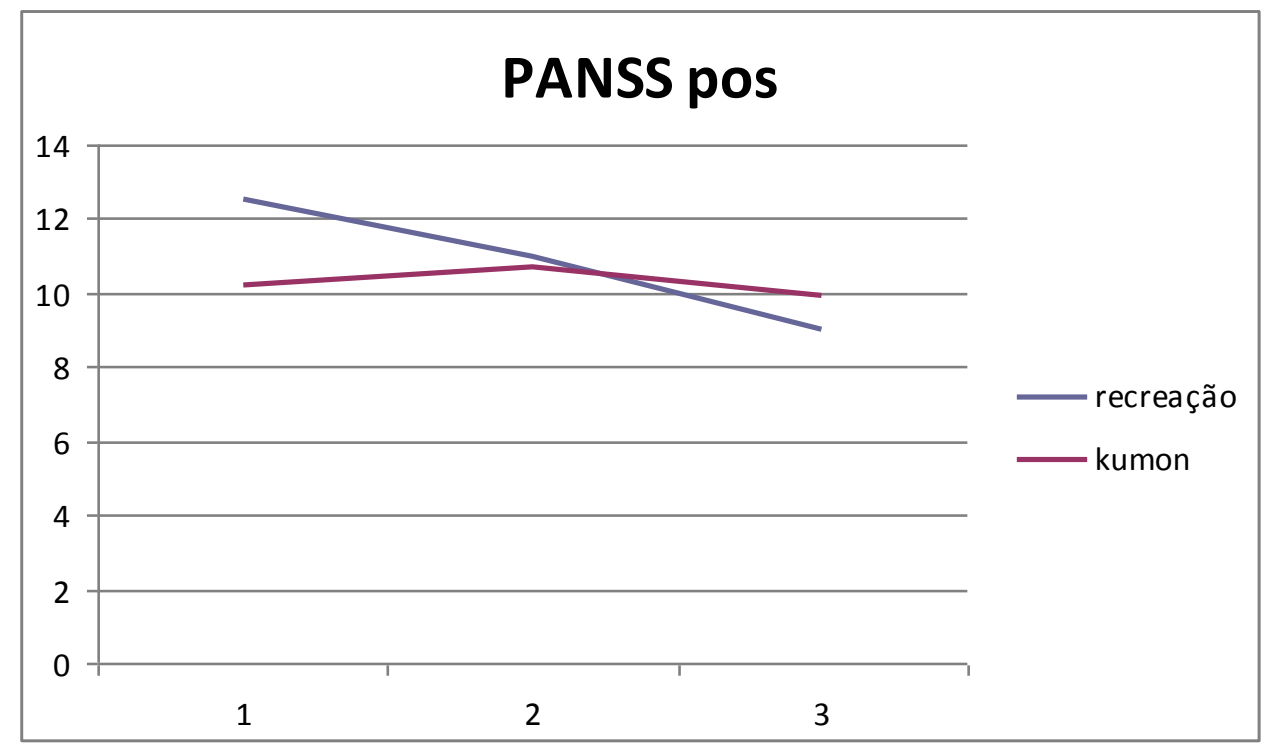

Gráfico 35 - Comparação do grupo Kumon e controle após 6 e 12meses de treinamento (tempo 2) no fator "desorganização" da PANSS

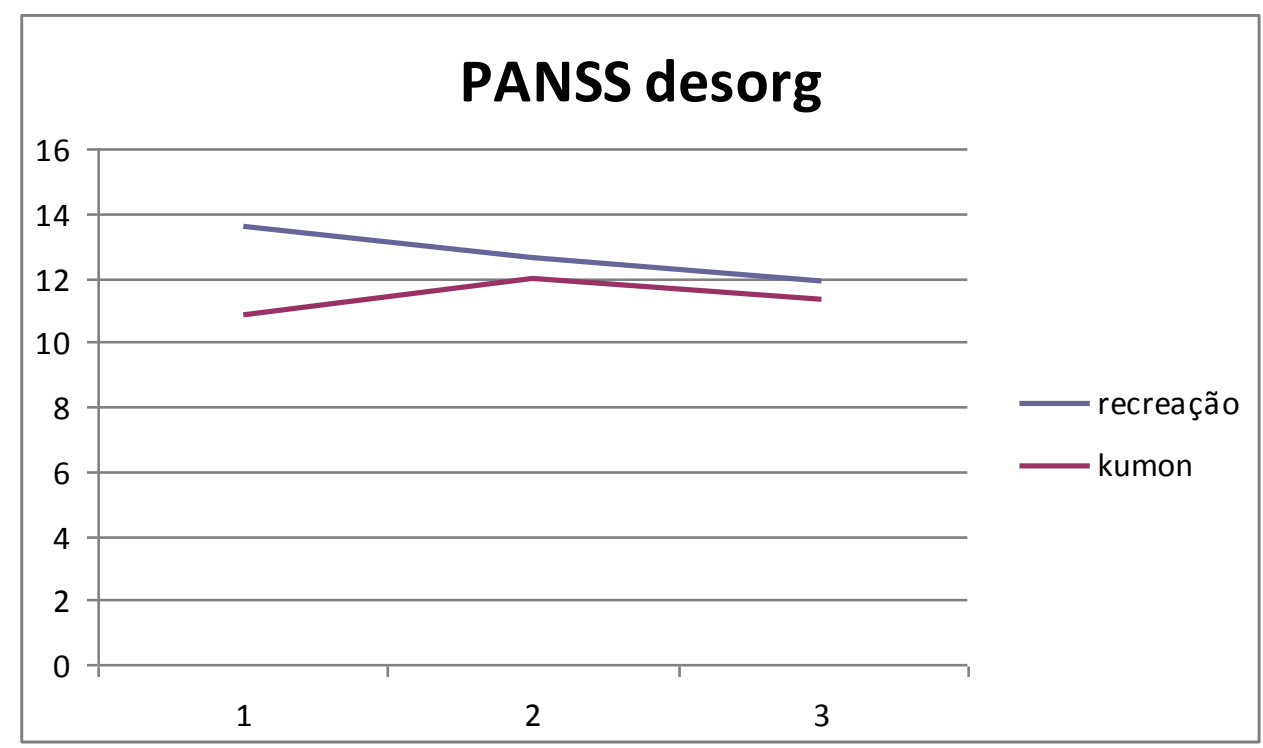


Resultados

Tabela 25 - Resultados da escala de sintomas positivos e negativos - PANSS, segundo 5 fatores de Van der Gaag (2006)

\begin{tabular}{|c|c|c|c|c|c|c|c|c|c|c|}
\hline \multirow[b]{2}{*}{ Fatores da PANSS } & \multirow[b]{2}{*}{ Condição } & \multicolumn{2}{|c|}{ Média $\pm d p$} & \multicolumn{3}{|c|}{ P-valor } & \multirow{2}{*}{$\begin{array}{c}\text { Média } \pm d p \\
\text { Tempo } 3\end{array}$} & \multicolumn{3}{|c|}{ P-valor } \\
\hline & & Baseline & Tempo 2 & $\begin{array}{c}\text { Entre - } \\
\text { indivíduos }\end{array}$ & $\begin{array}{c}\text { Intra - } \\
\text { indivíduos }\end{array}$ & Interação & & $\begin{array}{c}\text { Entre - } \\
\text { indivíduos }\end{array}$ & $\begin{array}{c}\text { Intra - } \\
\text { indivíduos }\end{array}$ & Interação \\
\hline $\begin{array}{l}\text { Estresse emocional/ } \\
\text { emotional distress }\end{array}$ & $\begin{array}{c}\text { Experimental } \\
\text { (n2=19; } \mathrm{n} 3=18) \\
\text { Controle } \\
(\mathrm{n} 2=18 ; \mathrm{n} 3=16)\end{array}$ & $\begin{array}{l}8,32 \pm 2,90 \\
8,15 \pm 3,15\end{array}$ & $\begin{array}{l}7,42 \pm 2,78 \\
8,28 \pm 2,56\end{array}$ & 0,465 & 0,393 & 0,195 & $\begin{array}{l}8,08 \pm 1,72 \\
8,14 \pm 2,10\end{array}$ & 0,874 & 0,904 & 0,385 \\
\hline “Excitação/ excitement" & $\begin{array}{c}\text { Experimental } \\
\text { (n2=19; } \mathrm{n} 3=18) \\
\text { Controle } \\
(\mathrm{n} 2=18 ; \mathrm{n} 3=16)\end{array}$ & $\begin{array}{l}6,36 \pm 2,69 \\
5,35 \pm 2,11\end{array}$ & $\begin{array}{l}6,16 \pm 2,12 \\
6,67 \pm 2,52\end{array}$ & 0,078 & 0,721 & $0,056^{\star}$ & $\begin{array}{l}5,83 \pm 1,52 \\
5,85 \pm 2,28\end{array}$ & 0,656 & 0,309 & 0,140 \\
\hline Desorganização & $\begin{array}{c}\text { Experimental } \\
(\mathrm{n} 2=19 ; \mathrm{n} 3=18) \\
\text { Controle } \\
(\mathrm{n} 2=18 ; \mathrm{n} 3=16)\end{array}$ & $\begin{array}{l}13,44 \pm 3,16 \\
10,85 \pm 3,91\end{array}$ & $\begin{array}{l}12,58 \pm 3,86 \\
12,00 \pm 2,45\end{array}$ & $0,005^{*}$ & 0,252 & 0,084 & $\begin{array}{l}11,33 \pm 1,92 \\
11,85 \pm 2,62\end{array}$ & 0,076 & 0,614 & 0,169 \\
\hline $\begin{array}{l}\text { Sintomas } \\
\text { negativos }\end{array}$ & $\begin{array}{c}\text { Experimental } \\
\text { (n2=19; } \mathrm{n} 3=18) \\
\text { Controle } \\
(\mathrm{n} 2=18 ; \mathrm{n} 3=16)\end{array}$ & $\begin{array}{l}23,40 \pm 5,68 \\
20,75 \pm 6,21\end{array}$ & $\begin{array}{l}22,84 \pm 6,93 \\
23,50 \pm 5,72\end{array}$ & 0,255 & 0,690 & 0,166 & $\begin{array}{l}18,16 \pm 2,72 \\
17,92 \pm 3,97\end{array}$ & 0,710 & 0,164 & 0,470 \\
\hline Sintomas positivos & $\begin{array}{c}\text { Experimental } \\
\text { (n2=19; } n 3=18) \\
\text { Controle } \\
(n 2=18 ; n 3=16)\end{array}$ & $\begin{array}{l}12,68 \pm 5,03 \\
9,80 \pm 3,72\end{array}$ & $\begin{array}{l}10,95 \pm 5,63 \\
10,72 \pm 3,54\end{array}$ & 0,085 & 0,226 & 0,306 & $\begin{array}{l}9,91 \pm 3,98 \\
9 \pm 2,67\end{array}$ & 0,531 & 0,263 & 0,290 \\
\hline PANSS total & $\begin{array}{c}\text { Experimental } \\
\text { (n2=19; } \mathrm{n} 3=18) \\
\text { Controle } \\
(\mathrm{n} 2=18 ; \mathrm{n} 3=16)\end{array}$ & $\begin{array}{l}30,62 \pm 9,30 \\
36,20 \pm 7,22\end{array}$ & $\begin{array}{l}33,76 \pm 7,03 \\
33,28 \pm 6,84\end{array}$ & 0,460 & 0,367 & $0,009^{*}$ & $\begin{array}{l}29 \pm 0 \\
34,5 \pm 4,5\end{array}$ & 0,664 & 0,524 & $0,017^{*}$ \\
\hline
\end{tabular}




\subsubsection{Resultados de desempenho social e pessoal}

Em escala de desempenho social e pessoal (PSP), as medidas avaliadas mantiveram-se estáveis, ou seja, não houve mudanças de desempenho ao longo do tempo nos grupos e não se constatou interação entre os grupos na comparação antes e depois de 6 meses de atividade (tabela 26).

Tabela 26 - Resultados da escala de desempenho social e pessoal - PSP

\begin{tabular}{|c|c|c|c|c|c|c|c|c|c|c|}
\hline \multirow[b]{2}{*}{ Instrumento } & \multirow[b]{2}{*}{ Condição } & \multicolumn{2}{|l|}{ Média $\pm d p$} & \multicolumn{3}{|c|}{ P-valor } & \multirow{2}{*}{$\begin{array}{c}\text { Média } \pm d p \\
\text { Tempo } 3\end{array}$} & \multicolumn{3}{|c|}{ P-valor } \\
\hline & & Baseline & Tempo 2 & $\begin{array}{c}\text { Entre - } \\
\text { indivíduos }\end{array}$ & $\begin{array}{c}\text { Intra - } \\
\text { indivíduos }\end{array}$ & Interação & & $\begin{array}{c}\text { Entre - } \\
\text { indivíduos }\end{array}$ & $\begin{array}{c}\text { Intra - } \\
\text { indivíduos }\end{array}$ & Interação \\
\hline \multirow[t]{2}{*}{ Escala PSP } & $\begin{array}{c}\text { Experimental } \\
(\mathrm{n} 2=19 ; \mathrm{n} 3=18)\end{array}$ & $56,80 \pm 16,62$ & $61,85 \pm 12,05$ & 0,237 & 0,088 & 0,704 & $56,33 \pm 8,08$ & 0,213 & 0,060 & 0,824 \\
\hline & $\begin{array}{c}\text { Controle } \\
(n 2=18 ; n 3=16)\end{array}$ & $51,08 \pm 13,70$ & $58,07 \pm 15,71$ & & & & $50,50 \pm 10,47$ & & & \\
\hline
\end{tabular}




\section{DISCUSSÃO}

\subsection{Perfil demográfico}

A população atendida pelo estudo caracteriza-se por uma preponderância de homens, brancos, solteiros e com diagnóstico de esquizofrenia paranóide. Em relação ao gênero dos participantes da pesquisa, em todos os estudos levantados encontrou-se predominância da população masculina entre usuários de serviços psiquiátricos ambulatoriais ou de internação no Brasil (Coutinho et al, 2002; Medeiros, 2005; Rabelo et al, 2005).

Em alguns estudos, como o de Miranda et al (2008), a diferença relacionada ao gênero é considerada muito significativa, com pior prognóstico em relação ao número de reinternações psiquiátricas se comparado às mulheres. Além disso, Chaves (2000) aponta para maior freqüência de transtornos da personalidade pré-mórbida, maior probabilidade de permanecerem solteiros e idade de início da doença mais precoce. 
Comparando os dados dos dois grupos (Kumon e controle), não encontramos diferenças significativas, exceto um número maior de pacientes do grupo controle que apresentam pelo menos uma internação ao longo do curso da doença. No entanto, na literatura observa-se que, ao contrário do estudo, o número de internações é bastante alto entre os pacientes ambulatoriais brasileiros com diagnóstico de esquizofrenia (Coutinho et al, 2002). 


\subsection{Considerações sobre o treinamento matemático Kumon}

Não foram encontrados resultados significativos da terapia de remediação cognitiva Kumon, em comparação com placebo, na população com esquizofrenia nos domínios cognitivos específicos avaliados: atencional, função executiva e memória de trabalho, mesmo estes sendo considerados na literatura subjacentes à habilidade matemática (Oberauer, 2003; Conway et al, 2001; Kyttälä, 2010; McLean \& Hitch, 1999; Geary et al, 1999). Ao contrário do presente estudo, embora ainda não exista um padrão de dificuldade matemática relacionada à cognição, os pacientes com esquizofrenia exibem déficits cognitivos que podem afetar seu desempenho em tarefas de cálculos (Gray et al., 1991). Isto pode ser confirmado através dos resultados diagnósticos referentes ao conhecimento prévio aritmético dos pacientes para o planejamento do treino cognitivo aritmético de Kumon, sugerindo dificuldade matemática com início em estágio muito elementar e com pouco progresso nos estágios, sendo necessário constante repetição dos exercícios até total de acertos para a fixação do conteúdo, apesar da assiduidade de freqüência (média de 95\%). Na literatura as causas de dificuldade de aprendizagem em diversas populações compreendem diversos déficits cognitivos como a memória de trabalho, processamento visuo-espacial ou atenção (Rubinsten \& Henik, 2009).

Por outro lado, o estudo não utilizou nenhum instrumento de avaliação referente ao uso indireto da aritmética na rotina dos pacientes incluídos nos dois grupos, como por exemplo, quando o paciente calcula os gastos no supermercado, programa o uso do salário, consegue fazer leitura de 
partituras musicais, etc. Assim, não há como afirmar a inexistência de estimulação cognitiva fora do contexto de intervenção interferindo nos resultados.

A metodologia Kumon propõe o estimulo do raciocínio lógico matemático através de aritmética mental de operações e contas repetidas. Assim, o treinamento de cálculos aritméticos Kumon pressupõe, principalmente, o estímulo nos domínios cognitivos de memória de trabalho, pois esta corresponde a um espaço mental que pode flexivelmente ser usada como suporte para atividades cognitivas diárias que requerem processamento e estocagem, tais como a aritmética mental (Alloway et al., 2004). Contudo, neste estudo não foi encontrado melhor desempenho em memória de trabalho atribuído ao grupo Kumon, com melhora de desempenho em ambos os grupos.

Mudanças cognitivas significativas foram observadas, mas não ocorreu especificamente em função do treino de remediação cognitiva aritmética, pois ambos os grupos apresentaram melhoras significativas em velocidade de processamento e atenção seletiva, função executiva, controle inibitório para respostas competitivas e memória de trabalho, dado também relatado em outros estudos experimentais com terapia de remediação cognitiva (Hogarty et al, 2004; Farreny et al 2012; Kurtz et al, 2007).

A não ocorrência de diferenças significativas entre os grupos nestas medidas pode ser compreendido pelo fato do treino placebo possivelmente ter proporcionado um efeito positivo sobre estes aspectos de cognição básica. A proposta do grupo placebo consistiu em oferecer atividades 
inespecíficas que se revezavam durante o período de Trial, mas assim como no treino de Kumon podem ter estimulado determinados domínios cognitivos ligados à matemática como noção de magnitude, percepção visuo-espacial e laço fonológico da memória de trabalho. Foi exigido, por exemplo, a noção de quantidade de bolinhas com papel de seda ou miçangas para preencher todo o espaço do desenho e confecção de bijuterias, atividade de leitura e redação, etc. O esboço visuo-espacial é responsável pela manipulação de imagens mentais ao passo que o laço fonológico é responsável pelo armazenamento temporário da informação verbal para, posteriormente, serem processados pela memória de longo prazo (Swanson \& Sachse-Lee, 2001; Repovs \& Baddeley, 2006).

Os resultados cognitivos avaliados pelos instrumentos neuropsicológicos apontaram apenas tendência de melhora cognitiva no subdomínio de atenção concentrada no grupo de Kumon. No conceito proposto por Norman e Shallice (1982) as tarefas de demanda de atenção ocupam lugar como uma demanda específica de central executiva. Assim, apesar da pouca melhora, o controle da atenção em conjunto com um padrão habitual de aprendizagem é considerado primordial para a formação de um padrão de respostas habituais para o inicio de um novo comportamento frente a um estímulo diferente, como por exemplo, aprender a andar de bicicleta. De fato, o método Kumon utiliza a medição do tempo na resolução dos exercícios como parâmetro na avaliação do conteúdo estudado, o que pode ter aprimorado a capacidade de concentração (Kumon, 1999). Embora os resultados sejam pequenos, mostram-se 
relevantes, pois na literatura os déficits atencionais estão associados a prejuízos funcionais (Cadenhead e Braff, 2000), especialmente no funcionamento social (Harvey e Sharma, 2002).

Por outro lado, a tendência de melhora cognitiva do grupo Kumon em atenção sustentada não foi mantida 6 meses após o término da intervenção, sinalizando a necessidade da remediação cognitiva sempre ser exercitada para a habilidade não ser esquecida em um prazo maior. Isto confirma a eficácia do método Kumon ser atribuída ao trabalho contínuo para a fixação dos conteúdos (Kumon, 1999; O’ Carrol et al, 1999; Velligan et al, 2006).

De acordo com Baddeley (2002), o executivo central teria a função de coordenar as informações advindas dos outros subsistemas, ou seja, focar a atenção, dividi-la, deslocá-la e de realizar o intercâmbio entre memória de trabalho e memória de longo prazo. Neste sentido, além dos recursos cognitivos específicos subjacentes à memória visuo-espacial e verbal, outros domínios cognitivos gerais também estariam envolvidos com a retenção das informações, como a função executiva e atenção avaliada no estudo. Contudo, apesar da importância da atenção concentrada em função executiva, a sua melhora não pôde ser associada com o desempenho de função executiva, pois ambos os grupos obtiveram melhor desempenho em função executiva após 6 meses de intervenção (categorias completas e respostas perseverativas do WCST), não podendo, portanto, ser atribuída à remediação cognitiva de cálculos aritméticos Kumon.

Para Wykes e colaboradores (2011), a validação teórica de uma terapia de remediação cognitiva (CRT) só se dá após considerar os prejuízos e seus 
efeitos cognitivos. Embora muitos dos déficits cognitivos apontados nos estudos da população com esquizofrenia sejam equivalentes àqueles subjacentes à matemática, não encontramos estudos exploratórios de remediação cognitiva utilizando cálculos aritméticos para estimulação cognitiva. Assim, para o desenvolvimento de modelos de terapias para 0 estímulo da cognição específica de matemática serão necessários mais estudos longitudinais randomizados no futuro.

$\mathrm{Na}$ literatura, encontramos muitos estudos randomizados controlados para avaliação da eficácia de diferentes métodos de remediação cognitiva (Hogarty et al, 2004; Wykes et al., 2007). Entretanto, não fica claro quão destes se utilizam de um treinamento de remediação cognitiva matemática e através de técnicas errorless learning como o método Kumon para o estímulo específico em domínios cognitivos associados à matemática para a comparação de seus resultados com o nosso estudo.

Estudos exploratórios da cognição subjacente à matemática têm sido acessados, assim como neste estudo, através de tarefas aritméticas complexas de baterias de testes de inteligência tais como o WAIS-R (Wechsler, 1999), no qual são baseados em várias funções cognitivas (Green, 1996; Bilder, 1997). Além destes, para a escolha da bateria neuropsicológica buscou-se testes específicos dos domínios cognitivos em memória de trabalho, função executiva e atenção presentes na bateria cognitiva consensual Matrics (Measurement and Treatment Research to Improve Cognitive in Schizophrenia) (Kern et al., 2008). 
Na pesquisa de Iseman e Naglieri (2011) apesar da melhora cognitiva em estudantes com TDAH e dificuldade de aprendizagem matemática através do treino de computação matemática este resultado se deu em testes muito semelhantes ao treino matemático avaliado. Dickinson e colaboradores (2007) também conduziram um estudo randomizado controlado que apontou o quanto a CRT melhorou os domínios cognitivos bem como a cognição global quando testados fazendo uso dos mesmos instrumentos incluídos no programa de remediação. Contudo, esta melhora não foi encontrada na cognição geral nem nos domínios cognitivos quando testados com uma bateria neuropsicológica padrão, ilustrando o perigo em se testar o treinamento usando uma bateria cognitiva similar às tarefas praticadas no programa de terapia de remediação cognitiva. Os testes neuropsicológicos padrão escolhidos para avaliação cognitiva dos pacientes neste estudo se mostrou neutro, de forma a evitar um possível viés dos resultados de desempenho favorável ao grupo experimental. Por outro lado, alguns estudos sugerem a inespecificidade de instrumentos neuropsicológicos padrão para medidas cognitivas específicas da matemática como a proposta no estudo (Hurford et al, 2011).

Baddeley e colaboradores (1996) apontam problemas na análise de central executiva através somente de um número limitado de processos executivos. Este postula a necessidade de processos que operam somente através de uma gama de diferentes materiais e situações. Ainda está em aberto se sua organização é hierárquica, com um ou mais subsistemas dominantes ou se há uma ou mais estruturas hierárquicas envolvidas (Bull e 
Scerif, 2001). Neste estudo, o funcionamento executivo foi avaliado por poucos testes padrão, o que pode ter restringido a avaliação e todas as possíveis demandas executivas, limitando-se a utilizar subtestes do Wisconsing Card Test, Trail Making Test e Stroop Color-Word Test.

\subsection{Cognição e fatores motivacionais}

A capacidade cognitiva é considerada por muitos autores um fator que impacta a habilidade de aprender e os déficits neuropsicológicos, tão prevalentes em esquizofrenia, é tido como limitadores para o desfecho do tratamento. Assim, as habilidades para prestar atenção, lembrar e processar a informação a ser apreendida são críticas para o desfecho do tratamento. No entanto, estudos recentes sugerem que a aprendizagem não só depende da capacidade cognitiva, mas também sofre influência de técnicas de instrução e motivação do paciente para se engajar na atividade e aprender a habilidade, embora ainda não seja claro na literatura sua interferência na cognição (Velligan et al, 2006; Twanley et al, 2011; Wykes et al, 2011). 
$\mathrm{Na}$ esquizofrenia a falta de vontade em realizar algo faz parte dos sintomas negativos, sendo capaz de impactar no desfecho psicossocial, na habilidade de engajamento e no benefício do tratamento. E, neste estudo, embora não tenha sido aplicada uma escala específica de medida motivacional, pudemos observar através dos relatos verbais dos pacientes que freqüentaram ambos os grupos às terapeutas a existência de sentimentos de motivação associada ao prazer e pensamentos positivos em relação à atividade realizada. Isso pode ter ocorrido, por exemplo, em consequência do acolhimento das queixas dos pacientes pelas terapeutas ou demais colegas participantes de um grupo de intervenção qualquer (Medalia e Saperstein, 2011).

O primeiro episódio psicótico pode ser compreendido como uma interrupção no desenvolvimento normal de vida, caracterizado por uma grande dificuldade de reconstrução do cotidiano e inserção social. Assim, não há um indivíduo que vive o tempo, mas um tempo que anuncia atividades, de sobrevivência e cuidados clínicos, incorporadas no seu dia-adia. Dentro do dia-a-dia dos pacientes incluídos na pesquisa, inclusive àqueles que freqüentaram o grupo controle, acreditamos que o simples caminho de casa até a escola, os encontros no horário do seu atendimento, a relação constituída com as atividades realizadas e a terapeuta, passaram a compor seu cotidiano, ampliando-o. Desta forma, os indivíduos podem ter passado de um comportamento mais passivo a uma atitude participativa em relação aos acontecimentos da vida, reconhecendo-se nelas e podendo compor uma narrativa das situações (Takatori, 2001). 
Para Delgado e colaboradores (1997), mais importante do que os tipos de atividades desenvolvidas nestes espaços é a noção deste lugar enquanto facilitador da comunicação e das relações interpessoais, favorecendo deste modo a integração, a interação e reinserção social. Apesar de o estudo ter proposto um grupo controle composto por atividades recreativas apenas para entreter e ocupar os indivíduos que permanecessem na escola durante o período de 50 minutos, provavelmente devido ao vazio e ausência total de estímulos psicossociais - exceto o uso medicamentoso - em que viviam os pacientes, a atividade controle acabou se transformando em um local propiciador de reinvenção da vida em seus aspectos mais cotidianos e de rompimento com o isolamento e inserção no mundo social (Valadares et al, 2003). 
Assim, o uso de um grupo placebo psicossocial, a fim de torná-lo mais próximo do que seria o grupo experimental, pode vir a implicar também em uma estimulação dos pacientes através de fatores não-específicos relacionados à participação em uma atividade, independente de sua modalidade adotada e sistematização, tais como: auto-estima, autoeficiência e autoconfiança em completar as tarefas proporcionadas pelo estabelecimento de uma nova rotina de trabalho e a interação pacienteterapeuta (Vita et al., 2011). Para Wykes (2011) as abordagens e pesquisas com terapia de remediação cognitiva (CRT) necessitam estar atentas para os efeitos da relação com o terapeuta e o estabelecimento de uma nova rotina, onde embora seja raramente investigado pode ser considerado o segredo de maior eficácia de um tratamento psicossocial (Wykes e Spaulding, 2011). Tanto a terapia de remediação cognitiva quanto outras intervenções psicossociais, podem ser afetadas tanto por intervenções nãoespecíficas (esperança, motivação, etc) quanto por intervenções específicas (escolha do nível e tipo de treinamento). 


\subsection{Psicopatologia e funcionamento social}

O objetivo de qualquer programa de remediação cognitiva é a generalização (da Costa \& Carvalho, 2000). Contudo, a avaliação funcional deste estudo não apresentou diferenças significativas em nenhum dos grupos. Na literatura, os resultados cognitivos favoráveis à terapia de remediação cognitiva foram maiores em programas que fizeram uso em conjunto de estratégias de aprendizagem social (McGurk et al, 2007). Estudos tem se aprofundado para compreender o modo como a cognição integrada à cognição social exerce influência sobre o desfecho funcional, demonstrando o treinamento de aprendizagem sem erros como facilitador da aprendizagem de novas habilidades através da melhora de variados níveis de memória (Kurzban et al, 2010; Vesterager et al, 2011; Leschener et al, 2012).

Muitos estudos apontam para uma mediação parcial dos sintomas negativos na relação entre cognição e desfecho funcional (Ventura et al, 2009), entretanto, assim como no estudo, não foram encontradas mudanças significativas nos grupos em sintomas negativos, positivos e desorganização. Os resultados em sintomas de "excitação" foram significativamente piores no grupo experimental. É possível que a atenção profissional tenha diminuído a ansiedade no grupo controle (Kurzban et al, 2010; Vesterager et al, 2011; Leschener et al, 2012). 
A questão central da reabilitação cognitiva refere-se aos conceitos de generalização/transferência. Ocorre transferência quando o aprendido pode ser aplicado a outro contexto similar de forma direta, enquanto que, na generalização, o novo conhecimento pode ser aplicado com sucesso em uma variedade de novos contextos, explorando estratégias de memória e habilidades cognitivas. $\mathrm{O}$ objetivo final de qualquer programa de reabilitação cognitiva é a generalização, que pode proporcionar autonomia e independência (da Costa et al, 2000). Contudo, a avaliação funcional não apresentou diferenças significativas em nenhum dos grupos.

$\mathrm{Na}$ literatura, os resultados cognitivos favoráveis à terapia de remediação cognitiva (CRT) foram maiores em programas que fizeram uso em conjunto de estratégias de aprendizagem social ao invés de programas que usavam somente práticas repetidas como a técnica de errorless learning proposto pelo Kumon (McGurk et al, 2007). Estudos recentes tem se aprofundado na compreensão do modo como a cognição básica integrada à cognição social exerce influência sobre o desfecho funcional, no qual tem demonstrado o treinamento de errorless learning como facilitador da aprendizagem de novas habilidades através da melhora de variados níveis de memória. No entanto, conforme mencionado por Reeder et al (2006) e Kern et al (2002) a relação entre mudança no funcionamento cognitivo e funcional não ocorre de forma direta e simples, podendo ter fatores mediadores como a motivação intervindo e que precisam ainda ser melhor estudados. 
Nos dias atuais, para a implantação de novos tratamentos terapêuticos, também é sugerido na literatura a necessidade desta intervenção ser eficaz (funcione em condições ideais) e efetiva (funcione em condições reais), cujo benefício possa justificar o seu custo (Daltio et al., 2007). Na literatura não encontramos estudos específicos dos custos diretos com tratamento psicossocial, entretanto, investimentos em tratamento extra-hospitalares são apontados como mais baratos e tendem a trazer menos sofrimento à família que as internações (Leitão et al., 2006; Soares e Menezes., 2001). Neste sentido, embora não testado no estudo, o método de cálculo matemático Kumon se propõem como uma alternativa de terapia de remediação cognitiva extra-hospitalar para pacientes com esquizofrenia a um baixo custo. 


\section{LIMITAÇÕES DO ESTUDO}

O estudo apresenta diversas limitações. Apesar da amostra deste estudo ser compatível com estudos anteriores (Twanley et al, 2003), trata-se de uma amostra pequena, gerando efeitos estatísticos pequenos e que podem não conseguir identificar diferenças sutis de mudanças cognitivas entre os grupos. Seria importante sua replicação em uma amostra maior.

Os instrumentos neuropsicológicos foram estatisticamente analisados utilizando-se os totais brutos. A transformação dos escores brutos em pontuações ponderadas permitiria analisar os dados considerando a idade de cada sujeito, o que poderia gerar resultados diferentes. Muitos instrumentos psicológicos não se mostram sensíveis para apontar variações menores na cognição (Wilson et al, 2003).

A duração do treinamento de cálculos aritméticos pode ter contribuído para a melhora cognitiva menos significativa encontrada. Durante o período de 6 meses de treinamento, só foi possível trabalhar intensamente os estágios iniciais do programa, caracterizada basicamente por questões mais fáceis e simples para o desenvolvimento de uma disciplina de estudo, concentração e incentivar sentimentos de prazer e auto-confiança do aluno em relação ao material estudado. Conforme Bell e colaboradores (2008), são necessários de 6 meses a dois anos para gerar mudanças cognitivas em população com esquizofrenia. 
Quanto ao tamanho da amostra, a literatura relata que os estudos de treino cognitivo na esquizofrenia têm incluído amostras com tamanho variado, de 10 a 91 pacientes (Twanley et al, 2003). Assim, apesar da amostra deste estudo ser compatível com relatos de estudos anteriores, trata-se de uma amostra bastante pequena, o que gera efeitos estatísticos pequenos e que podem não ter o poder de identificar diferenças sutis de mudanças cognitivas entre os grupos. A literatura aponta que testes estatísticos não paramétricos possuem vantagens em relação aos paramétricos, incluindo o fato de evitarem contaminação por outliers (Suslow et al, 2001), tornando-se uma vantagem em estudos com amostras pequenas. No entanto, seria importante que este estudo fosse replicado com uma amostra maior, que pudesse gerar tamanhos de efeitos maiores. 
Mesmo o treino placebo tendo sido elaborado para que os pacientes do grupo controle tivessem uma rotina similar à do grupo experimental, exceto o treino de cálculos aritméticos, este propiciou algum grau de treinamento cognitivo, apesar de inespecífico. Contrário aos resultados cognitivos modestos do estudo, quatro revisões de terapia de remediação cognitiva randomizados controlados em pacientes com esquizofrenia demonstraram melhora dos prejuízos cognitivos em função executiva, atenção e memória, obtendo um tamanho de efeito robusto (0.51), do qual pode ser considerado um efeito mediano (Kurtz \& Richardson, 2011; Twanley et al, 2012). Entretanto, não foi utilizado como critério somente os estudos constituídos por grupos controles caracterizados por tratamento somente farmacológico ou tratamento de intervenção psicossocial não específico, não ficando evidente se os resultados são realmente benefícios da técnica específica de remediação cognitiva. Outros estudos usaram como placebo o treament as usual e os pacientes deste grupo compareciam a consulta a cada 2 meses enquanto os pacientes do grupo controle vinham semanalmente à atividade, criando uma diferença muito grande em termos de estimulação inespecífica entre os dois grupos. Para Jaeger (1999), muitos autores falham em fornecer um grupo controle adequados quando as condições controle não envolvem situação similar ao tratamento experimental. 
Quanto aos instrumentos psicológicos, alguns deles não estão adaptados à população brasileira, e assim, as análises estatísticas foram feitas utilizando-se os totais brutos dos testes. A transformação dos escores brutos em pontuações ponderadas permitiria analisar os dados levando em conta a idade de cada sujeito, o que poderia gerar alguns resultados diferentes.

Outro fator importante em relação aos instrumentos psicológicos é que muitos não se mostram sensíveis para apontar variações menores na cognição. Vários prejuízos cognitivos podem gerar pontuações idênticas ou globalmente deficientes nos testes neuropsicológicos (Wilson et al, 2003). Reeder (2006) e Green (2000) afirmam que os instrumentos neuropsicológicos foram desenvolvidos para diferenciar desempenho cognitivo prejudicado de normal, não conseguindo medir a correlação com domínios funcionais. Sendo assim, em estudos futuros acerca da eficácia de um treinamento de cálculos aritméticos sugere-se a utilização de instrumentos de neuroimagem para um entendimento mais aprofundado das áreas cerebrais estimuladas pela intervenção proposta. Desta forma, as mudanças cognitivas não perceptíveis em medidas de testes neuropsicológicos poderão ser identificadas através do exame de imagem.

Não pode se deixar de considerar a ocorrência de um efeito de treino nos instrumentos neuropsicológicos, pois cada paciente foi submetido a duas avaliações, mas tal efeito foi minimizado pelo fato das avaliações terem ocorrido com um intervalo de tempo de 6 meses, e afetariam os dois grupos igualmente. 
Estudos relatados pela literatura (Twanley et al, 2003; Heydebrand, 2007) mostram uma grande variação na duração total (um dia a nove meses), quantidade de sessões (de uma única sessão a 36), duração das sessões (de 20 a 60 minutos) e freqüência do treino, não havendo ainda um consenso quanto ao que seria ideal neste sentido. Procurou-se manter a programação original Kumon em frequência (duas vezes semanais) e duração das sessões (50 minutos) a fim se obter dados os mais fidedignos possíveis do que seja o treinamento de cálculos aritméticos administrados pelo método Kumon, porém também se mostrou compatível com o que descreve a literatura. No entanto, conforme descrito por Bell e colaboradores (2003), pode ser que mais tempo seja necessário para propiciar mudanças na neuroplasticidade em atenção, memória e funções executivas, podendo levar em média de 6 meses a dois anos para apresentar resultados em população com esquizofrenia. Além disso, conforme a metodologia experimental avaliada, inicialmente, é oferecida operações matemáticas mais fáceis e de fácil domínio para incentivo da autoconfiança e prazer do aluno ao conteúdo estudado, necessitando de um período de tempo maior para avançar em estágios mais complexos e estimuladores do raciocínio lógico propriamente dito. 
Outro fator relatado importante na literatura é a questão da motivação e o quanto esta pode interferir nos ganhos obtidos com o treino cognitivo (Velligan et al, 2006; Wykes \& Spaulding, 2011). No entanto, não está claro como os fatores emocionais atuam sobre a cognição e medidas de avaliação da motivação precisam ainda ser desenvolvidas (Medalia e Saperstein, 2011). No entanto, ainda que este estudo não tenha incluído um instrumento para avaliação da motivação, as atividades controle ocorreram de maneira prazerosa e consequentemente, pode ter estimulado cognitivamente os pacientes.

Assim, mesmo o treino placebo ter sido cuidadosamente elaborado de modo a facilitar o cegamento dos pacientes e manter algumas características do treino cognitivo (mesmo local, freqüência semanal e duração), este parece ter propiciado algum grau de treinamento cognitivo, pois em uma população ambulatorial muito cronificada como a incluída na pesquisa, qualquer recrutamento de funções cognitivas, mesmo advindas de atividades inespecíficas, acabaram estimulando a cognição desta população. Neste sentido, seria interessante que este estudo fosse replicado utilizandose outro tipo de atividade para o grupo controle, que fizesse menos exigências sobre o desempenho cognitivo. 
$\mathrm{Na}$ literatura, recomenda-se que em estudos randomizados os raters e neuropsicólogos mantenham-se totalmente cegos ao tratamento realizado pelo paciente, a fim de amenizar as chances de viés por parte dos avaliadores, ou seja, interferência dos resultados através de uma interpretação subjetiva durante a avaliação dos pacientes (de Vreese et al, 2001). No entanto, neste estudo não foi possível a ocorrência da avaliação duplo-cega, pois durante a avaliação eram comuns os relatos dos pacientes relativos aos grupos que participaram no estudo. 


\section{CONCLUSÕES}

Os resultados do estudo foram modestos e respondem parcialmente às hipóteses, indicando que o treino cognitivo através do cálculo aritmético Kumon durante 6 meses propicia poucas melhoras cognitivas na população com esquizofrenia, sendo mais evidente sobre o subdomínio de atenção sustentada. Contudo, a sua melhora não pôde ser associada com função executiva e memória de trabalho, além das mudanças cognitivas não terem sido suficientes para impactar significativamente a vida pessoal e social dos indivíduos. A estimulação inespecífica oferecida pela recreação (grupo placebo) indica que mesmo atividades simples que se propõem a não estimular cognitivamente o paciente tende a melhorar déficits cognitivos da esquizofrenia. Outros ensaios por períodos mais longos de tempo são necessários para avaliar o impacto do método Kumon na cognição de pacientes com esquizofrenia. 


\section{REFERÊNCIAS BIBLIOGRÁFICAS}

Ackerman PL, Beier ME, Boyle MO.Working memory and intelligence: the same or different constructs?Psychol Bull. 2005 Jan;131(1):30-60.

Alloway, T. P. How does working memory work in the classroom? Educational Research and Reviews Vol. 1 (4), pp. 134-139, July 2006.

Alloway TP, Alloway RG. Investigating the predictive roles of working memory and IQ in academic attainment. J Exp Child Psychol. 2010 May;106(1):20-9.

American PsichiatricAssociation. Manual de diagnóstico e estatística DSM-IV TR tm. $4^{\circ}$ ed. Porto Alegre: ArtesMédicas; 2002.

Andersson U, Lyxell B. Working memory deficit in children with mathematical difficulties: a general or specific deficit? J Exp Child Psychol. 2007 Mar;96(3):197-228.

Ashkenazi S, Henik A. Does attentional training improve numerical processing in developmental dyscalculia? Neuropsychology. 2012 Jan;26(1):45-56.

Ashkenazi S, Henik A. Attentional networks in developmental dyscalculia.Behav Brain Funct. 2010 Jan 7;6:2.

Baddeley A, Della Sala S, Papagno C, Spinnler H. Dual-task performance in dysexecutive and nondysexecutive patients with a frontal lesion.Neuropsychology. 1997 Apr;11(2):187-94.

Baddeley A, Della Sala S. Working memory and executive control.Philos Trans R SocLond B Biol Sci. 1996 Oct 29; 351(1346):1397-403; discussion 1403-4.

Baddeley A, Gathercole S, Papagno C. The phonological loop as a language learning device.Psychol Rev.1998 Jan;105(1):158-73.

Baddeley A. Working memory: theories, models, and controversies.Annu Rev Psychol. 2012 Jan 10; 63:1-29.

Baddeley, A.D. e Hitch, G. (1974).Working Memory.Em: Bower, G.A. (Ed). Recent advances in learning and motivation. New York: Academic Press. 
Baddeley A. The episodic buffer: a new component of working memory? Trends Cogn Sci. 2000Nov 1;4(11):417-423.

Baddeley AD. Is working memory still working? Am Psychol. 2001 Nov;56(11):851-64.

Baddeley A. Working memory and language: an overview. J Commun Disord. 2003 May-Jun;36(3):189-208.

Baddeley AD, Allen RJ, Hitch GJ. Binding in visual working memory: the role of the episodic buffer. Neuropsychologia. 2011 May;49(6):1393-400.

Baddeley AD. (2002). Fractionating the central executive. In D.T. Atnss \& R.T. Knight (Eds.). Principles of frontal lobe function (pp. 246-260). New York: Oxford University Press.

Bak M, Krabbendam L, Delespaul P, Huistra K, Walraven W, Van OSJ. Executive function does not predict coping with symptoms in stable patients with a diagnosis of schizophrenia. BMC Psychiatry. 2008; 29; 8:39.

Banhato EFC, Nascimento E. Função Executiva em idosos: um estudo utilizando subtestes da Escala WAIS-II. Psico-USF.2007; 12: 65-73.

Bell M, Bryson G, Wexler BE. Cognitive remediation of working memory deficits: durability of training effects in severely impaired and less severely impaired schizophrenia. Acta Psychiatr Scand. 2003 Aug;108(2):101-9.

Berg DH. Working memory and arithmetic calculation in children: the contributory roles of processing speed, short-term memory, and reading. $\mathrm{J}$ Exp Child Psychol. 2008 Apr;99(4):288-308.

Bilder RM. Neirocognitive impairment in schizophrenia and how it affects treatment options. Can. J. Psychiatric 42. 1997; 255-264.

Brasil, Ministério da Educação e Cultura. Instituto Nacional de Estudos e Pesquisas Educacionais- SAEB: relatório nacional 2003, Brasília, O Instituto, p. 1-90, 2006. Disponível em:<htttp/www.inep.gov.br>.

Bell M, Tsang HWH, Greig TC, Bryson GJ. Neurocognition, social cognition, perceived social discomfort, and vocational outcomes in schizophrenia. Schizophr Bull 2008;35:738-747.

Bull R, Espy KA, Wiebe SA. Short-term memory, working memory, and executive functioning in preschoolers: longitudinal predictors of mathematical achievement at age 7 years. DevNeuropsychol. 2008; 33(3):205-28.

Bull R, Johnston R. S, Roy A. J. Exploring the roles of the visual-spacial sketch pad and central executive in children's arithemetical skills: views from 
cognition and developmental neuropsychology. 1999; Developmental Neuropsychology, 15(3), 421-442.

Bull R, Scerif G. Executive functioning as a predictor of children's mathematics ability: inhibition, switching, and working memory. DevNeuropsychol. 2001; 19(3):273-93.

Butterworth B, Varma S, Laurillard D. Dyscalculia: from brain to education.Science. 2011 May 27; 332(6033): 1049-53.

Chaves, A. C. Diferenças entre sexos na esquizofrenia. Revista Brasileira de Psiquiatria, v. 22: 21-22, s. 1. São Paulo mayo 2000.

Choi K, Kwon J.(2006). Social Cognition Enhancement Training for Schizophrenia: A Preliminary Randomized Controlled Trial. Community Mental Health Journal, 42, 2, (April 2006), pp. 177-187.

Conners, K. Conners' CPT II - Continuous Performance Test II. Multi-Health Systems Inc., 2002.

Costa AJ, Silva JB, Chagas PP, Krinzinger H, Lonneman J, Willmes K, Wood G, Haase VG. A hand full of numbers: a role for offloading in arithmetics learning? Front Psychol. 2011;2:368.

Conway MA. Cognitive neuroscience: Repression revisited. Nature. 2001 Mar $15 ; 410(6826): 319-20$.

Conway, ARA; Cowan, N.; Bunting, MF; Therriault, DJ e Minkoff, SRB. (2002). A latent variable analysis of working memory capacity, short-term memory capacity, processing speed, and general fluid Intelligence, 30, 63183.

Corso, LV. Dificuldades na leitura e na matemática: um estudo dos processos cognitivos em alunos da $3^{\mathrm{a}}$ a $6^{\mathrm{a}}$ série do ensino fundamental. 2008, 218f. Tese (Doutorado em Educação) - Universidade Federal do Rio Grande do Sul, Porto Alegre, 2008.

Coutinho, E S F et al. Censo de pacientes internados em uma instituição asilar no estado do Rio de Janeiro: dados preliminares. Cadernos de Saúde Pública, v. 18, n. 6, p. 1803-1807, 2002.

Coutinho ESF, Almeida Filho N, Mari JJ. Fatores de risco para morbidade psiquiátrica menor: resultados de um estudo transversal em três áreas urbanas no Brasil. Rev Psiq Clín 1999; 26(5).

Dahaene S, Cohen L. Towards an anatomical and functional model of number processing. Math cognition 1995;1:83-120. 
da Costa, RMEM; de Carvalho' LAV. The acceptance of virtual reality devices for cognitive rehabilitation: a report of positive results with schizophrenia. Computer Methods and Programs in Biomedicine, Volume 73, Issue 3, March 2004, Pages 173-182.

Daltio CS, Mari JJ, Ferraz MB. Estudos farmacoeconômicos e carga da doença em esquizofrenia. Rev. Psiq. Clín. 34, supl2; 208-212, 2007.

Dawes SE, Jeste DV, Palmer BW. Cognitive profiles in persons with chronic schizophrenia. J ClinExpNeuropsychol. 2011; 33(8):929-36.

Dawes SE, Jeste DV, Palmer BW. Cognitive profiles in persons with chronic schizophrenia. J ClinExpNeuropsychol.2011Oct;33(8):929-36.

De Vreese LP; Neri M; Fiovaranti M; Belloi L; Zanneti O. - Memory Rehabilitation in Alzheimer's disease: a review of progress. Int. Journal of Geriatric Psychiatry 16: 794-809, 2001.

Delgado P, Leal E, Venâncio A. O campo da atenção psicossocial Anais do 1 Congresso de Saúde Mental do Rio de Janeiro. Rio de Janeiro: TeCora, 1997.

Dickinson D, Bellack AS, Gold JM. Social/communication skills, cognition, and vocational functioning in schizophrenia. Schizophr Bull. 2007 Sep;33(5):1213-20.

Farreny A, Aguado J, Ochoa S, Huerta-Ramos E, Marsà F, López-Carrilero $R$, Carral V, Haro JM, Usall J. REPYFLEC cognitive remediation group training in schizophrenia: Looking for an integrative approach. Schizophr Res. 2012 Dec;142(1-3):137-44

Frith, CD. The cognitive Neuropsychologic of Schizophrenia. Eribaum, Hove,1992.

Fuchs LS, Fuchs D. Mathematical problem-solving profiles of students with mathematics disabilities with and without comorbid reading disabilities. J Learn Disabil. 2002 Nov-Dec;35(6):563-7.

Gathercole SE, Pickering SJ, Ambridge B, Wearing H. The structure of working memory from 4 to 15 years of age. Dev Psychol. 2004 Mar;40(2):177-90. 
Gathercole SE, Alloway TP. Practitioner review: short-term and working memory impairments in neurodevelopmental disorders: diagnosis and remedial support. J Child Psychol Psychiatry. 2006 Jan;47(1):4-15.

Geary DC, Wiley JG. Cognitive addition: strategy choice and speed-ofprocessing differences in young and elderly adults. Psychol Aging. 1991 Sep;6(3):474-83.

Geary DC, Hoard MK, Hamson CO. Numerical and arithmetical cognition: patterns of functions and deficits in children at risk for a mathematical disability. J Exp Child Psychol. 1999 Nov;74(3):213-39.

Geary DC. Consequences, characteristics, and causes of mathematical learning disabilities and persistent low achievement in mathematics.J DevBehavPediatr. 2011 Apr; 32(3):250-63.

Geary DC. Mathematical Disabilities: Reflections on Cognitive, Neuropsychological, and Genetic Components. Learn Individ Differ. 2010 Apr $1 ; 20(2): 130$.

Green MF. What are the functional consequences of neurocognitive deficits in schizophrenia? Am. J. Psychiat. 1996; 153, 3121-330.

Gray JA, Feldon J, Rawlins JNP, Hemsley DR, Smith AD. The neuropsychologic of schizophrenia. Behav. Brain Sci. 1991; 14, 1-84.

Gross-Tsur V, Manor O, Shalev RS.Developmental dyscalculia: prevalence and demographicfeatures. Dev Med Child Neurol.1996 Jan;38(1):25-33.

Harvey PD, Sharma T (2002) Understanding and Treating Cognition in Schizophrenia: A Clinician's Handbook. London: Martin Dunitz.

Heaton RK. WCST-64: Computer Version 2 - Research Edition. Psychological assessment Resources, Inc., 2003.

Heydebrand G. Cognitive deficits in the families of patients with schizophrenia. Curr Opin Psychiatry. 2006 May;19(3):277-81.

Hitch G, McAuley E. Working memory in children with specific arithmetical learning difficulties. British Journal of Psychology. vol 82, issue 3, pp. 375386, August 1991.

Henson RN, Burgess N, Frith CD. Recoding, storage, rehearsal and grouping in verbal short-term memory: an fMRI study. Neuropsychologia. 2000;38(4):426-40. 
Hogarty GE, Flesher S, Ulrich R, Carter M, Greenwald D, Pogue-Geile M, Kechavan M, Cooley S, DiBarry AL, Garrett A, Parepally H, Zoretich R. Cognitive enhancement therapy for schizophrenia: effects of a 2-year randomized trial on cognition and behavior. Arch Gen Psychiatry. 2004 Sep;61(9):866-76.

Hope ACA. A simplified Monte Carlo Significance Test Procedure. JR Stat Soc Ser B, 1968; 30(3): 582-98.

Horan WP, Kern RS, Shokat-Fadai K, Sergi MJ, Wynn JK, Green MF.(2008). Social cognitive skills training in schizophrenia: an initial efficacy study of stabilized outpatients. Schizophrenia Research, 107,1, (January 2009), pp. 47-54.

Horton HK, Silverstei SM.(2008). Social cognition as a mediator of cognition and outcome among deaf and hearing people with schizophrenia.Schizophrenia Research, 105, (August 2008), pp. 125-137.

Hurford IM, Marder SR, Keefe RS, Reise SP, Bilder RM. A brief cognitive assessment tool for schizophrenia: construction of a tool for clinicians. Schizophr Bull. 2011 May;37(3):538-45.

Iseman JS, Naglieri JA. A cognitive strategy instruction to improve math calculation for children with ADHD and LD: a randomized controlled study. J Learn Disabil. 2011 Mar-Apr;44(2):184-95.

Jaeger J. Studying the effectiveness of neurocognitive remediation in schizophrenia. Schizophrenia Bulletin, 25(2): 193-194, 1999.

Jaeger J. Letters to the Editor - Studying the Effectiveness of Neurocognitive Remediation in Schizophrenia. Schizophrenia Bulletin, Vol. 25, No. 2, 1999.

Juckel G, Schaub D, Fuchs N, Naumann U, Uhl I, Witthaus H, Hargarter L, Bierhoff $\mathrm{H}$, Brüne M. Validation of the Personal and Social Performance (PSP) Scale in a German sample of acutely ill patients with schizophrenia.Schizophr Res. 2008; 104(1-3):287-93.

Kaufmann L. More evidence for the role of the central executive in retrieving arithmetic facts - a case study of severe developmental dyscalculia. J Clin Exp Neuropsychol. 2002 May;24(3):302-10.

Kawashima R, Okita K, Yamazaki R, Tajima N, Yoshida H, Taira M, Iwata K, Sasaki T, Maeyama K, Usui N, Sugimoto K. Reading aloud and arithmetic calculation improve frontal function of people with dementia. J Gerontol A BiolSci Med Sci. 2005 Mr; 60(3): 380-4.

Kay SR, Fizbein A, Opler LA.The positive and negative syndrome scale for schizophrenia.Schizphr Bull. 1987; 13:261-76. 
Kern RS, Green MF, Mitchell S, Kopelowicz A, Mintz J, Liberman RP. Extensions of errorless learning for social problem-solving deficits in schizophrenia.Am J Psychiatry. 2005 Mar;162(3):513-9.

Kern RS, Liberman RP, Becker DR, Drake RE, Sugar CA, Green MF. Errorless learning for training individuals with schizophrenia at a community mental health setting providing work experience.Schizophr Bull. 2009 Jul;35(4):807-15.

Kern RS, Liberman RP, Kopelowicz A, Mintz J, Green MF. Applications of errorless learning for improving work performance in persons with schizophrenia. Am J Psychiatry. 2002 Nov;159(11):1921-6.

Kern RS, Nuechterlein KH, Green MF, Baade LE, Fenton WS, Gold JM, Keefe RS; Mesholan-Gateli R, Mintz J,Seidman LJ, Stover E, Marder SR. The MATRICS Consensus Cognitive Battery, part 2: co-norming and standardization. J Psychiatry. 2008; 165(2):214-20.

Kiefer M, Apel A, Weisbrod M. Arithmetic fact retrieval and working memory in schizophrenia. Schizophr Res. 2002 Jan 15;53(3):219-27.

Keefe RS, Harvey PD. Cognitive impairment in schizophrenia. Handb Exp Pharmacol. 2012;(213):11-37.

Kraemer HC, Kupter DJ. Size of treatment effects and their importance to clinical research and practice.Biol Psychiatry. 2006; 59(11):990-6.

Kramer P, Bressan P, Grassi M. Time estimation predicts mathematical intelligence. PLoS One. 2011;6(12):e28621.

Kraus MS, Keefe RS.Cognition as an outcome measure in schizophrenia.J PsychiatrySuppl. 2007; 50:46-51.

Kyttälä $M$, Aunio $P$, Hautamäki J. Working memory resources in young children with mathematical difficulties. Scand J Psychol. 2010 Feb;51(1):115.

Kokubo N, Inagaki M, Gunji A, Kobayashi T, Ohta H, Kajimoto O, Kaga M. Developmental change of visuo-spatial working memory in children: Quantitative evaluation through an Advanced Trail Making Test. Brain Dev. 2012 Mar 5.

Kumon T. Buscando o infindável potencial humano. Ed. Kumon, 1999. 
Kumon T. Estudo gostoso de matemática - O segredo do método Kumon. $10^{\circ}$ ed. - São Paulo: Kumon Instituto de Educação, 2005.

Kurtz MM, Seltzer JC, Shagan DS, Thime WR, Wexler BE. Computerassisted cognitive remediation in schizophrenia: what is the active ingredient? Schizophr Res. 2007 Jan;89(1-3):251-60.

Kurtz MM, Richardson CL. (2011). Social cognitive training for schizophrenia: a meta-analytic investigation of controlled research. Schizophrenia Bulletin, (April 2011), pp. 1-12.

Kurzban S, Davis L, Brekke JS. Vocational, social, and cognitive rehabilitation for individuals diagnosed with schizophrenia: a review of recent research and trends. Curr Psychiatry Rep. 2010 Aug;12(4):345-55

Lagace DC, Kutcher SP, Robertson HA.Mathematics deficits in adolescents with bipolar I disorder. Am J Psychiatry. 2003 Jan;160(1):100-4.

Landerl K, Bevan A, Butterworth B. Developmental dyscalculia and basic numerical capacities: a study of 8-9-year-old students. Cognition. 2004 Sep;93(2):99-125.

Le CT. Introductory Biostatistics.New York, 2003: Wiley and Sons, 210-224.

Leitão RJ, Ferraz MB, Chaves AC, Mari JJ.Cost of schizophrenia: direct costs and use of resources in the State of São Paulo. RevSaudePublica. 2006 Apr;40(2):304-9.

Lee KM, Kang SY. Arithmetic operation and working memory: differential suppression in dual tasks. Cognition. 2002 Apr;83(3):B63-8.

Lee K, Ng SF, Pe ML, Ang SY, Hasshim MN, Bull R. The cognitive underpinnings of emerging mathematical skills: executive functioning, patterns, numeracy, and arithmetic. Br J Educ Psychol. 2012 Mar;82(Pt 1):82-99.

Lezak MD. The problem of assessing executive functions. Int J Psychol 1982; 17: 281-97.

Logie R.H. (1995). Visuo-espacial working memory. Hove: Lawrence Eribanm.

Louzã Neto MR, Elkis H. Esquizofrenia. In: LouzãNeto MR, Elkis H. e cols. Psiquiatria Básica. 2 ed. São Paulo: Artmed, 2007. 
Luck ST, Gold JM. The Construct of Attention in Schizophrenia. Biol Psychiatry. 2008; 64(1):34-9.

Luria AR. Higher cortical functions in man. New York, NY: Basic Books; 1966.

McCloskey M, Caramazza A, Basili A. Cognitive mechanisms in number processing and calculation: evidence from dyscalculia. Brain Cognition 1985;4:171-96.

McGurk SR, Twamley EW, Sitzer DI, McHugo GJ, Mueser KT. A metaanalysis of cognitive remediation in schizophrenia. Am J Psychiatry. 2007 Dec;164(12):1791-802.

McLean JF, Hitch GJ. Working memory impairments in children with specific arithmetic learning difficulties. J Exp Child Psychol. 1999 Nov;74(3):240-60.

Medalia A, Saperstein A. The role of motivation for treatment success.Schizophr Bull. 2011; 37(Suppl 2).

Medalia A, Richardson $R$. What predicts a good response to cognitive remediation interventions? Schizophr Bull. 2005 Oct;31(4):942-53.

Medeiros, E. N. Prevalência dos transtornos mentais e perfil sócioeconômico dos usuários atendidos nos serviços de saúde dos municípios paraibanos. 119 p. Dissertação (Mestrado). Centro e Ciências da Saúde da UFP, João Pessoa, PB, 2005.

Mesholam-GatelyRI, Giuliano AJ, Goff KP, Faraone SV, Seidman LJ. Neurocognition in first-episode schizophrenia:a meta-analytic review. Neuropsychology. 2009; 23(3): 315-36.

Menon V. Developmental cognitive neuroscience of arithmetic: implications for learning and education. ZDM. 2010 Oct;42(6):515-525.

Miyake A, Friedman NP, Emerson MJ, Witzki AH, Howerter A, Wager TD. The unity and diversity of executive functions and their contributions to complex "Frontal Lobe" tasks: a latent variable analysis.CognPsychol. 2000 Aug;41(1):49-100.

Miranda Casas A, Meliá de Alba A, Marco Taverner R. [Mathematical abilities and executive function in children with attention deficit hyperactivity disorder and learning disabilities in mathematics]. Psicothema. 2009 Feb;21(1):63-9. 
Miranda, C. A.; Tarasconi, C. V.; Scortegagna, S. A. Estudo epidêmico dos transtornos mentais. Avaliação Psicológica (online), v.7, n.2, p.249-267, 2008 [acesso em 23 outubro 2009].Disponívelem:http://pepsic.bvspsi.org.br/scielo.php?script=sci_arttext\& pid=S167704712008000200015\&lng=pt\&nrm=iso\&tlng=pt.

Miller EK \& Cohen JD (2001). An integrative theory of prefrontal córtex function. Annual Review of Neuroscience, 24, 167-202.

Monteiro LC, Louzã MR. Alterações cognitivas na esquizofrenia: consequêencias funcionais e abordagens terapêuticas. Rev. Psiquiatr clín. 2007; 34: 179-83.

Navarro JI, Aguilar M, Marchena E, Ruiz G, Menacho I, Van Luit JE. Longitudinal study of low and high achievers in early mathematics. Br J Educ Psychol. 2012 Mar;82(Pt 1):28-41.

Newcombe NS, Ambady N, Eccles J, Gomez L, Klahr D, Linn M, Miller K, Mix $\mathrm{K}$. Psychology's role in mathematics and science education. Am Psychol. 2009 Sep;64(6):538-50.

Nuechterlein KH, Green MF, Kern RS, Baade LE, Barch DM, Cohen JD, Essock S, Fenton WS, Frese FJ 3rd, Gold JM, Goldberg T, Heaton RK, Keefe RS, Kraemer H, Mesholam-GatelyR, Seidman LJ, Stover E, Weinberger DR, Young AS, Zalcman S, Marder SR. The MATRICS Consensus Cognitive Battery, part 1: test selection, reliability, and validity. Am JPsychiatry. 2008 Feb;165(2):203-1

Norman DA \& Shallice T. (1986). Attention to action:Willed and automatic control of behavior: In R.J. Davidson, G.E.Schwartz, D. Shapiro (Eds.), Consciousness and self-regulation (v.4.pp. 1-18). New York:Plenum.

Oberauer K, Wendland M, Kliegl R. Age differences in working memory--the roles of storage and selective access.MemCognit. 2003 Jun;31(4):563-9.

O'Brien PC, Zhang D, Bailey KR. Semi-parametric and non-parametric methods for clinical trials with incomplete data. Stat Med. 2005; 24(3):341358.

O'Carroll RE, Russell HH, Lawrie SM, Johnstone EC.Errorless learning and the cognitive rehabilitation of memory-impaired schizophrenic patients.Psychol Med. 1999 Jan;29(1):105-12.

O'donnel BF. Cognitive impairment in schizophrenia: a life span perspective. Br J Psychiatry. 2008; 192(4):248-57. 
O'Donnell K, O'Connor TG, Glover V. Prenatal stress and neurodevelopment of the child: focus on the HPA axis and role of the placenta.DevNeurosci. 2009; 31(4):285-92.

Passolunghi MC, Lanfranchi S. Domain-specific and domain-general precursors of mathematical achievement: a longitudinal study from kindergarten to first grade. Br J Educ Psychol. 2012 Mar;82(Pt 1):42-63.

Passolunghi MC, Siegel LS. Short-Term Memory, Working Memory, and Inhibitory Control in Children with Difficulties in Arithmetic Problem Solving. Journal of Experimental Child Psychology 80, 44-57 (2001).

Passolunghi MC, Siegel LS. Working memory and access to numerical information in children with disability in mathematics. J. Experimental Child Psychology 88 (2004) 348-367.

Pavuluri MN, O'Connor MM, Harral EM, Moss M, Sweeney JA. Impact of Neurocognitive Function on Academic Difficulties Pediatric Bipolar Disorder: A clinical Translation. Biol Psychiatry. 2006 Nov 1;60(9):951-6.

Pope JW, Kern RS.An "errorful" learning deficit in schizophrenia?J ClinExpNeuropsychol. 2006 Jan;28(1):101-10.

Prentice KJ, Gold JM, Buchanan RW. The Wisconsin Card Sorting impairment in schizophrenia is evident in the first four trials. Schizophr Res. 2008; 106(1):81-87.

Rabelo, A. R.; Cardoso, E.; Melo, A. Características sociodemográficas da população psiquiátrica internada nos hospitais do sistema único de saúde do estado da Bahia. Revista Baiana de Saúde Pública, v. 29, n. 1, p. 43-56, 2005.

Reber PJ, Squire LR.Parallel brain systems for learning with and without awareness.Learn Mem.1994 Nov-Dec;1(4):217-29.

Reed RA, Harrow M, Herbener ES, Martin EM. Executive function in schizophrenia: is it linked to psychosis and poor life functioning? J NervMent Dis. 2002; 190(11):725-32.

Reeder C, Smedley N, Butt K, Bogner D, Wykes T. Cognitive predictors of social functioning improvements following cognitive remediation for schizophrenia. Schizophr. Bull, 2006; 32 (S1) : S123-31.

Reitan RM. Validity of the Trail Making Test as a indicator of organic brain damage. Percept Motor, Skills.1958; 8:271-6. 
Repovs G, Baddeley A. The multi-component model of working memory: explorations in experimental cognitive psychology. Neuroscience. 2006 Apr 28;139(1):5-21.

Rey A. Teste de cópia e de reprodução de memória de figuras geométricas complexas. Adaptação brasileira. Tradução Oliveira, M.S., São Paulo: Casa do Psicólogo, 1998; 1999.

Rosca EC. A case of acalculia due to impaired procedural knowledge. Neurol Sci. 2009 Apr; 30(2):163-70.

Roussel $\mathrm{M}$, Dujardin $\mathrm{K}$, Hénon $\mathrm{H}$, Godefroy $\mathrm{O}$. Is the frontal dysexecutive syndrome due to a working memory deficit? Evidence from patients with stroke. Brain. 2012 Jul; 135(Pt 7):2192-201.

Rubinsten O, Henik A. Developmental dyscalculia: heterogeneity might not mean different mechanisms. Trends Cogn Sci. 2009 Feb; 13(2):92-9.

Rubinsten O, Henik A. Developmental dyscalculia: heterogeneity might not mean different mechanisms. Trends Cogn Sci. 2009 Feb;13(2):92-9.

Ruiz JC, Soler MJ, Fuentes I, Tomás P. Intellectual functioning and memory deficits in schizophrenia. Compr Psychiatry. 2007; 48(3):276-82.

Shalev RS, Gross-Tsur V.Developmental dyscalculia.Pediatr Neurol. 2001 May;24(5):337-42.

Shallice T, Burgess $P$. The domain of supervisory processes and temporal organization of behaviour.Philos Trans R SocLond B Biol Sci. 1996 Oct 29;351(1346):1405-11.

Sigmundsson H, Anholt SK, Talcott JB. Are poor mathematics skills associated with visual deficits in temporal processing? NeurosciLett. 2010 Jan 22; 469(2):248-50.

Simon AE, Giacomini V, Ferrero F, Mohr S. Dysexecutive syndrome and social adjustment in schizophrenia. Aust N Z J Psychiatry. 2003 Jun;37(3):340-6.

Soares CR, Menezes PR. Avaliação do impacto econômico em famílias de pacientes com transtornos mentais graves. Rev. Psiq. Clín. 28 (4):183-190, 2001. 
Spreen O, Etrauss E. A Compedium of Neuropsychological Tests: Administration, Norms, and Commentary. New York: Oxford University Press, 1998.

Squire L.R. Declarative and nondeclarative memory: multiple brain systems supporting learning and memory. J CognNeurosci 1992;99:195-231.

Strauss ME. Strauss ME. Schizophr Bull. 1993; 19(2):215-31.

Stroop JR. Studies of interference in serial verbal reactions.J Exp Psychol. $1935 ; 18: 643-62$.

Swerdlow NR. Are we studying and treating schizophrenia correctly? Schizophr Res. 2011 Aug; 130(1-3):1-10.

Szöke A, Trandafir A, Dupont ME, Méary A, Schürhoff F, Leboyer M. Longitudinal studies of cognition in schizophrenia: meta-analysis. $\mathrm{Br} \mathrm{J}$ Psychiatry. 2008 Apr;192(4):248-57.

Swanson HL, Sachse-Lee C. Mathematical problem solving and working memory in children with learning disabilities: both executive and phonological processes are important. J Exp Child Psychol. 2001 Jul;79(3):294-321.

Suslow T, Schonauer K, Arolt V. Attention training in the cognitive rehabilitation of schizophrenic patients: a review of efficacy studies. Acta Psychiatr Scand. 2001 Jan;103(1):15-23.

Takatori, Marisa. A terapia ocupacional no processo de reabilitaçäo: construçäo do cotidiano. Mundo saúde (Impr.) (1995); 25(4):371-377, out.dez. 2001.

Toll SW, Van der Ven SH, Kroesbergen EH, Van Luit JE. Executive functions as predictors of math learning disabilities. J Learn Disabil. 2011 NovDec;44(6):521-32.

Uchida S, Kawashima R. Reading and solving arithmetic problems improves cognitive functions of normal aged people: a randomized controlled study. Age (Dordr). 2008 Mar; 30(1): 21-9.

Van der Gaag M, Cuijpers A, Hoffman T, Remijsen M, Hijman R, de Haan L, van Meijel B, van Harten PN, Valmaggia L, de Hert M, Wiersma D. The fivefactor model of the Positive and Negative Syndrome Scale I: confirmatory factor analysis fails to confirm 25 published five-factor solutions. Schizophrenic Res. 2006 Jul; 85(1-3):273-9. 
Van der Gaag M, Hoffman T, Remijsen M, Hijman R, de Haan L, van Meijel B, van Harten PN, Valmaggia L, de Hert M, Cuijpers A, Wiersma D. The fivefactor model of the Positive and Negative Syndrome Scale II: a ten-fold cross-validation of a revised model. Schizophr Res. 2006 Jul;85(1-3):280-7.

Velligan DI, Kern RS, Gold JM. (2006a). Cognitive Rehabilitation for Schizophrenia and the Putative Role of Motivation and Expectancies. Schizophr Bull, 32(3):474-85

Veltro F, Mazza M, Vendittelli N, Alberti M, Casacchia M, Roncone R. A comparison of the effectiveness of problem solving training and of cognitiveemotional rehabilitation on neurocognition, social cognition and social functioning in people with schizophrenia.ClinPractEpidemiolMent Health.2011; 7:123-32.

Ventura, J; Hellemann, GS; Thames, AD; Koellner, V; Nuechterlein, KH. Symptoms as mediators of the relationship between neurocognition and functional outcome in schizophrenia: A meta-analysis Schizophr Res. 2009 September; 113(2-3): 189-199.

Vesterager L, Christensen TØ, Olsen BB, Krarup G, Forchhammer HB, Melau M, Gluud C, Nordentoft M. Cognitive training plus a comprehensive psychosocial programme (OPUS) versus the comprehensive psychosocial programme alone for patients with first-episode schizophrenia (the NEUROCOM trial): a study protocol for a centrally randomised, observerblinded multi-centre clinical trial. Trials. 2011 Feb 9;12:35.

Vita A, De Peri L, Barlati S, Cacciani P, Deste G, Poli R, Agrimi E, Cesana $B M$, Sacchetti E. Effectiveness of different modalities of cognitive remediation on symptomatological, neuropsychological, and functional outcome domains in schizophrenia: A prospective study in a real-world setting. Schizophr Res. $2011 ; 8$.

Van der Ven SH, Kroesbergen EH, Boom J, Leseman PP. The development of executive functions and early mathematics: a dynamic relationship. $\mathrm{Br} J$ Educ Psychol. 2012 Mar;82(Pt 1):100-19.

Walker DM, Standen PJ.Level and pattern of neuropsychological functioning in early-onset psychoses. Eur Child Adolesc Psychiatry.2011; 12.

Wechsler D. Wechsler Abbreviates Scaled of intelligence - San Antonio: Psychological Corporation, 1999.

Wechsler D. Wechsler D. Wechsler Intelligence Scale - 3o ed. New York: Psychological Corporation, 1997. 
Wilson BA. Case studies in neurophisicological rehabilitation. Oxford: Oxford University Press, 1999.

Wilson, BA; Herbert, C; Sheil, A. (2003) Behavioural Approaches in Neuropsychological Rehabilitation: Optimising rehabilitation procedures, Psychological Press.

Wykes T, Newton E, Landau S, Rice C, Thompson N, Frangou S. Cognitive remediation therapy (CRT) for young early onset patients with schizophrenia: an exploratory randomized controlled trial. Schizophr Res. 2007; 94(1-3):22130

Wykes T, Huddy V, Cellard C, McGurk SR, Czobor P. A meta-analysis of cognitive remediation for schizophrenia: methodology and effect sizes. Am J Psychiatry. 2011; 168(5):472-85.

Wykes T, Reeder C, Landau S, Everitt B, Knapp M, Patel A, Romeo R. Cognitive remediation therapy in schizophrenia: randomised controlled trial. J Psychiatry.2007; 190:421-7.

Wykes T, Spaulding WD. Thinking about the future cognitive remediation therapy--what works and could we do better? Schizophr Bull. 2011; 37(suppl 2).

Wykes $T$, van der Gaag M. Is it time to develop a new cognitive therapy for psychosis--cognitive remediation therapy (CRT)? ClinPsychol Rev.2001 Nov;21(8):1227-56.

Zheng X, Swanson HL, Marcoulides GA. Working memory components as predictors of children's mathematical word problem solving. J Exp Child Psychol. 2011 Dec;110(4):481-98. 


\section{ANEXOS}

Relação de atividades executadas no grupo controle.

\begin{tabular}{|c|c|}
\hline 1 & RABALHO DE TEMA LIVRE COM RECORTES DE REVISTA E P/ \\
\hline 2 & PINTURA EM TELA - TEMA LIVRE \\
\hline 3 & TRABALHO LIVRE COM PVA \\
\hline 4 & TRABALHO COM CANUDOS FEITOS COM PAPEL DE REVISTA \\
\hline 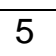 & TRABALHO LIVRE COM BOLINHAS DE PAPEL DE SEDA \\
\hline 6 & CONFECÇÁO DE MURAL COM ISOPOR \\
\hline 7 & DESENHO LIVRE EM PAPEL PARDO COM HIDROCOR \\
\hline 8 & DESENHO LIVRE EM PAPEL OFICIO COM TINTA \\
\hline 9 & CONFECÇÃO DE CARTAZ COM RECORTES E COLAGENS DE REVISTAS \\
\hline 10 & CONFECÇÃO DE HISTÓRIA EM QUADRINHOS \\
\hline 11 & PINTURA DE MANDALA \\
\hline 12 & ONFECÇÃO DE CARTAZ COM RECORTES DE PAPEL SEDA SOBRE PAPEL PARDC \\
\hline 13 & CONFECÇÃO DE OBJETO COM SUCATA \\
\hline 14 & CONFECÇÃO DE CADERNO DE ANOTAÇÕES/TRABALHO NO CADERNO \\
\hline 15 & LEITURA DE HISTÓRIAS/FABULAS \\
\hline 16 & TRABALHO COM POTES DE VIDRO E PAPEL DE SEDA \\
\hline 17 & TRABALHO LIVRE COM LÃ SOBRE PAPEL OFÍCIO \\
\hline 18 & CONFECÇÃO DE REDAÇÃO/DESEJOS \\
\hline 19 & DESENHO LIVRE COM GIZ DE CERA \\
\hline 20 & TRABALHO DE RECORTES E COLAGENS COM PAPEL LAMINADO \\
\hline 21 & TRABALHO COM ROLO DE PAPEL HIGIENICO \\
\hline 22 & CONFECÇÃO DE CHAVEIROS COM MIÇANGAS \\
\hline 23 & CONFECCÇÃO DE PRESILIAS COM TECIDO \\
\hline 24 & CONFECCÇÃO DE DESENHOS VAZADOS \\
\hline 25 & TEMA LIVRE COM PALITOS E SULFITE \\
\hline 26 & DESENHO TEMA LIVRE COM COLA COLORIDA \\
\hline 27 & CONFECCÇÃO DE PORTA RETRATO COM PAPEL CARTÃO E COLA QUENTE \\
\hline 28 & CONFECÇÃO DE PULSEIRA COM CAIXA DE LEITE \\
\hline 29 & PINTURA EM CARTOLINA \\
\hline 30 & CONFECCÇÃO DE CARTÃO EM PAPEL CARTÃO \\
\hline 31 & CONFECCÇÃO DE CAIXA DE PRESENTE COM PAPEL DE PÃO \\
\hline 32 & CONFECCÇÃO DE COLAR COM MIÇANGAS \\
\hline 33 & DESENHO TEMA LIVRE COM BARBANTE \\
\hline 34 & DESENHO LIVRE COM COLA E PURPURINA \\
\hline 35 & PINTURA EM RX \\
\hline 36 & CONFECÇÃO EM TEMA LIVRE UTILIZANDO COPO PLASTICO DESCARTÁVEL \\
\hline 37 & CONFECCÇÃO DE CAIXA DE PRESENTE COM FOLHAS SECAS \\
\hline 38 & DESENHO TEMA LIVRE COM UTILIZAÇÃO DE ALGODÃO \\
\hline 39 & CONFECCÇÃO DE ATIVIDADE COMEMORATIVA (DEPENDE DA C \\
\hline
\end{tabular}




\section{Conteúdo e objetivos dos estágios no grupo Kumon atingidos pelos}

pacientes.

Estágio 2A - Desenvolver a habilidade no cálculo mental da soma. O aluno avança de acordo com o seu próprio ritmo até que sejam capazes de se desenvolver de maneira tranqüila. Contas de adição na sequência.

Estágio A - Desenvolver habilidade de cálculo nas adições e subtrações de um ou mais dígitos.

Estágio C - Memorizar as tabuadas dos 2 ao 9.Multiplicar com números de 1 algarismos.Dividir com números de 1 algarismo.

Estágio D - Resolver a multiplicação até 3 algarismos. Resolver a divisão por 2 ou 3 algarismos. Transformar frações impróprias em números mistas e vice-versa.Simplificar as frações. 
Documento de aprovação CAPPesq.

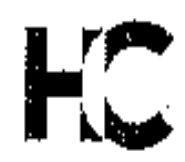

\section{APROVAÇĀO}

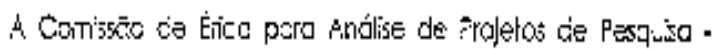

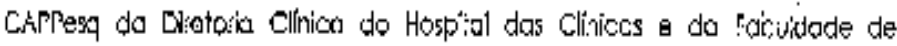

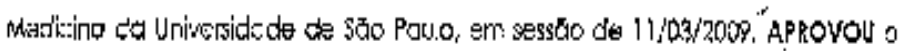

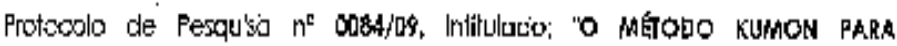
REMEDIAÇRO COGNITYÁ DE PORTADORES DE ESGUIZOFRENIA: UM ENSAIO ClínICO RANDOMIZADO, CONTROLADO COM PLACEBO. " upresentofo pe'o

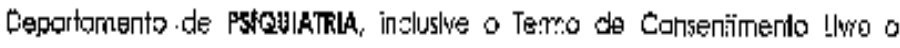
Esclarec'co.

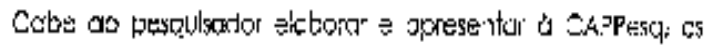

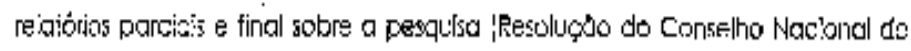
Scúde $\Pi^{\circ}$ 196, de 10/10/1996, incizo 1X.2, 'stra 'c"'.'.

Pesquisodor ;ał iRespornsóvel: Mário Rodtigues Louzq Nefo

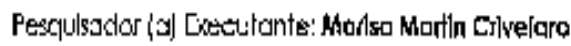

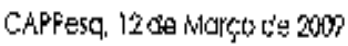

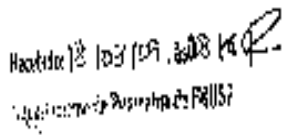<smiles>CC(C)[14CH3]</smiles>

Prof. Dr. Edvorda Masgad Presldente da Com|sș̄o de Éticci para Anéllese do Projitios de'Perquisa

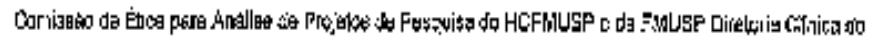

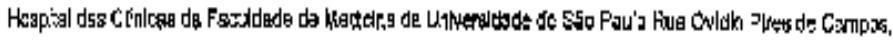

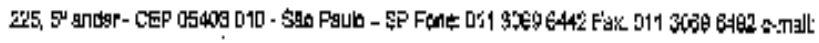

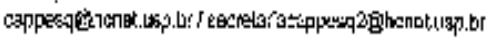

